\author{
UNIVERSIDADE DE SÃO PAULO \\ ESCOLA DE ENGENHARIA DE SÃO CARLOS \\ DEPARTAMENTO DE ENGENHARIA DE ESTRUTURAS
}

MARCELA AMARAL

Análise teórica e experimental de um sistema de treliças padronizadas em perfis de aço formados a frio 



\title{
Análise teórica e experimental de um sistema de treliças padronizadas em perfis de aço formados a frio
}

\author{
VERSÃO CORRIGIDA \\ A versão original encontra-se na Escola de Engenharia de São Carlos
}

Dissertação apresentada ao Programa de Pósgraduação em Engenharia Civil (Engenharia de Estruturas) da Escola de Engenharia de São Carlos da Universidade de São Paulo para obtenção do título de Mestre em Ciências.

Área de concentração: Estruturas

Orientador: Prof. Tit. Maximiliano Malite 

AUTORIZO A REPRODUÇAO TOTAL OU PARCIAL DESTE TRABALHO,POR
QUALQUER MEIO CONVENCIONAL OU ELETRONNICO, PARA FINS DE
ESTUDO E PESQUISA, DESDE QUE CITADA A FONTE.

Ficha catalográfica elaborada pela Biblioteca Prof. Dr. Sérgio Rodrigues Fontes da EESC/USP com os dados inseridos pelo(a) autor(a).

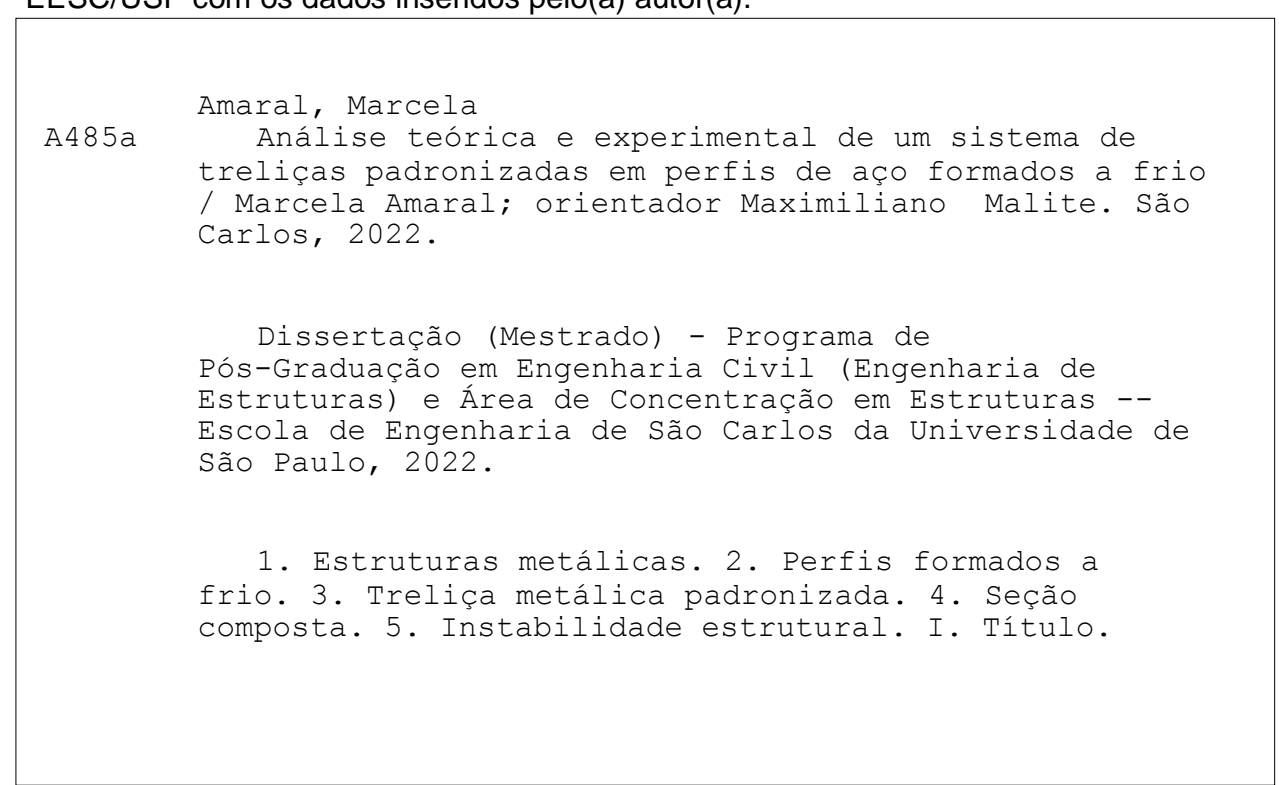

Eduardo Graziosi Silva - CRB - 8/8907 


\section{FOLHA DE JULGAMENTO}

Candidata: Engenheira MARCELA AMARAL.

Título da dissertação: "Análise teórica e experimental de um sistema de treliças padronizadas em perfis de aço formados a frio".

Data da defesa: 10/01/2022.

Comissāo Julgadora

Prof. Titular Maximiliano Malite

(Orientador)

(Escola de Engenharia de São Carlos - EESC/USP)

Prof. Dr. Luiz Carlos Marcos Vieira Junior

ADROVADA

(Universidade Estadual de Campinas/UNICAMP)

Prof. Dr. Wanderson Fernando Maia

(Universidade Federal de São Carlos/UFSCar)
Resultado

ADROVADA 



\section{AGRADECIMENTOS}

Agradeço a Deus por me proporcionar coragem e resiliência nesta etapa.

Agradeço aos meus pais e minha irmã pelo apoio, incentivo e todo suporte necessário.

Ao professor Maximiliano Malite, pela atenção, paciência, por toda a ajuda e conhecimento trasmitido no desenvolvimento desta pesquisa.

À Modular Sistema Construtivo pelo apoio à pesquisa e fornecimento dos protótipos do programa experimental.

A toda a equipe do Laboratório de Estruturas: Amaury, Fabiano, Romeu e Vareda, por toda a ajuda na realização deste trabalho. Aos funcionários da Oficina Mecânica da escola, do NEMAF, e do LAMEM.

A todos do Departamento de Engenharia de Estruturas da Escola de Engenharia de São Carlos pela formação acadêmica e auxilio prestado durante o mestrado.

Aos integrantes da M05, em especial à Jéssica, Isabela, Maycon e Vinicius pela amizade. Ao grupo da área de estruturas metálicas, Maria, Fernando, Anne, Juliana, por todo auxílio. A todos que de alguma forma contribuíram com este trabalho.

O presente trabalho foi realizado como apoio da Coordenação de Aperfeiçoamento de Pessoal de Nível Superior Brasil (CAPES) - Código de Financiamento 001. 



\section{RESUMO}

AMARAL, Marcela. Análise teórica e experimental de um sistema de treliças padronizadas em perfis de aço formados a frio. 2022, 130 p. Dissertação (Mestrado em Engenharia Civil (Estruturas)) - Escola de Engenharia de São Carlos, Universidade de São Paulo, São Carlos, 2022.

A utilização de seção composta em perfis de aço formados a frio em treliças planas possibilita, em geral, que as ligações sejam realizadas de forma mais fácil e promove um aumento da capacidade da barra em relação ao uso de um perfil único. O desempenho estrutural da barra composta depende da eficiência das presilhas, que são elementos que interligam os perfis componentes. Devido a pouca informação na literatura sobre o assunto, o objetivo deste trabalho é analisar o comportamento estrutural de um sistema de treliça padronizada com os banzos em seção composta. Foram realizadas análises teórica e experimental, sendo esta última em duas etapas: (i) ensaios de flexão de barras compostas isoladas a fim de se determinar a ação composta em função da quantidade de presilhas (ensaios de rigidez) e (ii) ensaios de flexão da treliça com variação da seção dos banzos, da quantidade de presilhas e da contenção lateral. A análise teórica consistiu na utilização do Método da Resistência Direta para determinação dos esforços resistentes das barras e um modelo simplificado em elementos finitos para representar o ensaio de rigidez. Os resultados experimentais dos ensaios de rigidez indicaram a baixa eficiência do uso da presilha em perfil aberto conectada à alma dos perfis do banzo, devido à sua deformabilidade ao fluxo de cisalhamento. As barras com presilhas formadas por talas conectadas às mesas dos perfis apresentaram melhor desempenho por absorver de forma mais eficaz o fluxo de cisalhamento. Por meio do modelo numérico simplificado do ensaio das presilhas verificou-se que a posição dos parafusos na seção afeta a rigidez. As treliças com banzos de maior altura apresentaram força normal resistente inferior às referências normativas para a barra isolada e modo de falha distorcional, o qual foi mais pronunciado em um dos conjuntos mesa e enrijecedor devido ao efeito da flexão nas barras. Além disso, notou-se que uma maior quantidade de presilhas impõe uma restrição à deformada havendo mudança do comprimento de semionda. As treliças com perfil de menor altura exibiram o modo global por flexão, e a resistência experimental foi superior a previsão teórica que considera a ação isolada.

Palavras-chave: estruturas metálicas; perfis formados a frio; treliça metálica padronizada; seção composta; instabilidade estrutural. 



\begin{abstract}
AMARAL, Marcela. Theoretical and experimental analysis of cold-formed steel joists. 2022, 130 p. Dissertation (M. Sc. in Civil Engineering (Structures)) - São Carlos School of Engineering, University of São Paulo. São Carlos, 2022.

The use of built-up members in cold-formed steel profiles on flat trusses generally facilitates connections and increases the bar capacity in comparison to the use of a single profile. The structural performance of such members depends on the efficiency of intermediate fasteners, which are elements that interconnect the component profiles. Due to the lack of information reported in the literature on the subject, this study investigates the structural behavior of a standardized truss system with chords in the built-up section. Theoretical and experimental analyses were conducted, and the latter was performed in two stages: (i) bending tests of isolated built-up members for determining the composite action as a function of number of fasteners (stiffness tests) and (ii) truss bending tests with variations in section of the chords, number of intermediate fasteners, and lateral bracing. The theoretical analysis employed the Direct Strength Method to determine the theorical strength of the bars and a simplified finite element model to represent the stiffness test. The experimental results of the stiffness tests indicated a low efficiency of the intermediate fastener constituted by an open profile connected to the web of the chord profiles, due to its deformability to the shear flow. Bars with intermediate fasteners formed by batten connected to the profiles flange showed better performance, since they absorbed the shear flow better. The simplified numerical model of the intermediate fastener test revealed the position of the screws in the section affected the rigidity. Trusses with higher chords showed a lower normal strength in comparison to the standard prediction and distortional buckling mode, which was more pronounced in one of the flange and stiffener sets due to the bending effect on the bars. Moreover, a higher number of intermediate fasteners imposed a restriction on the distortional deformations with a change in wavelength. Joists of shorter height profile exhibited flexural buckling mode, and the experimental strength was higher than the theoretical prediction, which consider only the mechanical behavior of each profile separately.
\end{abstract}

Keywords: steel structures; cold-formed steel member; steel joist; built-up member; structural instability. 


\section{LISTA DE FIGURAS}

Figura 1.1- Exemplos de seções transversais compostas com perfis em contato....................20

Figura 1.2- Treliça padronizada com banzos em barra composta........................................20

Figura 2.1- Isométrico esquemático de um módulo padrão. ................................................26

Figura 2.2- Comparativo das curvas da análise de estabilidade elástica para o perfil enrijecido.

Figura 2.3- Deformadas obtidas para $850 \mathrm{~mm}$ de comprimento de semionda.......................28

Figura 2.4-Deformadas obtidas para $170 \mathrm{~mm}$ de comprimento de semionda........................29

Figura 2.5- Configuração geométrica e equilíbrio de forças em um painel típico..................34

Figura 2.6- Modos de flambagem para seções compostas proposto por Johnston...................38

Figura 2.7- Seções estudas por Temple e Elmahdy................................................................ 39

Figura 2.8- Modos de instabilidade da seção composta estudada por Rondal e Niazi............39

Figura 2.9- Seção estudada por Georgieva, Schueremans e Pyl. ...........................................40

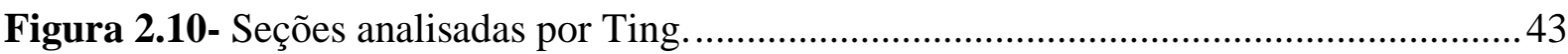

Figura 2.11- Seção e esquema de montagem utilizado por Dabaon, Ellobody e Ramzy........45

Figura 2.12- Seções estudadas por Kherbouche e Megnounif. .............................................47

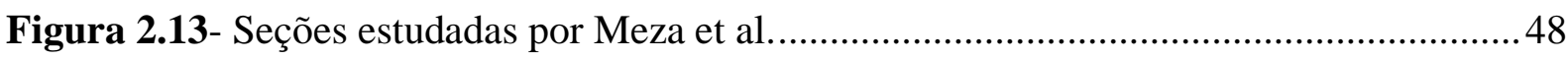

Figura 2.14- Curva força versus alongamento para o comportamento da ligação. .................49

Figura 2.15- Seção com 3 e 4 perfis respectivamente. ........................................................52

Figura 2.16- Deformações na mesa e alma causadas pela instalação dos parafusos................53

Figura 3.1- Seções transversais dos perfis utilizados na treliça. ..........................................55

Figura 3.2- Hipóteses utilizadas para as estimativas do ensaio de flexão. ...............................56

Figura 3.3- Análise de estabilidade elástica para o perfil de 120 mm submetido à flexão em y

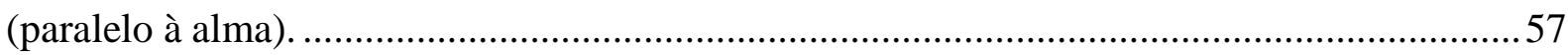

Figura 3.4-Análise de estabilidade elástica para o perfil de $210 \mathrm{~mm}$ submetido à flexão em y.

Figura 3.5- Análise de estabilidade elástica do perfil UAE do banzo submetido à compressão.

Figura 3.6- Deformadas dos modos de instabilidade dos perfis submetidos à compressão....60

Figura 4.1- Esquema estático do ensaio de flexão em torno de y. ........................................65

Figura 4.2- Deslocamento relativo entre vigas devido à flexão. .............................................66

Figura 4.3- Protótipo com uma chapa de ligação interna ao vão. .........................................67

Figura 4.4- Posicionamento e numeração dos transdutores de deslocamento..........................69 
Figura 4.5- Posicionamento dos extensômetros e corte genérico sem escala. 69

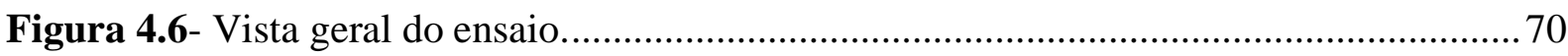

Figura 4.7- Esquema geral para o ensaio da treliça........................................................... 72

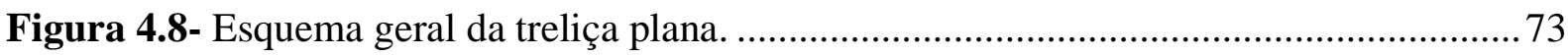

Figura 4.9- Sistema utilizado para realizar a medida do deslocamento horizontal. ................74

Figura 4.10- Posição do extensômetro na seção transversal e numeração utilizada. ..............75

Figura 4.11- Esquema utilizado para realizar a medida de deslocamento horizontal. ............75

Figura 4.12- Pórticos de travamento e viga de distribuição do carregamento. ........................76

Figura 5.1- Deformadas associadas ao carregamento e aos esforços.................................... 78

Figura 5.2- Curvas força versus deslocamento da série UB180..........................................79

Figura 5.3- Distância entre os parafusos na seção transversal para os protótipos 3A e 5A

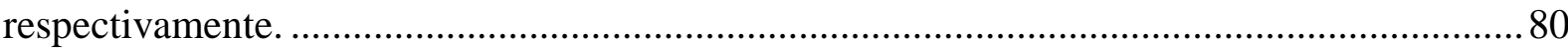

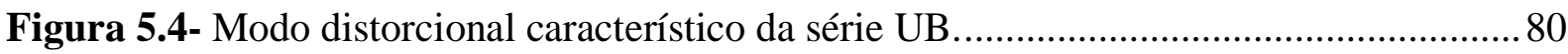

Figura 5.5- Curvas força versus deslocamento da série UB180 com três presilhas................81

Figura 5.6- Curvas força versus deslocamento da série UB360 ............................................82

Figura 5.7- Deformação medida no perfil superior e inferior (UB360-3A) ..........................83

Figura 5.8- Curvas força versus deslocamento da série UA180. ..........................................84

Figura 5.9- Curvas força versus deslocamento da série UA360. .........................................84

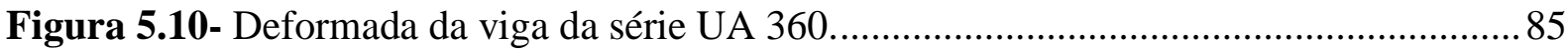

Figura 5.11- Deformada da presilha devido ao efeito da flexão e cortante............................86

Figura 5.12- Curvas força versus deslocamento para os protótipos com chapas nas mesas...87

Figura 5.13- Deformação medida no perfil superior e inferior (UB180-1C).........................8 88

Figura 5.14- Modo distorcional no protótipo UB180-1C ao final do ensaio. .........................89

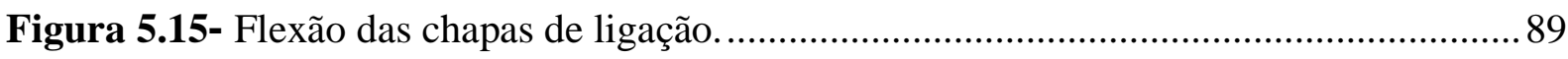

Figura 5.16- Curvas força versus deslocamento vertical para as treliças da série 210J360 ...90 90

Figura 5.17- Deformada distorcional típica da série 210J360 ..........................................91

Figura 5.18- Curvas força versus deslocamento horizontal para as treliças da série 210J360.

Figura 5.19- Mecanismo plástico formado ao final do ensaio (210J360.P1) ........................92

Figura 5.20- Mecanismo plástico associado com o deslocamento fora do plano (210J360.P1).

Figura 5.21- Valores médios utilizados nas curvas força versus deformação específica........92

Figura 5.22- Curva força versus deformação específica para a peça 210J360.P2 ................93

Figura 5.23- Curva força versus deformação específica para a peça 210J360.P1 .................94 
Figura 5.24- Curvas força versus deslocamento vertical para as treliças da série $210 \mathrm{~J} 180 \ldots 95$

Figura 5.25- Curvas força versus deslocamento horizontal para as treliças da série $210 \mathrm{~J} 180$.

Figura 5.26- Mudança de comprimento de semionda distorcional entre as peças. ................96

Figura 5.27- Curvas força versus deslocamento vertical para a série $120 \mathrm{~J} 360 \ldots \ldots \ldots \ldots \ldots \ldots \ldots . . . . .97$

Figura 5.28- Curvas força versus deslocamento horizontal para a série 120J360 ................98

Figura 5.29- Instabilidade por flexão fora do plano para as treliças da série $120 \mathrm{~J} 360$..........98

Figura 5.30- Curva força versus deslocamento vertical para a série $120 \mathrm{~J} 180 \ldots \ldots \ldots \ldots \ldots \ldots \ldots . . . . .99$

Figura 5.31- Curva força versus deslocamento horizontal para a série $120 \mathrm{~J} 180 \ldots \ldots \ldots \ldots \ldots . . . . . .100$

Figura 5.32- Instabilidade por flexão fora do plano para as treliças $120 \mathrm{~J} 180 \ldots \ldots \ldots \ldots \ldots \ldots \ldots . . . . . . . .100$

Figura 5.33- Deformada plástica característica para a série $120 \mathrm{~J} 180$ ao final do ensaio......101

Figura 5.34- Resultados para a flexo-compressão considerando os esforços resistentes dos perfis isolados.

Figura 5.35- Resultados para a flexo-compressão considerando os esforços resistentes dos perfis isolados e $\mathrm{K}_{\mathrm{y}} \mathrm{L}_{\mathrm{y}}$ reduzido para a série $120 \mathrm{~J} 360$.

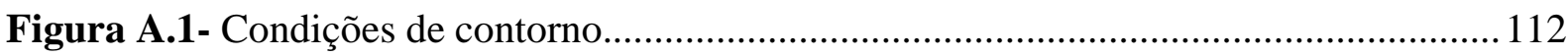

Figura A.2- Esquema geral e região da aplicação do carregamento.

Figura A.3- Modos de instabilidade adotados para a imperfeição geométrica inicial ampliado em 20 vezes.

Figura A.4- Redução da área de ligação pela dimensão no sentido da altura dos perfis principais.

Figura A.5- Exemplo de área de contato em um dos protótipos.

Figura A.6- Curva força versus deslocamento para UB180-1A considerando $\mathrm{P}(\Delta>\mathrm{d})=0,75$.

Figura A.7- Curva força versus deslocamento para UB180-1A considerando $P(\Delta>d)=0,25$.

Figura A.8- Curva força versus deslocamento para UB180-3x considerando $\mathrm{P}(\Delta>\mathrm{d})=0,75$.

Figura A.9- Curva força versus deslocamento para UB180-3x considerando $P(\Delta>d)=0,25$.

Figura A.10- Curva força versus deslocamento para UB180-5x considerando $P(\Delta>d)=0,75$.

Figura A.11- Curva força versus deslocamento para UB180-5x considerando $\mathrm{P}(\Delta>\mathrm{d})=0,25$. 
Figura A.12-Curva força versus deslocamento para UB360-5A considerando $\mathrm{P}(\Delta>\mathrm{d})=0,75$.

Figura B.1 - Dimensões dos corpos de prova (em milímetros) ......................................... 124

Figura B.2- Locais de extração dos corpos de prova: perfil UAE 120 ................................124

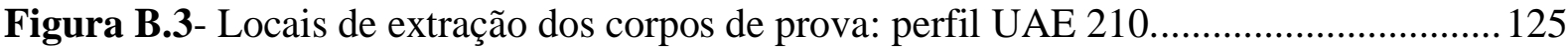

Figura B.4- Locais de extração dos corpos de prova: perfil UE 110 ..................................125

Figura C.1- Análise de estabilidade elástica para os perfis submetido à flexão em torno do eixo perpendicular à alma.

Figura D.1- Curva força versus deformação específica para os extensômetros no protótipo 210J360.P2 e localização dos extensômetros.

Figura D.2- Curva força versus deformação específica para os extensômetros no protótipo 210J360.P1. 130 


\section{LISTA DE TABELAS}

Tabela 3.1- Momento fletor resistente e deslocamento máximo para os perfis.

Tabela 3.2- Força axial de compressão resistente caraterística para o banzo considerando travamento lateral a cada dois nós.

Tabela 3.3- Força axial de compressão resistente caraterística para o banzo considerando travamento a cada nó.

Tabela 3.4- Índice de esbeltez dos perfis individuais.

Tabela 3.5-Esbeltez máxima do conjunto para o comprimento de flambagem fora do plano de $180 \mathrm{~cm}$.

Tabela 3.6-Esbeltez máxima do conjunto para o comprimento de flambagem fora do plano de

$360 \mathrm{~cm}$. 63

Tabela 4.1- Descrição dos protótipos com presilha para o ensaio de rigidez. .68

Tabela 4.2- Descrição dos protótipos com chapa de ligação para o ensaio de rigidez...... .68

Tabela 4.3- Descrição dos protótipos para a prova de carga da treliça. 73

Tabela 5.1- Resultados obtidos para os protótipos UB180 79

Tabela 5.2- Resultados obtidos para os protótipos UB360.....

Tabela 5.3- Resultados de rigidez obtidos para os protótipos da série UA180. 83

Tabela 5.4- Resultados obtidos para os protótipos da série UA360. 85

Tabela 5.5- Resultados obtidos para os protótipos UB180 com chapas nas mesas. 87

Tabela 5.6- Resultados obtidos para os protótipos considerando a flexo-compressão. 102

Tabela 5.7- Resultados obtidos para os protótipos considerando a flexo-compressão e propriedades da barra composta.

Tabela A.1- Razão entre o valor experimental e o numérico para o protótipo com uma presilha interna (UB180-1A).

Tabela A.2- Razão entre o valor experimental e o numérico para o protótipo com 3 presilhas internas

Tabela A.3- Razão entre o valor experimental e o numérico para o protótipo com 5 presilhas internas

Tabela A.4- Razão entre o valor experimental e o numérico para o protótipo com cinco presilhas internas no vão de $3600 \mathrm{~mm}$.

Tabela A.5- Razão entre o valor experimental e o numérico para o protótipo com três presilhas internas no vão de $3600 \mathrm{~mm}$. 
Tabela A.6- Razão entre o valor experimental e o numérico para o protótipo com uma presilha interna no vão de $3600 \mathrm{~mm}$.

Tabela B.1-Resultados da caracterização do material do ensaio de flexão das barras isoladas. 126

Tabela B.2-Resultados da caracterização do material do ensaio de flexão das treliças. ........126

Tabela C.1- Valores de tensão crítica elástica e esforços caraterísticos.................................128 


\section{SUMÁRIO}

1. INTRODUÇÃO ................................................................................................................. 18

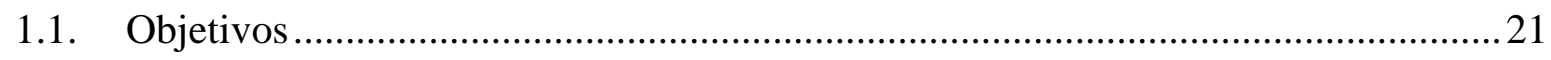

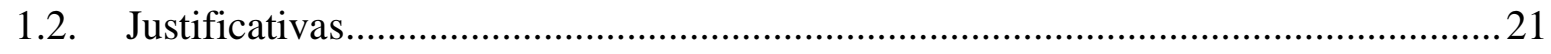

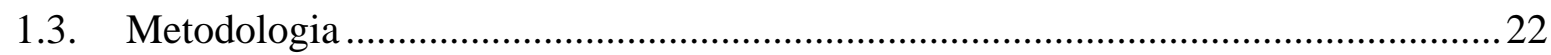

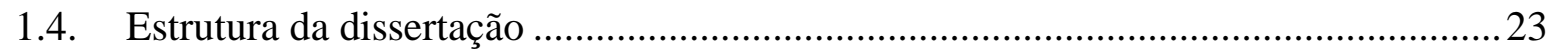

2. ESTRUTURAS TRELIÇADAS ...................................................................................25

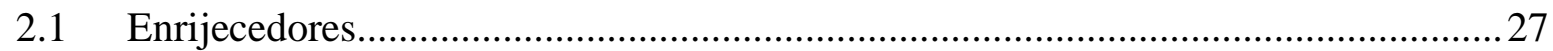

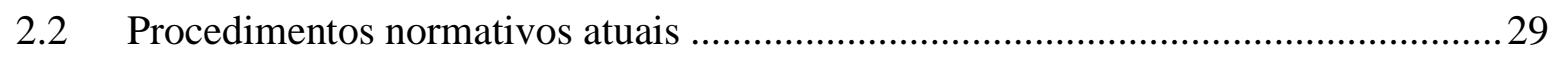

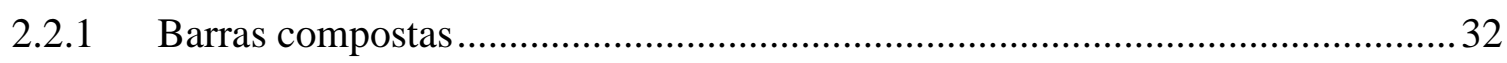

2.3 Estudos realizados com seções compostas ................................................................ 38

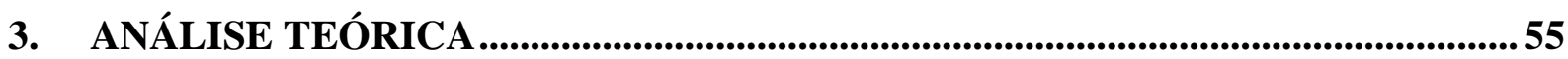

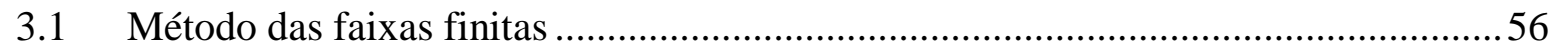

3.2 Avaliação da eficiência das presilhas .......................................................................56

3.2.1 Esforço resistente e deslocamento ................................................................58

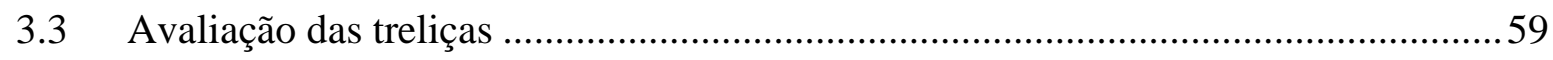

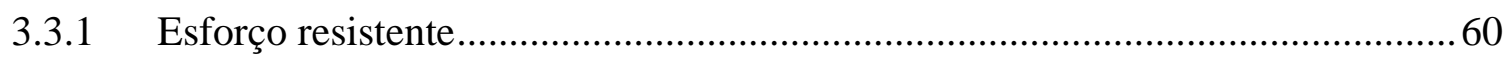

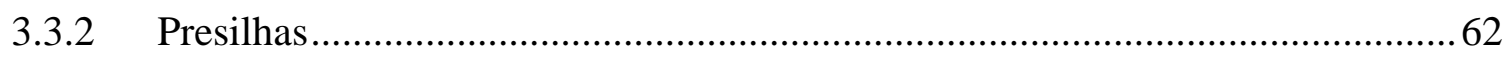

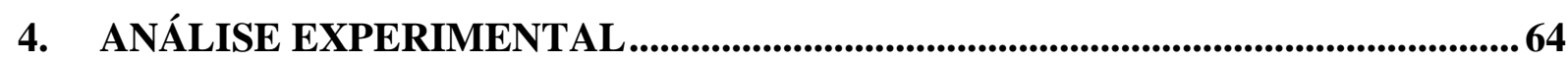

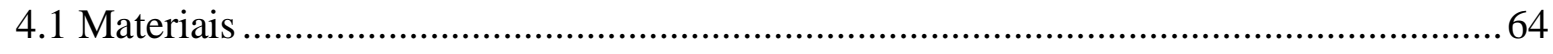

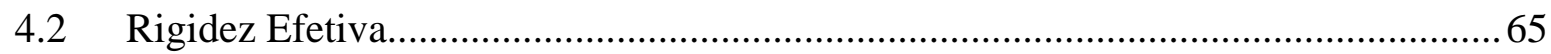

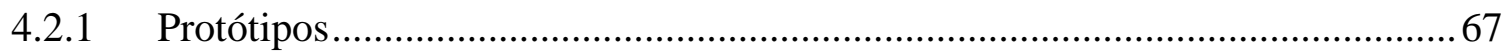

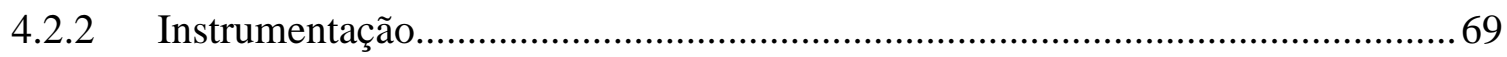

4.2.3 Montagem e Procedimento Experimental .......................................................... 70

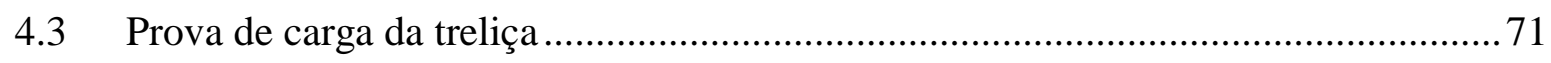

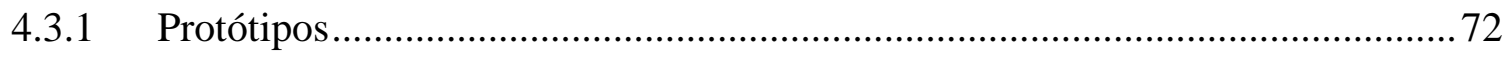

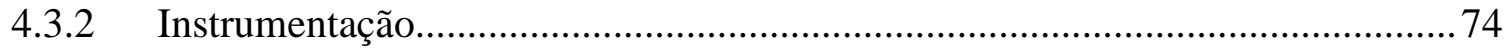

4.3.3 Montagem e Procedimento Experimental …………………………………....75

5. RESULTADOS DA ANÁLISE EXPERIMENTAL .......................................................78

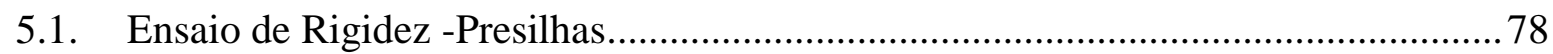

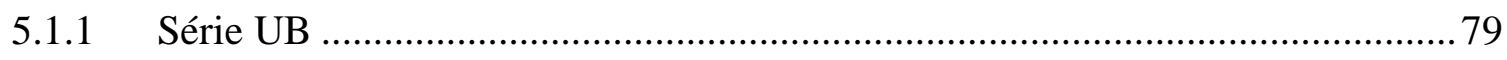




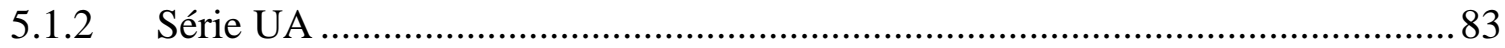

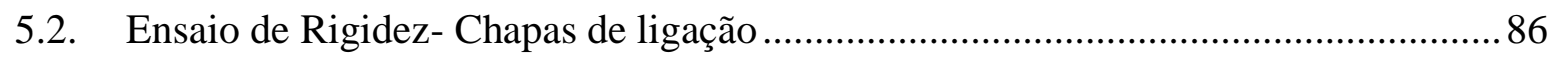

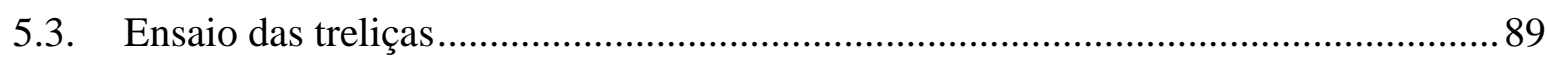

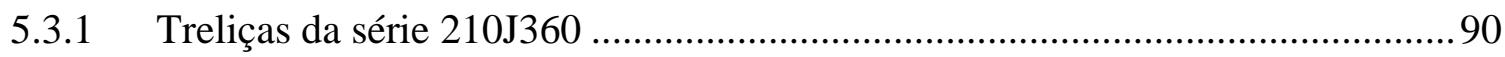

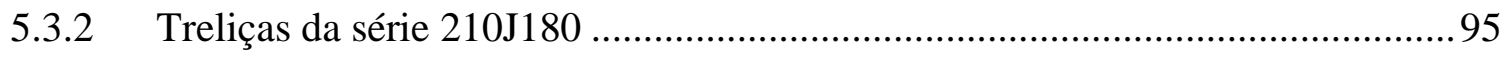

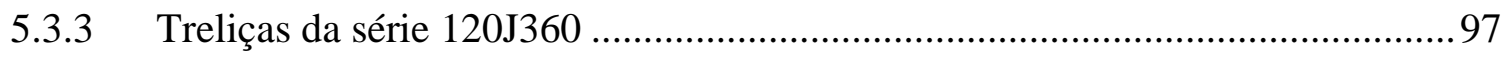

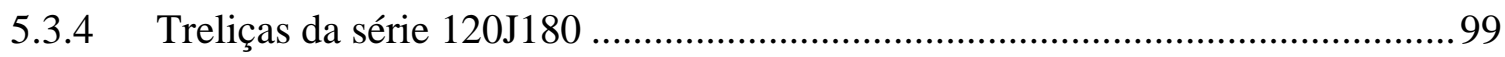

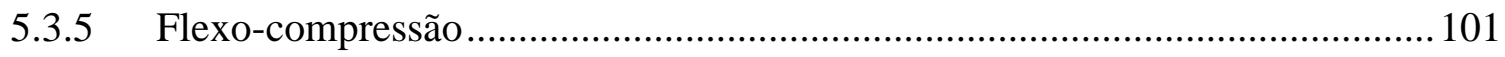

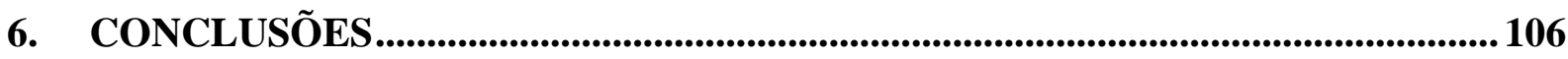

REFERÊNCIAS BIBLIOGRÁFICAS ................................................................ 108

APÊNDICE A - MODELO NÚMERICO SIMPLIFICADO: ENSAIO DE RIGIDEZ 112

APÊNDICE B - CARACTERIZAÇÃO DO MATERIAL ............................................... 124

APÊNDICE C - MOMENTO FLETOR SOLICITANTE E RESISTENTE EM RELAÇÃO AO EIXO PRINCIPAL PERPENDICULAR À ALMA DO PERFIL ....... 127 APÊNDICE D - RESULTADOS DO ENSAIO DAS TRELIÇAS- EXTENSÔMETROS 129 


\section{INTRODUÇÃO}

Os perfis de aço formados a frio (PFF) vêm sendo cada vez mais utilizados devido a sua eficiência estrutural, que reúne elementos com peso reduzido e uma boa capacidade resistente, além de inúmeras formas possíveis de seções transversais associadas ao seu processo de produção.

Devido à sua forma, muitas seções podem ser armazenadas em um espaço menor, contribuindo para uma redução no custo de transporte, e aliando-se ao fato de que uma estrutura mais leve facilita e agiliza a execução do serviço. Outra característica é a existência de chapas com revestimento, em geral de zinco, que melhoram a resistência à corrosão, contribuindo para maior durabilidade.

Esses perfis são produzidos por dobragem de chapas de aço finas e planas em temperatura ambiente, de modo que a resistência da forma final se torna maior quando comparada com a da chapa plana. A espessura reduzida das chapas faz com que a relação entre a largura e a espessura dos elementos que compõem o perfil se torne elevada, favorecendo a ocorrência de instabilidade localizada; outra consequência é a menor rigidez à torção da seção transversal (HANCOCK; MURRAY; ELLIFRITT, 2001).

Os PFF são comumente empregados em treliças planas e espaciais, sistemas de cobertura, de armazenamento, fechamento lateral, sistemas construtivos (light steel framing) entre outras aplicações. Dentro do sistema de cobertura metálica, existem basicamente os seguintes componentes: a viga principal, os contraventamentos, as telhas e as terças. Este último tem como característica servir de apoio às telhas e transmitir as ações decorrentes para a estrutura principal. As terças são usualmente constituídas por perfis com seções resistentes à flexão, tais como as do tipo $\mathrm{U}$ e $\mathrm{Z}$, podendo ser empregadas de forma contínua ou não. Além das vigas de alma cheia, existe a possibilidade do uso de um componente treliçado.

As terças treliçadas planas, usualmente chamadas de joists, são treliças de banzos paralelos que estão sendo utilizadas em substituição aos perfis usuais para terças, os quais normalmente não possibilitam vencer vãos maiores que doze metros (SAMARRA, 2007).

Portanto, as joists são geralmente aplicadas para grandes vãos com reduzido número de pilares internos, onde viga de alma cheia necessária para resistir aos esforços torna-se maior, consequentemente, mais pesada a partir de determinado comprimento. Essas treliças leves têm sido amplamente empregadas em obras no exterior, principalmente nos Estados Unidos, onde são tabeladas e catalogadas pelas empresas fabricantes (VIEIRA,2009). 
Essas treliças possuem barras com seções formadas por apenas um perfil ou mais, Ting (2013) cita que as seções compostas quando comparadas com as simples apresentam maior capacidade resistente, entretanto exibem comportamentos de instabilidade particulares que as resoluções normativas não possuem especificações abrangentes.

Além do maior esforço resistente, a combinação dos perfis pode fazer com que certos modos de instabilidade que se manifestavam nas seções únicas deixem de ocorrer, como por exemplo, a formação de seções duplamente simétricas e as seções fechadas que contribuem com uma maior rigidez à torção. Com a aplicação dessas seções em projetos, torna-se fundamental compreender o comportamento do sistema que pode atuar de forma conjunta ou isolada, caso a ligação entre os componentes não seja efetiva.

As normas americanas ANSI/AISI S100:2020 e ANSI/AISC 360:2016 consideram para seções compostas em contato submetidas à compressão a utilização do índice de esbeltez modificado, para os modos de flambagem que produzam esforços cisalhantes nos elementos de conexão entre os perfis. Também consideram um requisito de espaçamento entre as presilhas com o intuito de se evitar a instabilidade por flexão das formas individuais que compõem a seção. Esse espaçamento é limitado de tal forma que o índice de esbeltez individual não exceda a metade da razão de esbeltez do conjunto, este requisito considera a possibilidade de que uma das presilhas venha a falhar.

Uma questão importante sobre o índice de esbeltez modificado é o fato de que esse parâmetro foi proposto nas especificações de projeto de perfis laminados, que eventualmente pode não representar os perfis formados a frio em função de diferentes caraterísticas, sendo relevante mais informações sobre a sua aplicabilidade.

A norma brasileira de dimensionamento de estruturas de aço constituídas por perfis formados a frio, ABNT NBR 14762:2010, considera para barras compostas submetidas à compressão as seguintes exigências: respeitar o índice de esbeltez geral para barras comprimidas e o mesmo requisito que limita a esbeltez do perfil componente em relação à esbeltez do conjunto contido na ANSI/AISI S100:2020, definindo assim o espaçamento entre as presilhas a fim de que as barras possam trabalhar de forma conjunta.

$\mathrm{Na}$ literatura, observa-se frequentemente seções em que os componentes estão em contato ao longo de todo comprimento, como ilustra a Figura 1.1. Podem existir situações onde as seções com perfis espaçados se tornam mais vantajosas. 
Figura 1.1- Exemplos de seções transversais compostas com perfis em contato.
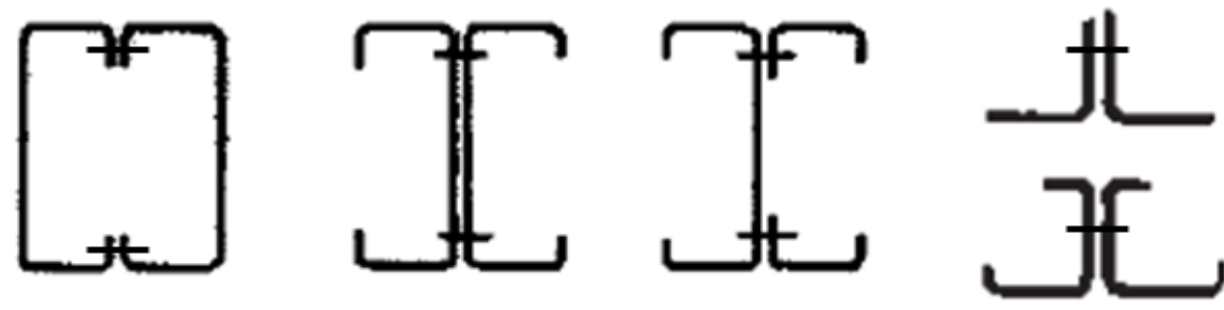

Fonte: Adaptado de Yu e LaBoube (2010).

Outra característica importante que pode ser usada para melhorar a eficiência dos perfis é a presença de enrijecedores de borda e intermediários. Os enrijecedores de borda possibilitam um aumento de rigidez para os elementos vinculados e os intermediários inseridos na alma propiciam uma redução da sua dimensão, melhorando assim seu desempenho em relação à instabilidade local.

A Figura 1.2 ilustra a treliça padronizada em estudo, ela possui banzos constituídos por perfis $\mathrm{U}$ formados a frio com enrijecedores de borda e intermediário (UAE). Foi desenvolvida pela empresa Modular Sistema Construtivo considerando os aspectos relacionados a sua utilização em sistemas treliçados de cobertura, com o objetivo de vencer grandes vãos e associado a um sistema que possua um bom desempenho estrutural.

Figura 1.2- Treliça padronizada com banzos em barra composta.

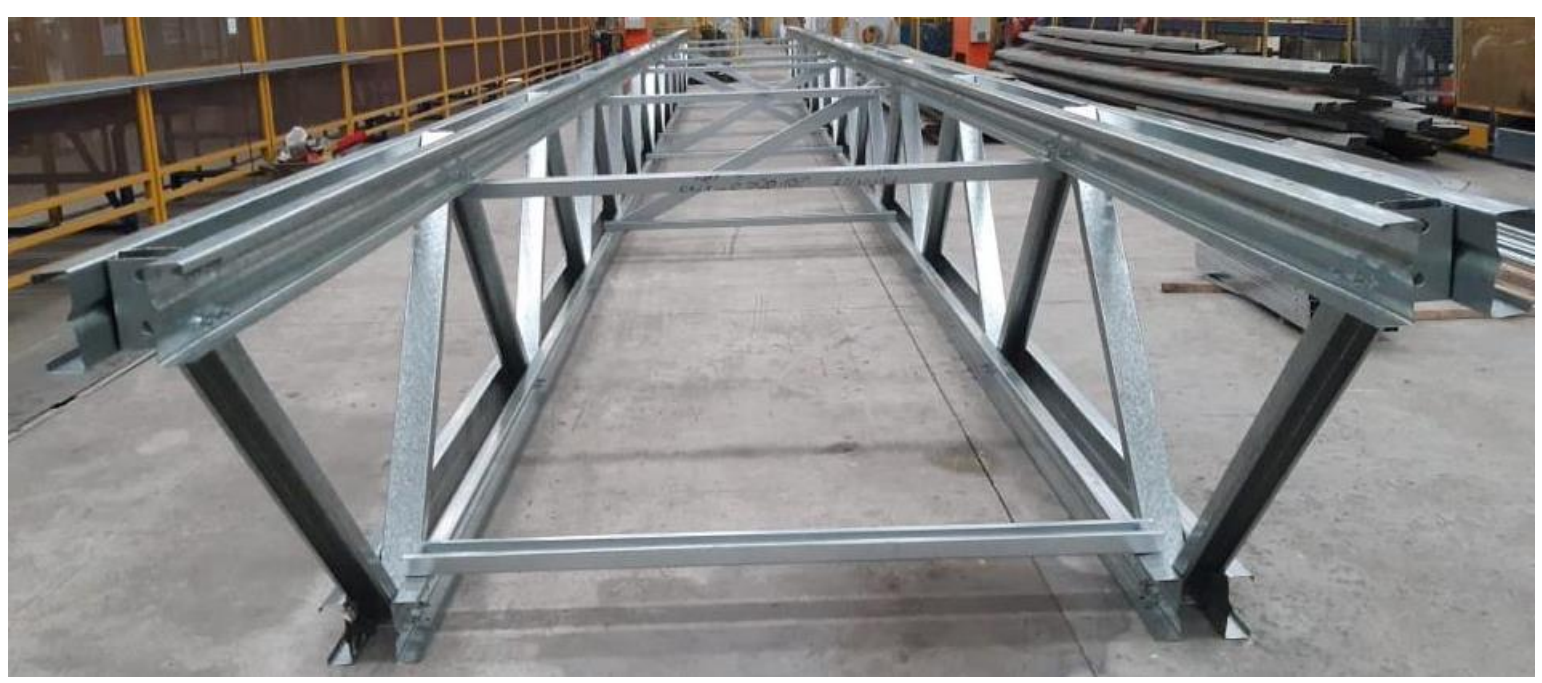

Fonte: Modular Sistema Construtivo (2020).

Nessa estrutura os banzos são constituídos por dois perfis UAE afastados pela largura da alma da diagonal, a ligação desses elementos é feita por meio de parafusos sextavados que 
conectam a alma dos banzos com as mesas da diagonal. A conexão entre os dois perfis é feita por meio de presilhas, constituídas por um segmento do próprio perfil da diagonal.

Neste contexto, este trabalho traz uma análise teórica e experimental do comportamento estrutural do sistema treliçado formado pelos perfis UAE para os banzos e U enrijecido para a diagonal. Portanto, este trabalho trata-se de uma análise de sistema estrutural, no entanto utilizase o estudo do elemento (barra) como ponto de partida.

Outra característica é a utilização do aço zincado ZAR-450, com resistência mínima ao escoamento de $450 \mathrm{MPa}$, que por apresentar uma alta resistência possibilita a produção de perfis com espessuras menores, tornando os fenômenos de instabilidade mais acentuados.

\subsection{Objetivos}

Com este trabalho pretende-se analisar a estabilidade do sistema de treliça padronizada visando à compreensão do comportamento da barra composta submetida predominantemente à compressão, em razão da quantidade de presilhas; realizar o comparativo dos resultados obtidos com as previsões teóricas obtidas considerando o elemento, isto é a barra isolada.

\subsection{Justificativas}

A utilização dos perfis de paredes finas intensificou-se devido à sua leveza e diversas aplicações. O uso de barras compostas em treliças planas tem-se tornado uma alternativa para grandes vãos, pois facilita o detalhamento das ligações do banzo com as diagonais e montantes e possibilita maior capacidade resistente, no entanto o comportamento da barra como um todo é complexo e depende de vários fatores, como por exemplo a deformabilidade das ligações, que afeta a rigidez à flexão e ao cisalhamento.

As resoluções normativas não possuem considerações abrangentes sobre 0 comportamento das seções composta. A ABNT NBR 14762:2010 indica apenas uma limitação da esbeltez dos perfis em relação à do conjunto, estabelecendo, assim, um espaçamento máximo entre as presilhas, porém essa indicação pode não refletir um comportamento otimizado para a estrutura.

Para realizar estimativas da capacidade resistente utilizando os equacionamentos existentes nas normas, faz-se necessário o conhecimento das características efetivas da seção transversal como, por exemplo, os momentos de inércia à flexão e à torção, constante de empenamento e demais propriedades geométricas. A obtenção de alguns destes parâmetros 
apenas pode ser feita de modo estimado, pois é dependente de como a ação composta se apresenta na estrutura, portanto está relacionada a diversos aspectos da ligação entre os componentes da seção e ao modo como os esforços são transferidos.

A ausência de um conhecimento amplo sobre o comportamento de seções com perfis espaçados faz com que os projetistas optem por uma abordagem mais conservadora, assumindo que o desempenho estrutural seja semelhante ao de duas barras individuais, ou que toda a inércia da seção esteja atuante, isto é, desconsidera-se a flexibilidade que possa existir nas ligações. Essas considerações podem gerar um dimensionamento antieconômico e inviável, além das questões que envolvem a segurança estrutural.

Neste contexto, a falta de uma metodologia de projeto inserida nas normas que represente o comportamento das seções formadas por mais de um perfil leva à necessidade de novas investigações, para que se desenvolva um método analítico de previsão da capacidade resistente ou se possa utilizar de forma confiável o que está disponível nas normas, possibilitando sua aplicação nas mais diversas obras.

\subsection{Metodologia}

A metodologia empregada neste trabalho consistiu em uma análise teórica e experimental. $\mathrm{O}$ método de cálculo utilizado para estimar os esforços resistentes na análise teórica foi o método da resistência direta, a análise de estabilidade elástica foi realizada com o uso do software CUFSM v.5.01, que utiliza o método das Faixas Finitas (MFF).

Com essa análise é possível determinar os valores dos esforços críticos associados aos modos de instabilidade local e distorcional e os respectivos comprimentos de semionda. Para o modo global, como a barra é constituída por dois perfis, faz-se necessário realizar algumas considerações de cálculo, como por exemplo: obter a força axial de flambagem elástica com as propriedades do perfil individual ou utilizar as propriedades geométricas da seção composta, de modo a obter um limite superior, considerando o grau máximo de ação composta, e um limite inferior, que configura apenas a soma de capacidades individuais.

A etapa experimental consistiu inicialmente de um ensaio de flexão da barra do banzo, considerando dois comprimentos, devido à possibilidade de se restringir lateralmente a treliça a cada nó ou a cada dois nós. Além do comprimento, foram analisadas duas alturas para o perfil previamente selecionadas e também a variação do tipo de parafuso na ligação do banzo com as presilhas; foram utilizados dois tipos de presilhas, um perfil de seção transversal aberta igual ao da diagonal da treliça e chapas. 
Este ensaio foi realizado considerando a flexão em torno do eixo que mobiliza os elementos de ligação, a fim de se obter a rigidez da barra ao se variar a quantidade de presilhas, possibilitando mensurar a eficiência dessa ligação quanto à formação de uma barra que trabalhe de forma conjunta. Um modelo numérico utilizando o Método dos Elementos Finitos (MEF) foi realizado com o objetivo de se fazer uma verificação dos resultados obtidos e assim permitir uma melhor compreensão.

Posteriormente, foram realizadas algumas provas de carga em escala reduzida da treliça plana, considerando a estrutura com o seu comportamento próximo ao real, em razão da existência do travejamento, e, com isso, as possíveis restrições que o conjunto pode gerar. Deste modo, foi possível verificar e comparar com os resultados previstos teoricamente, gerando uma contribuição com novas informações acerca do estudo das seções compostas com a finalidade de utilização em treliças planas.

\subsection{Estrutura da dissertação}

O presente trabalho está organizado da seguinte maneira:

O Capítulo 1 traz uma introdução ao tema de estudo, descrevendo as características dos perfis formados a frio, e sua aplicação como elemento da cobertura metálica, mais especificamente como treliça padronizada com barra composta, as quais não possuem comportamento estrutural bem conhecido e nem considerações normativas abrangentes. Nesse capítulo, também são indicados os objetivos do trabalho, a justificativa e a metodologia empregada.

No Capítulo 2, é apresentada a revisão bibliográfica, com as informações retiradas da literatura sobre o tema desenvolvido.

No Capítulo 3, são descritas a análise teórica realizada via faixas finitas e utilizando o Método da Resistência Direta, a fim de se obter as possíveis capacidades resistentes, modos de falhas e a quantidade de presilha requerida por norma.

O Capítulo 4 descreve a análise experimental indicando: a idealização dos ensaios, a descrição dos protótipos, os materiais, a instrumentação, a montagem e o procedimento experimental.

No Capítulo 5, são apresentados os resultados da análise experimental. Além disso, nesse capítulo, os resultados são discutidos e comparados com os valores teóricos obtidos no Capítulo 3 e Apêndice A; este último traz um modelo simplificado do ensaio de flexão das barras isoladas (ensaio de rigidez). 
O Capítulo 6 apresenta as conclusões.

Por fim, são apresentadas as referências bibliográficas utilizadas neste estudo, e os apêndices. $\mathrm{O}$ apêndice A descreve o modelo numérico simplificado do ensaio de rigidez. $\mathrm{O}$ apêndice B traz os resultados do ensaio de caracterização do material utilizado nos ensaios. O apêndice $\mathrm{C}$ reúne os valores de momentos resistentes e solicitantes característicos para a análise de flexo-compressão das treliças. $\mathrm{O}$ apêndice $\mathrm{D}$ reúne os resultados de deformação específica do ensaio das treliças. 


\section{ESTRUTURAS TRELIÇADAS}

No sistema de cobertura, tanto a viga principal como as secundárias podem ser elementos treliçados. A aplicação das estruturas treliçadas para grandes vãos se deve ao fato de que os perfis de alma cheia necessitam de alturas maiores para resistir aos esforços de flexão, consequentemente, isso contribui para uma estrutura mais pesada, que, a partir de determinado comprimento, passa a ser inviável. A substituição da viga de alma cheia pela treliça de banzos paralelos possibilita esse ganho em altura por meio da utilização das diagonais e montantes.

Fazendo uma comparação entre estes dois sistemas estruturais observa-se que o momento fletor solicitante atuante na viga passa a ser resistido pelos banzos da treliça por meio da formação de um binário de forças, e o esforço cortante passa a ser resistido pelas diagonais e montantes por meio de solicitações axiais.

As terças são peças que servem de apoio às telhas de cobertura e conduzem as solicitações para a estrutura principal; estão submetidas às ações provenientes do peso próprio das telhas, das sobrecargas de utilização e devido ao vento, gerando um carregamento distribuído ao longo das barras.

Com relação ao tipo de apoio, as terças podem ser classificadas em um sistema biapoiado ou contínuo, o que influencia na distribuição de esforços e, portanto, no seu dimensionamento. A continuidade da viga treliçada está associada ao modo como é realizada sua fixação no sistema de cobertura. O banzo superior é sempre fixo à viga principal para que exista o equilíbrio; quando o banzo inferior também está conectado, ocorre a formação de um binário de forças nas extremidades dos banzos, gerando um momento fletor; dessa forma se garante a continuidade da terça. Usualmente as treliças leves são empregadas de maneira biapoiada.

Para que se garanta a estabilidade lateral, a estrutura plana treliçada deve possuir elementos que interligue as peças adjacentes. Essa contenção é feita por meio de barras rígidas e tirantes e é realizada no banzo comprimido, em virtude da existência de instabilidade fora do plano. Em razão da possibilidade de inversão dos esforços, existe a necessidade de que ambos os banzos estejam contidos.

O travamento pode ser do tipo horizontal, quando localizado no plano dos banzos (Figura 2.1), e do tipo diagonal, quando o banzo superior de uma peça é conectado ao banzo inferior de outra adjacente. Além da estabilidade lateral, essa contenção propicia a redução do comprimento de flambagem fora do plano dos banzos. 
A telha metálica fixada por meio de parafusos autoatarraxantes permite a interação entre a terça e a telha, devido à influência do efeito diafragma do painel, possibilitando uma maior estabilidade lateral (BASÁGLIA, 2004).

Figura 2.1- Isométrico esquemático de um módulo padrão.

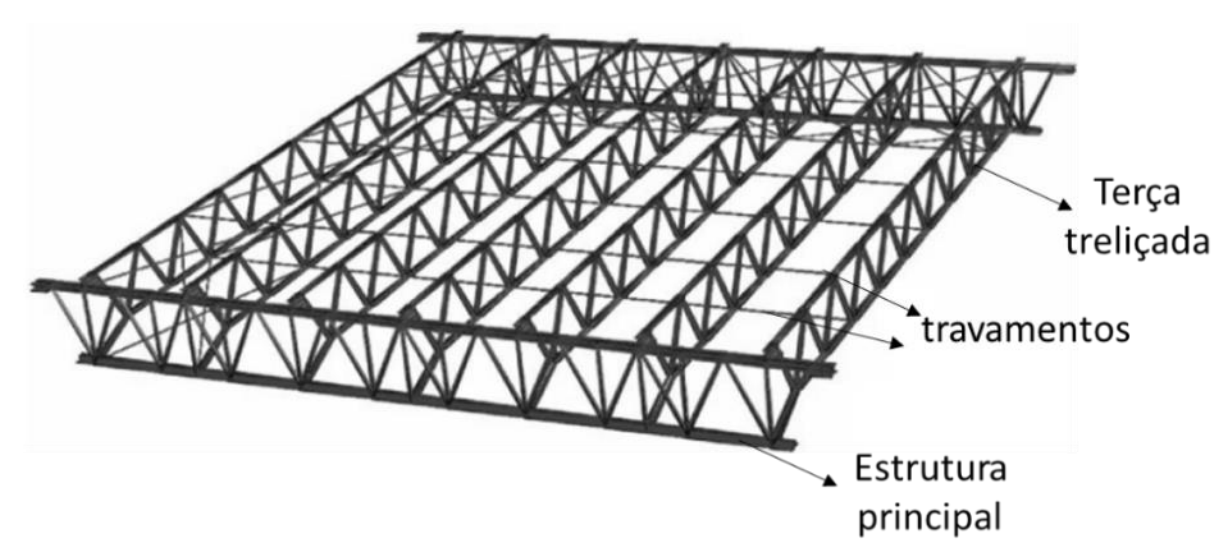

Fonte: Adaptado de CBCA (2007).

A ligação entre as barras da treliça pode ser realizada de forma direta ou com uso de chapas de ligação, onde se considera o ponto de trabalho (P.T.) da ligação coincidindo com a linha de centro do banzo; dessa forma, não se introduz excentricidade.

Considerando o aspecto econômico, devem-se selecionar diagonais e banzos que possibilitem a ligação de forma direta, porém, muitas vezes por motivos construtivos, essa configuração introduz excentricidades nos nós (CHIEN; RITCHIE, 1984). A ocorrência de excentricidades provoca o surgimento de esforços de flexão. Além disso, outros fatores induzem flexão nas barras. Segundo Pfeil (2009), as forças aplicadas fora dos nós e a existência de rigidez das próprias ligações fazem com que o modelo de rótulas perfeitas não ocorra.

Essas treliças leves, também conhecidas como joist, foram padronizadas e catalogadas pelos fabricantes em vários países. No Brasil, o Centro Brasileiro da Construção em Aço (CBCA, 2007) possui um manual sobre o assunto, no entanto aborda apenas o emprego de seções simples em perfil formado a frio.

Essas treliças são usualmente constituídas por barras que apresentam seção aberta ou tubular. Considerando os perfis de seção aberta com eixo de simetria perpendicular à alma, é possível compor uma seção duplamente simétrica, como foi utilizada neste trabalho. Ao realizar um comparativo dessa composição, constata-se um aumento proporcional à quantidade de perfis para as seguintes propriedades geométricas: momento de inércia em relação ao eixo perpendicular à alma, momento de inércia à torção e na área. As propriedades que são afetadas 
pela mudança do centro geométrico, como é o caso do momento de inércia em relação ao eixo paralelo à alma e a constante de empenamento, podem apresentar um incremento mais acentuado, porém dependem do grau de ação composta. Além da capacidade resistente, o comportamento em relação à instabilidade também pode ser afetado.

Dentre as tipologias de treliças existentes, a utilizada neste trabalho foi a treliça plana do tipo Warren sem montantes; essa configuração é bastante utilizada, pois permite um desempenho semelhante ao ser solicitada por cargas gravitacionais ou de sucção, devido à inclinação das diagonais. A relação vão-altura que se pretende utilizar na treliça é de aproximadamente 20, sendo a altura entre eixos de $100 \mathrm{~cm}$. As ligações entre as barras são realizadas de forma direta por meio de ligação parafusada.

\subsection{Enrijecedores}

A barra do banzo da treliça em estudo apresenta enrijecedores; seu uso possibilita um aumento da capacidade resistente em relação ao modo local. Os inseridos na alma reduzem a relação largura-espessura devido à mudança na dimensão, e o localizado na borda aumenta a rigidez do elemento com o qual está vinculado.

Desmond et al. (1980) estudaram o comportamento de enrijecedores intermediários caracterizando dois modos de instabilidade: o local e do enrijecedor, sendo este último conhecido como modo distorcional. Também constataram que o enrijecedor pode ser considerado totalmente eficaz quando o elemento se comporta como duas placas enrijecidas separadas e como parcialmente eficaz quando isso não ocorre.

Schafer e Peköz (1998b) indicaram que o comportamento da alma se subdivide em elementos de chapas separados pelo enrijecedor, em que cada subelemento terá a sua própria distribuição de tensão e largura efetiva.

A introdução de enrijecedores na alma do perfil pode alterar a deformada do modo localizado, que normalmente se manifesta inicialmente na alma, fazendo com que ocorra primeiramente nas mesas e gere pequenas deformações na alma (MARTINS; DINIS; CAMOTIM, 2016).

Ádány (2004) analisou a inserção do enrijecedor intermediário triangular na alma de perfis do tipo $U$ enrijecido, no qual variou o comprimento do enrijecedor na direção perpendicular à alma e na direção paralela se manteve com $20 \mathrm{~mm}$. Por meio de uma comparação das curvas obtidas da análise de estabilidade elástica, ilustradas na Figura 2.2, verificou-se que esses perfis não apresentavam pontos de mínimos bem definidos, sendo o 
primeiro o local e o segundo distorcional como nos perfis sem o enrijecimento na alma, mostrando-se mais evidente quanto maior o enrijecedor.

Figura 2.2- Comparativo das curvas da análise de estabilidade elástica para o perfil enrijecido.

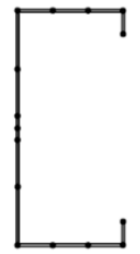

(a)

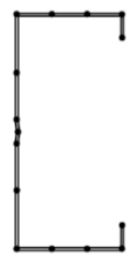

(b)

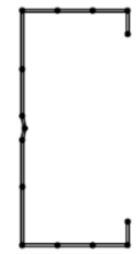

(c)

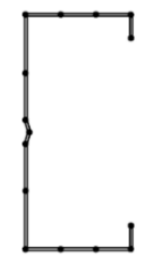

(d)

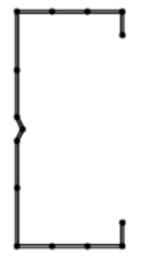

(e)

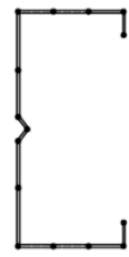

(f)

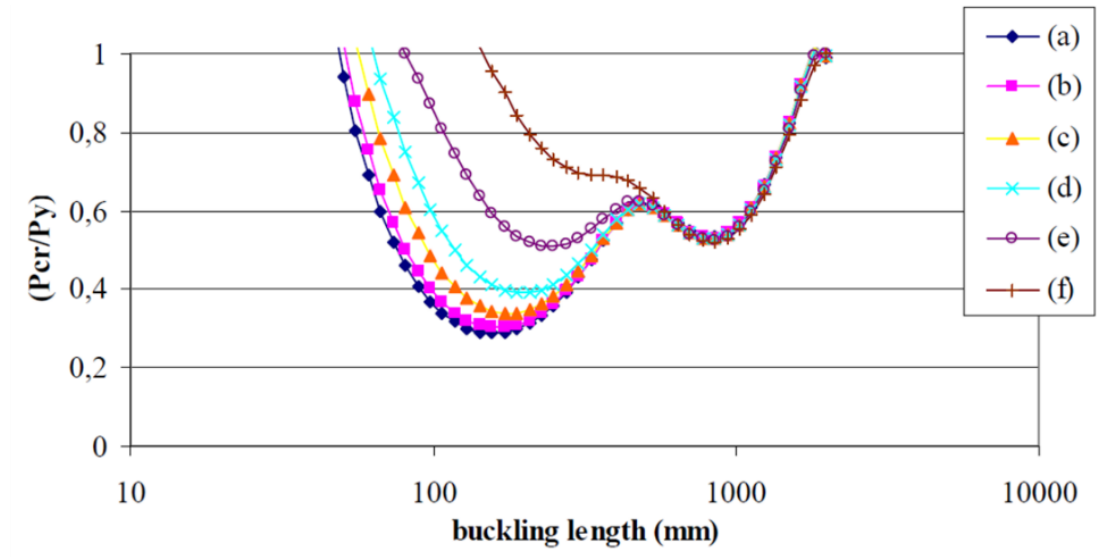

Fonte: Ádány (2004).

Apenas o mínimo localizado em torno de $850 \mathrm{~mm}$ de comprimento de semionda ficou definido e apresentou uma deformada característica do modo distorcional para todas as seções indicadas, como ilustrado na Figura 2.3.

Figura 2.3- Deformadas obtidas para $850 \mathrm{~mm}$ de comprimento de semionda.

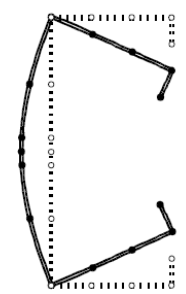

(a)

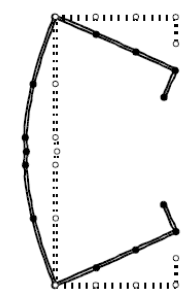

(b)

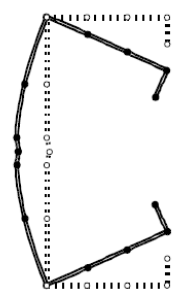

(c)

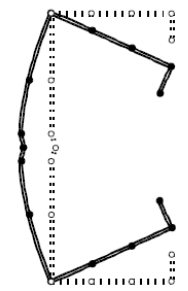

(d)

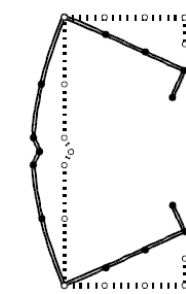

(e)

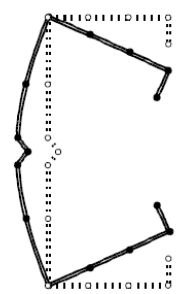

(f)

Fonte: Ádány (2004).

Observando as curvas em comprimentos de semionda menores, não se obteve o mesmo comportamento, a presença do enrijecedor intermediário implica em uma classificação do modo de flambagem que pode depender de como as linhas de interseção dos elementos são definidas. Considerando a definição geralmente utilizada, a deformada no comprimento de $170 \mathrm{~mm}$ seria 
considerada local principalmente na seção (a) e distorcional na seção mais enrijecida (f), devido à alteração da posição do nó do enrijecedor (Figura 2.4). O autor conclui que definir qual será a força crítica quando as formas das deformadas não são tipicamente definidas se torna um obstáculo.

Figura 2.4-Deformadas obtidas para $170 \mathrm{~mm}$ de comprimento de semionda.

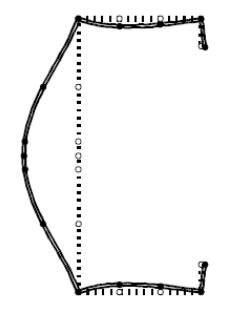

(a)

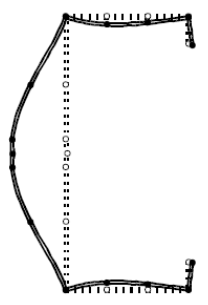

(b)

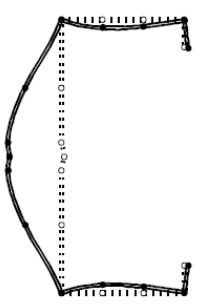

(c)

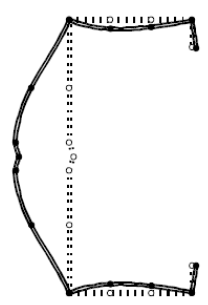

(d)

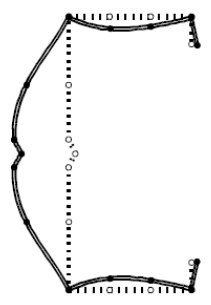

(e)

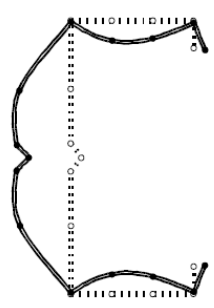

(f)

Fonte: Ádány (2004).

\subsection{Procedimentos normativos atuais}

Por se tratar de um sistema treliçado, os esforços predominantemente atuantes nas barras são os axiais. De acordo com a norma brasileira sobre dimensionamento de estruturas constituídas por perfis formados a frio, ABNT NBR 14762:2010, o comportamento estrutural de um elemento submetido à tração deve ser verificado de acordo com os seguintes itens:

1) Estado limite último (ELU) de escoamento da seção bruta;

2) ELU de ruptura da seção líquida fora da região da ligação;

3) ELU de ruptura da seção líquida na região da ligação;

4) Índice de esbeltez não deve exceder 300, tanto em seções com um perfil ou mais.

Para a compressão deve ser considerada a estabilidade da estrutura. As curvas de dimensionamento à compressão do SSRC (Structural Stability Research Council) utilizadas nas normas americanas de projeto em aço e adotadas pela norma brasileira, foram desenvolvidas com resultados experimentais de perfis laminados e soldados, e têm sido utilizadas para os formados a frio.

De acordo com Yu e LaBoube (2010), as especificações de projeto para a construção com uso dos perfis pesados de aço laminado a quente não abrangem completamente todas as informações necessárias de projeto para o aço formado a frio, devido às características e comportamentos distintos, portanto, por meio de pesquisas os métodos de dimensionamentos foram desenvolvidos. 
Uma dessas características é a tensão residual, que são tensões auto equilibradas existentes antes da aplicação do carregamento e que dependem da geometria da seção transversal, do tipo de aço e do processo de fabricação (REIS; CAMOTIM, 2001). Nos perfis laminados e soldados essas tensões ocorrem devido ao gradiente térmico, nos perfis formados a frio surgem principalmente de ações mecânicas. Essa tensão causa uma redução da tensão de proporcionalidade no diagrama tensão-deformação e uma não linearidade da curva para valores acima da proporcionalidade, o que pode ocasionalmente fazer com que elementos passem do trecho elástico para o inelástico antes do esperado.

Além da tensão residual, existem outros fatores que influenciam na resistência à compressão, como as propriedades mecânicas do aço e as imperfeições geométricas iniciais oriundas do processo de fabricação, da montagem e do transporte.

As imperfeições iniciais fazem com que a compressão não seja centrada, mas ocorra uma flexo-compressão desde o início do carregamento. O trabalho a frio possibilita o aumento da resistência à tração e no limite de escoamento, porém gera uma redução na ductilidade, além de gerar propriedades diferentes em uma mesma seção, pois determinadas regiões como as dobras sofrem maior influência do trabalho a frio do que as regiões planas.

A ABNT NBR 14762:2010 traz os seguintes métodos de dimensionamento: método da largura efetiva (MLE), método da seção efetiva (MSE) e método da resistência direta (MRD). O método da largura efetiva se caracteriza por uma análise dos elementos separados, determinando as propriedades efetivas da seção, este método se torna mais trabalhoso quando a seção transversal vai se tornando mais complexa, como, por exemplo, com a introdução de enrijecedores.

O MSE também utiliza as propriedades reduzidas da seção, mas leva em consideração o comportamento da seção como um todo para a obtenção de um coeficiente de flambagem local, o que também se torna complicado para seções não usuais.

O método da resistência direta proposto por Schafer e Peköz (1998c), utiliza as propriedades brutas da seção e é baseado em uma análise de estabilidade elástica, a qual pode ser obtida pelo método das faixas finitas (MFF), onde se considera todos os modos de instabilidade envolvidos. Este método possibilita a análise e o dimensionamento de uma grande quantidade de seções transversais prismáticas, as quais, nos outros métodos de cálculos, demandariam um maior tempo gasto em análises e cálculos. Além do método das faixas finitas, a análise de estabilidade elástica pode ser realizada por meio da teoria generalizada de vigas e do método dos elementos finitos (MEF). 
Assim como outros métodos de projeto, o MRD é semiempírico e foi desenvolvido a partir de seções pré-qualificadas e determinadas propriedades para o aço, nos quais estão associados fatores de confiabilidade. Para uma nova seção transversal, indica-se que quando houver dúvida na definição de determinado modo de flambagem, é importante adotar uma abordagem mais conservadora, assumindo que se trata de ambos os modos. Desse modo, garante-se a redução da resistência de pós-flambagem em comprimentos intermediários destravados e a inclusão de efeitos de interação (SCHAFER,2008).

Neste procedimento de cálculo, parte-se dos valores críticos da análise de estabilidade elástica para a obtenção dos esforços resistentes, utilizando as expressões contidas no Anexo C da ABNT NBR 14762:2010. Para a compressão centrada, considerando a instabilidade global, o valor característico da força axial de compressão resistente $\left(N_{c, R e}\right)$ pode ser calculado pelas equações 2.1 a 2.3 :

$$
\begin{gathered}
N_{c, R e}=\left(0,658^{\lambda_{0}{ }^{2}}\right) A f_{y} \quad \text { para } \lambda_{0} \leq 1,5 \\
N_{C, R e}=\left(0,877 / \lambda_{0}{ }^{2}\right) A f_{y} \quad \text { para } \lambda_{0}>1,5 \\
\lambda_{0}=\left(A f_{y} / N_{e}\right)^{0,5}
\end{gathered}
$$

Os parâmetros considerados nas expressões são:

$\lambda_{0}:$ Índice de esbeltez reduzido associado à flambagem global;

$N_{e}$ : Força axial de flambagem global elástica;

$A$ : Área bruta da seção transversal da barra;

$f_{y}$ : Resistência ao escoamento do aço.

Os valores exatos da força axial de flambagem global elástica $\left(N_{e}\right)$ podem ser obtidos pelas fórmulas contidas na subseção 9.7.2 da norma.

O valor característico da força axial de compressão resistente, associado à flambagem local $\left(N_{C, R l}\right)$ é obtida pelas expressões 2.4 a 2.6:

$$
\begin{gathered}
N_{c, R l}=N_{c, R e} \quad \text { para } \lambda_{l} \leq 0,776 \\
N_{c, R l}=\left(1-0,15 / \lambda_{l}^{0,8}\right) N_{c, R e} / \lambda_{l}^{0,8} \text { para } \lambda_{l}>0,776
\end{gathered}
$$




$$
\lambda_{l}=\left(N_{c, R e} / N_{l}\right)^{0,5}
$$

Onde:

$\lambda_{l}$ : Índice de esbeltez reduzido associado à flambagem local;

$N_{l}$ : Força axial de flambagem local elástica;

$N_{c, R e}$ :Valor característico da força axial de compressão resistente, associado à flambagem global.

Considerando o modo distorcional, valor característico da força axial de compressão resistente, é obtido nas expressões 2.7 a 2.9:

$$
\begin{gathered}
N_{c, \text { Rdist }}=A f_{y} \text { para } \lambda_{\text {dist }} \leq 0,561 \\
N_{c, \text { dist }}=\left(1-0,25 / \lambda_{\text {dist }}^{1,2}\right) A f_{y} / \lambda_{\text {dist }}^{1,2} \text { para } \lambda_{\text {dist }}>0,561 \\
\lambda_{\text {dist }}=\left(A f_{y} / N_{\text {dist }}\right)^{0.5}
\end{gathered}
$$

Os parâmetros considerados nas equações são:

$\lambda_{\text {dist }}$ : Índice de esbeltez reduzido associado à flambagem distorcional;

$N_{\text {dist }}$ : Força axial de flambagem distorcional elástica;

$A$ : Área bruta da seção transversal da barra;

$f_{y}$ : Resistência ao escoamento do aço.

\subsubsection{Barras compostas}

Historicamente as barras compostas foram amplamente empregadas em pontes metálicas treliçadas em aço laminado. Essas seções podem ser formadas por perfis colocados em contato ou espaçados, sendo que a ligação entre os componentes pode ocorrer pontualmente ao longo do comprimento ou de forma contínua.

Nos estudos realizados constatou-se o efeito do esforço cortante na capacidade resistente e no comportamento de deformação dessas seções. Galambos (1998) afirma que o efeito do cisalhamento faz com o dimensionamento das barras compostas comprimidas seja diferente do realizado nas seções simples. 
Quando ocorre o fenômeno da instabilidade global, surge um momento fletor formado pela força axial aplicada e o deslocamento lateral da barra, fazendo com que exista um esforço cortante atuando nas seções transversais da barra. Desse modo, a deformada final é constituída por um somatório que envolve a contribuição desses dois esforços, de modo que a solução da equação diferencial passa a ter um termo associado ao cisalhamento que reduz o valor da força crítica, como indicado na equação (2.10):

$$
P_{c r}=\frac{P_{\text {Euler }}}{1+\frac{n}{G A} \cdot P_{\text {Euler }}}
$$

Onde:

$P_{\text {Euler }}:$ Força crítica de Euler obtida desprezando a deformação devido ao cisalhamento; $n$ : Coeficiente que depende da forma da seção transversal;

$G$ : Módulo de elasticidade transversal;

A: Área da seção transversal.

A influência de considerar a deformação devido ao esforço cortante varia com o tipo de seção transversal, de modo que se a relação $\frac{n}{G A}$ for um valor relativamente pequeno, o valor da força crítica final pouco se altera em relação ao valor de Euler, podendo ser desprezado esse efeito, como é o caso das barras simples constituídas por exemplo por seções I, U, maciças, entre outras.

No entanto quando o valor da relação $\frac{n}{G A}$ é significativo ocorre uma redução da força axial de flambagem elástica. Nas barras compostas esse efeito ganha importância, pois o esforço cortante deve ser resistido principalmente pela alma da seção, a qual possui uma rigidez inferior a apresentada em uma seção maciça, como por exemplo em barras formadas por perfis espaçados e conectados de forma intermitente.

Nas barras espaçadas comprimidas conectadas por chapas observa-se que as chapas agem como a alma da seção, e transmitem o cortante para os componentes principais pela ação de flexão em combinação com o momento local desses componentes. As barras compostas formadas por chapas regularmente espaçadas formam um travamento em quadro, análogo em um sistema Vierendel, isto é, essas chapas são consideradas ligadas rigidamente as barras principais (TIMOSHENKO, GERE, 1961; GALAMBOS,1998). A hiperestaticidade da 
configuração é retirada admitindo a introdução de uma rótula no meio das barras entre cada ponto de ligação e também no meio da chapa, como ilustrado na Figura 2.5

Se a ligação entre a chapa e as barras principais for rotulada não ocorre a transmissão do cisalhamento para os elementos longitudinais, dessa forma, a chapa simplesmente espaça os componentes. A fixação das chapas pela alma dos elementos longitudinais não transmite o momento de forma eficaz atuando também como uma barra espaçada (GALAMBOS,1998).

Figura 2.5- Configuração geométrica e equilíbrio de forças em um painel típico.

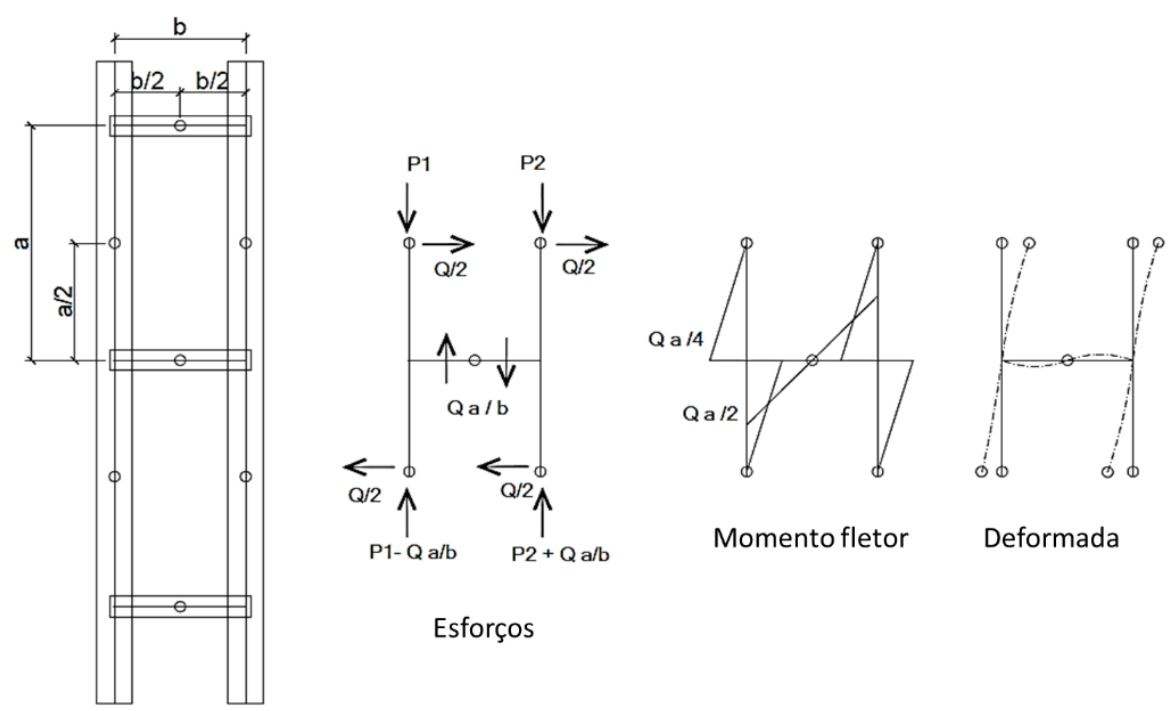

Fonte: Adaptado de Galambos (1998).

O desenvolvimento de deformação por cisalhamento ocorre particularmente nos modos de instabilidade por flexão, onde se observa a influência das ligações entre os componentes, pois elas possibilitam a manutenção da integridade da seção e influenciam as deformações entre os componentes de uma maneira compatível. Além disso, elas resistem ao esforço cortante propiciando uma redução do deslizamento longitudinal das seções gerando assim um certo grau de ação composta (FRATAMICO, 2017).

Os elementos de conexão possibilitam manter o espaçamento entre os perfis, fornecendo certa restrição à torção dos componentes principais. Estes elementos estão sujeitos a esforços como o cisalhamento e momento fletor que acompanham a flexão da barra composta (TEMPLE; ELMAHDY, 1996).

A forma como as barras compostas são unidas afeta o seu comportamento, quando os perfis são conectados continuamente possuem força resistente maior do que as barras conectadas em apenas alguns pontos. A menor resistência dos perfis unidos em alguns pontos 
se deve ao fato da força cortante introduzir um efeito maior nos deslocamentos. Além disso, o layout dessa ligação e qual elemento de conexão será utilizado também interfere na capacidade resistente, como por exemplo, o uso de chapas separadoras que podem estar dispostas inclinadas, horizontais ou ambas (MAIA, 2012).

Com relação as normativas atuais, a especificação americana (ANSI/AISI S100:2020) no item I1.2 considera para duas seções em contato submetidas à compressão os seguintes itens:

- $\quad$ Índice de esbeltez modificado;

- $\quad$ Estabelece o espaçamento entre as presilhas por meio de uma relação entre a esbeltez do conjunto e à da seção individual;

- $\quad$ O elemento de ligação intermediário deve ser capaz de transmitir uma força em qualquer direção de $2,5 \%$ da força axial final do conjunto, em qualquer ponto ao longo do comprimento;

- Especifica que os componentes individuais devem ser conectados nas extremidades por uma solda longitudinal com um comprimento de pelo menos a largura máxima da seção composta ou por um grupo de parafusos, os quais devem ser espaçados longitudinalmente pelo menos de 4 vezes o diâmetro do parafuso e a uma distância de pelo menos 1,5 vezes a largura máxima do elemento.

O princípio contido no primeiro item, citado anteriormente, considera que não se pode assumir que as barras individuais de uma seção composta estejam totalmente conectadas, de modo que as forças de cisalhamento sejam transferidas continuamente de um parafuso para outro (FRATAMICO, 2018).

O efeito da força cortante inserido na formulação do índice de esbeltez modificado foi derivado dos primeiros estudos em elementos compostos; a equação (2.11) é aplicável para as barras compostas sujeitas à instabilidade por flexão em relação ao eixo que solicita a ligação.

$$
(K L / r)_{m}=\sqrt{(K L / r)^{2}{ }_{o}+\left(a / r_{i}\right)^{2}}
$$

Onde:

$(K L / r)_{m}:$ Índice de esbeltez modificado;

$(K L / r)_{o}$ : Índice de esbeltez da barra composta;

$a$ : Distância entre os elementos de conexão intermediários (presilhas);

$r_{i}$ : Raio de giração mínimo da seção individual. 
Este equacionamento apresentado na norma reduz o valor da força associada à flambagem elástica por flexão, devido ao aumento do índice de esbeltez da seção composta. O uso do parâmetro modificado foi proposto a partir da equação de Bleich, que foi elaborada considerando um número relativamente grande de pontos de conexão uniformemente espaçados ao longo do comprimento, de modo que o efeito da resistência ao cisalhamento pode ser considerado constante, dessa forma, não se consegue explicar com precisão o efeito da ação parcialmente composta (RASMUSSEN et al, 2020).

O estudo da aplicação desse índice em elementos formados a frio ainda é recente, sendo conveniente verificar se as suposições assumidas no desenvolvimento da formulação podem ser aplicadas.

Stone e LaBoube (2005) investigaram experimentalmente o uso desse parâmetro em seções do tipo I, formada por duas seções U. Constataram que para perfis de maiores espessuras o uso do parâmetro modificado não era necessário, podendo-se utilizar a esbeltez da seção composta; para as espessuras menores, a razão entre força experimental e a de norma apresentou valores maiores que 1 na maior parte dos corpos de provas, portanto, em média a utilização do índice de esbeltez modificado se mostrou a favor da segurança.

Whittle e Ramseyer (2009) fizeram uma análise sobre a capacidade resistente à compressão em seção composta do tipo fechada, formada por perfis $U$, onde os enrijecedores de borda foram unidos por meio de pontos de solda.

Os ensaios realizados consideraram as barras bi apoiadas, havendo variações na quantidade e localização dos pontos de soldas, assim como da espessura do perfil. As forças máximas obtidas experimentalmente foram maiores que as obtidas através do uso da razão de esbeltez modificada em todos os corpos de provas. O uso do índice se mostrou mais conservador para as espessuras maiores e nas peças mais esbeltas globalmente, a capacidade axial determinada pela razão de esbeltez do conjunto foi considerada menos conservadora do que a calculada com base na razão modificada.

Segundo Fratamico et al (2018) a abordagem da esbeltez modificada não possibilita a previsão dos efeitos devido à distribuição e a quantidade de fixadores na flambagem por torção, flexo torção, local e distorcional, e pressupõem uma perda da rigidez ao cisalhamento nos elementos de fixação.

O índice de esbeltez modificado não é aplicável quando o espaçamento das ligações entre os componentes for muito grande e quando a resistência ao deslizamento entre as seções for pequena, como por exemplo, na superfície galvanizada presente nos perfis formados a frio (GEORGIEVA; SCHUEREMANS; PYL, 2012). 
De acordo com os estudos citados anteriormente, a utilização do parâmetro modificado nas configurações analisadas indica que seu uso estaria a favor da segurança, pois reduz o valor da força crítica. Em determinados casos essa diferença entre o valor estimado e o experimental pode se tornar significativo, levando a um dimensionamento conservador. Além disso, a depender do espaçamento utilizado e das condições de superfície desses perfis seu uso pode se tornar inadequado. Assim, devido a quantidade de variáveis que podem influenciar o esforço resistente e os modos de instabilidade das barras compostas torna-se complicada a aplicação do índice de esbeltez modificado em qualquer caso.

Além da consideração da modificação do índice de esbeltez, a norma americana especifica que para se evitar a flambagem por flexão das barras individualmente o espaçamento entre as presilhas não deve exceder a metade da esbeltez do conjunto, como indicado na equação 2.12, esse item também é empregado pela norma brasileira.

$$
a / r_{i} \leq 0,5(K L / r)_{0}
$$

Onde:

$a$ : Distância entre os elementos de conexão intermediários (presilhas);

$r_{i}$ : Raio de giração mínimo da seção individual;

$(K L / r)_{o}:$ Índice de esbeltez da seção composta.

A especificação europeia para projeto de estruturas metálicas, na parte que trata dos formados a frio (EN 1993-3-1:2006), não fornece muitas informações sobre o dimensionamento das seções compostas, apenas especifica qual curva de flambagem global deve ser usada para determinar a resistência final da composição para um número bem limitado de seções. Meza (2020) cita que a norma europeia não fornece nenhuma orientação sobre o espaçamento máximo dos elementos de conexão, ou como esse espaçamento e o tipo do elemento utilizado na ligação pode afetar a capacidade final.

Rasmussen et al (2020) cita que quando o cisalhamento ocorre como uma ação secundária, por exemplo, durante a flambagem, é viável a aplicação de torque nos parafusos; nas barras onde o cisalhamento nos pontos de fixação é uma ação primária, como nas vigas, deve-se verificar se a força de cisalhamento não excede a força de atrito disponível. Embora o atrito suficiente possa estar disponível para assumir a ação composta em vigas, a capacidade final provavelmente será afetada pelo deslizamento assumindo a existência de nenhuma ação composta. 
2.3 Estudos realizados com seções compostas

Johnston (1971) apud Galambos (1998) definiu quatro modos de flambagem (Figura 2.6) para barras de seções compostas espaçadas em aço laminado, que apresentam chapas de extremidades rigidamente conectadas. Esses modos variam de acordo com as vinculações das barras. Para barras bi apoiadas constatou-se a possibilidade de ocorrer dois possíveis modos, os quais dependem da razão entre o momento de inércia do conjunto e o individual do perfil, e também do comprimento da chapa de fixação da extremidade em relação ao comprimento total da barra.

Figura 2.6- Modos de flambagem para seções compostas proposto por Johnston.

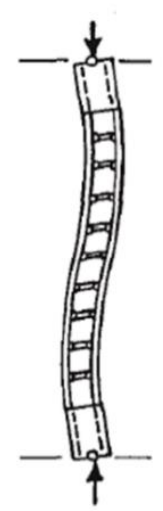

a) Apoiadoapoiado

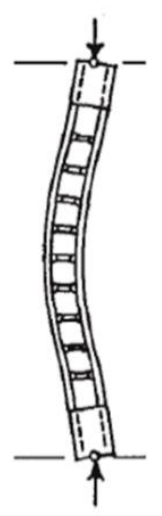

b) Apoiadoapoiado

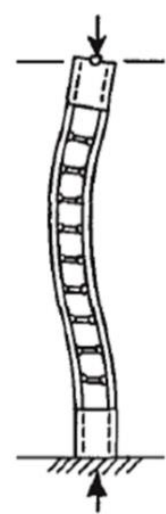

c) Apoiadoengastado

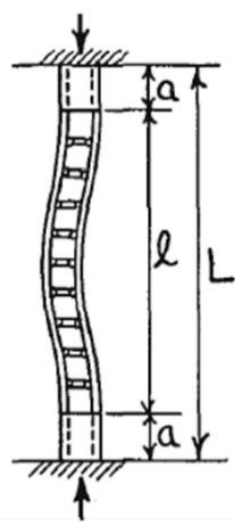

d) Engastadoengastado

Fonte: Traduzido de Johnston (1971) apud Galambos (1998).

O modo "a" foi chamado de curvatura em $\mathrm{S}$, neste não há mudança diferencial no comprimento entre as duas barras individuais, e a força crítica não se altera com a relação entre as inércias; no modo "b" existe um encurtamento diferente entre as barras. Sendo que o ganho de resistência se dá apenas nos casos "b" e "c", onde as mudanças diferenciais no comprimento do componente estão associadas com rotações diferentes em magnitude e ou sentido das extremidades. Seus resultados trouxeram importantes contribuições no estudo das barras compostas, onde se verificou o efeito da ligação rígida nas extremidades da barra.

Temple e Elmahdy (1996) realizaram um programa experimental com perfis soldados, o objetivo foi investigar o efeito do número de chapas conectoras na capacidade última de barra com seção composta. A seção estudada considerava dois perfis do tipo U formando uma seção fechada, como ilustra a Figura 2.7. Com os resultados concluiu-se que a força crítica de instabilidade em torno do eixo x não era afetada pelo número de chapas, em relação ao eixo y, 
a capacidade resistente obtida era crescente com o aumento da quantidade de ligações, indicando a influência das chapas quando a barra é solicitada no eixo que as mobiliza.

Figura 2.7- Seções estudas por Temple e Elmahdy.
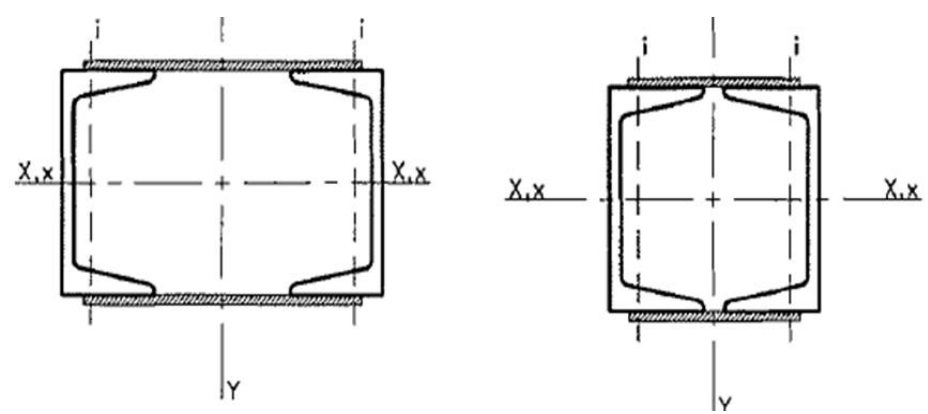

Fonte: Adaptado de Temple and Elmahdy (1996).

Sherman e Yura (1998) observaram que um dos fatores de maior importância na capacidade resistente à compressão de barras compostas, duplas cantoneiras laminadas a quente, é o impedimento do deslizamento entre os perfis, principalmente nas ligações localizadas nas extremidades. Com o aumento do número das ligações ao longo do comprimento e do aperto do parafuso ocorria um aumento de resistência, sendo que esse aumento não era proporcional com a quantidade de ligações inseridas.

Partindo para as pesquisas em perfis formados a frio (PFF) um dos primeiros trabalhos relatados foi realizado por Rondal e Niazi (1990), este possui como objeto de estudo barras formadas por dois perfis do tipo U conectados por chapas igualmente espaçadas (batten columns) e por meio de um outro perfil unindo as almas dos componentes principais.

Em suas análises observou-se a existência de dois modos de instabilidade global para a ligação que utiliza como conector o perfil, ilustrado na Figura 2.8, e também uma maior flexibilidade em comparação com a ligação por chapas.

Figura 2.8- Modos de instabilidade da seção composta estudada por Rondal e Niazi.
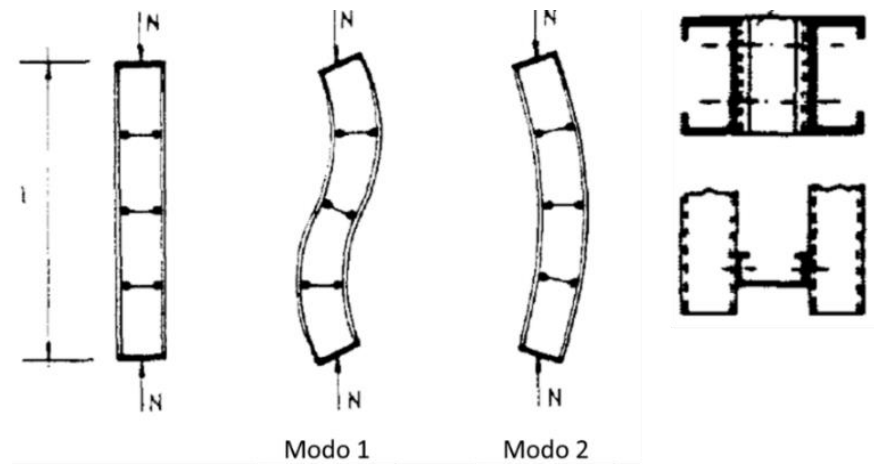

Fonte: Rondal e Niazi (1990). 
No trabalho de Georgieva, Schueremans e Pyl (2012) foi analisada a capacidade resistente à compressão de seções formadas por perfis do tipo $\mathrm{Z}$ unidos pelo enrijecedor de borda da mesa superior (Figura 2.9). O objetivo foi avaliar a aplicabilidade das recomendações europeias disponíveis para o projeto, e apontar quais são as informações que não estão disponíveis para um bom dimensionamento.

Figura 2.9- Seção estudada por Georgieva, Schueremans e Pyl.

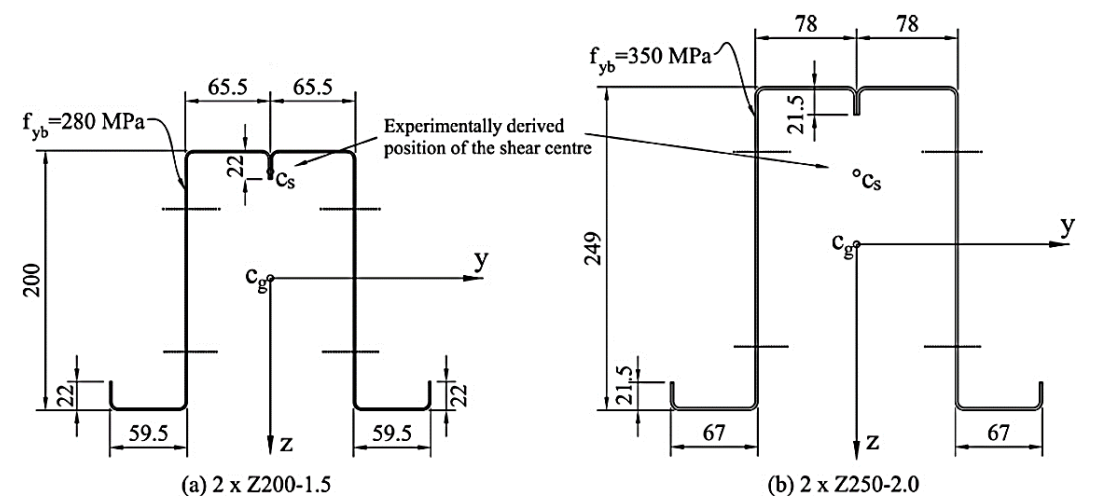

Fonte: Georgieva, Schueremans e Pyl (2012).

O ensaio consistiu em barras isoladas submetidas à compressão. Os corpos de provas utilizados apresentavam as seguintes características: comprimento de 4,45 metros, as ligações de extremidades foram consideradas semirrígidas, a distância dos espaçadores intermediários, de espessura de $6 \mathrm{~mm}$, variou entre um e dois metros, de forma a verificar os possíveis efeitos benéficos da utilização de mais elementos de conexão que o necessário.

A previsão teórica considerou alguns valores de propriedades geométricas vindas de trabalhos experimentais realizados concomitantes. Foram consideradas as seguintes suposições na obtenção da resistência da barra:

- $\quad$ Dois perfis $\mathrm{Z}$ independentes;

- Seção U com enrijecedores complexos. Consideração adotada, pois, no código europeu a força axial elástica para a flexo torção não é fornecida para elementos simétricos em relação ao seu eixo de menor inércia, e esse modo foi verificado experimentalmente;

- Limite inferior que considera a inércia à torção e a constante de empenamento igual a duas vezes a do perfil $\mathrm{Z}$ individual;

- $\quad$ Limite superior que considera as mesmas propriedades do outro limite, mas obtidas para a seção do tipo U com enrijecedores complexos.

Os resultados experimentais obtidos quando comparados aos procedimentos gerais de cálculo da norma americana e europeia indicaram um conservadorismo das normas na 
estimativa da capacidade resistente à compressão. Os autores citam também que o projeto de elementos compostos depende das propriedades da seção transversal, as quais não podem ser obtidas com precisão, como a constante de empenamento e a inércia à torção, e outras que para serem obtidas requerem ensaios complementares, como a posição do centro de cisalhamento em relação ao centro geométrico, o momento de inércia da seção em relação ao eixo que solicita as conexões. Por meio deste estudo, indicou-se a influência dos elementos de conexão para determinar a resistência de barras compostas, sendo necessário recomendações sobre sua forma, rigidez e a folga do furo.

Georgieva et al (2012a) realizaram estudos experimentais em seções de duplo Z parafusadas (Figura 2.9) com objetivo de determinar a rigidez à flexão em relação ao eixo que solicita a ligação e o comportamento global do elemento em compressão. Nos ensaios de flexão a quatro pontos, a força foi distribuída uniformemente na alma do perfil sobre os espaçadores impedindo a rotação da seção e evitando sua distorção devido às forças concentradas. Foram utilizados transdutores de deslocamentos em três pontos ao longo do vão de $4 \mathrm{~m}$ em estudo e as imperfeições iniciais foram aferidas.

O resultado do ensaio mostrou que a rigidez à flexão era maior que a rigidez total de duas seções $\mathrm{Z}$ independentes, mas significativamente abaixo do valor de uma seção com ação composta completa. O perfil de maior altura apresentou menores rigidezes e a uma falha prematura devido principalmente às grandes imperfeições iniciais que prejudicou o contato entre os perfis. Os autores mencionaram que a superfície galvanizada dos perfis não permitiu que o deslizamento nas conexões parafusadas fosse eliminado, e que as folgas existentes nas ligações resultaram em um deslizamento longitudinal substancial entre os perfis.

No ensaio de compressão, o modo de falha predominante foi por flexo torção, sendo observado também o modo local nos estágios iniciais de carregamento e nos finais o distorcional nas mesas do perfil, e posteriormente o escoamento. Quanto à capacidade final, este valor não se tornou maior quanto menor era o espaçamento das peças de conexão, pelo fato de que os espaçamentos utilizados não foram suficientes para excluir os efeitos da flambagem por distorção. Os autores citam que as futuras normas de projeto devem considerar o efeito das ligações, pois estas afetam o comportamento global da estrutura e os vários efeitos da instabilidade nos elementos de paredes finas.

Além da parte experimental Georgieva et al (2012b) realizou um estudo numérico com base nos resultados obtidos, nesse trabalho citou-se a importância de se introduzir as imperfeições e a rigidez das ligações para que se possa capturar os vários efeitos de instabilidade 
possíveis, além da necessidade de se obter um modelo em elementos finitos que possua o equilíbrio entre precisão e eficiência.

No modelo utilizou-se o elemento de casca não linear, as propriedades do material foram definidas por uma relação de tensão e deformação bi linear. Na modelagem os cantos arredondados da seção foram substituídos por cantos vivos, sendo que essa alteração introduz pequenas quantidades adicionais de material e, portanto, de rigidez.

As peças de conexão foram conectadas aos perfis nos locais onde estariam os parafusos por meio de molas, a flexibilidade da ligação parafusada foi introduzida por meio de uma relação trilinear entre a força e o deslocamento, caracterizando o comportamento de um parafuso submetido ao cisalhamento.

O primeiro trecho do diagrama representa o estágio de atrito estático antes da ocorrência do escorregamento, o segundo compreende o estágio de escorregamento e o terceiro é caracterizado pelo fenômeno de esmagamento da parede do furo. A obtenção dessas rigidezes pode ser feita por meio de análises teóricas, ensaios experimentais ou também por expressões fornecidas na literatura. Os autores obtiveram a primeira rigidez por meio da calibração do modelo, onde o valor foi comparado por meio dos deslocamentos verticais medidos no ensaio de flexão, os valores para o segundo e terceiro estágio foram obtidos do ensaio de cisalhamento.

As imperfeições iniciais da seção foram inseridas dos resultados de uma análise linear de flambagem, em que uma determinada amplitude dos autovetores principais foram selecionadas, foram também introduzidas as imperfeições globais por meio de outros valores de referência. Os resultados obtidos apresentaram boa concordância com os dados experimentais.

Zaharia e Dubina (2006) estudaram o comportamento de nós de treliça parafusados em aço formado a frio, tendo como objetivo obter um modelo teórico para a rigidez da ligação. A expressão (2.13) proposta possibilita obter o terceiro valor de rigidez do diagrama tensão deformação de um parafuso submetido ao cisalhamento.

O equacionamento proposto possui como variáveis o diâmetro do parafuso e a espessura das chapas conectadas. Os autores indicam que o intervalo de validade da equação ocorre para: parafusos com diâmetro nominal entre 8 e $16 \mathrm{~mm}$, espessura da chapa no intervalo de 2 a $4 \mathrm{~mm}$, uma folga de $1 \mathrm{~mm}$ para o furo e que o plano de corte passe pela rosca do parafuso. A rigidez a rotação da ligação também pode ser estimada adicionando mais uma variável, que é a distância entre os parafusos. 


$$
K=6,8 \frac{\sqrt{D}}{\left(\frac{5}{t_{1}}+\frac{5}{t_{2}}-1\right)}(\mathrm{kN} / \mathrm{mm})
$$

Onde:

$D$ : Diâmetro do parafuso $(\mathrm{mm})$;

$t_{1}$ e $t_{2}$ : São as espessuras das chapas dos perfis conectados;

Os autores também citam que a ligação das diagonais e montantes com os banzos em barra composta pode modificar a suposição clássica de nós articulados, quando se relaciona a esbeltez do elemento com a utilização de dois ou mais parafusos para cada mesa da seção do tipo U conectada aos banzos. Desse modo, pode-se alterar o comprimento de flambagem da barra e introduzir esforços adicionais, a possibilidade de considerar os nós rígidos também não condiz com a realidade pois existe deformabilidade na ligação.

Ting (2013) realizou um estudo teórico e experimental sobre o comportamento de seções constituídas por perfis do tipo U enrijecido em duas configurações. Na primeira os perfis são unidos pela alma e na segunda eles possuem um afastamento como ilustrado na Figura 2.10.

Utilizaram duas dimensões para os perfis, sendo um com altura de $75 \mathrm{~mm}$ e outro com $90 \mathrm{~mm}$, mas ambos com espessura de 1,2 mm. Também foram consideradas variações na esbeltez global e no espaçamento dos elementos de fixação entre os perfis. O aço empregado apresentava revestimento em zinco e alumínio e uma resistência mínima ao escoamento de 550 MPa. Ao todo foram realizados 138 corpos de provas, deste total dividiu-se em: 48 seções com espaçamento entre os perfis, 66 com seções justapostas e 24 perfis únicos; as condições de contorno consideradas para as barras curtas, intermediárias e esbeltas foi a biarticulada e para as barras de $30 \mathrm{~cm}$ de comprimento foi a engastada.

Figura 2.10- Seções analisadas por Ting.
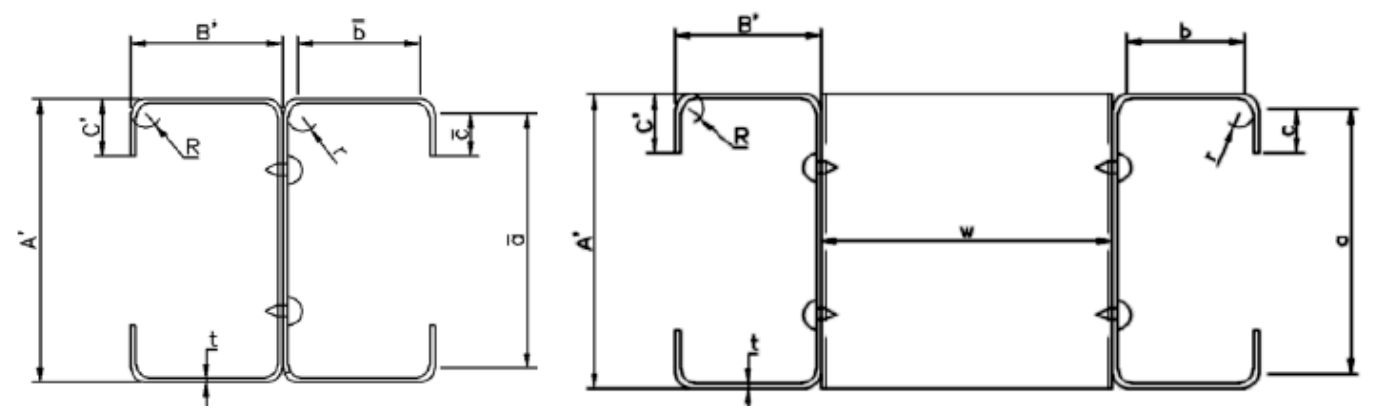

Fonte: Ting (2013). 
Verificou-se que a resistência das barras foi governada principalmente pelas seguintes variáveis: o espaçamento dos elementos de conexão ao longo do comprimento, os vínculos de extremidade, a esbeltez e pelo espaçamento entre os perfis.

O comparativo realizado entre as duas configurações mostrou que para o perfil menor a resistência da seção com uma lacuna foi superior a outra na maioria dos resultados, no perfil de maior dimensão houve uma pequena redução no valor da força última, para os comprimentos de barra analisadas, devido à alteração em relação ao o eixo em que ocorria o maior momento de inércia.

Considerando o efeito do espaçador, observou-se que com menores quantidades a barra ficava menos restringida e dificultava a ação conjunta, afetando assim a estabilidade, esse comportamento se tornava mais evidente quando o espaçamento não atendia à especificação da norma americana. Para uma quantidade de presilhas situada dentro do intervalo que respeita as especificações da norma verificou-se que os valores finais de resistência foram próximos, assim como as deformadas; notou-se que a fixação no comprimento médio é vital para que ocorra alguma ação conjunta, independentemente do tipo de seção e da quantidade de espaçadores, se tornando este um ponto crítico devido à ocorrência da máxima deflexão.

Para a configuração em que os perfis estão justapostos constatou-se um certo conservadorismo quanto os valores de resistência obtidos pelo MLE e pelo MRD, em relação aos dados experimentais, assim como, a aplicação da esbeltez modificada para barras mais longas em relação as curtas, pois estas barras tendem a sofrer a instabilidade global que é afetada pelo uso do índice modificado, o qual reduz as tensões previstas.

Uma metodologia de cálculo foi proposta para a seção com perfis separados, em que se considerou toda a inércia devido ao espaçamento dos perfis e propriedades como a constante de empenamento e inércia à torção iguais as da seção com os perfis unidos; os valores de tensão críticas dos modos local e distorcional foram obtidos de análise de estabilidade elástica que considera uma seção do tipo I com espessura reduzida para a alma. Essa abordagem se apresentou conservadora para as barras mais longas e não conservadora para as mais curtas.

Dabaon, Ellobody e Ramzy (2015) realizaram um estudo experimental com 5 barras em seção composta em aço formado a frio com espessura de $2 \mathrm{~mm}$. Os perfis foram espaçados e suas mesas foram conectadas por chapas com ligação soldada, a condição de contorno utilizada no ensaio foi bi apoiada. Os autores utilizaram diferentes razões de esbeltez, onde a seção foi alterada, mas mantiveram o comprimento da barra igual para todos os corpos de prova. $\mathrm{O}$ espaçamento entre os perfis variou de 25 a $75 \mathrm{~mm}$ e o das chapas conectoras de 150 a $400 \mathrm{~mm}$. A Figura 2.11 ilustra a seção transversal e uma das variações realizadas. 
Figura 2.11- Seção e esquema de montagem utilizado por Dabaon, Ellobody e Ramzy.

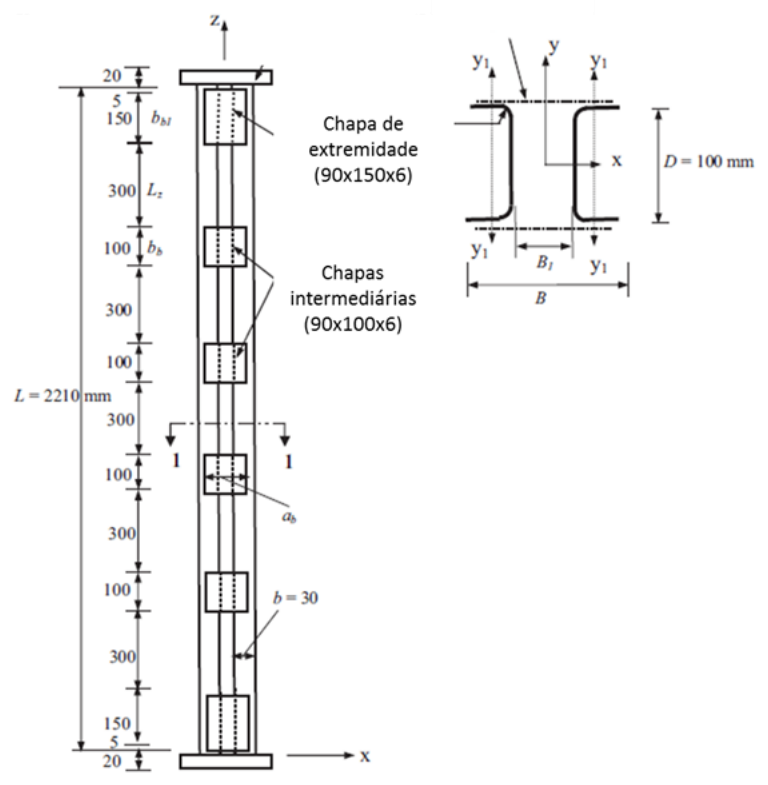

Fonte: Dabaon, Ellobody e Ramzy (2015).

Os valores experimentais foram comparados com os valores obtidos das especificações americana, europeia e dos padrões utilizados na Austrália e Nova Zelândia. Os resultados mostraram que as especificações foram contra a segurança para os corpos de provas que tinham como modo de falha principal o local, porém para o modo global por flexão as especificações foram conservadoras.

Quanto ao efeito do aumento do espaçamento entre os perfis, verificou-se um acréscimo na força crítica para uma mesma quantidade de pontos de conexão; em relação ao número de chapas conectoras houve uma redução da resistência da barra quando existia uma menor quantidade de chapas para uma mesma seção analisada. A deformada localizada foi observada quando em uma dada seção o espaçamento das chapas e o distanciamento entre os componentes se tornavam maiores, considerando o contrário o modo global se manifestava na barra.

O efeito dos espaçadores na resistência última e no comportamento de barras compostas formadas por perfis do tipo U foi analisado por Vijayanand e Anbarasu (2017) por meio de um estudo teórico. Os valores analíticos foram obtidos por meio do método da resistência direta e o da largura efetiva, que posteriormente foram comparados aos obtidos pelo modelo em elementos finitos. A validação do modelo numérico foi realizada utilizando os resultados experimentais do trabalho de Rondal e Niazi (1990).

Posteriormente foram selecionadas duas seções com espessura de 1,6 mm, onde fixouse o espaçamento entre os elementos, de forma que os momentos de inércia em x e y fossem 
praticamente iguais, o espaçamento das chapas conectoras foi obtido considerando o item estabelecido na norma americana, o comprimento dos corpos de prova variou em função de obter barras mais ou menos esbeltas.

Os resultados obtidos com base em uma análise comparativa mostraram que as barras esbeltas apresentaram o modo global por flexão, a razão entre o valor obtido pelo MEF em relação aos de norma foi inferior a 1, indicando que a estimativa fornecida pelas normas não possibilitaria um projeto seguro. Para esbeltezes menores verificou-se a ocorrência do modo local, a comparação dos métodos indicou valores próximos a 1 ou superiores, portanto, nesse caso os métodos atuais de obtenção da capacidade resistente apresentariam estimativas mais realistas e a favor da segurança.

Ting et al (2018) pesquisaram o efeito do espaçamento da ligação parafusada no comportamento de seções compostas por perfis do tipo U justapostos pela alma, e submetidos a um carregamento axial. Os resultados dos testes experimentais e do modelo em elementos finitos apresentaram valores inferiores ou próximos aos da norma AISI para barras curtas, intermediárias e esbeltas, que falharam devido a uma combinação de flambagem local e global ou somente pelo modo global. O efeito observado em relação ao espaçamento dos parafusos foi o de uma redução da resistência com uma menor quantidade de ligações; no caso da barra curta quando o espaçamento dos parafusos foi dobrado e a resistência foi reduzida em cerca de 5\% a $10 \%$, nas barras intermediárias, a redução foi de cerca de $10 \%$ a 15\%. Nas barras esbeltas não houve alterações significativas com espaçamento variável dos parafusos, pois sua falha se deu principalmente pela flambagem global.

O comportamento da instabilidade global foi abordado por Fratamico et al (2018) em seções U unidas pela alma por meio de pares de parafusos autoperfurantes distribuídos ao longo do comprimento da barra. As condições de contorno foram avaliadas por meio da obtenção da rigidez. Foram avaliadas duas configurações para os fixadores, uma com espaçamento uniforme no comprimento e outra com um grupo maior de elementos de ligação nas extremidades conforme determinado na norma americana; esta variação teve como objetivo verificar a influência da ligação de extremidade na capacidade resistente. Os autores citam que esse grupo de parafusos reduz o escorregamento entre os componentes possibilitando o aumento da ação composta e, portanto, da resistência e da rigidez à flexão.

Para obter a rigidez da extremidade utilizaram o deslocamento lateral a meia altura e o método de Southwell para estimar o valor do fator K (coeficiente de flambagem), aplicado para obter o comprimento efetivo de flambagem. 
O resultado dos ensaios das barras mostrou que o efeito benéfico do aumento de rigidez e da resistência com o uso do grupo de parafusos só foi observado quando não prevalecia a ocorrência da interação do modo local e global, sendo assim, seu efeito foi mais pronunciado para as seções com espessura maior e menor altura de alma. Portanto, pode-se indicar que o grupo de parafusos foi mais eficaz quando o modo global era predominante em relação ao local. Com relação aos valores de coeficiente de flambagem por flexão $(\mathrm{K})$, mesmo havendo um certo incremento na rigidez com o grupo de parafusos seu efeito foi pequeno, em média o fator $\mathrm{K}$ foi igual a 0,72 e 0,89 , considerando respectivamente a inércia calculada como ação composta ou não.

Algumas abordagens para a obtenção da capacidade resistente por meio do método da resistência direta foram feitas utilizando análises de estabilidade via o MFF e o MEF, os dados obtidos com condições de contorno rotuladas mostraram-se conservadores, e quando se considerou as extremidades fixas e com inércia calculada pelo teorema dos eixos paralelos, verificou-se que a força última pode ser superestimada.

Kherbouche e Megnounif (2019) propuseram um estudo numérico sobre o comportamento de seções compostas fechadas e abertas submetidas ao esforço de compressão uniforme, com a utilização de chapas como conectores (Figura 2.12).

Este trabalho baseou-se nos resultados experimentais obtidos por Dabaon, Ellobody e Ramzy (2015) para elaboração e validação do modelo em elementos finitos não linear. Um estudo paramétrico foi realizado variando-se o espaçamento dos perfis, o comprimento da barra e o comprimento de flambagem; e os resultados da capacidade resistente à compressão foram comparados com valores normativos.

Figura 2.12- Seções estudadas por Kherbouche e Megnounif.

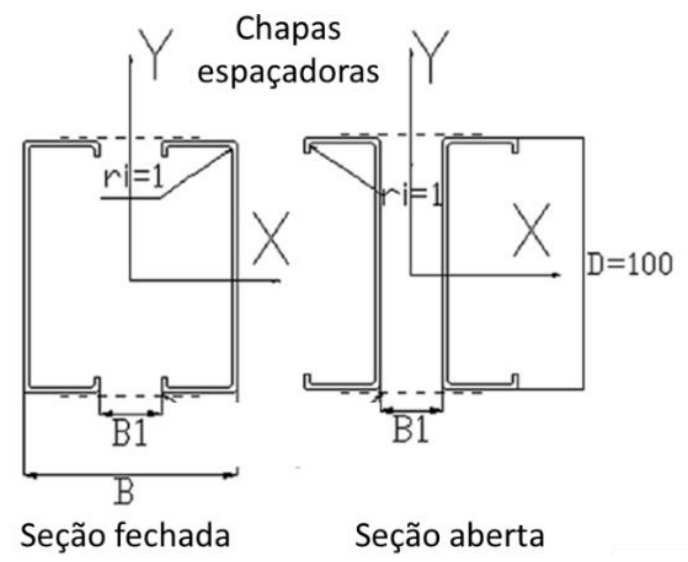

Fonte: Adaptado de Kherbouche e Megnounif (2019). 
Concluiu-se que as especificações da AISI foram mais conservadoras para barras que falham pelo modo global do que pelo modo local considerando a seção aberta; para a seção fechada o valor médio da relação entre a força última de norma em relação a do modelo também se mostrou a favor da segurança. A relação espaçamento dos perfis e a largura da alma assim como a esbeltez influenciam os modos de falha e sua resistência para ambas as seções. Os autores citam também que o comportamento dos elementos de paredes finas é muito sensível a pequenos detalhes na seção transversal, sendo importante uma análise de estabilidade para toda a seção.

Meza (2018) e Meza et al (2020) testaram algumas barras de aço formadas a frio com diferentes seções transversais (Figura 2.13), com intuito de investigar os efeitos do espaçamento das peças de conexão e o contato entre os componentes na capacidade resistente final, e nas diferentes interações de instabilidade. As chapas ou perfis utilizados para unir os componentes nas seções são elementos contínuos. Nos ensaios, a força foi aplicada com uma determinada excentricidade e com condição de contorno rotulada; e utilizaram parafusos sextavados e autoperfurantes para conectar os componentes. Os autores relatam que os dois tipos de ligação podem gerar comportamentos diferentes quando submetidos à solicitação, comportamento investigado por meio de um ensaio de cisalhamento simples.

Figura 2.13- Seções estudadas por Meza et al.

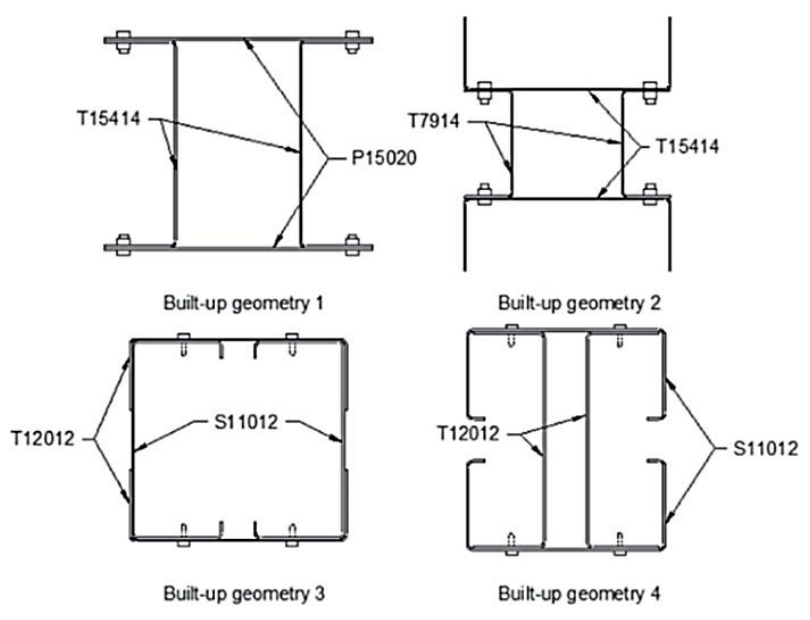

Fonte: Meza et al (2020).

No ensaio de cisalhamento para a ligação com o parafuso sextavado, a espessura ensaiada foi maior que a utilizada para o autoperfurante. Os resultados foram plotados em um gráfico de força versus alongamento (Figura 2.14). 
Figura 2.14- Curva força versus alongamento para o comportamento da ligação.

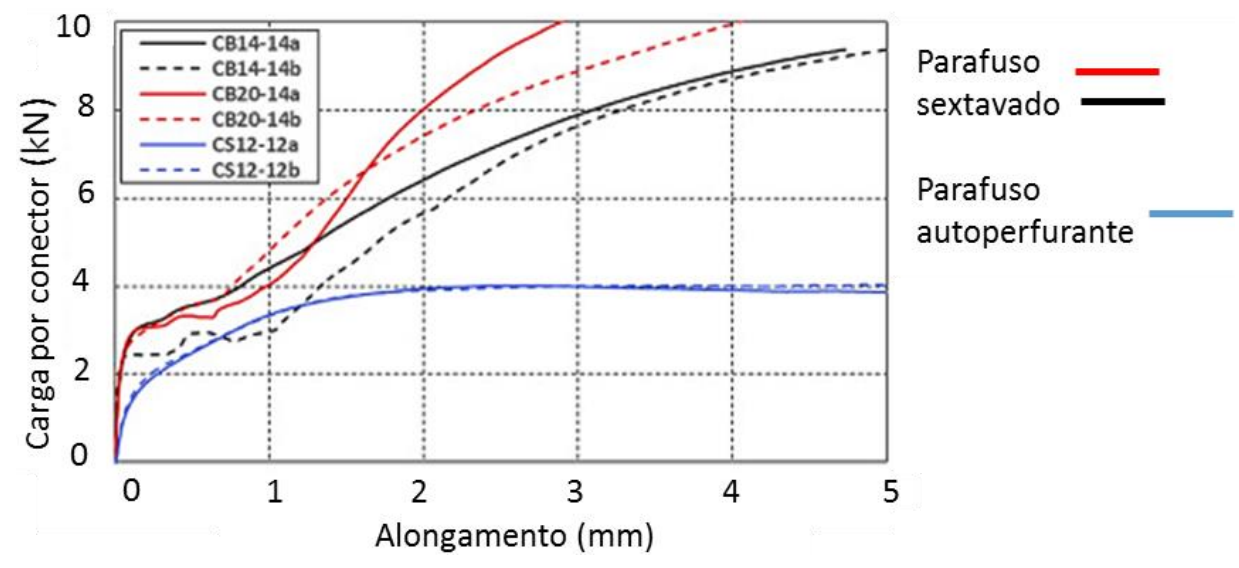

Fonte: Adaptado de Meza et al (2020).

Observou-se que, com o aumento da força, o alongamento para a ligação com o parafuso sextavado foi menor em comparação com o outro tipo até determinado estágio de carregamento, sendo seguido por uma pequena estabilização e posteriormente uma curva crescente. Para o outro tipo de parafuso a curva apresentou uma forma diferente, em que, para um determinado valor constante de força os alongamentos se tornavam maiores. Como não foram utilizadas as duas formas de fixação para uma mesma seção, não é possível verificar de forma comparativa a contribuição do tipo de fixação na capacidade resistente final, mas se pode concluir que apresentam comportamentos distintos à solicitação cisalhante.

O modo local foi observado em todos os corpos de prova antes da ocorrência do modo global por flexão da barra como um todo. Para todas as seções, verificou-se uma força crítica ligeiramente maior para o carregamento aplicado com a menor excentricidade (L/1500). Em relação ao espaçamento dos parafusos, os autores indicaram um efeito insignificante na capacidade final, quando a flambagem dos componentes entre os pontos de ligação não era a crítica.

Phan e Rasmussen (2019) realizaram um estudo experimental e teórico sobre o efeito da configuração das ligações e da geometria do perfil sobre a rigidez à flexão das barras compostas em aço formado a frio. Foram realizados ensaios de flexão em relação ao eixo de que solicita a ligação; a seção consistia em dois perfis tipo $U$ unidos pela alma, em que foram selecionadas duas alturas e duas espessuras. Além da variação da seção, foram analisadas três formas de ligação: com o uso de parafusos sextavados, autoperfurantes e solda.

A obtenção da rigidez equivalente foi realizada considerando o comportamento elástico linear, mas o ensaio prosseguiu até a falha. $\mathrm{O}$ ensaio de flexão a 4 pontos teve um vão central 
de momento constante igual a 2,3 $\mathrm{m}$; foram realizadas medidas de deslocamento em 5 pontos por meio de transdutores de deslocamento (LVDT) nos dois metros centrais. As configurações testadas foram as seguintes:

- Seção simples, utilizada como referência para o limite inferior da rigidez à flexão;

- Seções unidas com 2, 4 ou 8 pontos de conexão distribuídos com espaçamentos uniformes ao longo do comprimento analisado;

- $\quad$ Seções unidas com 4 pontos de conexão nas extremidades;

- $\quad$ Pontos de solda intermitentes ao longo de todo o comprimento, localizados perto das junções da mesa com a alma.

Os resultados com o uso do autoperfurante indicaram que o aumento da rigidez efetiva está associado ao aumento da quantidade dos elementos de fixação distribuídos ao longo do comprimento; considerando o caso com 4 pontos de ligação, o aumento é maior para aqueles instalados nas extremidades do trecho, isso se deve ao fato de que, quanto mais próximo das extremidades, maiores são os deslocamentos relativos entre os perfis, utilizando assim a resistência ao cisalhamento da ligação.

Para a ligação parafusada, considerou-se a fixação com o aperto manual e com aplicação de um torque. Na a primeira situação não se verificou nenhum acréscimo de rigidez quando comparada com o limite inferior que representa a inércia de duas seções individuais, pois a folga existente na ligação permitiu que houvesse um deslizamento entre os perfis, fazendo com que eles trabalhassem como barras individuais.

Com o emprego do torque o atrito existente fez com que o movimento relativo entre barras fosse menor, assim o valor efetivo da rigidez teve um aumento significativo em relação ao limite inferior para a seção menor. Para o perfil de maior altura, não se verificou um grande aumento de rigidez em ambos os tipos de ligação, devido à falta de planicidade existente na alma, o que requereria não só uma maior quantidade de parafusos autoperfurantes para melhorar o contato como também a aplicação de um torque suficiente para evitar o deslizamento entre os componentes. A ligação soldada foi considerada como o limite superior com valores até superiores aos teóricos previstos.

Portanto, pode-se concluir que a rigidez à flexão efetiva é um dos parâmetros principais que afetam a resistência da seção composta na flexão e na compressão, de modo que a resistência final obtida fica dentro do intervalo que compreende a soma das resistências dos componentes individuais e a força assumindo a ação composta total. 
Rasmussen et al (2020) apresenta um método de análise para as seções compostas justapostas em que o efeito do cisalhamento é considerado discretamente nos pontos de fixação. $\mathrm{O}$ artigo considerou três tópicos para o estudo: as vigas sujeitas à flexão, à torção e à instabilidade à flexão.

A análise das vigas fletidas partiu das seguintes considerações: peças prismáticas e suficientemente longas de modo que a deformação da seção por cisalhamento pudesse ser desconsiderada. Considerou-se uma viga estaticamente determinada externamente e assumiuse que as curvaturas das peças superior e inferior são as mesmas. As barras são separadas e são aplicadas as condições de equilíbrio, compatibilidade e as de contorno a fim de se obter as deformações e os esforços internos e posteriormente a rigidez efetiva.

Uma expressão para a rigidez à flexão efetiva é derivada para cada trecho entre pontos de ligação, porém um valor médio para a rigidez é proposto considerando o deslocamento máximo da viga. Essa rigidez varia ao longo do comprimento, dependendo das seguintes características do elemento de fixação: espaçamento utilizado, da localização e rigidez; também apresenta variação com os diagramas dos esforços.

Para uma viga bi apoiada com carregamento simétrico sujeita a um momento uniforme ou com variação linear, observa-se que com o aumento do número de fixadores o valor da rigidez aumenta, sendo que inserir mais ligações localizadas nas extremidades possibilita um incremento maior. Para vigas com condições de extremidades fixas, os próprios vínculos evitam os deslocamentos relativos, portanto as ligações não geram um ganho de rigidez.

$\mathrm{Na}$ análise da instabilidade por flexão, utilizou-se o princípio dos trabalhos virtuais na obtenção da equação para a força crítica, no qual buscou-se uma solução aproximada. A força crítica pode ser obtida através de um fator que multiplica a soma de rigidez das barras isoladas, esse fator é dependente da rigidez ao cisalhamento do fixador, da sua quantidade e localização.

Os resultados destacam a influência das condições de vinculação na força de flambagem, de modo que, em determinado grau, os suportes finais evitam as deformações por cisalhamento longitudinal entre as barras que compõem a seção. As soluções obtidas são comparadas com os valores calculados com a abordagem de esbeltez modificada, em que se verifica que a abordagem da norma americana possui uma sensibilidade substancial ao número de fixadores, principalmente quando um número relativamente pequeno de fixadores é usado, enquanto o método de análise apresentado não apresenta. Discrepâncias são observadas para valores relativamente baixos de rigidez do fixador ao cisalhamento, ao mesmo tempo em que, para altos níveis de rigidez do fixador e um grande número de fixadores, a abordagem AISI fornece resultados relativamente precisos. 
Com relação ao estudo da torção, verificou-se que a rigidez à torção não é alterada pela ação composta, já o momento de inércia setorial e sua rigidez associada podem ser aumentados a depender da geometria formada e da distribuição longitudinal das ligações.

Zhou et al (2020) analisaram a flambagem por flexão em seções compostas justapostas propondo uma formulação pelo método da energia, o qual permite quantificar o efeito da deformação por cisalhamento na ligação. Assim como na expressão obtida por Rasmussen et al (2020), a força crítica depende da rigidez ao cisalhamento dos conectores, logo, para obter essa rigidez os autores propõem um modelo que considera o fluxo de cisalhamento na seção transversal, porém eles citam que esse modelo proposto ainda necessita de validação experimental.

Dar et al (2020) fizeram uma investigação experimental de barras isoladas conectadas por chapas formando uma seção fechada, verificou-se que as normativas americana e europeia superestimam a capacidade resistente da maior parte das barras, exceto para as barras curtas. Todas as barras curtas apresentaram modo de falha local e apenas para a de esbeltez intermediária ocorreu a interação do modo local e flexão.

Phan et al (2021) analisaram experimentalmente barras comprimidas constituídas por três e quatro perfis do tipo U conectados por parafusos de forma intermitente (Figura 2.15), que apresentam interação de modos globais e localizados. Os autores utilizam uma abordagem que considera a rigidez efetiva da seção associada ao método da resistência direta.

Figura 2.15- Seção com 3 e 4 perfis respectivamente.
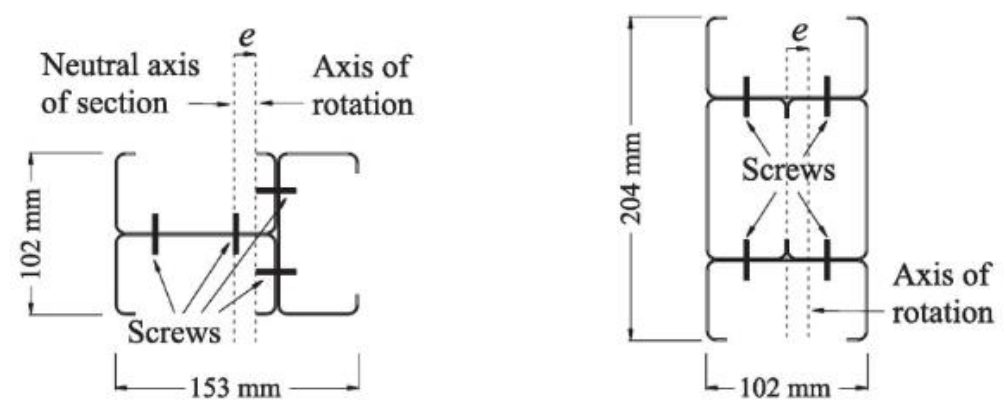

Fonte: Phan et al (2021).

Os autores citam que a presença das presilhas, elemento que conecta os perfis, pode aumentar a tensão de flambagem do modo distorcional, alterar sua deformada assim como o comprimento de semionda. Na fabricação da barra a partir de seções simples, a fixação do parafuso pode alterar as geometrias dos elementos nestes pontos, como ilustra a Figura 2.16, e 
consequentemente introduzir mais imperfeições, gerando uma possível redução na resistência final da barra. Essas alterações na geometria são difíceis de medir.

Figura 2.16- Deformações na mesa e alma causadas pela instalação dos parafusos.

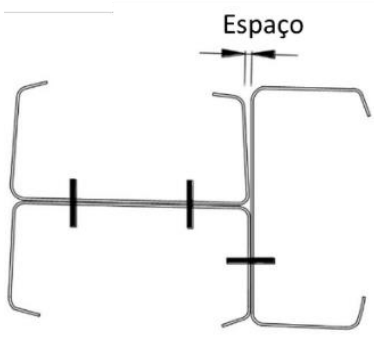

a) Antes da fixação do último parafuso

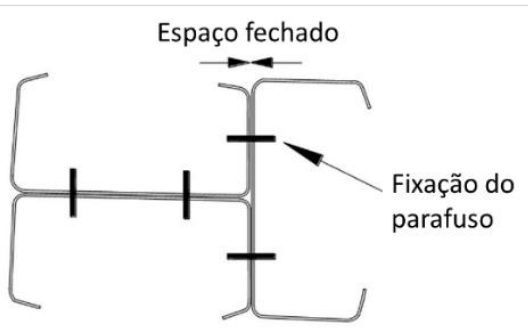

b) Depois da fixação do último parafuso

Fonte: Traduzido de Phan et al (2021).

Em resumo dos estudos relatados, conclui-se que o uso do método das faixas finitas na análise de estabilidade elástica possui uma limitação para as seções compostas devido ao próprio método, em virtude da impossibilidade de variação da seção transversal ao longo do comprimento. Desse modo, para seções com perfis espaçados, a obtenção do valor de tensão crítica para o modo global não é possível de imediato com o uso do método, sendo necessário fazer certas considerações que faz com que a capacidade resistente varie consideravelmente.

Para o modo local e distorcional, pode ser realizada uma previsão analítica, pois esses modos ocorrem em geral em comprimentos de semionda pequenos, menores até mesmo que os espaçamentos adotados para as presilhas, sendo possível considerar a análise do perfil individual. Segundo Georgieva et al (2012a), esse procedimento em relação aos modos localizados pode ser conservador, porque a interação entre os perfis pode diminuir certos efeitos de flambagem em comprimentos de onda mais curtos.

Foi possível compreender que a flexibilidade das ligações entre os componentes afeta a capacidade resistente das barras e é dependente das características dessa conexão e das seções transversais utilizadas. Portanto, o grau de ação composta possui como variáveis: a geometria da seção, as condições de contorno, a rigidez ao cisalhamento das ligações, e as imperfeições.

Quando as imperfeições iniciais são grandes, de modo que o contato entre os componentes da seção composta seja dificultado, podem ocorrer falhas prematuras, reduzindo o esforço resistente. A conexão pontual ao longo do comprimento entre os componentes apresenta uma maior flexibilidade ao cisalhamento quanto comparada às ligações contínuas, devido ao deslizamento relativo entre os componentes; as superfícies galvanizadas dos perfis 
contribuem para a ocorrência de maiores deslizamentos, o que favorece para uma menor rigidez e consequentemente uma menor ação composta.

Dessa forma, a resistência dos membros constituídos por mais de um perfil usualmente se localiza em um intervalo que compreende a resistência das seções isoladas e um valor obtido considerando a ligação rígida entre as peças, isto é, a barra totalmente composta. Quando o número de presilhas é inferior a um determinado limite, as barras passam a se comportar de maneira isolada; porém, quando a quantidade é além de uma considerada ótima para o membro, não se verifica um ganho de resistência. Verificou-se que a conexão no meio do comprimento em barra comprimida é importante em função do fato de essa ser a região onde ocorre a maior deflexão devido ao modo global por flexão. 


\section{ANÁLISE TEÓRICA}

As análises teóricas deste trabalho foram realizadas com o intuito de se obter estimativas da capacidade resistente e dos modos de instabilidade que podem ocorrer no sistema de treliças padronizadas com seção composta, assim como possibilitar um maior entendimento sobre seu comportamento.

Foram selecionadas duas alturas para a seção transversal que contribuíssem com o objetivo de analisar o modo global de instabilidade da estrutura. Para isso, a esbeltez global é aumentada e os efeitos localizados (local e distorcional) reduzidos, como por exemplo optandose por um perfil de maior espessura e de menor altura. A relação entre os momentos de inércia também foi analisada, pois se buscou que o modo global por flexão em relação ao eixo que mobiliza as ligações fosse dominante em relação ao outro eixo.

Além dessas considerações, para o ensaio da treliça foi adotada a possibilidade de desconsiderar a ocorrência do modo global por torção no cálculo da força resistente à compressão, pois a barra do banzo não é um elemento isolado. Ao final, os valores foram comparados sendo adotado o menor entre eles e seu respectivo modo de falha.

Os perfis utilizados neste trabalho foram produzidos pela empresa Modular Sistema Construtivo. A seção UAE utilizada nos banzos possui alma enrijecida, a seção UE utilizada nas diagonais e presilhas apresenta alma plana, ambas as seções possuem enrijecedores de borda a $90^{\circ}$. A Figura 3.1 ilustra as seções, onde as dimensões nominais estão em milímetros.

Figura 3.1- Seções transversais dos perfis utilizados na treliça.
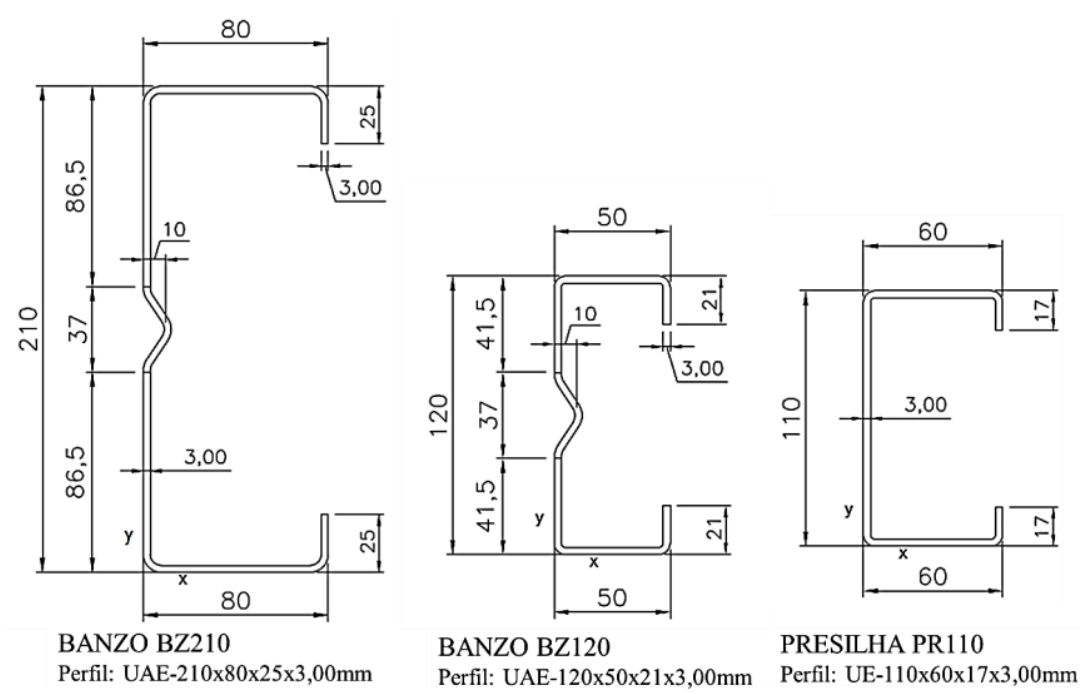

Fonte: Modular Sistema Construtivo (2020). 


\subsection{Método das faixas finitas}

Por meio do software CUFSM v.5.01 (SCHAFER; ÁDÁNY, 2018), que utiliza o método das faixas finitas, foi realizada a análise de estabilidade elástica. Essa análise permite a determinação dos esforços críticos e seus respectivos modos.

As duas seções utilizadas nos ensaios foram modeladas com as dimensões referentes à espessura do aço, pois a camada de revestimento não contribui para o desempenho estrutural, devendo ser descontada nos cálculos de obtenção de resistência.

O revestimento de zinco (Z275) utilizado nas chapas possui uma massa mínima total em ambas as superfícies revestidas igual a $275 \mathrm{~g} / \mathrm{m}^{2}$, que apresenta um valor típico entre $0,02 \mathrm{~mm}$ a 0,025 $\mathrm{mm}$ de espessura por superfície. Portanto, da espessura nominal de $3 \mathrm{~mm}$, reduziu-se 0,05 mm. O módulo de elasticidade (E) utilizado para o aço foi igual a $200.000 \mathrm{MPa}$, coeficiente de Poisson de 0,3 e módulo de elasticidade transversal $(\mathrm{G})$ de $77.000 \mathrm{MPa}$.

\subsection{Avaliação da eficiência das presilhas}

A previsão teórica para o ensaio que avalia o efeito das presilhas, indicado no item 4.2, foi realizada por meio de duas hipóteses: a primeira delas considera a flexão isolada da seção (Figura 3.2a) e a outra, a ação totalmente composta (Figura 3.2b). O carregamento aplicado foi um momento fletor em torno do eixo paralelo à alma, que gera uma tensão unitária de compressão no enrijecedor de borda; a condição de contorno utilizada foi a simplesmente apoiada.

Figura 3.2- Hipóteses utilizadas para as estimativas do ensaio de flexão.

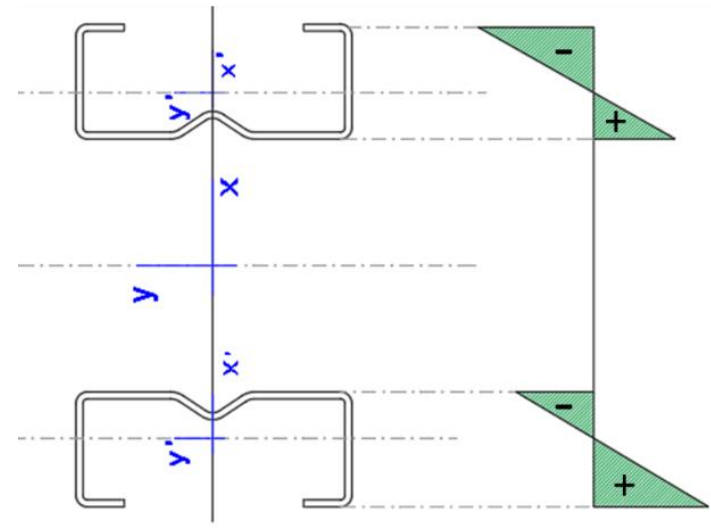

a) Flexão Isolada

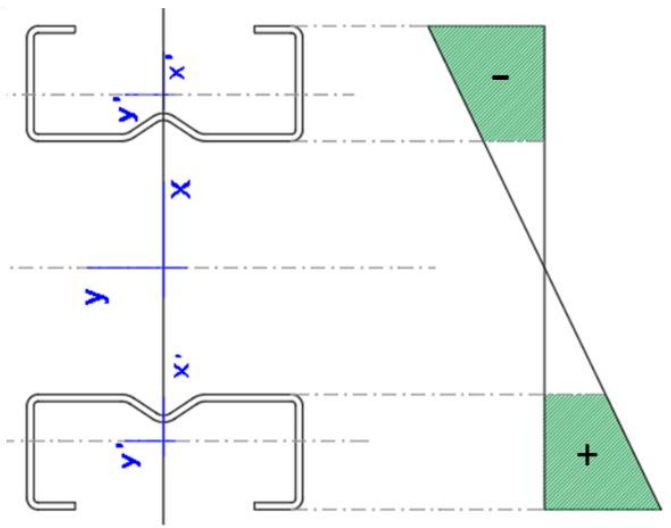

b) Ação composta

Fonte: Da autora. 
Os resultados obtidos pelo software CUFSM estão ilustrados nas Figura 3.3 e Figura 3.4 para os perfis de altura de $120 \mathrm{~mm}$ e $210 \mathrm{~mm}$ respectivamente. As tensões críticas para a ação conjunta são inferiores às da ação isolada, pois o perfil está totalmente comprimido, enquanto o outro está submetido a um gradiente. Consequentemente, as deformadas se apresentaram mais pronunciadas para as duas alturas na análise da ação composta.

Para o perfil de $120 \mathrm{~mm}$ de altura, considerando a ação composta, as tensões críticas obtidas foram de 3420,37 MPa para o modo local e de 932,87 MPa para o distorcional. A hipótese de flexão isolada apresentou valores iguais a 3932,24 MPa e de 1779,75 MPa para o modo local e distorcional respectivamente.

Figura 3.3- Análise de estabilidade elástica para o perfil de $120 \mathrm{~mm}$ submetido à flexão em y (paralelo à alma).

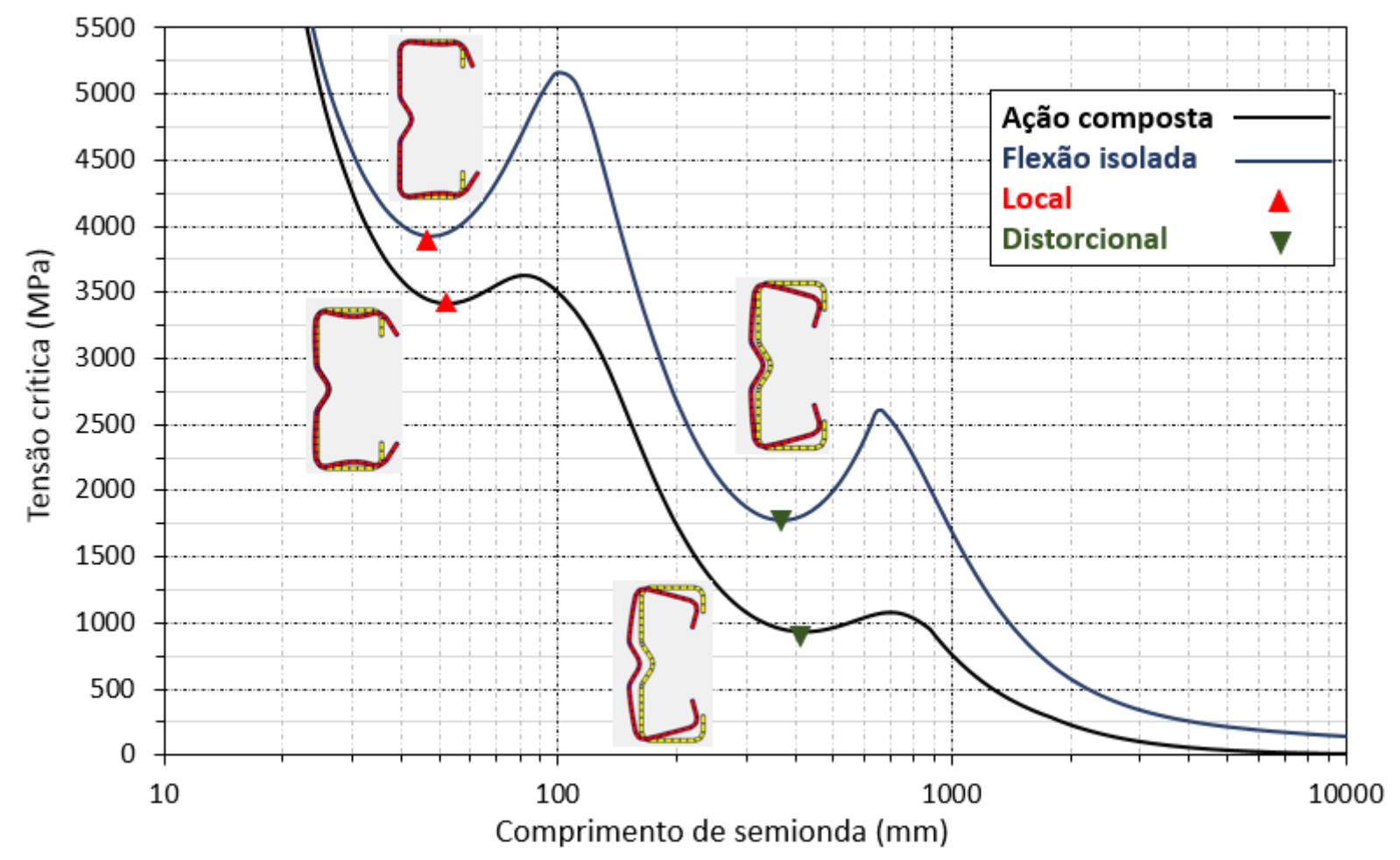

Fonte: Da autora.

A tensão crítica para o modo local no perfil de $210 \mathrm{~mm}$ de altura foi igual a 2364,19 MPa e 1649,66 MPa para as considerações de flexão isolada e ação composta respectivamente. Para o modo distorcional, os valores obtidos foram de 852,16 MPa para flexão isolada e de 477,65 MPa para flexão na seção composta. 
Figura 3.4-Análise de estabilidade elástica para o perfil de 210 mm submetido à flexão em y.

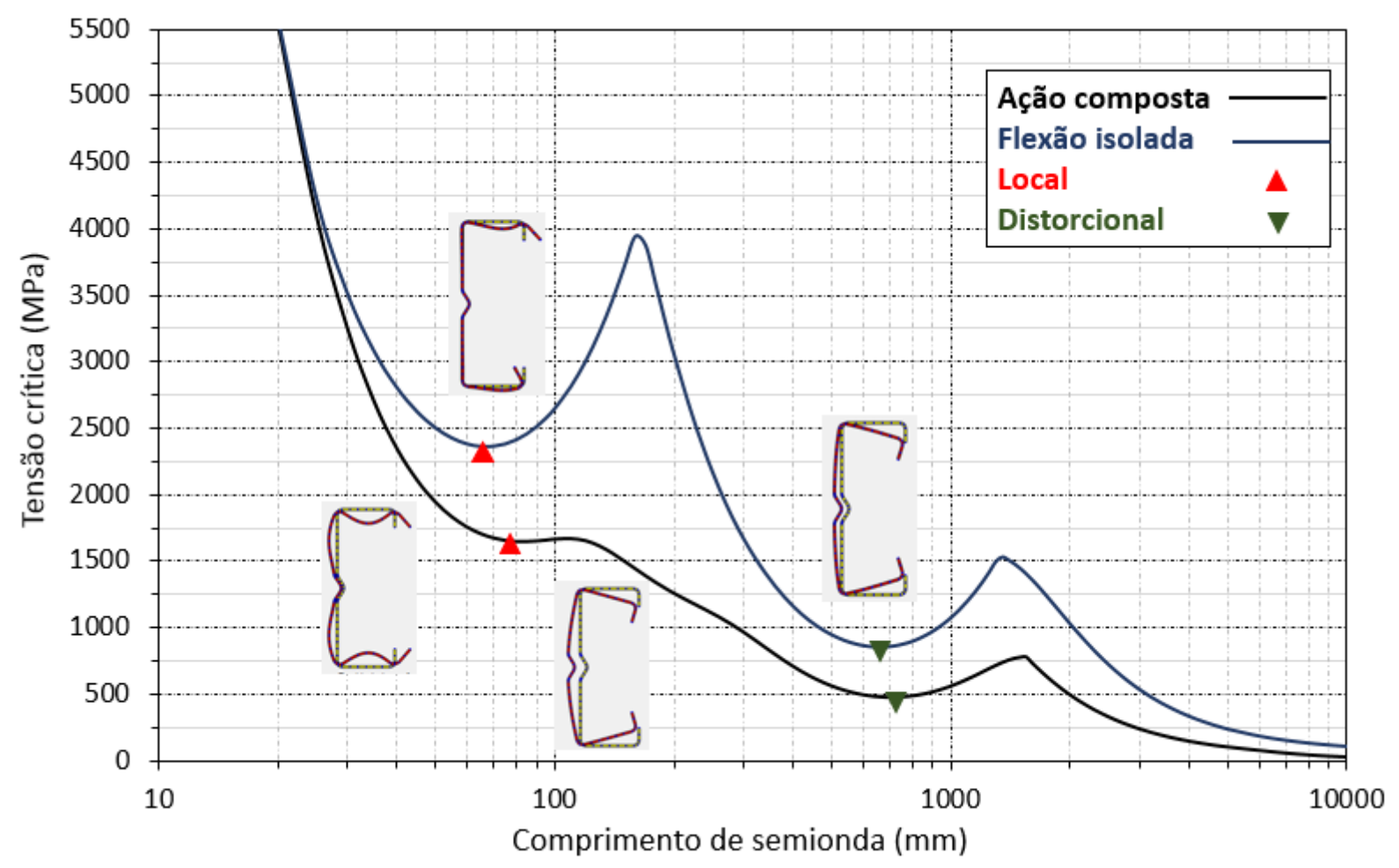

Fonte: Da autora.

\subsubsection{Esforço resistente e deslocamento}

Com os resultados da análise de estabilidade elástica, as estimativas para os valores de momento resistente foram realizadas considerando as equações do método da resistência direta para a flexão simples. Sendo obtido um limite superior associado à ação composta e um inferior representando a flexão isolada. O deslocamento vertical foi estimado através da equação diferencial da linha elástica para uma viga biapoiada submetida a uma força concentrada no meio do vão, correspondente à configuração do ensaio. A equação 3.1 traz a expressão para o deslocamento máximo; para o limite inferior, considerou-se a inércia de dois perfis individuais.

$$
\delta_{\text {máx }}=\frac{1}{48} \frac{P l^{3}}{E I}
$$

Os parâmetros considerados na fórmula são:

$P$ : Força aplicada no meio do vão;

$l$ : Comprimento da viga;

$E$ : Módulo de Elasticidade do aço (E=200.000 MPa);

I: Momento de inércia em torno do eixo paralelo à alma. 
Os valores obtidos foram organizados na Tabela 3.1. Os deslocamentos máximos indicados na tabela foram obtidos para força máxima no meio do vão, associada ao momento resistente característico. Por meio dos valores de deslocamento obtidos experimentalmente e pela expressão teórica com validade para o trecho elástico linear, foi possível estimar a rigidez efetiva da barra composta associada à quantidade de presilhas.

Tabela 3.1- Momento fletor resistente e deslocamento máximo para os perfis.

\begin{tabular}{ccccc}
\hline Momento fletor resistente & \multicolumn{2}{c}{ Perfil 120x50x21x3 } & \multicolumn{2}{c}{ Perfil 210x80x25x3 } \\
\cline { 2 - 5 }$(\mathbf{k N . c m})$ / Deslocamento $(\mathbf{c m})$ & $\begin{array}{c}\text { Ação } \\
\text { composta }\end{array}$ & $\begin{array}{c}\text { Ação } \\
\text { Isolada }\end{array}$ & $\begin{array}{c}\text { Ação } \\
\text { composta }\end{array}$ & $\begin{array}{c}\text { Ação } \\
\text { Isolada }\end{array}$ \\
\hline Flambagem global -M $\mathrm{Re}_{\mathrm{ne}}$ & 3452,92 & 324,66 & 5659,99 & 801,03 \\
Flambagem local- M & 3452,92 & 324,66 & 5659,99 & 801,03 \\
Flambagem distorcional - $\mathbf{M}_{\mathrm{Rdist}}$ & 3396,77 & 324,66 & 4509,57 & 768,58 \\
M $_{\mathrm{R}, \mathrm{k}}$ & 3396,77 & 324,66 & 4509,57 & 768,58 \\
Deslocamento máximo & 2,28 & 7,54 & 1,43 & 4,21 \\
\hline
\end{tabular}

Fonte: Da autora.

\subsection{Avaliação das treliças}

O carregamento aplicado consistiu em uma compressão unitária e uniforme; a condição de contorno utilizada foi a simplesmente apoiada. O resultado da análise de estabilidade elástica dos perfis é apresentado nas Figura 3.5 e Figura 3.6, em que a primeira ilustra as curvas que relacionam a tensão crítica e o comprimento de semionda, a segunda figura apresenta as deformadas dos modos de instabilidade associados a essas curvas.

A instabilidade local é caracterizada pela ocorrência em comprimentos de semionda menores, em geral da ordem de grandeza das dimensões do perfil. Por meio da Figura 3.5, observa-se que este modo não apresentou um ponto mínimo bem definido, foram observadas duas deformadas, uma puramente local e outra que envolve o deslocamento do enrijecedor.

Em vista disso, adotou-se o que apresentou menor valor de tensão crítica como o mínimo local, para o perfil com 120mm de altura a tensão foi de 2064,4 MPa, e, para o outro, igual a 517,8 MPa. O segundo ponto de mínimo indicado na envoltória corresponde à flambagem distorcional. Este ponto ocorreu com uma tensão crítica de 994,2 MPa para o perfil menor e de 320,4 MPa para o maior. 
Figura 3.5- Análise de estabilidade elástica do perfil UAE do banzo submetido à compressão.

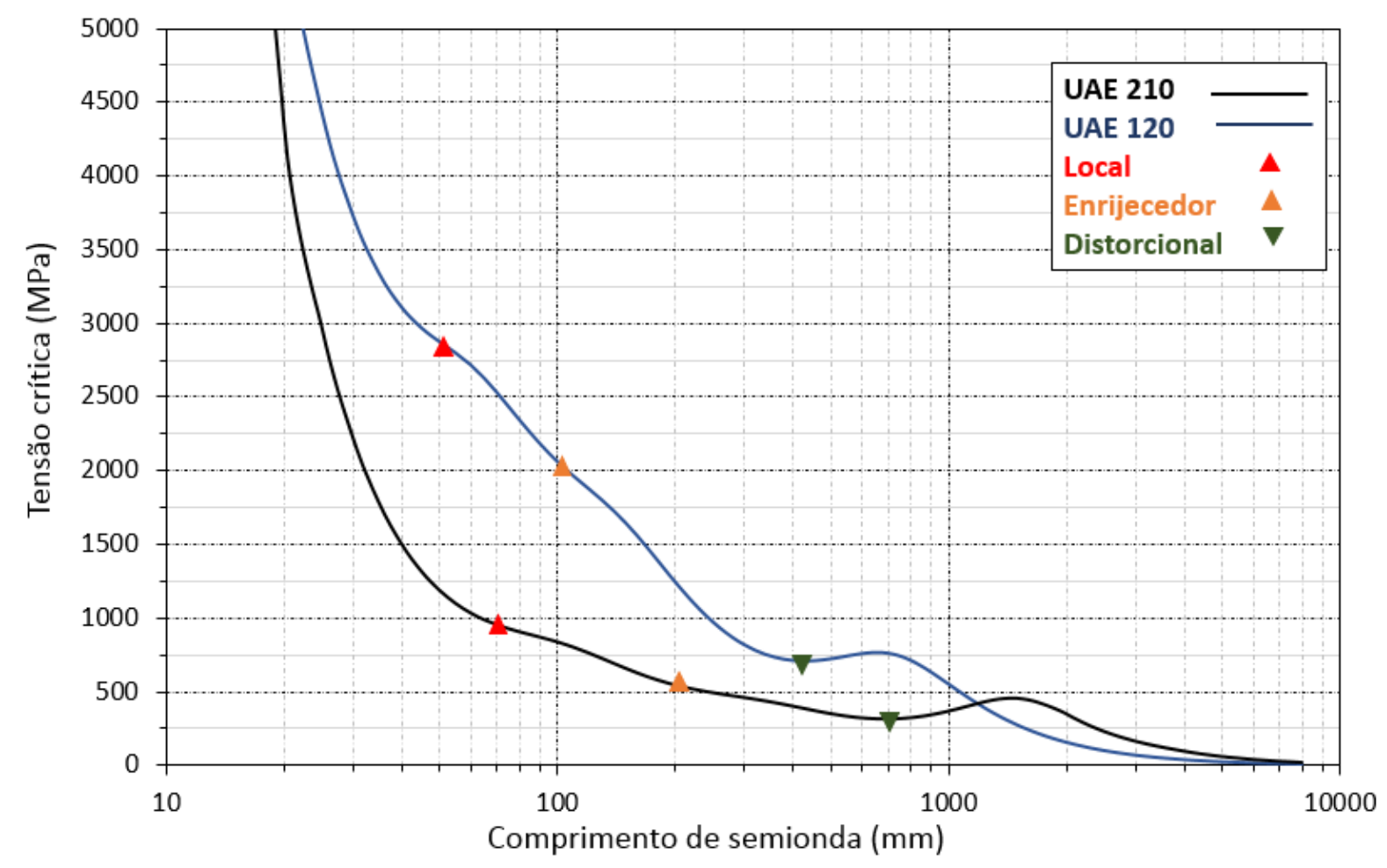

Fonte: Da autora.

Figura 3.6- Deformadas dos modos de instabilidade dos perfis submetidos à compressão.

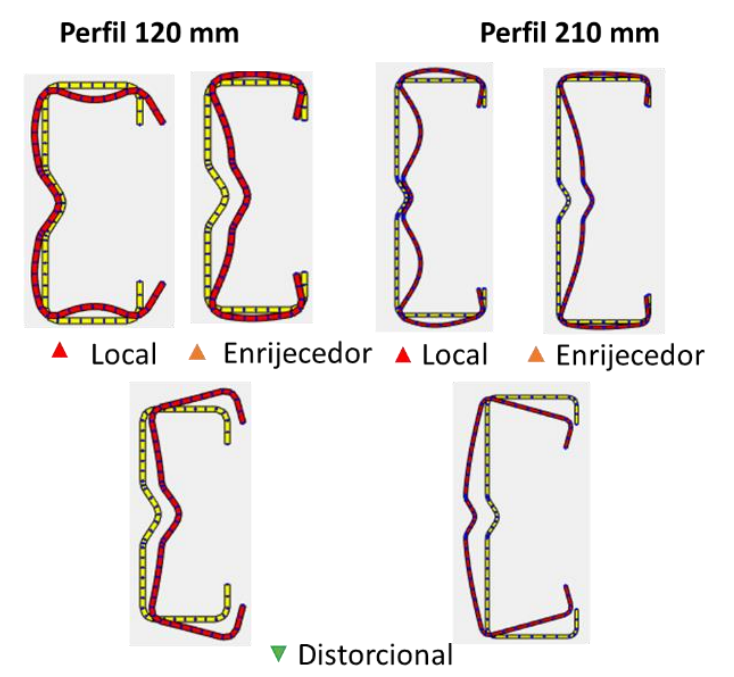

Fonte: Da autora.

\subsubsection{Esforço resistente}

Com os valores das tensões críticas elásticas, é possível estimar o esforço resistente característico à compressão com base nas equações indicadas no item 2.2. Foram adotadas duas 
possibilidades, a primeira considera a ação composta, portanto, nos cálculos da força axial de flambagem elástica $\left(N_{e}\right)$, considerou-se as seguintes propriedades da seção:

- Momento de inércia em torno do eixo y (paralelo à alma do perfil) obtido com o teorema dos eixos paralelos;

- $\quad$ Momento de inércia à torção foi multiplicada por 2;

- $\quad$ Constante de empenamento foi calculada pelo mesmo procedimento realizado em uma seção simples, que corresponde a integral na área da área setorial principal ao quadrado.

Foi admitido também um limite inferior, em que apenas se soma a força axial resistente dos perfis componentes, o que implica em uma ação independente entre os componentes da barra.

A treliça do tipo Warren em estudo possui as seguintes características: distância entre nós igual a $1800 \mathrm{~mm}$ e possibilidade de travamento lateral a cada nó ou a cada dois nós. Com estes dados e considerando o coeficiente de flambagem igual a 1 obtiveram-se os valores teóricos de força axial resistente característica à compressão. O valor utilizado para o módulo de elasticidade (E) foi de $200.000 \mathrm{MPa}$ e para a tensão de escoamento foram utilizados os valores experimentais indicado no Apêndice B deste texto.

Assim como indicado anteriormente, foi considerada a possibilidade de ocorrer ou não o modo global por torção. Os valores de força axial resistente à compressão e seus respectivos modos de instabilidade foram organizados na Tabela 3.2.

Tabela 3.2- Força axial de compressão resistente caraterística para o banzo considerando travamento lateral a cada dois nós.

\begin{tabular}{|c|c|c|c|c|}
\hline $\begin{array}{c}\text { Perfil UAE } \\
\text { (Dimensões } \\
\text { nominais em mm) }\end{array}$ & $\begin{array}{c}\mathrm{N}_{\mathrm{c}, \mathrm{Rk}}(\mathrm{kN}) \\
\text { Considerando } \\
\text { torção }\end{array}$ & $\begin{array}{c}\text { Modo de } \\
\text { Instabilidade }\end{array}$ & $\begin{array}{c}\mathbf{N}_{\mathrm{c}, \mathrm{Rk}}(\mathrm{kN}) \\
\text { Desconsiderando } \\
\text { torção }\end{array}$ & $\begin{array}{c}\text { Modo de } \\
\text { Instabilidade }\end{array}$ \\
\hline $120 \times 50 \times 21 \times 3,0$ & $62,14^{*}$ & Global $\left(\mathrm{N}_{\mathrm{ey}}\right)$ & $62,14^{*}$ & Global $\left(\mathrm{N}_{\mathrm{ey}}\right)$ \\
\hline $210 \times 80 \times 25 \times 3,0$ & $263,22 *$ & Global $\left(\mathrm{N}_{\mathrm{ey}}\right)$ & $263,22 *$ & Global $\left(\mathrm{N}_{\mathrm{ey}}\right)$ \\
\hline $\begin{array}{l}120 \times 50 \times 21 \times 3,0 \\
\text { Barra composta }\end{array}$ & 333,16 & Global $\left(\mathrm{N}_{\mathrm{ez}}\right)$ & 548,81 & Global $\left(\mathrm{N}_{\mathrm{ey}}\right)$ \\
\hline $\begin{array}{l}210 \times 80 \times 25 \times 3,0 \\
\text { Barra composta }\end{array}$ & 742,08 & Distorcional & 742,08 & Distorcional \\
\hline
\end{tabular}

Nota: * $\mathrm{O}$ valor corresponde a 2 x $\mathrm{N}_{\mathrm{c}, \mathrm{Rk} 1}$, em que $\mathrm{N}_{\mathrm{c}, \mathrm{Rk} 1}$ é a força axial resistente à compressão de um perfil componente.

Fonte: Da autora. 
Por meio da Tabela 3.2 é possível observar que para o perfil de menor altura o modo crítico predominante foi o global em torno do paralelo à alma (eixo y), isto é, fora do plano da treliça. No perfil de maior altura os valores de força axial estão associados a flambagem global em torno do eixo y e a flambagem distorcional.

Os valores do esforço resistente característico e seus respectivos modos de instabilidade para o comprimento destravado de $1800 \mathrm{~mm}$ foram organizados na Tabela 3.3.

Tabela 3.3- Força axial de compressão resistente caraterística para o banzo considerando travamento a cada nó.

\begin{tabular}{ccccc}
\hline $\begin{array}{c}\text { Perfil UAE } \\
\text { (Dimensões } \\
\text { nominais em mm) }\end{array}$ & $\begin{array}{c}\mathbf{N}_{\mathbf{c}, \mathbf{R k}}(\mathbf{k N}) \\
\text { Considerando } \\
\text { torção }\end{array}$ & $\begin{array}{c}\text { Modo de } \\
\text { Instabilidade }\end{array}$ & $\begin{array}{c}\mathbf{N}_{\mathbf{c}, \mathbf{R k}}(\mathbf{k N}) \\
\text { Desconsiderando } \\
\text { torção }\end{array}$ & $\begin{array}{c}\text { Modo de } \\
\text { Instabilidade }\end{array}$ \\
\hline $120 \times 50 \times 21 \times 3,0$ & $248,56^{*}$ & Global $\left(\mathrm{N}_{\mathrm{ey}}\right)$ & $248,56^{*}$ & Global $\left(\mathrm{N}_{\mathrm{ey}}\right)$ \\
$210 \times 80 \times 25 \times 3,0$ & $742,08^{*}$ & Distorcional & $742,08^{*}$ & Distorcional \\
$120 \times 50 \times 21 \times 3,0$ & 333,16 & Global $\left(\mathrm{N}_{\mathrm{ez}}\right)$ & 593,31 & Global $\left(\mathrm{N}_{\mathrm{ex}}\right)$ \\
Barra composta & & & & \\
$210 \times 80 \times 25 \times 3,0$ & 742,08 & Distorcional & 742,08 & Distorcional \\
Barra composta & & & & \\
\hline
\end{tabular}

Nota: * $\mathrm{O}$ valor corresponde a $2 \times \mathrm{N}_{\mathrm{c}, \mathrm{Rk} 1}$, em que $\mathrm{N}_{\mathrm{c}, \mathrm{Rk} 1}$ é a força axial resistente à compressão de um perfil componente.

Fonte: Da autora.

A Tabela 3.3 mostra que o modo crítico para a ação individual dos perfis de $120 \mathrm{~mm}$ foi o global por flexão em torno de eixo de menor inércia do perfil (eixo y). Na seção de maior altura a força axial de compressão resistente, está associado a flambagem distorcional, sendo que este valor não muda para a consideração de ação isolada ou composta.

\subsubsection{Presilhas}

A quantidade de peças de conexão entre as barras do banzo foram obtidas por meio da equação 2.12, contida no item 2.2.1 deste texto. Os valores de índice de esbeltez do perfil isolado considerando o comprimento entre nós igual a $180 \mathrm{~cm}$, o raio de giração mínimo, e o espaçamento entre as presilhas foram organizados na Tabela 3.4. 
Tabela 3.4- Índice de esbeltez dos perfis individuais.

\begin{tabular}{|c|c|c|c|c|c|}
\hline \multirow{2}{*}{$\begin{array}{l}\text { Número } \\
\text { de } \\
\text { presilhas }\end{array}$} & \multirow{2}{*}{$\begin{array}{l}\text { Dist. entre } \\
\text { presilhas: } \\
\text { a (cm) }\end{array}$} & \multicolumn{2}{|c|}{ Perfil 120x50x21x3 } & \multicolumn{2}{|c|}{ Perfil 210x80x25x3 } \\
\hline & & $\begin{array}{l}\text { Raio de giração } \\
\text { mínimo: } \mathbf{r}_{\mathbf{y}}(\mathrm{cm})\end{array}$ & $\begin{array}{c}\text { Relação } \\
\mathbf{a} / \mathbf{r}_{\mathbf{y}}\end{array}$ & $\begin{array}{l}\text { Raio de giração } \\
\text { mínimo: } r_{y}(\mathrm{~cm})\end{array}$ & $\begin{array}{c}\text { Relação } \\
\mathbf{a} / \mathbf{r}_{\mathbf{y}}\end{array}$ \\
\hline 0 & 180,00 & 1,80 & 100,00 & 2,89 & 62,28 \\
\hline 1 & 90,00 & 1,80 & 50,00 & 2,89 & 31,14 \\
\hline 2 & 60,00 & 1,80 & 33,33 & 2,89 & 20,76 \\
\hline 3 & 45,00 & 1,80 & 25,00 & 2,89 & 15,57 \\
\hline 4 & 36,00 & 1,80 & 20,00 & 2,89 & 12,46 \\
\hline 5 & 30,00 & 1,80 & 16,67 & 2,89 & 10,89 \\
\hline
\end{tabular}

Fonte: Da autora.

A esbeltez máxima para o conjunto considerando os devidos comprimentos de flambagem fora do plano, foi organizada na Tabela 3.5 e na Tabela 3.6.

Tabela 3.5-Esbeltez máxima do conjunto para o comprimento de flambagem fora do plano de $180 \mathrm{~cm}$.

\begin{tabular}{ccccccc}
\hline Seção Composta & $\mathbf{r}_{\mathbf{x}}$ & $\mathbf{r}_{\mathbf{y}}$ & $\mathbf{K}_{\mathbf{x}} \mathbf{L}_{\mathbf{x}}$ & $\mathbf{K}_{\mathbf{y}} \mathbf{L}_{\mathbf{y}}$ & \multicolumn{2}{c}{ Esbeltez do Conjunto } \\
Perfil UAE & $(\mathbf{c m})$ & $(\mathbf{c m})$ & $(\mathbf{c m})$ & $(\mathbf{c m})$ & $\mathrm{K}_{\mathrm{x}} \mathrm{L}_{\mathrm{x}} / \mathrm{r}_{\mathrm{x}}$ & $\mathrm{K}_{\mathrm{y}} \mathrm{L}_{\mathrm{y}} / \mathrm{r}_{\mathrm{y}}$ \\
\hline $\mathbf{1 2 0 x 5 0 \times 2 1 \times 3}$ & 4,57 & 7,50 & 180 & 180 & 39,4 & 24,0 \\
$\mathbf{2 1 0 x 8 0 x 2 5 x 3}$ & 8,15 & 8,47 & 180 & 180 & 22,1 & 21,2 \\
\hline
\end{tabular}

Fonte: Da autora.

Tabela 3.6-Esbeltez máxima do conjunto para o comprimento de flambagem fora do plano de $360 \mathrm{~cm}$.

\begin{tabular}{ccccccc}
\hline $\begin{array}{c}\text { Seção Composta } \\
\text { Perfil UAE }\end{array}$ & $\mathbf{r}_{\mathbf{x}}$ & $\mathbf{r}_{\mathbf{y}}$ & $\mathbf{K}_{\mathbf{x}} \mathbf{L}_{\mathbf{x}}$ & \multicolumn{2}{c}{$\mathbf{K}_{\mathbf{y}} \mathbf{L}_{\mathbf{y}}$} & \multicolumn{2}{c}{ Esbeltez do Conjunto } \\
\cline { 7 - 8 } & $(\mathbf{c m})$ & $(\mathbf{c m})$ & $(\mathbf{c m})$ & $(\mathbf{c m})$ & $\mathrm{K}_{\mathrm{x}} \mathrm{L}_{\mathrm{x}} / \mathrm{r}_{\mathrm{x}}$ & $\mathrm{K}_{\mathrm{y}} \mathrm{L}_{\mathrm{y}} / \mathrm{r}_{\mathrm{y}}$ \\
\hline $\mathbf{1 2 0 x 5 0 x 2 1 x 3}$ & 4,57 & 7,50 & 180 & 360 & 39,4 & 48,0 \\
$\mathbf{2 1 0 x 8 0 x 2 5 x 3}$ & 8,15 & 8,47 & 180 & 360 & 22,1 & 42,5 \\
\hline
\end{tabular}

Fonte: Da autora.

Com base neste conjunto de dados e na relação existente entre eles, as quantidades de presilhas requerida por norma para a seção com menor altura foram iguais a 5 e 4 para os comprimentos fora do plano de $180 \mathrm{~cm}$ e $360 \mathrm{~cm}$ respectivamente e, para o perfil maior, a quantidade obtida foi de 5 e 2 para os mesmos respectivos comprimentos. 


\section{ANÁLISE EXPERIMENTAL}

A análise experimental deste trabalho buscou avaliar o comportamento da seção composta existente em um sistema de treliça plana, principalmente quanto à quantidade dos elementos que conectam os perfis, os quais podem proporcionar o funcionamento da barra como elemento único.

Desse modo, foram realizadas duas etapas experimentais: a primeira consistiu em ensaios de flexão em torno do eixo que solicita a ligação de barras do banzo, a fim de obter o parâmetro de rigidez efetiva capaz de mensurar o quanto as barras estão trabalhando de forma conjunta.

Inicialmente foram utilizadas apenas presilhas como elemento de conexão; posteriormente, o ensaio foi complementado substituindo as presilhas internas por chapas conectadas pelas mesas das barras principais. Dessa forma, pode-se verificar a diferença entre a ligação feita pela alma e aquela feita pela mesa das barras principais.

$\mathrm{Na}$ segunda etapa, foram realizadas provas de carga da treliça padronizada em um comprimento menor que o seu vão estimado em projeto, e considerando apenas as presilhas como elemento de conexão.

\subsection{Materiais}

Os perfis selecionados foram fabricados a partir de chapas de aço estrutural zincado com resistência mínima ao escoamento de $450 \mathrm{MPa}$; o revestimento de zinco utilizado foi o Z275, com massa mínima total em ambas as superfícies revestidas igual a $275 \mathrm{~g} / \mathrm{m}^{2}$, com valor típico de 0,02 $\mathrm{mm}$ a $0,025 \mathrm{~mm}$ de espessura por superfície.

Para as ligações, foram utilizados parafusos sextavados de alta resistência em aço ASTM A325 e parafusos autoperfurantes (PB 12x14x3/4"' TCP3). A caracterização do aço foi realizada por meio de ensaios de tração direta, seguindo as diretrizes da norma americana ASTM A370-17a (AMERICAN SOCIETY FOR TESTING AND MATERIALS - ASTM, 2017); as propriedades mecânicas obtidas são apresentadas no apêndice B. 


\subsection{Rigidez Efetiva}

Os ensaios para análise da rigidez efetiva consistiram em barras biapoiadas, submetidas a um carregamento concentrado aplicado no meio do vão, portanto solicitada tanto ao esforço cortante quanto ao momento fletor.

A barra do banzo foi posicionada rotacionada em $90^{\circ}$ em relação a sua posição na estrutura, e o carregamento foi aplicado diretamente na alma do perfil superior na região da presilha central utilizando um calço de madeira, pois a seção composta formada é do tipo aberta.

Os comprimentos entre apoios foram iguais a $1,8 \mathrm{~m}$ e 3,6 $\mathrm{m}$, levando em conta as duas possibilidades de contenção lateral da treliça. A Figura 4.1 ilustra o esquema estático do ensaio de flexão em torno do eixo y, assim como o posicionamento da barra para aplicação do carregamento.

Figura 4.1- Esquema estático do ensaio de flexão em torno de y.

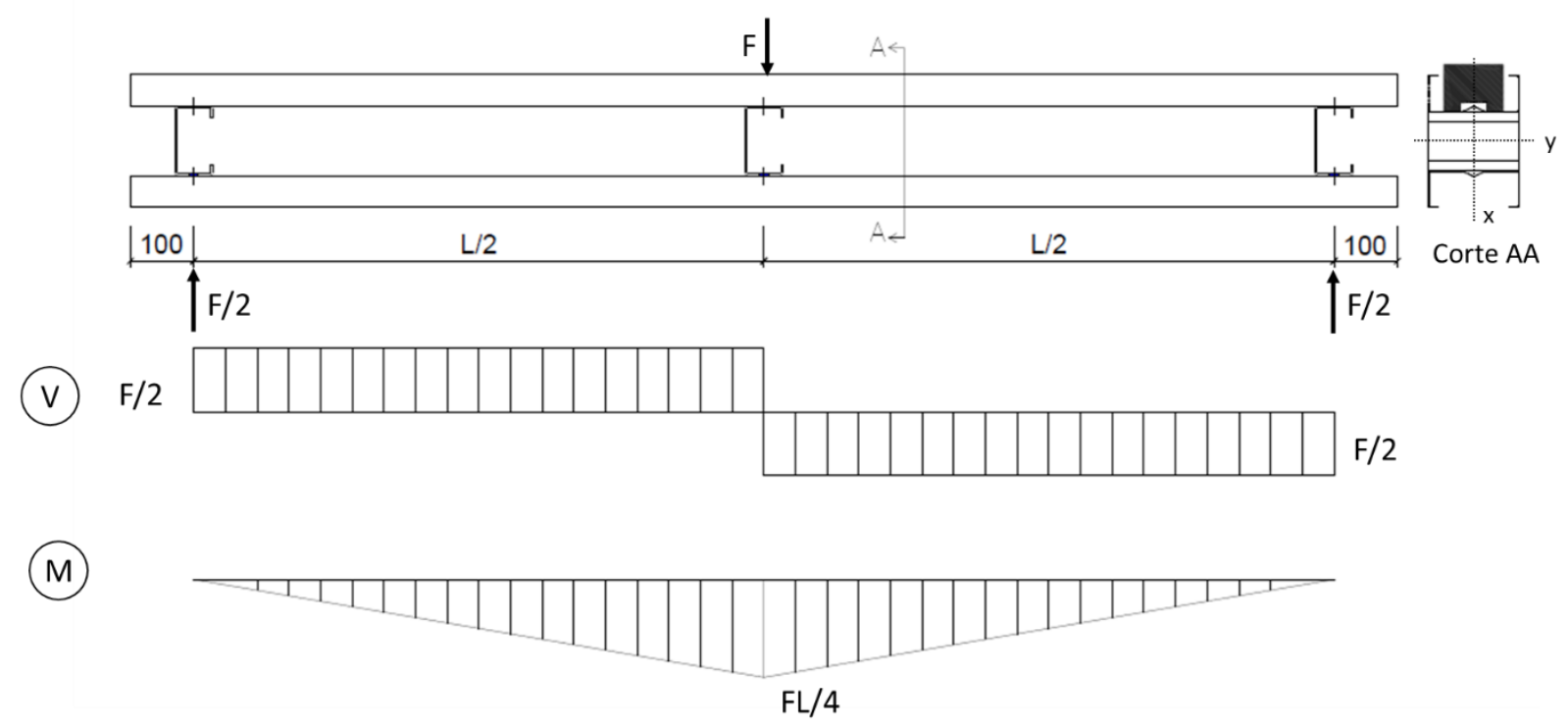

Fonte: Da autora.

Quando duas vigas justapostas são conectadas tensões de cisalhamento longitudinal são geradas na interface devido à reciprocidade com o cisalhamento desenvolvido pelo esforço cortante presente na viga. Nas seções em que os perfis apresentam certo espaçamento entre si, esse efeito também acontece, porém, em vez de ocorrer ao longo de todo comprimento, ocorre apenas nos pontos de contato com as presilhas.

O efeito devido à flexão na seção composta pode ser observado partindo da análise que considera as barras não conectadas, isto é, a flexão ocorre de forma isolada e consequentemente 
a deformação entre elas é independente. Assim, as faces em contato ou as que serão unidas por presilhas apresentam solicitações opostas, de modo que uma se alonga e a outra encurta, o que faz com que as seções inicialmente coincidentes se afastem. Considerando uma representação amplificada, o deslocamento relativo pode ser observado nas extremidades das barras (Figura 4.2).

Figura 4.2- Deslocamento relativo entre vigas devido à flexão.

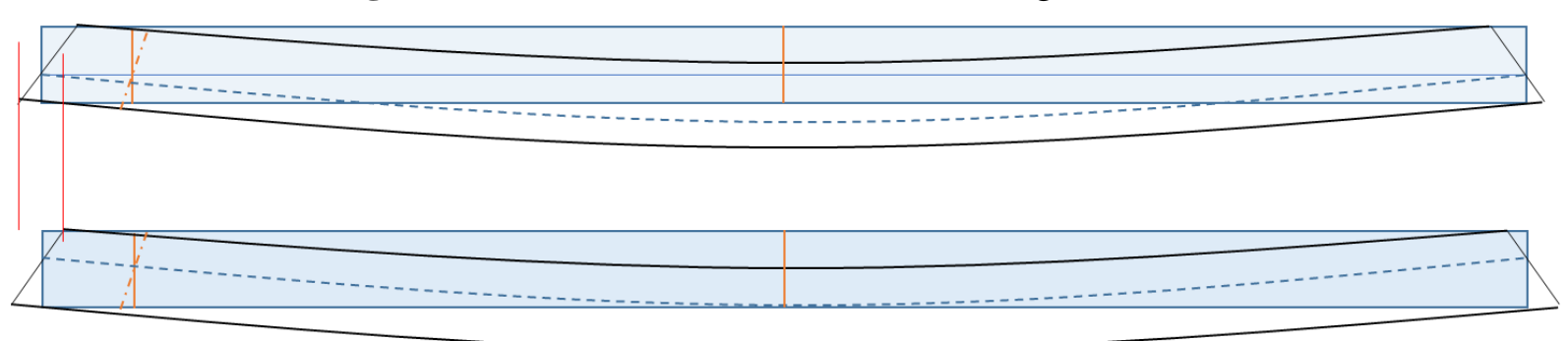

Fonte: Da autora.

A quantidade de elementos que conectam os banzos foi calculada de acordo com as especificações da norma brasileira. Apenas quantidades ímpares de presilhas foram adotadas devido à configuração do ensaio requerer inicialmente a presença de uma presilha no meio do vão, portanto com o intuito de manter o espaçamento constante entre as presilhas e solicitações iguais nos trechos de estudo como forma de controle.

A quantidade máxima de presilha analisada foi igual a cinco, número obtido conforme indicado no item 3.3.2 deste texto. Mesmo que a quantidade indicada por norma em uma dada combinação de altura e comprimento destravado fosse menor que 5 manteve-se o maior valor encontrado.

Nesse ensaio, também houve a variação do tipo de parafuso usado para unir as presilhas com os banzos. Foram utilizados parafusos sextavados e autoperfurantes na ligação entre a alma do banzo e as mesas da presilha, possibilitando verificar qual dos dois tipos de parafuso apresenta os melhores resultados. Foram utilizados dois parafusos por ligação em ambas as alturas.

Foram ensaiados três protótipos complementares, os quais apresentavam chapas de ligação em substituição às presilhas internas ao vão. Essas chapas foram parafusadas com três autoperfurantes por ligação nas mesas da barra principal, como ilustrado na Figura 4.3. 
Figura 4.3- Protótipo com uma chapa de ligação interna ao vão.

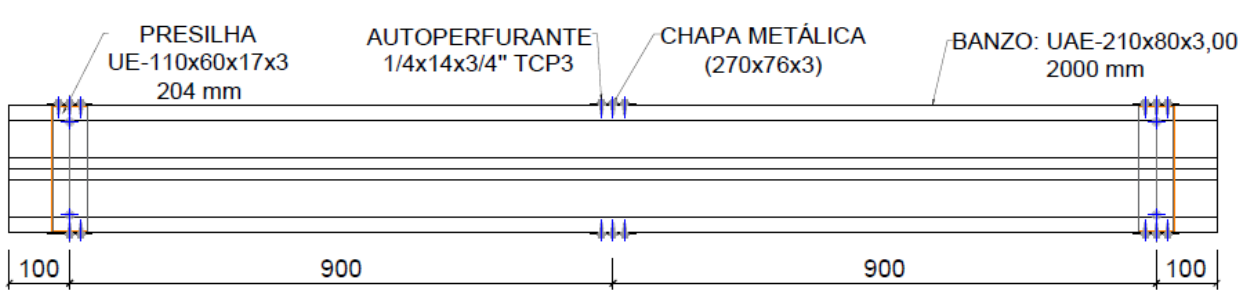

UB180-1C
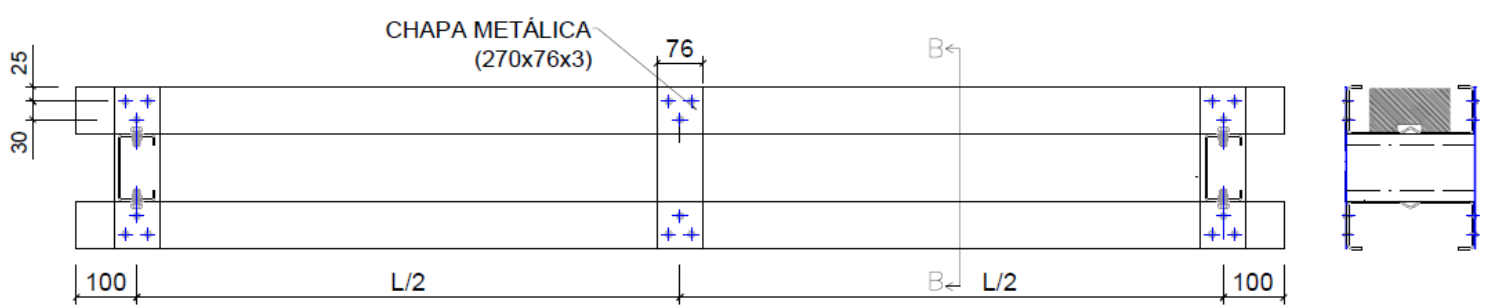

VISTA A

CORTE B

Fonte: Da autora.

\subsubsection{Protótipos}

Quanto à nomenclatura, os protótipos foram identificados da seguinte forma: pela altura da seção transversal, que compreende: a série A representa a altura de $120 \mathrm{~mm}$ e a B, a altura de $210 \mathrm{~mm}$; pelo comprimento do vão teórico em centímetros; e pelo número de presilhas e seu tipo de fixação. Por exemplo: UA180-1A.

- UA: perfil com seção transversal do tipo UAE da série A;

- 180: comprimento do vão em centímetros;

- 1: número de presilhas;

- A: fixação da presilha por meio de autoperfurante.

Nas peças com chapa de ligação, a última letra da nomenclatura indicada anteriormente foi substituída por C; nestas peças, as chapas foram ligadas por autoperfurantes e as presilhas dos apoios com parafusos sextavados.

Todos os protótipos foram fabricados pela empresa Modular Sistema Construtivo. A quantidade total de peças ensaiadas foi de 21, sendo três com chapa ligação e as demais com a presilha. Para as peças com presilhas, considerando a fixação com parafuso autoperfurante, foram realizadas todas as variações na quantidade de presilhas para ambos os comprimentos; para a outra forma de fixação, foram escolhidas apenas duas variações para o comprimento de $180 \mathrm{~cm}$ e uma para o comprimento de $360 \mathrm{~cm}$. 
A Tabela 4.1 apresenta uma descrição dos protótipos que utilizam as presilhas em perfil de seção aberta, e na Tabela 4.2 , estão descritas as peças que utilizam a chapa de ligação.

Tabela 4.1- Descrição dos protótipos com presilha para o ensaio de rigidez.

\begin{tabular}{|c|c|c|c|c|c|c|}
\hline Série & $\begin{array}{l}\text { Seção do } \\
\text { banzo }\end{array}$ & $\begin{array}{l}\text { Tipo de } \\
\text { fixação }\end{array}$ & $\begin{array}{l}\text { Nome dos } \\
\text { protótipos }\end{array}$ & $\begin{array}{l}\text { Vão } L_{t} \\
(\mathbf{m m})\end{array}$ & $\begin{array}{l}\text { Quant. de } \\
\text { presilhas }\end{array}$ & $\begin{array}{c}\text { Dist. entre } \\
\text { presilhas (mm) }\end{array}$ \\
\hline \multirow{9}{*}{$\begin{array}{c}\mathrm{A} \\
(\mathrm{H}=120)\end{array}$} & \multirow{9}{*}{ 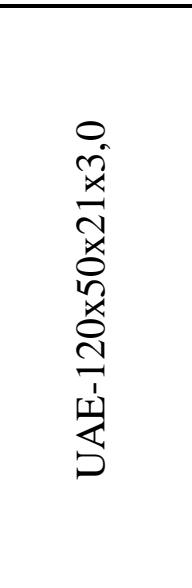 } & \multirow{6}{*}{ 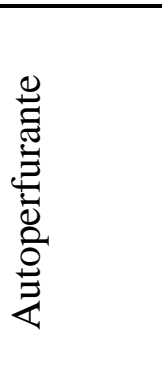 } & UA180-1A & 1800 & 1 & 900 \\
\hline & & & UA180-3A & 1800 & 3 & 450 \\
\hline & & & UA180-5A & 1800 & 5 & 300 \\
\hline & & & UA360-1A & 3600 & 1 & 1800 \\
\hline & & & UA360-3A & 3600 & 3 & 900 \\
\hline & & & UA360-5A & 3600 & 5 & 600 \\
\hline & & \multirow{3}{*}{ 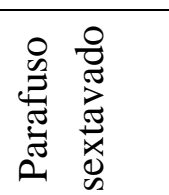 } & UA180-3P & 1800 & 3 & 450 \\
\hline & & & UA180-5P & 1800 & 5 & 300 \\
\hline & & & UA360-3P & 3600 & 3 & 900 \\
\hline \multirow{9}{*}{$\begin{array}{c}\text { B } \\
(H=210)\end{array}$} & \multirow{9}{*}{ 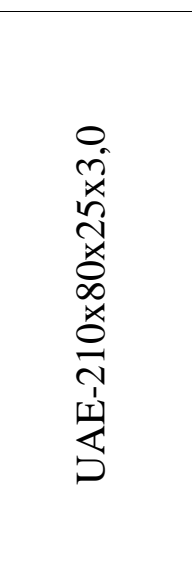 } & \multirow{6}{*}{ 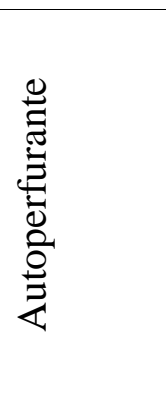 } & UB180-1A & 1800 & 1 & 900 \\
\hline & & & UB180-3A & 1800 & 3 & 450 \\
\hline & & & UB180-5A & 1800 & 5 & 300 \\
\hline & & & UB360-1A & 3600 & 1 & 1800 \\
\hline & & & UB360-3A & 3600 & 3 & 900 \\
\hline & & & UB360-5A & 3600 & 5 & 600 \\
\hline & & \multirow{3}{*}{ 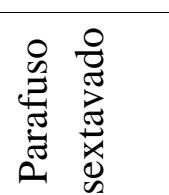 } & UB180-3P & 1800 & 3 & 450 \\
\hline & & & UB180-5P & 1800 & 5 & 300 \\
\hline & & & UB360-3P & 3600 & 3 & 900 \\
\hline
\end{tabular}

Fonte: Da autora.

Tabela 4.2- Descrição dos protótipos com chapa de ligação para o ensaio de rigidez.

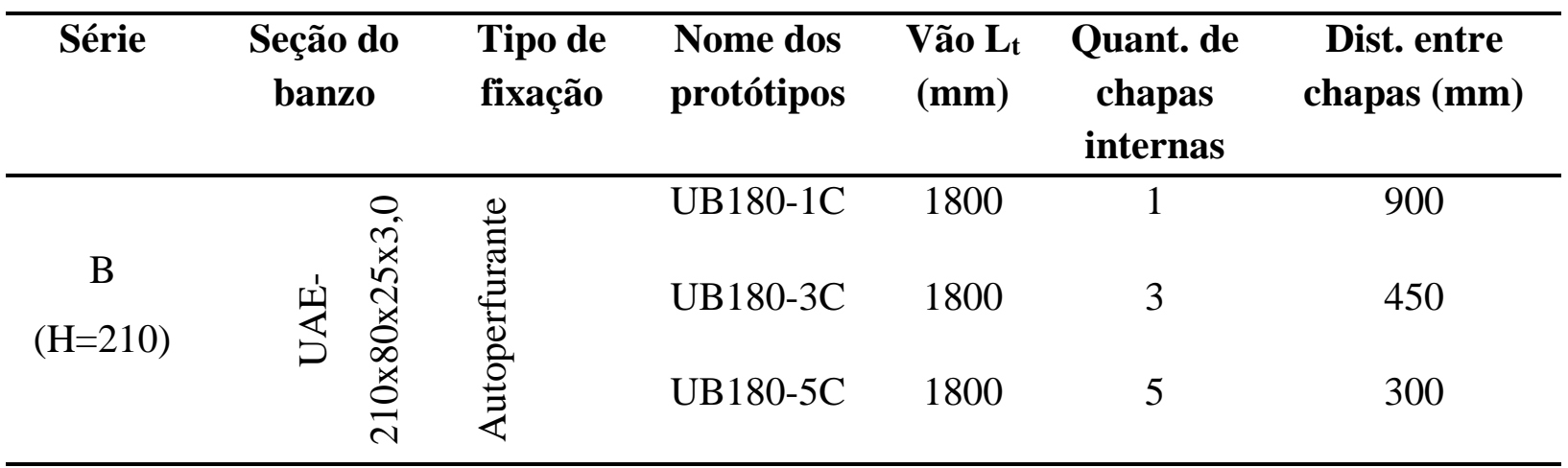

Fonte: Da autora. 


\subsubsection{Instrumentação}

A instrumentação dos ensaios consistiu em seis transdutores de deslocamento, posicionados dois por apoio e dois no meio do vão. As medidas foram realizadas com auxílio de uma cantoneira metálica que foi fixada na alma do perfil inferior próximo das presilhas ou das chapas. A Figura 4.4 mostra o posicionamento e a numeração dos transdutores de deslocamento nos ensaios realizados.

Figura 4.4- Posicionamento e numeração dos transdutores de deslocamento.

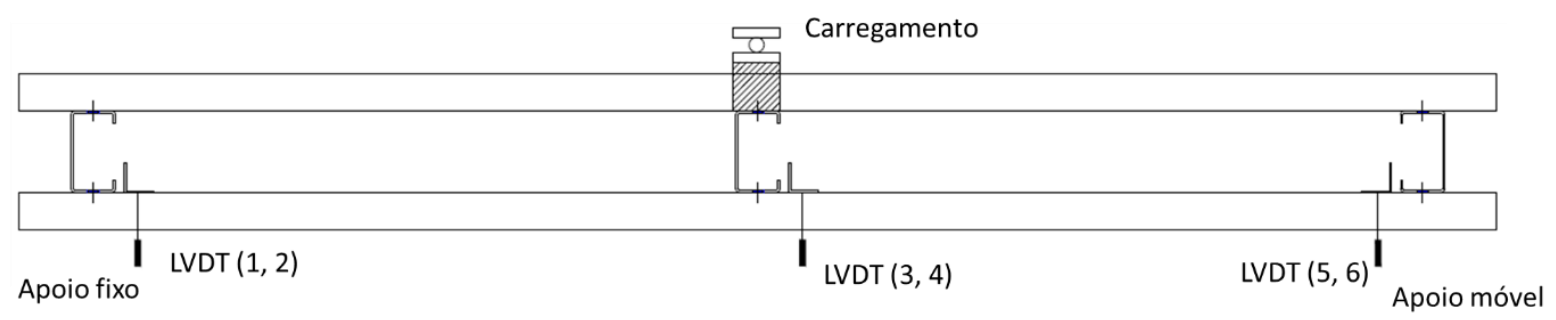

Fonte: Da autora.

Os protótipos UB360-3A e o UB180-1C foram instrumentados com extensômetros uniaxiais com o intuito de confirmar os resultados obtidos, isto é, verificar a presença ou não da flexão isolada ou parcialmente composta. Eles foram colados na alma próximo à mesa dos perfis componentes em uma seção situada entre a presilha central e a próxima na sequência (Figura 4.5).

Figura 4.5- Posicionamento dos extensômetros e corte genérico sem escala.
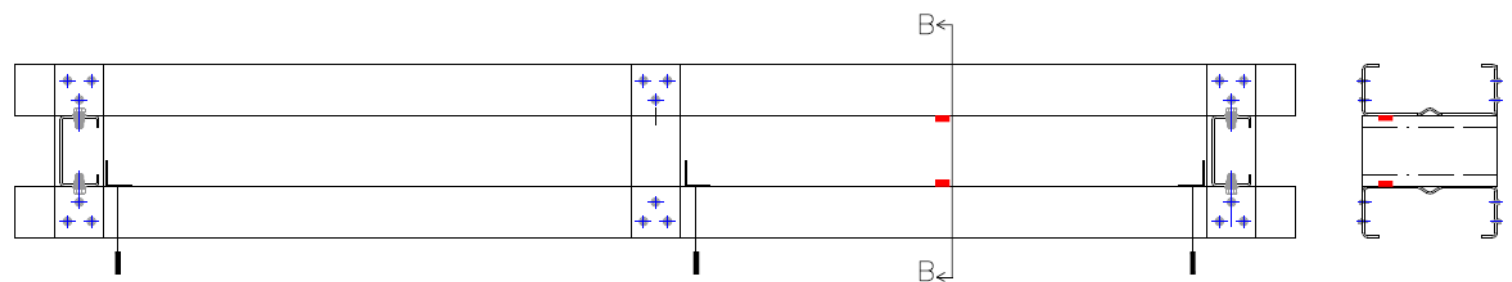

UB180-1C

CORTE B

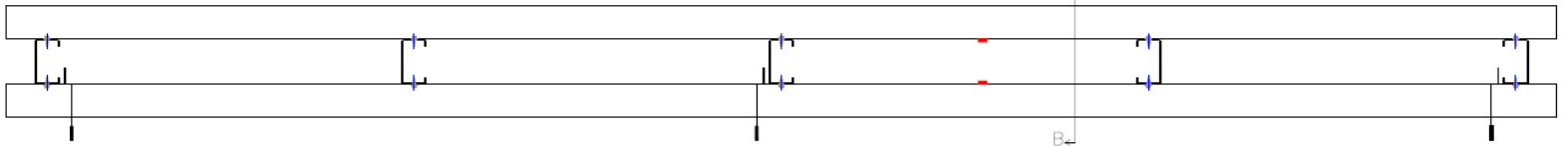

UB360-3A

Fonte: Da autora. 


\subsubsection{Montagem e Procedimento Experimental}

Os protótipos foram fornecidos pela empresa com as presilhas já fixadas nas barras que compõem a seção transversal. Um torque de 100 N.m foi padronizado nas peças que apresentavam a ligação com parafuso sextavado.

O primeiro passo da montagem experimental consistiu em apoiar os protótipos nos aparelhos de apoio do tipo rolete (fixo e móvel), que estavam posicionados sobre bases metálicas.

Durante essa etapa, verificou-se a necessidade de se utilizarem calços para que a barra ficasse devidamente estável sobre os apoios. Esse procedimento foi necessário para todos os corpos de prova, de forma mais expressiva para os da série A. Os protótipos também foram centralizados em relação ao ponto de aplicação da força, com o objetivo de assegurar a distribuição centrada da força aplicada pelo pistão.

A aplicação do carregamento monotônico foi realizada por meio de um atuador servohidráulico com capacidade nominal de $500 \mathrm{kN}$ e curso do pistão igual a $150 \mathrm{~mm}$. O carregamento foi introduzido pelo pistão sobre um sistema tipo rolete fixo que foi apoiado sobre o calço de madeira posicionado na alma do perfil superior. Foi utilizado o sistema System 5000 para a aquisição de dados no decorrer dos ensaios. A Figura 4.6 ilustra o esquema geral do ensaio.

Figura 4.6- Vista geral do ensaio.

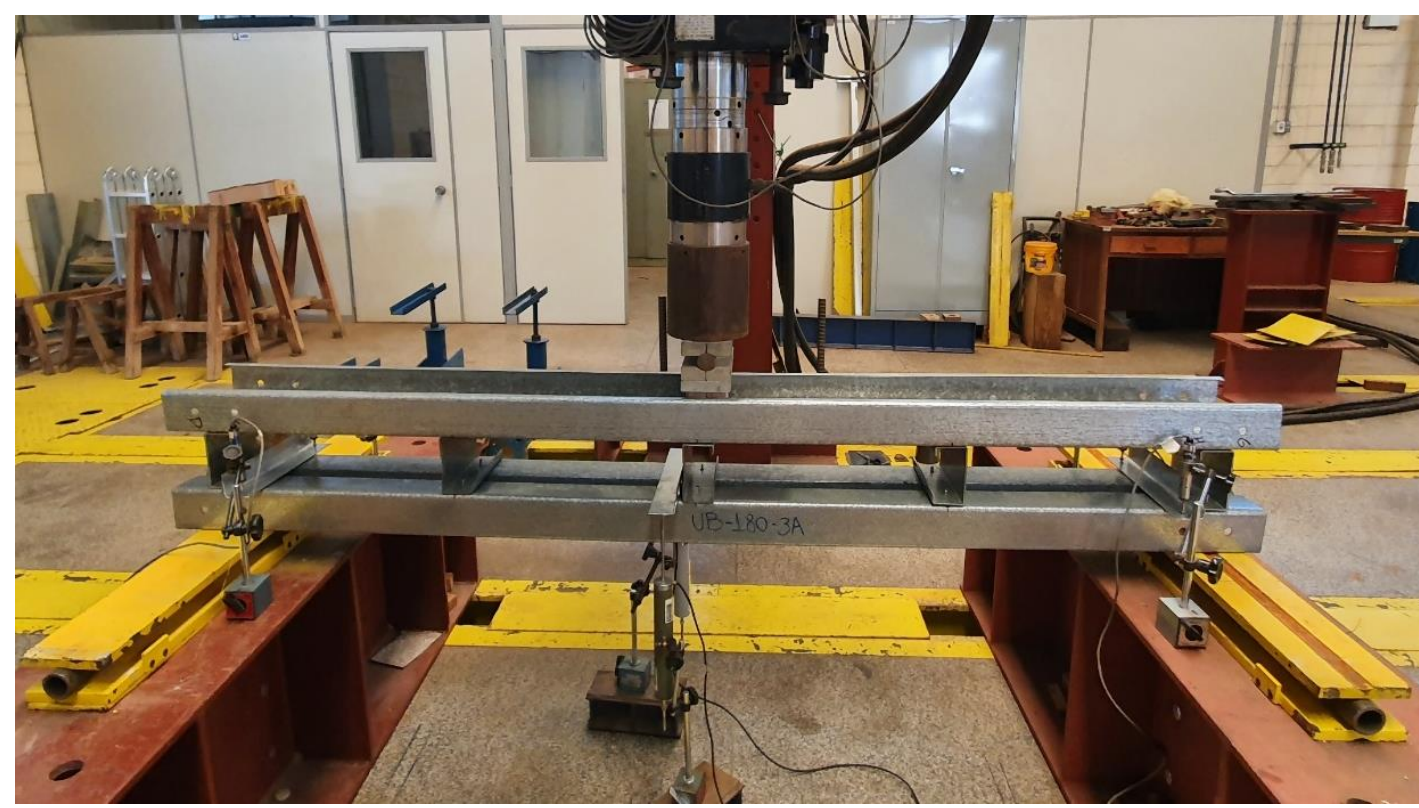

Fonte: Da autora. 
Inicialmente foi aplicado cerca de $10 \%$ da força máxima prevista a partir das análises teóricas, com o objetivo de eliminar folgas e fazer a verificação da instrumentação. Em seguida, os protótipos de menor comprimento com presilhas foram carregados até se atingir sua capacidade resistente (estado limite último); as três peças ligadas por chapas avançaram até o instante em que o sistema de carregamento apresentou uma rotação devido à deformação do perfil superior na região do carregamento.

Os corpos de prova de maior comprimento foram carregados até o limite do curso do atuador, sendo que dois desses protótipos foram preservados até cerca de $40 \%$ da força última observada para os outros da mesma série, com o objetivo de se mensurar a rigidez efetiva dos perfis individualmente. Dessa forma, a composição da soma de rigidez dos perfis individuais é mais realista.

Os ensaios foram realizados com controle de deslocamento do pistão do atuador servohidráulico. No início, para o vão menor foi utilizada uma velocidade de $0,01 \mathrm{~mm} / \mathrm{s}$ e de 0,03 $\mathrm{mm} / \mathrm{s}$ para o maior, que foi aumentada conforme a necessidade, isto é, quando acréscimos de deslocamento não provocavam aumento da força aplicada. A velocidade não superou o valor de $0,05 \mathrm{~mm} / \mathrm{s}$ para o vão de $1800 \mathrm{~mm}$, e em $0,07 \mathrm{~mm} / \mathrm{s}$ para o vão de $3600 \mathrm{~mm}$. Os registros de força e deslocamentos foram feitos a cada segundo.

\subsection{Prova de carga da treliça}

As treliças ensaiadas possuem as seguintes características: 7 painéis de $180 \mathrm{~cm}$ no banzo inferior e 6 painéis de $180 \mathrm{~cm}$ no banzo superior, sendo ambas barras contínuas, totalizando um vão teórico com comprimento de 12,60 m; a altura entre eixos dos banzos é de $100 \mathrm{~cm}$.

A prova de carga da viga treliçada plana consistiu em um ensaio de flexão a quatro pontos, com condições de contorno biapoiadas, o carregamento foi aplicado no banzo superior sobre o terceiro e quinto nó. Da configuração estática, resulta um diagrama de momento fletor com trecho central constante e esforço cortante nulo, sendo este o trecho em estudo.

A Figura 4.7 ilustra o esquema geral considerando a analogia de viga para o ensaio, assim como a distribuição do esforço normal nas barras, onde o de compressão está indicado em vermelho. Esse ensaio apresenta uma boa concordância com a estrutura utilizada em campo, pois, mesmo essa apresentando um diagrama de momentos fletores parabólico, a relação do vão pela altura, de aproximadamente 20, possibilita que o trecho central do diagrama apresente apenas uma pequena variação no momento fletor, podendo ser considerado constante no estudo. 
Figura 4.7- Esquema geral para o ensaio da treliça.

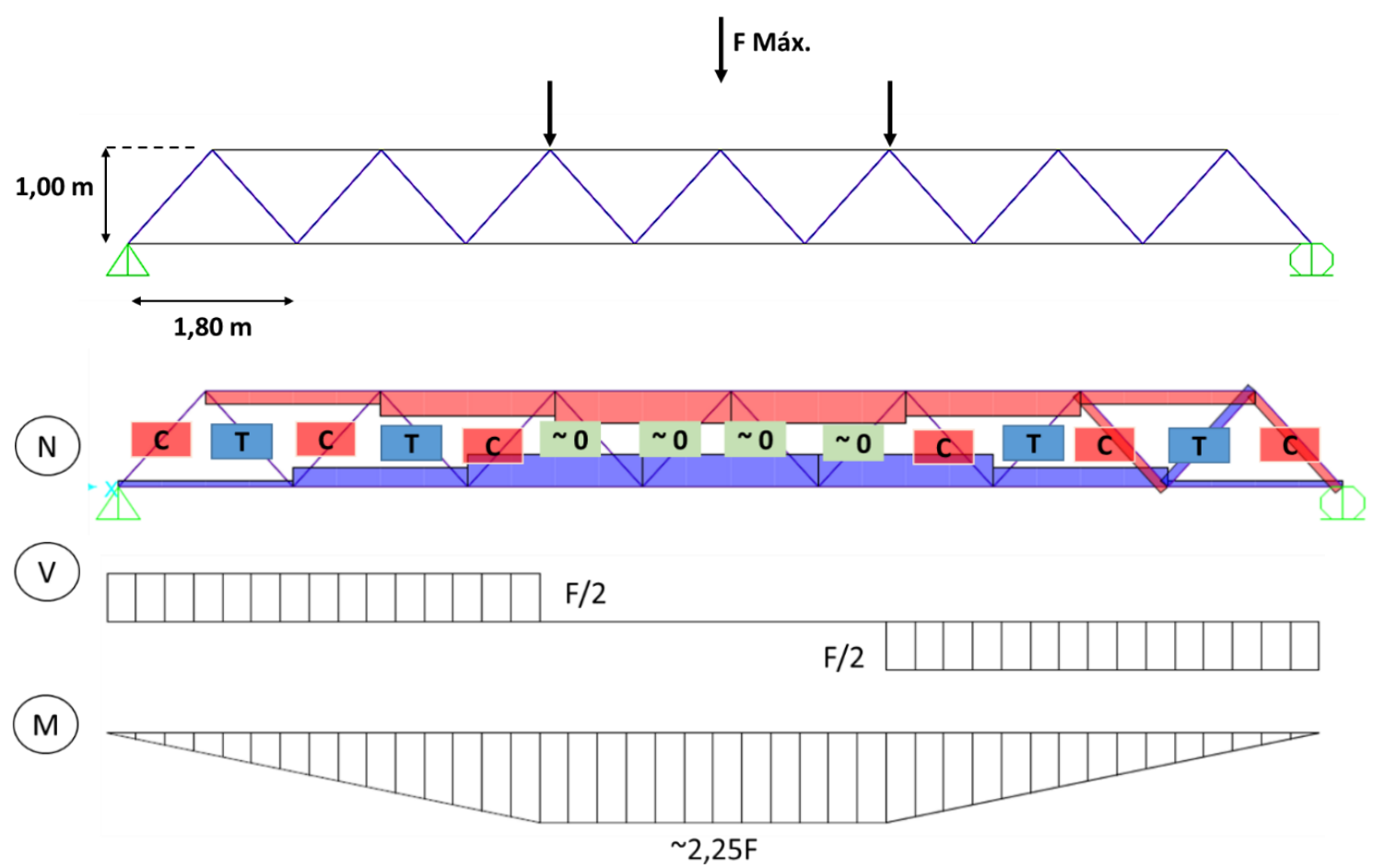

Fonte: Da autora.

\subsubsection{Protótipos}

As treliças apresentam seção transversal com alma enrijecida (UAE) para os banzos e sem enrijecimento para as diagonais, ambas as seções possuem enrijecedores de borda a $90^{\circ}$. A ligação da diagonal com o banzo foi realizada de forma direta por meio de parafusos sextavados.

Como o objetivo do ensaio é o comportamento da seção dupla dos banzos, a força máxima para o ensaio foi calculada considerando as estimativas da sua capacidade resistente à compressão. Por consequência, verificou-se a necessidade do uso de diagonais duplas da região dos pontos de aplicação do carregamento até as extremidades com o intuito de se evitar falhas devido ao esforço cortante.

As diagonais duplas foram ligadas pela alma com parafusos sextavados, foram utilizadas 2 presilhas (parafusos) para que a esbeltez isolada do perfil fosse menor que a metade da esbeltez máxima do conjunto, além das presilhas, foi utilizado um agrupamento de parafusos nas extremidades, como indica a ANSI/AISI S100:2020.

Suportes foram parafusados na corda inferior a fim de facilitar o apoio da peça sobre o aparelho de apoio. A Figura 4.8 ilustra a treliça plana em estudo com indicações do posicionamento das diagonais duplas e simples, dimensões gerais em milímetro e o suporte para o sistema de apoio. 
Figura 4.8- Esquema geral da treliça plana.

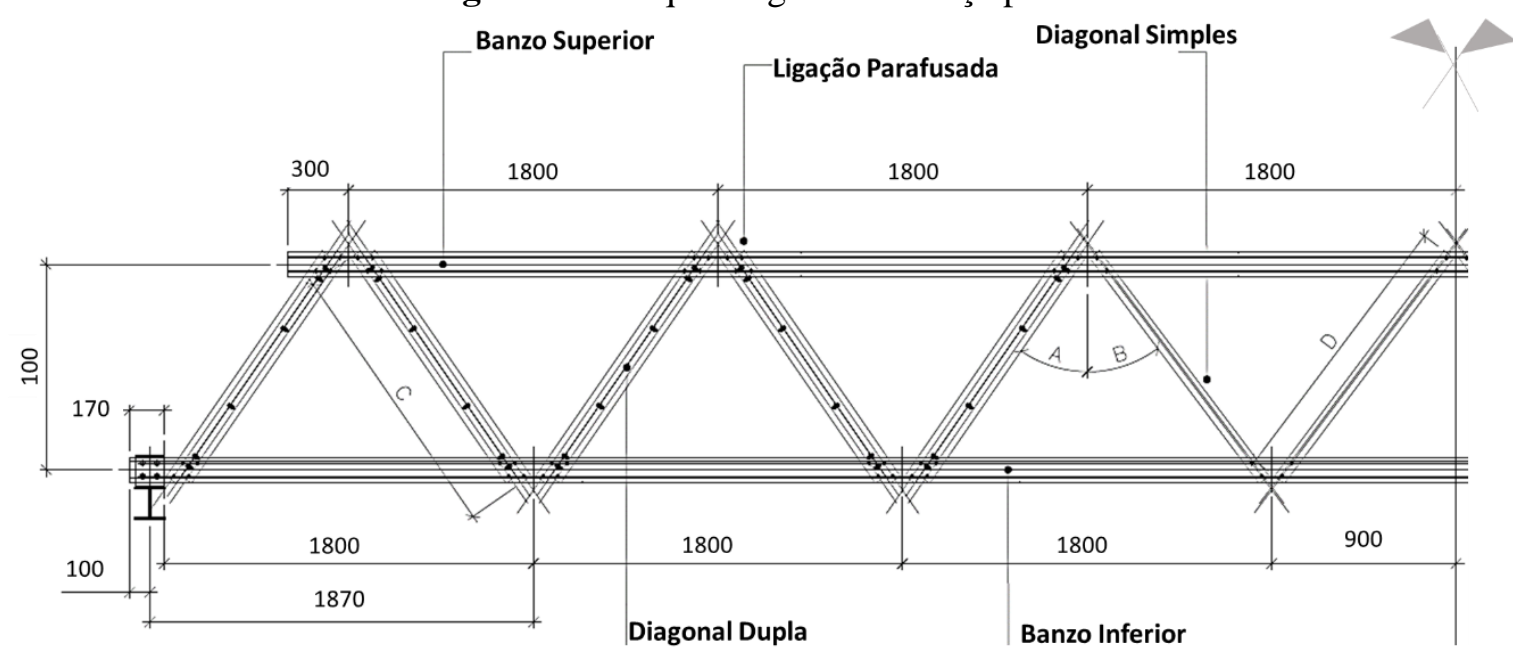

Fonte: Da autora.

Ao todo foram ensaiadas oito treliças, sendo quatro com o número de presilhas igual ao indicado pela norma e as demais com apenas uma presilha, condição selecionada como ideal do ponto de vista econômico. ATabela 4.3 apresenta uma descrição dos protótipos que foram ensaiados. Quanto à nomenclatura, os protótipos foram identificados pela altura total da seção e também pela distância do travamento fora do plano, em centímetros, e o número de presilhas entre nós. Por exemplo: 120J180.P5.

- 120J: Treliça com altura total da seção transversal de $120 \mathrm{~mm}$;

- 180: Travamento fora do plano igual a 180 centímetros;

- P5: Número de presilhas entre nós igual a 5.

Tabela 4.3- Descrição dos protótipos para a prova de carga da treliça.

\begin{tabular}{|c|c|c|c|c|c|}
\hline $\begin{array}{c}\text { Seção do } \\
\text { banzo }\end{array}$ & $\begin{array}{l}\text { Nome dos } \\
\text { protótipos }\end{array}$ & Quant. & $\begin{array}{l}\text { Travamento fora } \\
\text { do plano (mm) }\end{array}$ & $\begin{array}{l}\text { Quant. de } \\
\text { presilhas }\end{array}$ & $\begin{array}{c}\text { Dist. entre } \\
\text { presilhas }(\mathrm{mm})\end{array}$ \\
\hline \multirow{4}{*}{ 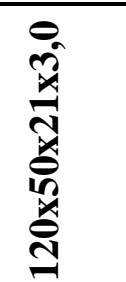 } & 120J180.P5 & 1 & 1800 & 5 & 300 \\
\hline & 120J360.P4 & 1 & 3600 & 4 & 360 \\
\hline & 120J180.P1 & 1 & 1800 & 1 & 900 \\
\hline & 120J360.P1 & 1 & 3600 & 1 & 900 \\
\hline \multirow{4}{*}{ 我 } & 210J180.P5 & 1 & 1800 & 5 & 300 \\
\hline & 120J360.P2 & 1 & 3600 & 2 & 600 \\
\hline & 210J180.P1 & 1 & 1800 & 1 & 900 \\
\hline & 120J360.P1 & 1 & 3600 & 1 & 900 \\
\hline
\end{tabular}

Fonte: Da autora. 


\subsubsection{Instrumentação}

A instrumentação consistiu em onze transdutores de deslocamento, sendo dez verticais e um horizontal. Os verticais foram posicionados da seguinte forma: dois por apoio, dois nos pontos de aplicação do carregamento e dois no meio do vão. As medidas foram realizadas diretamente na mesa superior do banzo inferior.

O deslocamento horizontal foi medido de forma indireta por meio de um fio metálico devidamente conectado à peça e ao transdutor localizado na laje de reação, como ilustra a Figura 4.9. A medida foi realizada no nó central do banzo superior para o travamento lateral a cada dois nós e entre o nó central e o seguinte para o travamento a cada nó.

Figura 4.9- Sistema utilizado para realizar a medida do deslocamento horizontal.

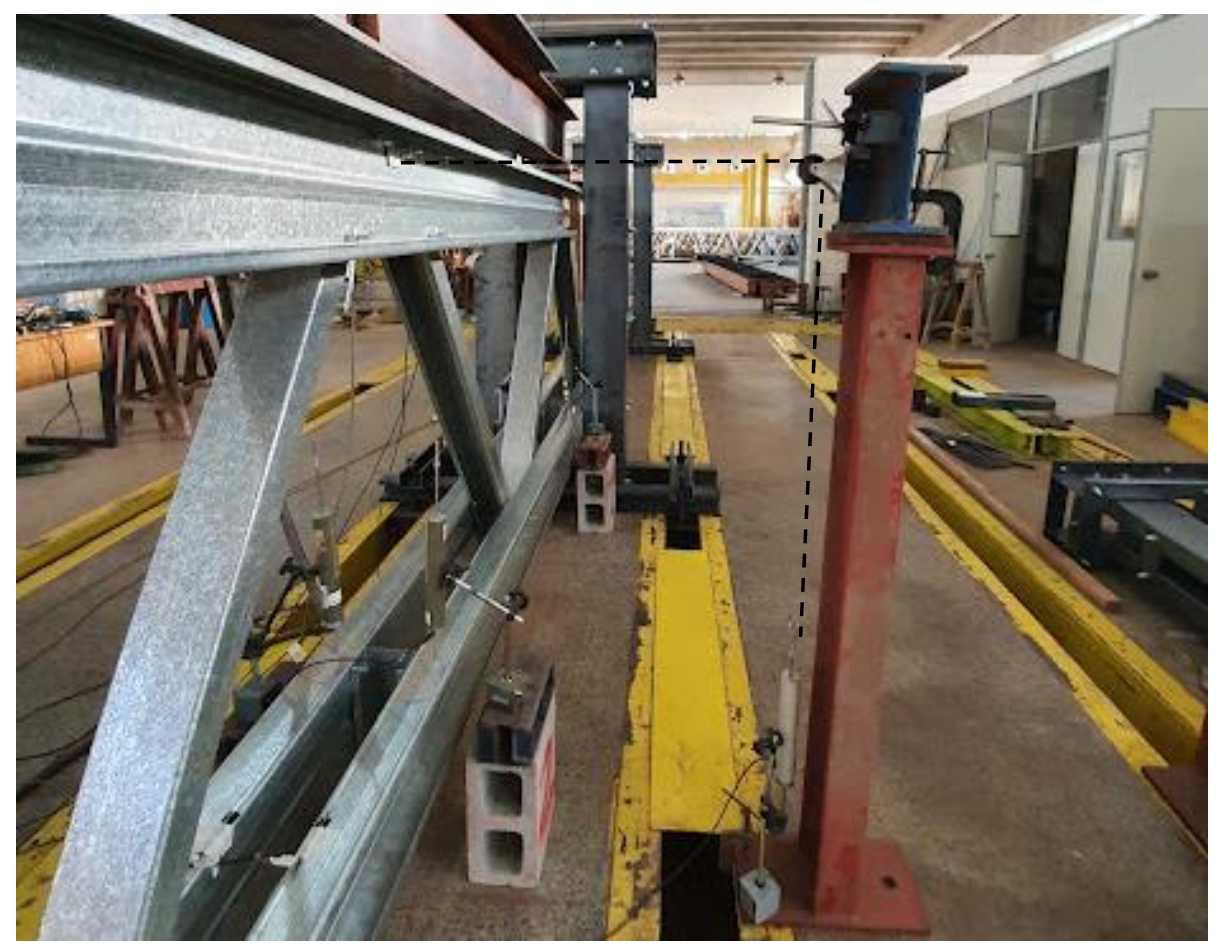

Fonte: Da autora.

Foram realizadas medidas de deformação específica nos protótipos travados lateralmente a cada dois nós e com altura de $210 \mathrm{~mm}$, a instrumentação foi realizada nos banzos superior e inferior com extensômetros uniaxiais nas mesas, próximos à alma, em uma seção que não continha a presilha. Foram instrumentadas ambas as barras do banzo, totalizando quatro extensômetros por banzo, conforme ilustra a Figura 4.10 que apresenta a posição do extensômetro na seção transversal e a numeração utilizada. 
Figura 4.10- Posição do extensômetro na seção transversal e numeração utilizada.
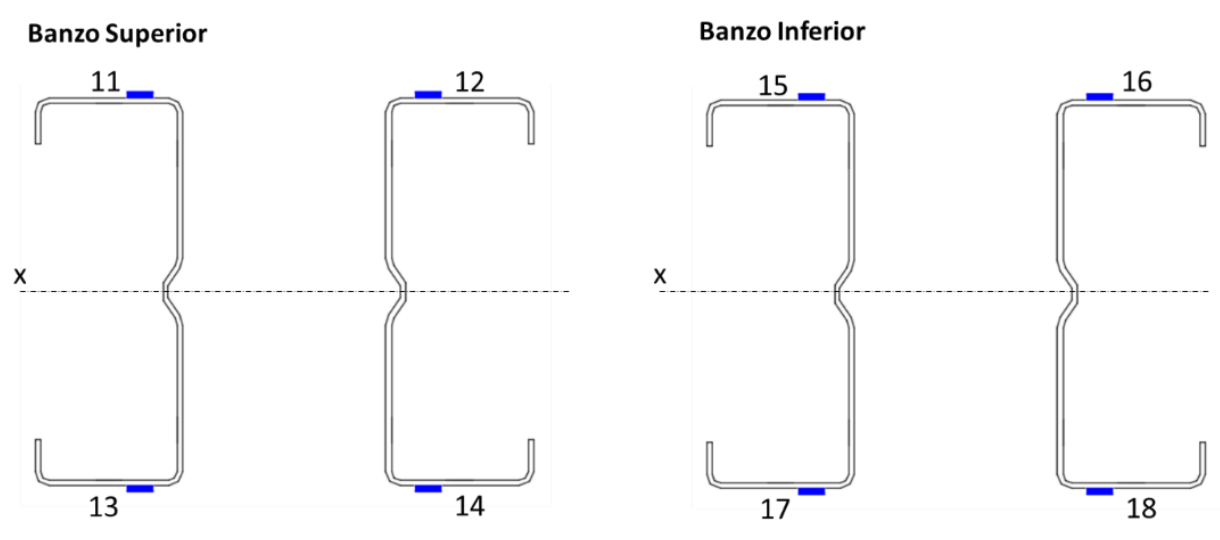

Fonte: Da autora.

A Figura 4.11 mostra o posicionamento e a numeração dos transdutores de deslocamento nos ensaios realizados, assim como a seção instrumentada com extensômetros em duas das peças.

Figura 4.11- Esquema utilizado para realizar a medida de deslocamento horizontal.

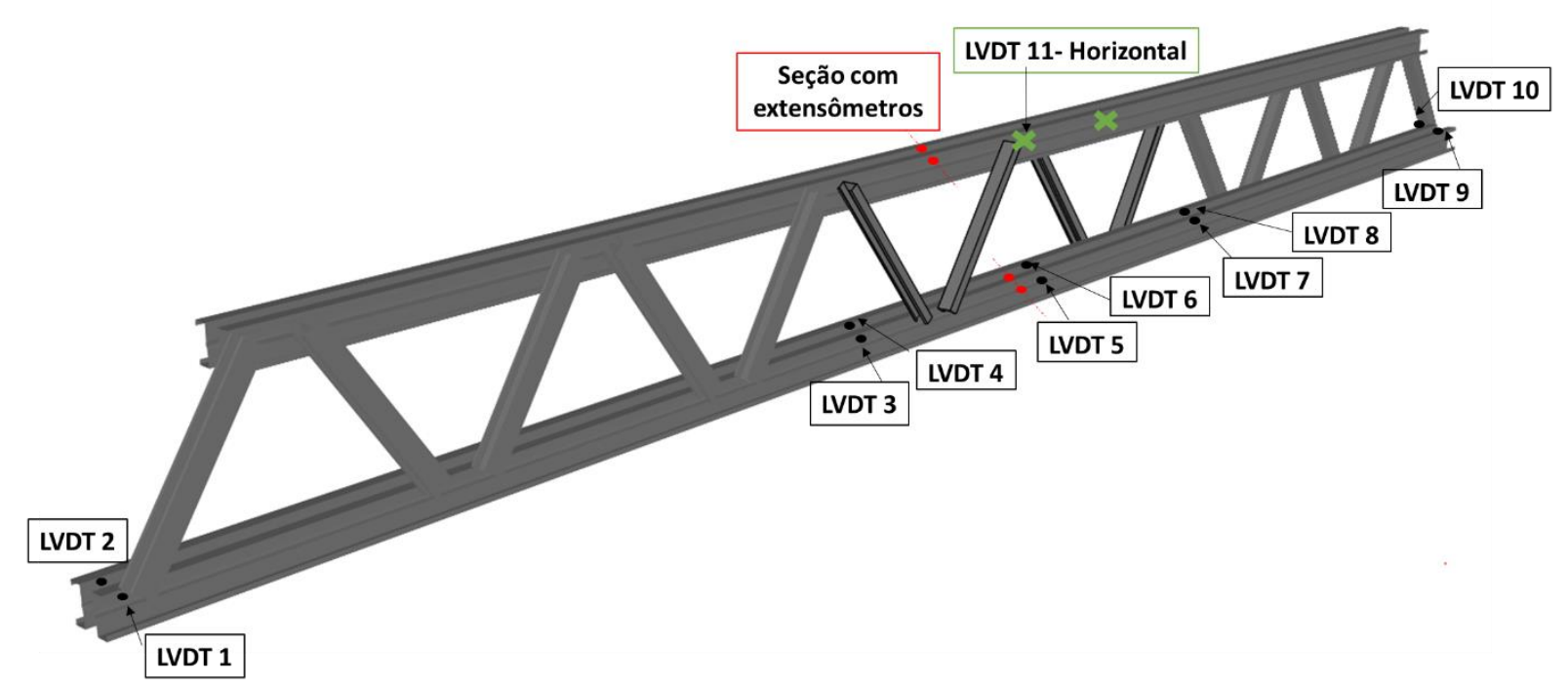

Fonte: Da autora.

\subsubsection{Montagem e Procedimento Experimental}

As treliças foram fornecidas pela empresa devidamente montadas, nas ligações parafusadas foi padronizado um torque de 120 N.m. O primeiro passo da montagem experimental consistiu em parafusar os suportes no banzo inferior da treliça e parafusar a viga 
de apoio no suporte. Após essa etapa, a peça foi centralizada em relação ao pórtico de reação apoiando o conjunto suporte e viga sobre os aparelhos de apoio do tipo rolete (fixo e móvel).

O carregamento foi introduzido pelo pistão do atuador sobre uma viga de distribuição simplesmente apoiada na região do nó da treliça, de modo que a força fosse devidamente distribuída na região. Para o travamento lateral da peça, foi utilizado um pórtico em perfil formado a frio, constituído por montantes, viga superior, viga inferior e travessa de ancoragem, como ilustra a Figura 4.12.

O travamento do nó central foi realizado ligeiramente deslocado devido à presença do atuador; além do travamento na região de estudo, os nós do banzo superior próximos aos apoios também foram contidos. Para que as peças ficassem devidamente em contato com o travamento lateral foram utilizadas chapas de madeira para eliminar as folgas existentes em determinados pontos.

Figura 4.12- Pórticos de travamento e viga de distribuição do carregamento.

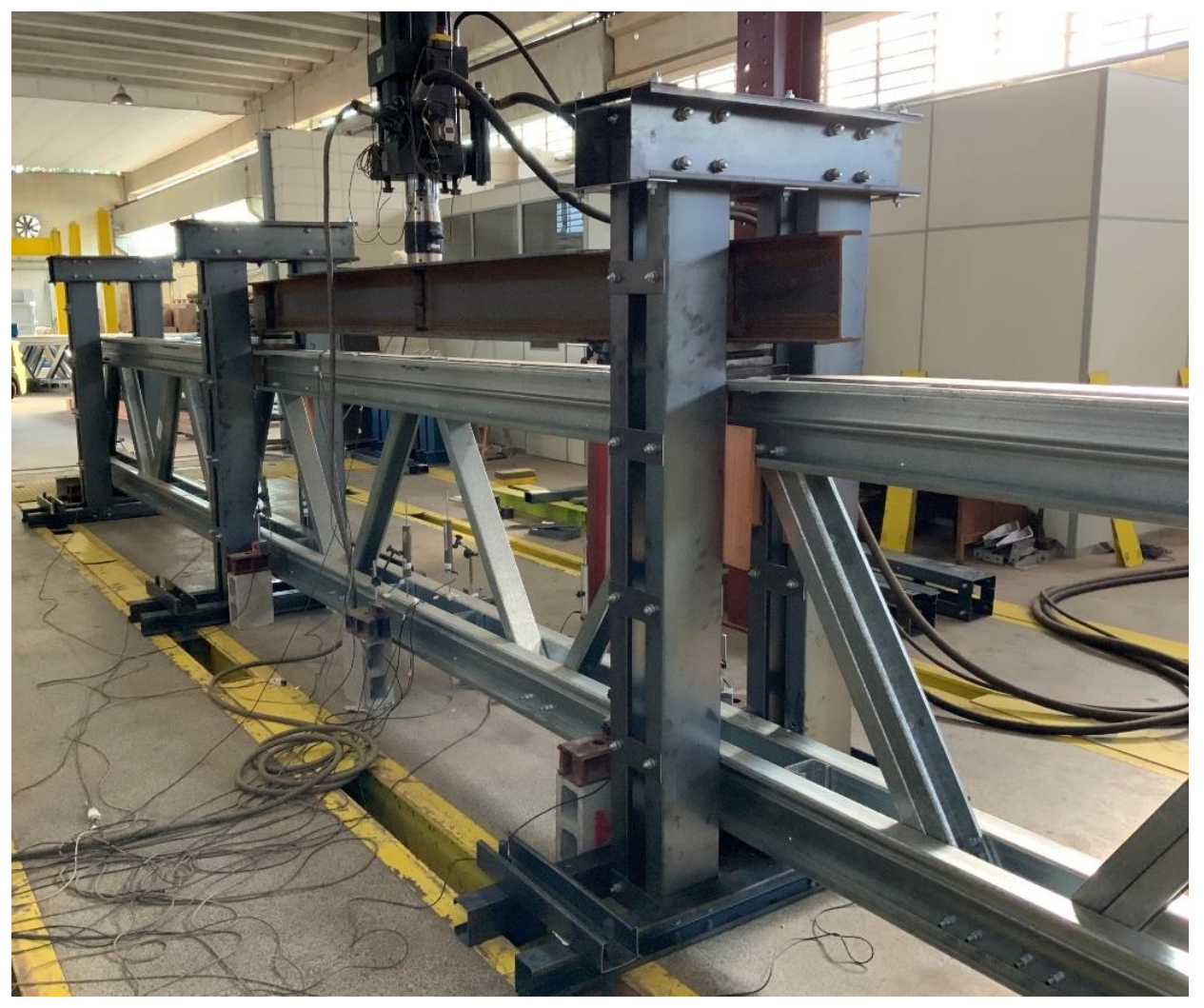

Fonte: Da autora.

Foi adicionada uma peça de madeira entre as mesas do perfil nos pontos de aplicação do carregamento com o intuito de reduzir a deformação da mesa superior devido ao efeito localizado, principalmente no perfil de maior altura. Inicialmente foi aplicada cerca de $10 \%$ da 
força última prevista a partir das análises teóricas, visando à eliminação de folgas e verificação da instrumentação. Em seguida, os protótipos foram carregados até o esgotamento de sua capacidade resistente (estado limite último) ou até o limite do curso do atuador.

Os ensaios foram realizados com controle de deslocamento do pistão do atuador servohidráulico. No início, foi utilizada uma velocidade de $0,05 \mathrm{~mm} / \mathrm{s}$ para as peças com o perfil de $210 \mathrm{~mm}$ e de $0,03 \mathrm{~mm} / \mathrm{s}$ para o perfil de $120 \mathrm{~mm}$, que foi aumentada conforme a necessidade, ou seja, quando acréscimos de deslocamento não provocavam aumento da força aplicada.

A velocidade utilizada nos ensaios não superou $0,07 \mathrm{~mm} / \mathrm{s}$ para a seção maior e 0,05 $\mathrm{mm} / \mathrm{s}$ para a menor. O sistema System 5000 foi utilizado para a aquisição de dados no decorrer dos ensaios. Os registros de força, deslocamentos e deformações foram feitos a cada segundo. 


\section{RESULTADOS DA ANÁLISE EXPERIMENTAL}

Este capítulo apresenta os resultados obtidos a partir da análise experimental e da verificação simplificada do ensaio de rigidez realizada via método dos elementos finitos. Os resultados do ensaio de flexão das barras do banzo se referem à rigidez em torno do eixo de menor inércia do perfil e ao comportamento das peças; já os do ensaio das treliças correspondem às capacidades resistentes, ao comportamento e aos modos de falha.

\subsection{Ensaio de Rigidez -Presilhas}

Com o decorrer do carregamento, aplicado na alma do perfil superior, a mesa superior da presilha se deforma perdendo rigidez, com isso o carregamento é transmitido pela alma da presilha para o perfil inferior (Figura 5.1). Dessa forma, ambas as barras estão solicitadas e as presilhas devem resistir ao fluxo de cisalhamento, sendo observada uma deformada de distorção (Figura 5.1). Não foi observada deformação localizada na região do carregamento.

Figura 5.1- Deformadas associadas ao carregamento e aos esforços.
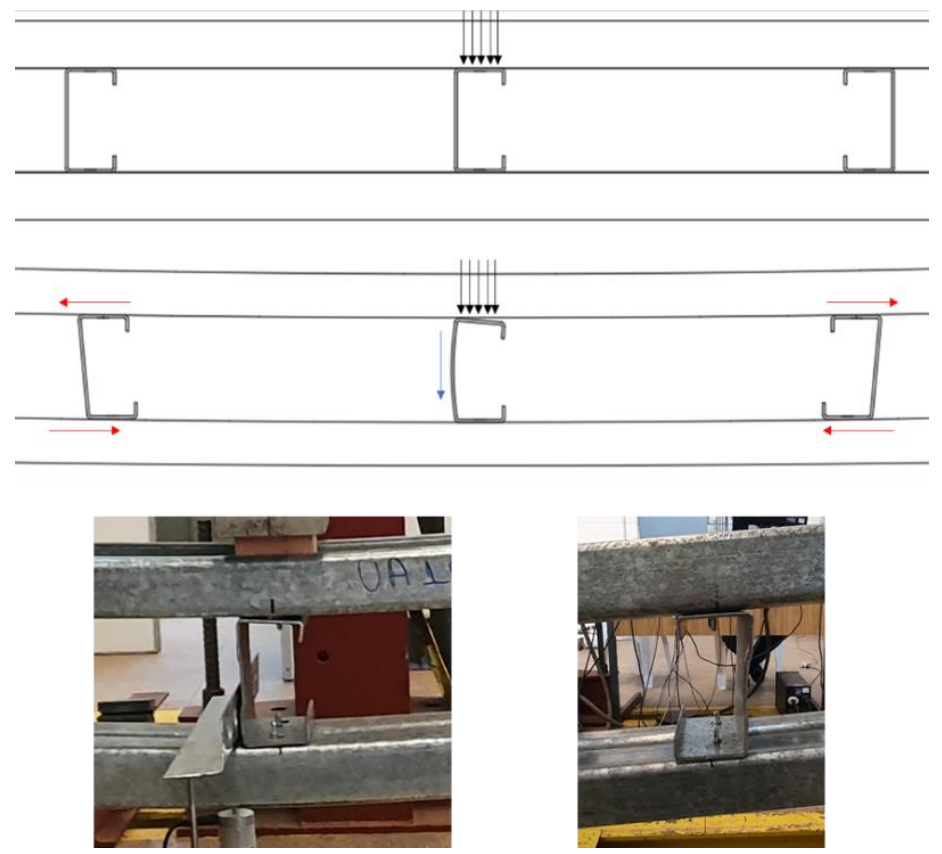

Fonte: Da autora.

Como a flexão ocorre de forma isolada ou parcialmente isolada, indicado nos resultados que seguem, o modo de instabilidade distorcional se manifesta na mesa e enrijecedor comprimido do perfil superior na região central (região de máximo momento fletor). 


\subsubsection{Série UB}

Os resultados obtidos para a série UB 180 seguem ilustrados na Figura 5.2 e organizados na Tabela 5.1. A rigidez foi calculada considerando o valor de $10 \%$ a $60 \%$ da força máxima, que corresponde ao trecho com comportamento aproximadamente linear nas curvas de força versus deslocamento. Nesse trecho foi aplicado um ajuste linear nos dados obtendo-se a inclinação da reta e o respectivo valor de rigidez do protótipo.

Figura 5.2- Curvas força versus deslocamento da série UB180.

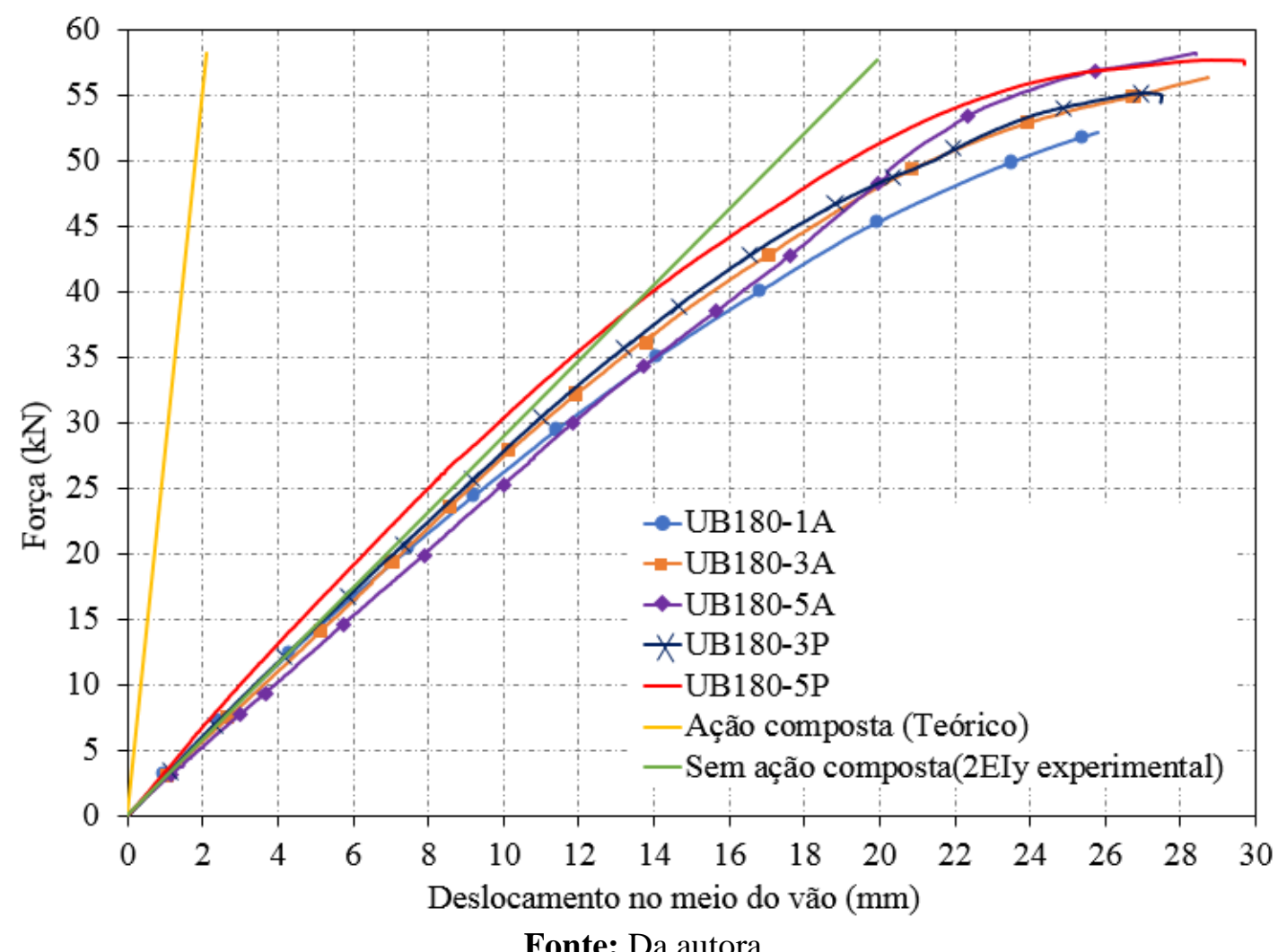

Tabela 5.1- Resultados obtidos para os protótipos UB180.

\begin{tabular}{|c|c|c|c|c|c|}
\hline \multirow[t]{2}{*}{ Protótipo } & \multicolumn{2}{|c|}{ Experimental } & \multicolumn{2}{|c|}{ Teórico } & \multirow{2}{*}{$\begin{array}{c}\left(\text { EI }_{\mathbf{y}} / 2 \mathrm{EI}_{\mathbf{y}}\right) \\
\text { Experimental }\end{array}$} \\
\hline & $\begin{array}{c}\mathrm{I}_{\mathrm{y}} \\
\left(\mathrm{cm}^{4}\right)\end{array}$ & $\begin{array}{c}2 \mathrm{I}_{\mathrm{y}} \text { individual } \\
\left(\mathrm{cm}^{4}\right)\end{array}$ & $\begin{array}{c}2 \mathrm{I}_{\mathrm{y}} \text { individual } \\
\left(\mathrm{cm}^{4}\right)\end{array}$ & $\begin{array}{c}\mathrm{I}_{\mathrm{y}} \text { composto } \\
\left(\mathrm{cm}^{4}\right)\end{array}$ & \\
\hline UB $1801 A$ & 151,52 & 175,93 & 197,06 & 1698,00 & 0,861 \\
\hline UB $1803 A$ & 165,66 & 175,93 & 197,06 & 1698,00 & 0,942 \\
\hline UB $1805 A$ & 152,83 & 175,93 & 197,06 & 1698,00 & 0,869 \\
\hline UB $1803 P$ & 164,74 & 175,93 & 197,06 & 1698,00 & 0,936 \\
\hline UB $1805 P$ & 181,06 & 175,93 & 197,06 & 1698,00 & 1,029 \\
\hline
\end{tabular}

Fonte: Da autora. 
Analisando os resultados apresentados verifica-se que os valores de rigidez são inferiores ou próximos ao limite inferior, isto é, a soma da rigidez de cada perfil individualmente. Também se observa a tendência de um pequeno aumento de rigidez com o acréscimo de presilhas para ambos os tipos de parafusos utilizados.

O protótipo com cinco presilhas conectadas por autoperfurantes (UB180-5A) apresentou rigidez inferior ao de três; isso se deve à posição dos parafusos mais distantes das mesas, como mostrado na Figura 5.3. A mudança da posição foi uma não conformidade em relação as demais peças. Um modelo numérico, descrito no apêndice A deste trabalho, foi realizado a fim de verificar esse efeito na rigidez.

Figura 5.3- Distância entre os parafusos na seção transversal para os protótipos 3A e 5A respectivamente.
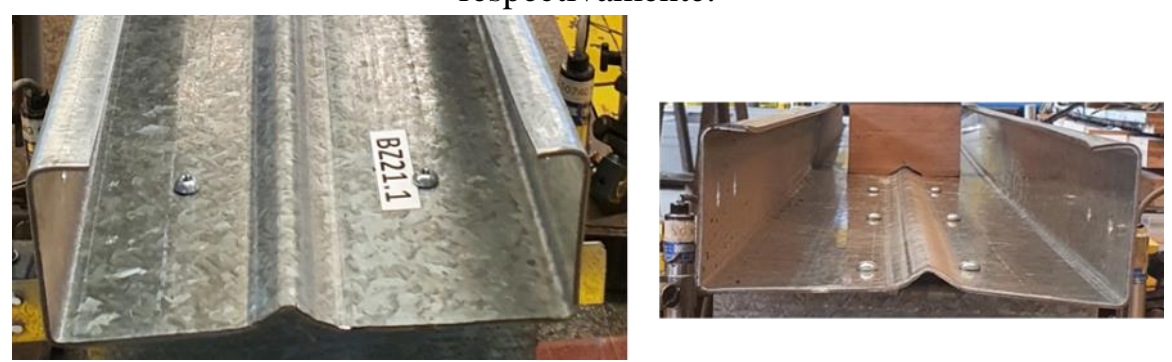

Fonte: Da autora.

Essa diferença da posição do parafuso na seção transversal levou a uma menor restrição entre o conjunto banzo/presilha com o decorrer do ensaio, devido à presença do modo distorcional para a mesa e enrijecedor comprimido do perfil superior observado para toda a série UB, como ilustra a Figura 5.4.

Figura 5.4- Modo distorcional característico da série UB.
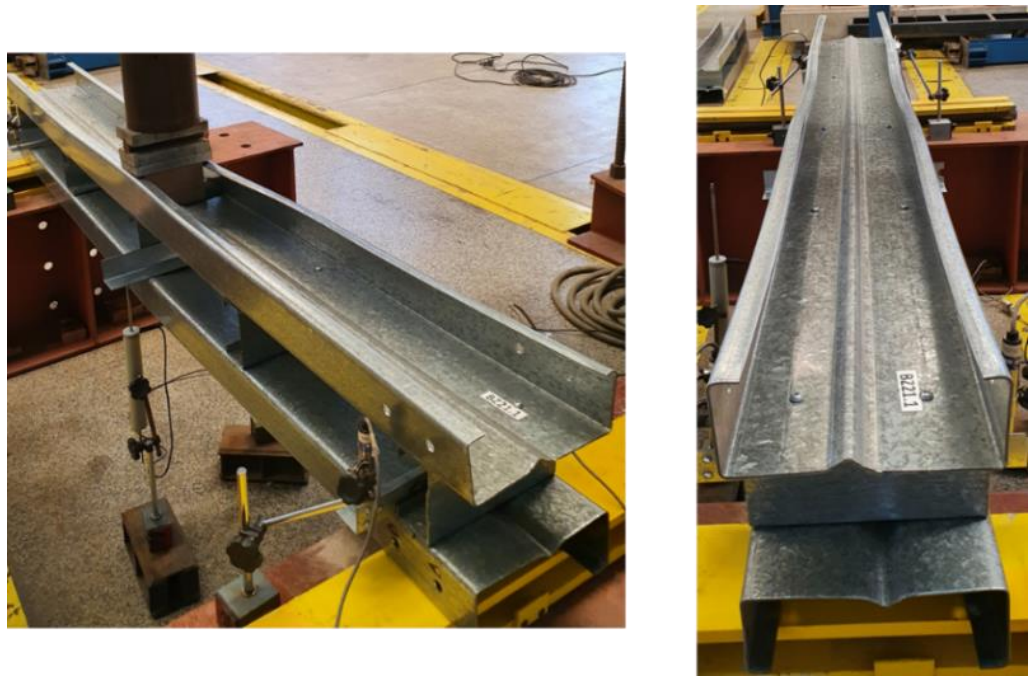

Fonte: Da autora. 
Realizando um comparativo entre os dois tipos de parafusos utilizados, observou-se um comportamento semelhante entre os protótipos com a mesma quantidade de presilhas como mostrado na Figura 5.5.

Figura 5.5- Curvas força versus deslocamento da série UB180 com três presilhas.

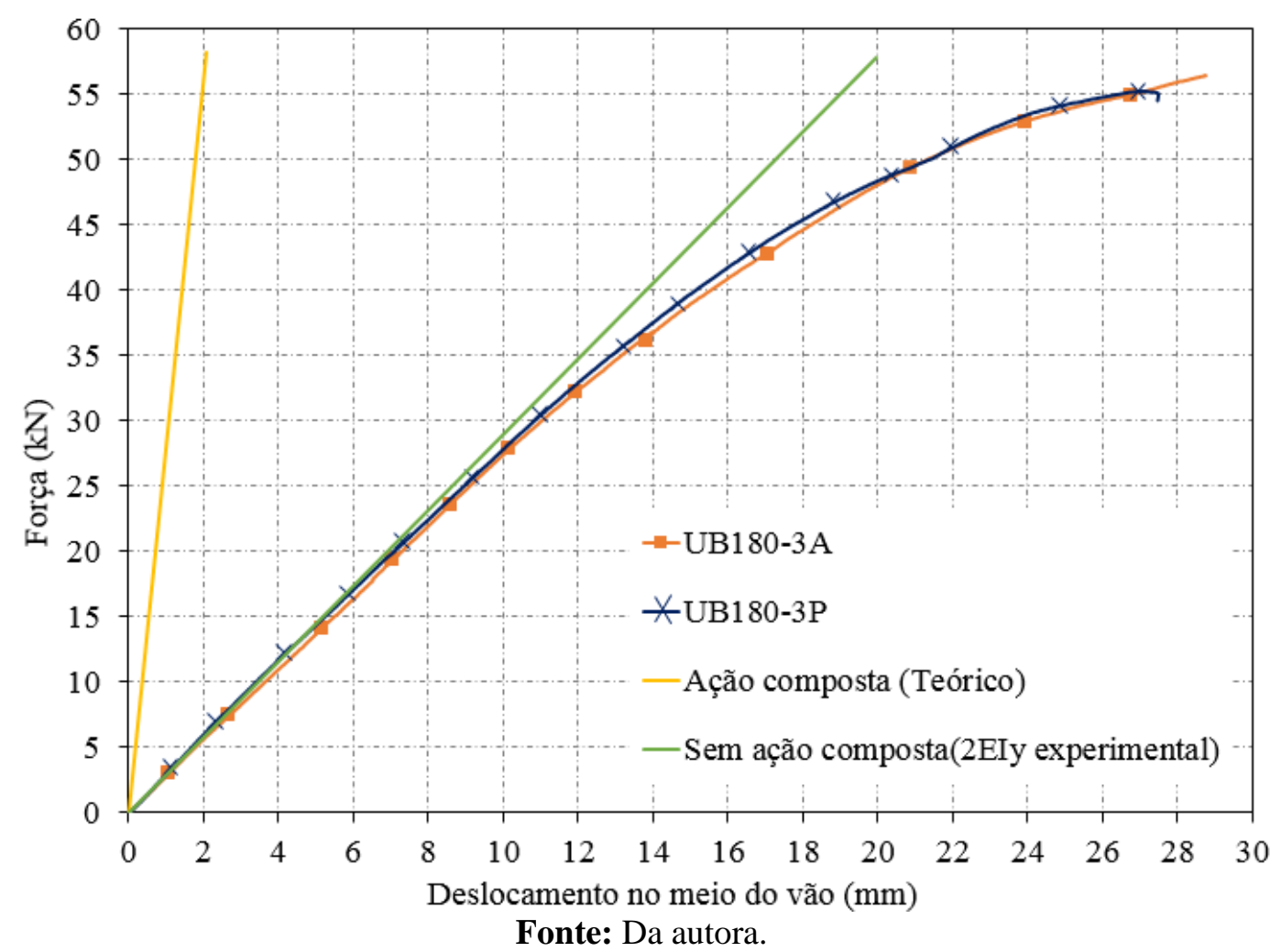

Para o comprimento de $3600 \mathrm{~mm}$, os valores de rigidez se apresentaram superiores ao limite inferior experimental para todos os protótipos, e com valor crescente com o acréscimo de presilhas. Os resultados obtidos foram organizados na Tabela 5.2 e estão ilustrados na Figura 5.6.

Tabela 5.2- Resultados obtidos para os protótipos UB360.

\begin{tabular}{cccccc}
\hline Protótipo & \multicolumn{2}{c}{ Experimental } & \multicolumn{2}{c}{ Teórico } & $\begin{array}{c}\text { (EI } / 2 \text { EI } \mathbf{y}) \\
\text { experimental }\end{array}$ \\
\cline { 2 - 5 } & $\begin{array}{c}\mathrm{I}_{\mathrm{y}} \\
\left(\mathrm{cm}^{4}\right)\end{array}$ & $\begin{array}{c}2 \mathrm{I}_{\mathrm{y}} \text { individual } \\
\left(\mathrm{cm}^{4}\right)\end{array}$ & $\begin{array}{c}2 \mathrm{I}_{\mathrm{y}} \text { individual } \\
\left(\mathrm{cm}^{4}\right)\end{array}$ & $\begin{array}{c}\mathrm{I}_{\mathrm{y}} \text { composto } \\
\left(\mathrm{cm}^{4}\right)\end{array}$ & \\
\hline UB 360 1A & 217,63 & 175,93 & 197,06 & 1698,00 & 1,237 \\
UB 360 3A & 222,93 & 175,93 & 197,06 & 1698,00 & 1,267 \\
UB 360 5A & 209,32 & 175,93 & 197,06 & 1698,00 & 1,190 \\
UB 360 3P & 222,64 & 175,93 & 197,06 & 1698,00 & 1,265 \\
\hline
\end{tabular}

Fonte: Da autora. 
Figura 5.6- Curvas força versus deslocamento da série UB360.

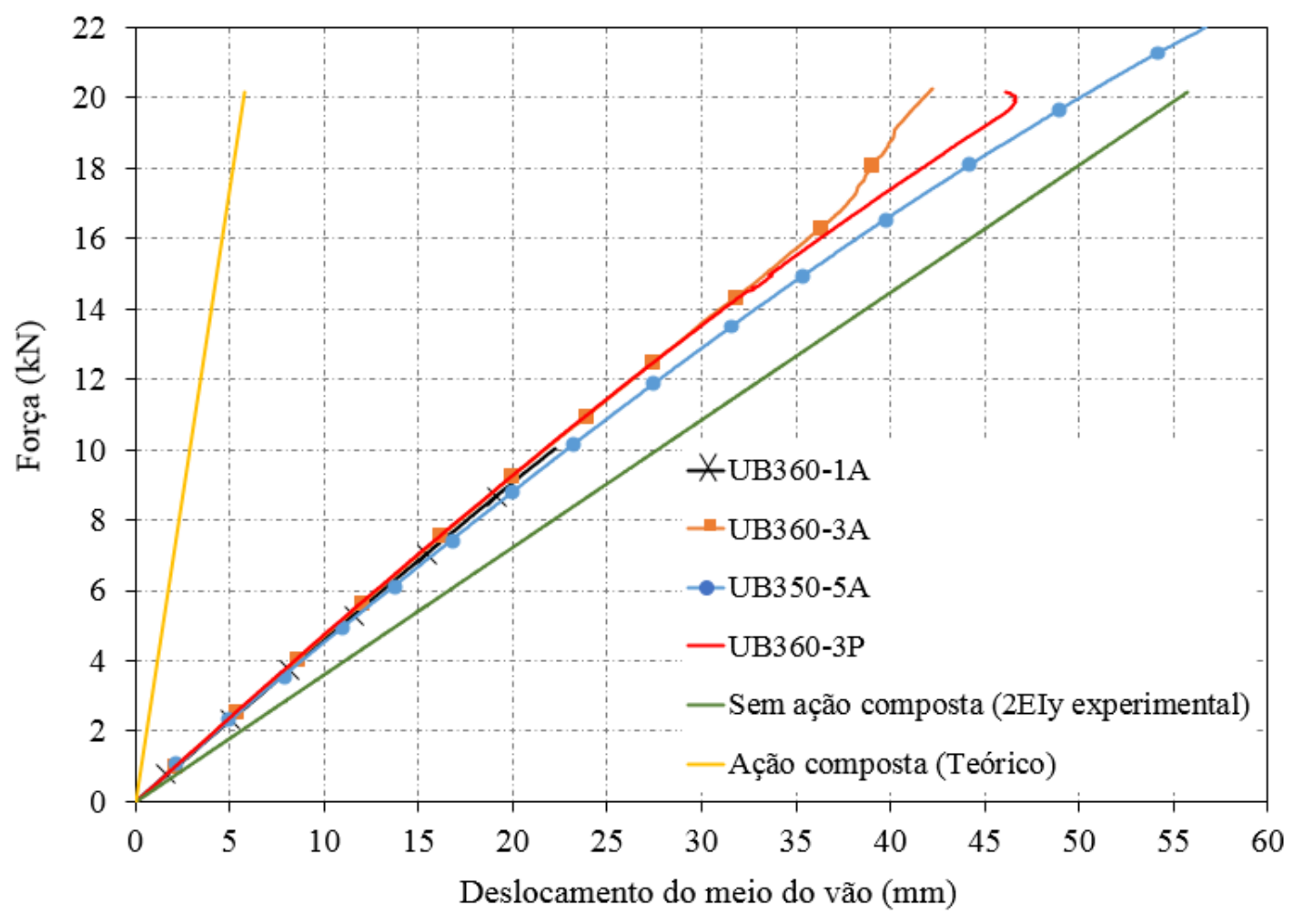

Fonte: Da autora.

A peça UB180-1A foi preservada até certo nível de carregamento para que os perfis fossem ensaiados individualmente, possibilitando obter a rigidez experimental das barras. $\mathrm{O}$ corpo de prova UB360-5A possuía três presilhas que não estavam devidamente conectadas aos dois perfis e apresentou rigidez inferior ao protótipo com apenas uma presilha.

Os dois tipos de parafusos utilizados na ligação apresentaram comportamento semelhantes para um mesmo número de ligações, resultando em uma rigidez praticamente igual. O modo distorcional exibido no menor vão também se manifestou no comprimento de $3600 \mathrm{~mm}$.

A Figura 5.7 mostra a curva força versus deformação obtida dos perfis superior e inferior, assim como, as curvas teóricas que representam o comportamento elástico linear das considerações definidas pela ação isolada e pela ação composta.

Por meio da figura observa-se a ocorrência de tração no perfil superior e compressão no inferior, e as deformações medidas situaram-se entre as curvas teóricas, de modo que uma ação parcialmente composta se desenvolve nos protótipos de maior vão, e consequentemente as deformações são um pouco menores que as do limite teórico da ação isolada. 
Figura 5.7- Deformação medida no perfil superior e inferior (UB360-3A).

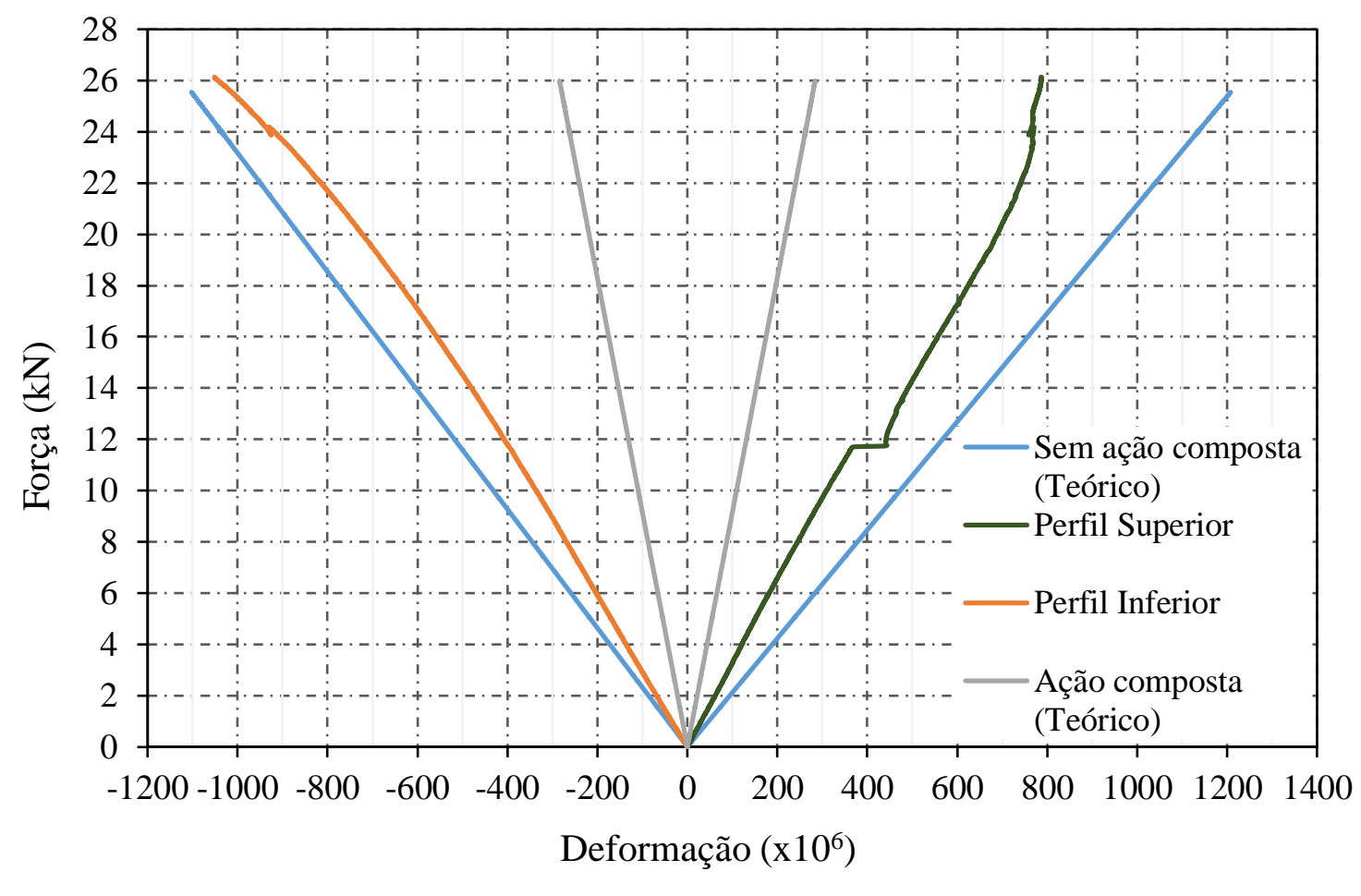

Fonte: Da autora.

\subsubsection{Série UA}

A série UA 180 apresentou rigidez próxima ao limite inferior obtido do ensaio das barras individuais $\left(2 \mathrm{EI}_{\mathrm{y}}\right.$ experimental) para todos os corpos de prova, como mostrado na Figura $5.8 \mathrm{e}$ na Tabela 5.3. Para a ligação com autoperfurante, observou-se um aumento de rigidez com o incremento de presilhas, para a ligação com parafuso sextavado o mesmo comportamento não foi verificado. O modo distorcional também foi observado para os protótipos dessa série.

Tabela 5.3- Resultados de rigidez obtidos para os protótipos da série UA180.

\begin{tabular}{|c|c|c|c|c|c|}
\hline \multirow[t]{2}{*}{ Protótipo } & \multicolumn{2}{|c|}{ Experimental } & \multicolumn{2}{|c|}{ Teórico } & \multirow{2}{*}{$\begin{array}{c}\left.\left(\mathrm{EI}_{\mathbf{y}} / 2 \mathrm{EI}\right)_{\mathrm{y}}\right) \\
\text { experimental }\end{array}$} \\
\hline & $\begin{array}{c}\mathrm{I}_{\mathrm{y}} \\
\left(\mathrm{cm}^{4}\right)\end{array}$ & $\begin{array}{l}2 \mathrm{I}_{\mathrm{y}} \text { individual } \\
\qquad\left(\mathrm{cm}^{4}\right)\end{array}$ & $\begin{array}{l}2 \mathrm{I}_{\mathrm{y}} \text { individual } \\
\left(\mathrm{cm}^{4}\right)\end{array}$ & $\begin{array}{c}\mathrm{I}_{\mathrm{y}} \text { composto } \\
\left(\mathrm{cm}^{4}\right)\end{array}$ & \\
\hline UA $1801 \mathrm{~A}$ & 51,72 & 55,13 & 46,52 & 805,68 & 0,938 \\
\hline UA $1803 A$ & 55,00 & 55,13 & 46,52 & 805,68 & 0,998 \\
\hline UA $1805 A$ & 55,74 & 55,13 & 46,52 & 805,68 & 1,011 \\
\hline UA $1803 P$ & 53,31 & 55,13 & 46,52 & 805,68 & 0,967 \\
\hline UA $1805 P$ & 52,88 & 55,13 & 46,52 & 805,68 & 0,959 \\
\hline
\end{tabular}

Fonte: Da autora. 
Figura 5.8- Curvas força versus deslocamento da série UA180.

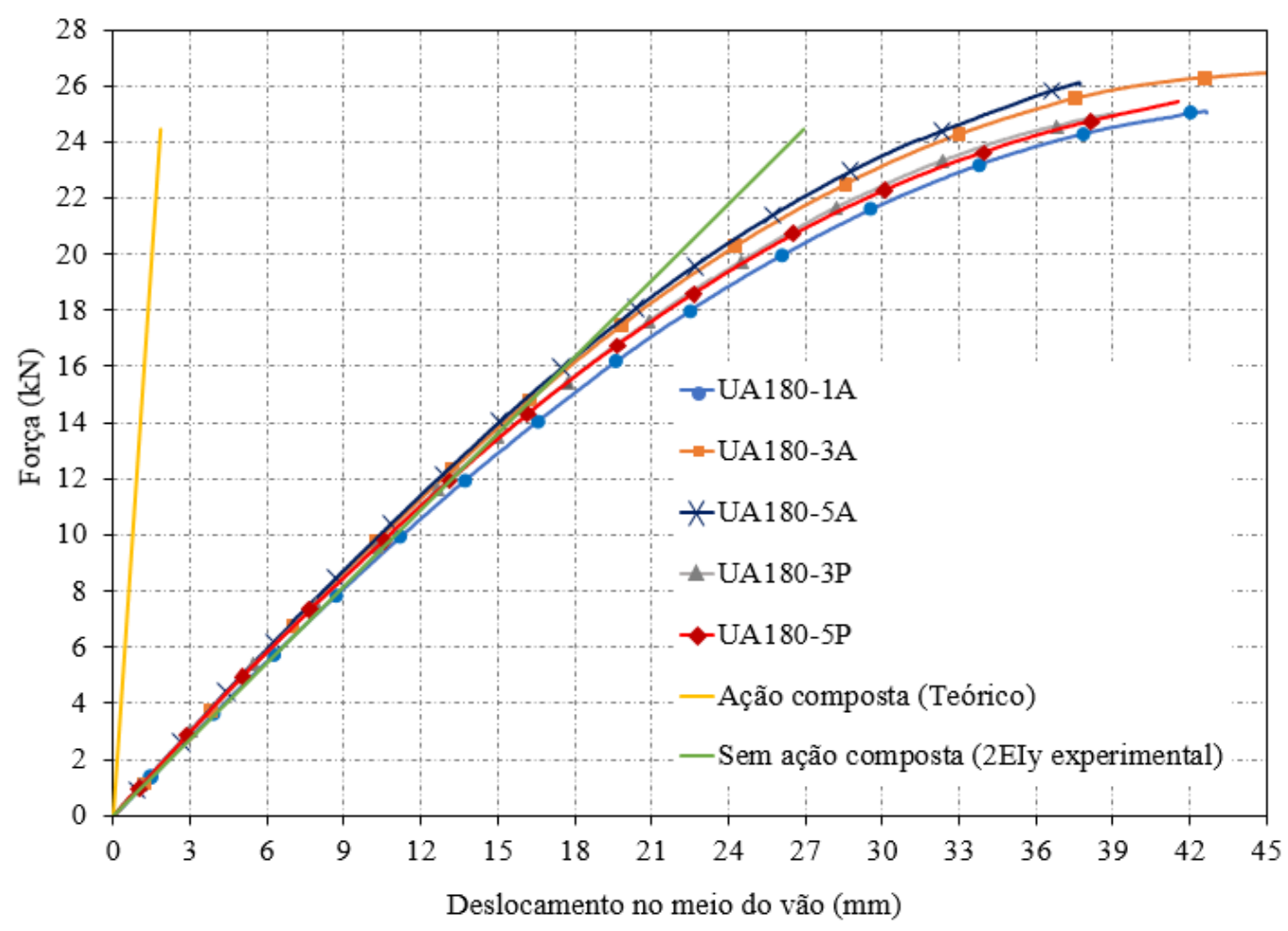

Fonte: Da autora.

A série UA 360 apresentou rigidez ligeiramente superior ao limite inferior experimental, como mostrado na Figura 5.9 .

Figura 5.9- Curvas força versus deslocamento da série UA360.

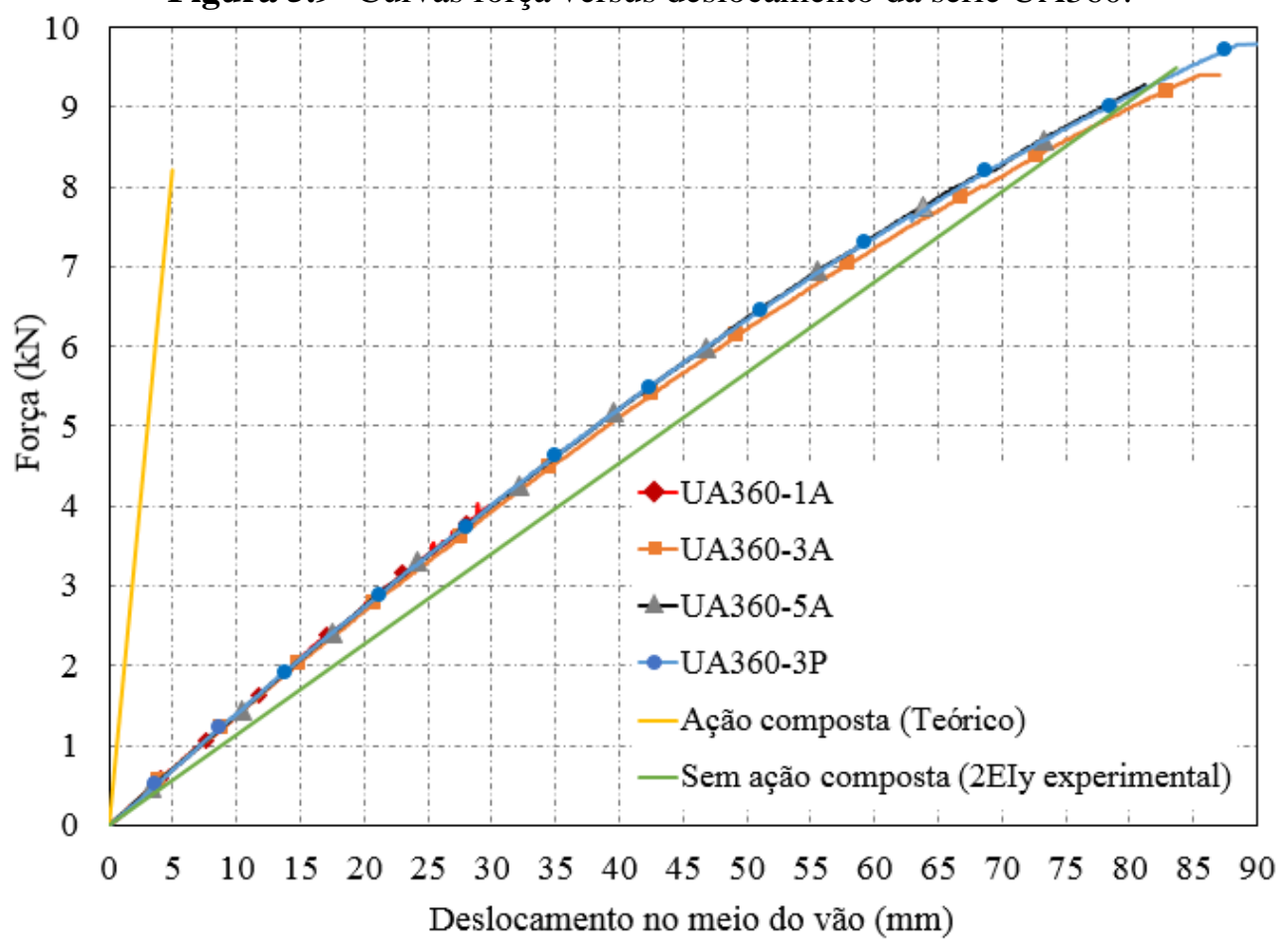

Fonte: Da autora. 
A rigidez para o protótipo ensaiado com cerca de $40 \%$ da força máxima foi superior aos demais com mesmo tipo de ligação. Assim como nos resultados já apresentados anteriormente, verificou-se a tendência de aumento da rigidez com a adição de mais presilhas. Em comparação para o mesmo número de presilhas a ligação com parafuso sextavado apresentou uma rigidez ligeiramente maior. Os resultados obtidos seguem organizados na Tabela 5.4.

Tabela 5.4- Resultados obtidos para os protótipos da série UA360.

\begin{tabular}{cccccc}
\hline Protótipo & \multicolumn{2}{c}{ Experimental } & \multicolumn{2}{c}{ Teórico } & $\begin{array}{c}\text { (EIy /2EIy } \\
\text { Experimental }\end{array}$ \\
\cline { 2 - 5 } & $\begin{array}{c}\mathrm{I}_{\mathrm{y}} \\
\left(\mathrm{cm}^{4}\right)\end{array}$ & $\begin{array}{c}2 \mathrm{I}_{\mathrm{y}} \text { individual } \\
\left(\mathrm{cm}^{4}\right)\end{array}$ & $\begin{array}{c}2 \mathrm{I}_{\mathrm{y}} \text { individual } \\
\left(\mathrm{cm}^{4}\right)\end{array}$ & $\begin{array}{c}\mathrm{I}_{\mathrm{y}} \text { composto } \\
\left(\mathrm{cm}^{4}\right)\end{array}$ & \\
\hline UA 360 1A & 64,93 & 55,13 & 46,52 & 805,68 & 1,178 \\
UA 360 3A & 62,35 & 55,13 & 46,52 & 805,68 & 1,131 \\
UA 360 5A & 63,91 & 55,13 & 46,52 & 805,68 & 1,159 \\
UA 360 3P & 63,81 & 55,13 & 46,52 & 805,68 & 1,157 \\
\hline
\end{tabular}

Fonte: Da autora.

Notou-se uma deformação mais perceptível das presilhas nos protótipos com perfil de menor altura e maior comprimento, principalmente as situadas próximas as extremidades, devido ao deslocamento vertical mais acentuado, como pode ser observado na Figura 5.10 e na Figura 5.11.

Figura 5.10- Deformada da viga da série UA 360.

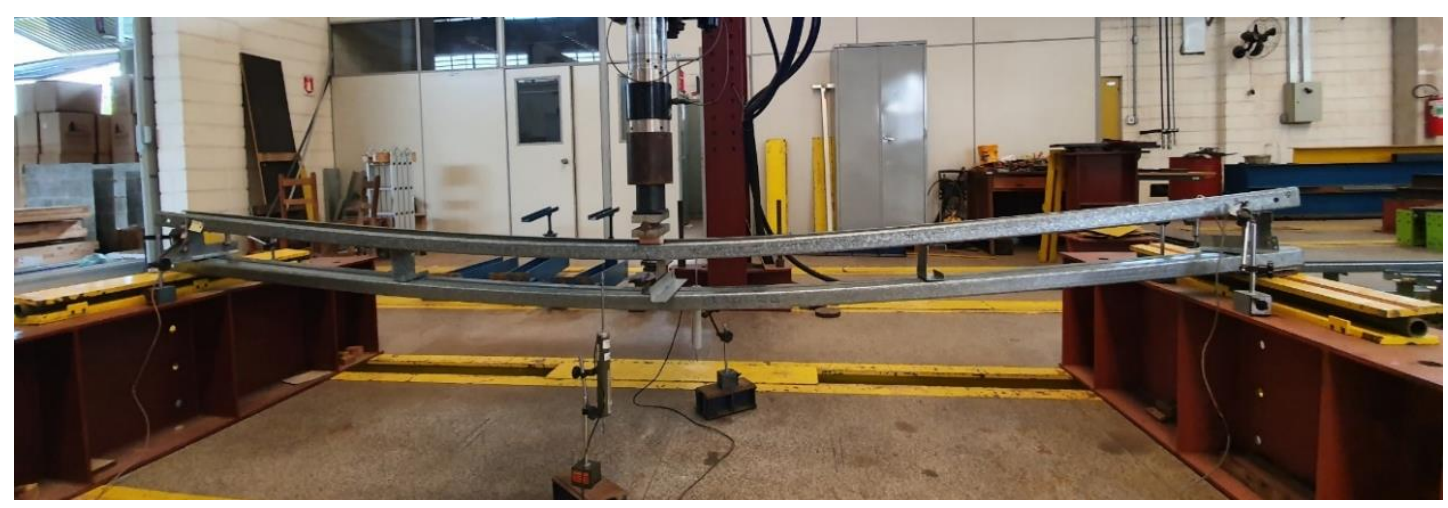

Fonte: Da autora. 
Figura 5.11- Deformada da presilha devido ao efeito da flexão e cortante.
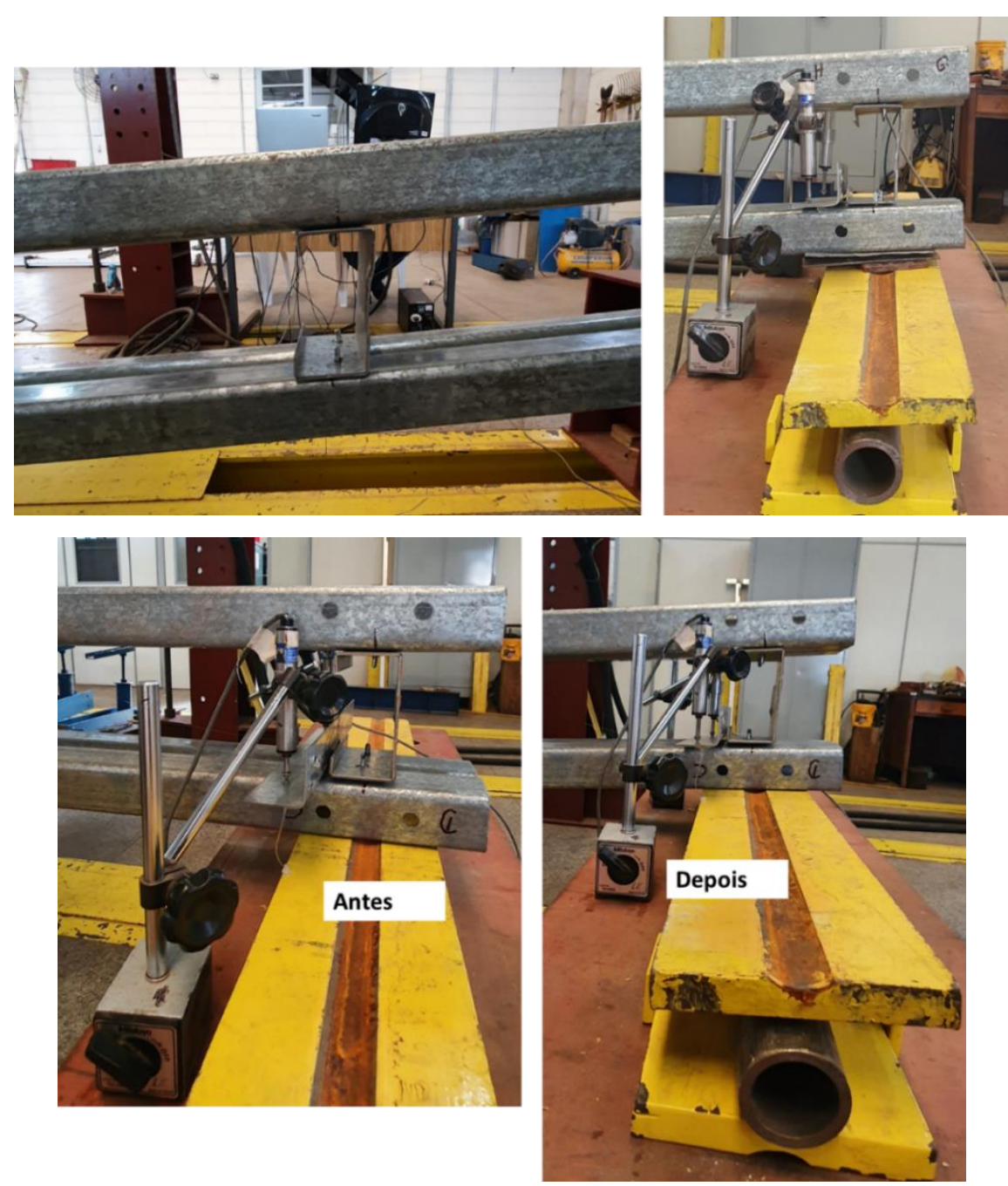

Fonte: Da autora.

\subsection{Ensaio de Rigidez- Chapas de ligação}

As chapas assim como as presilhas de seção aberta possibilitam a transferência do carregamento do perfil superior para o inferior. E associado a deformação do perfil superior as chapas apresentam flexão.

Os protótipos com chapas unindo as barras principais foram carregados até o momento em que o sistema do tipo rolete fixo apoiado sobre o calço de madeira apresentou uma rotação, devido à deformação do perfil superior na região do carregamento (efeito localizado).

As curvas força versus deslocamento no meio do vão são apresentadas na Figura 5.12, e os valores de rigidez obtidos foram organizados na Tabela 5.5. A rigidez foi calculada considerando o trecho entre $5 \mathrm{kN}$ e $20 \mathrm{kN}$, que apresenta comportamento aproximadamente 
linear nas curvas de força versus deslocamento. Nesse trecho foi aplicado um ajuste linear nos dados e obtida a inclinação da reta e o respectivo valor de rigidez associado.

$\mathrm{O}$ aumento no número de talas gerou um acréscimo de rigidez, sendo que todos os corpos de prova apresentaram rigidez superior a somatória da rigidez de cada perfil individual.

Para o mesmo comprimento, verificou-se uma maior eficiência da ligação realizada pelas mesas das barras principais utilizando as chapas como presilhas em comparação com o uso do perfil de seção aberta conectado pela alma.

Figura 5.12- Curvas força versus deslocamento para os protótipos com chapas nas mesas.

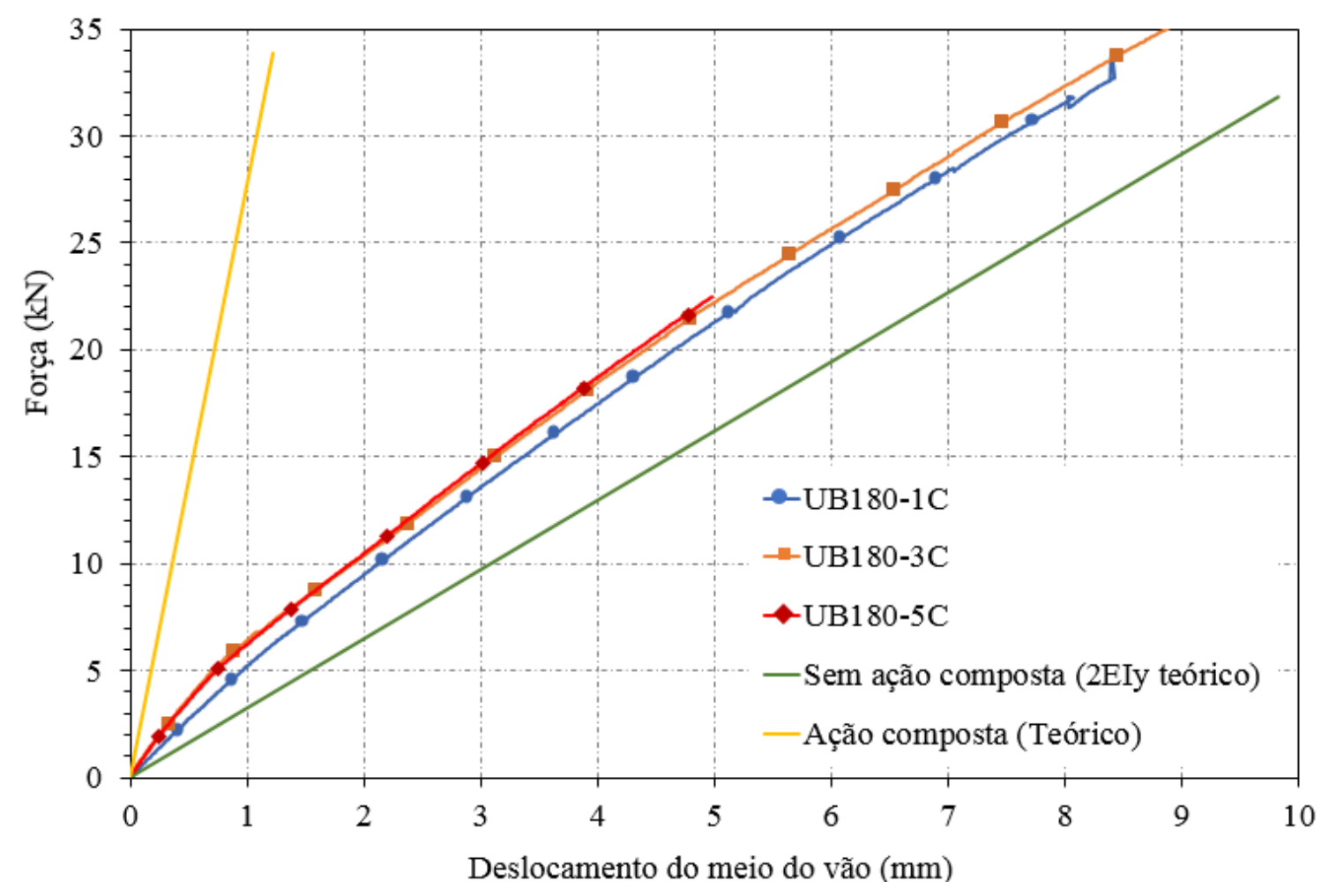

Fonte: Da autora.

Tabela 5.5- Resultados obtidos para os protótipos UB180 com chapas nas mesas.

\begin{tabular}{|c|c|c|c|c|}
\hline \multirow[t]{2}{*}{ Protótipo } & \multirow{2}{*}{$\begin{array}{c}\text { Experimental } \\
\mathrm{I}_{\mathrm{y}}\left(\mathrm{cm}^{4}\right)\end{array}$} & \multicolumn{2}{|c|}{ Teórico } & \multirow{2}{*}{$\frac{\left(I_{y}\right) \text { experimental }}{2 I_{y} \text { individual }}$} \\
\hline & & $\begin{array}{l}2 \mathrm{I}_{\mathrm{y}} \text { individual } \\
\left(\mathrm{cm}^{4}\right)\end{array}$ & $\mathrm{I}_{\mathrm{y}}$ composto $\left(\mathrm{cm}^{4}\right)$ & \\
\hline UB $1801 C$ & 240,11 & 197,06 & 1698,00 & 1,218 \\
\hline UB $1803 C$ & 241,61 & 197,06 & 1698,00 & 1,226 \\
\hline UB $1805 C$ & 252,00 & 197,06 & 1698,00 & 1,279 \\
\hline
\end{tabular}

Fonte: Da autora. 
A Figura 5.13 mostra a curva força versus deformação obtida dos perfis superior e inferior, assim como o valor teórico.

As deformações específicas medidas pelos extensômetros colados no protótipo UB1801C indicaram tração no perfil superior e compressão no inferior, no entanto, observa-se que uma ação parcialmente composta se desenvolve no protótipo, pois as deformações são menores que as teóricas para a ação isolada. Com isso, a rigidez é maior que a soma dos valores individuais como indicado anteriormente.

Figura 5.13- Deformação medida no perfil superior e inferior (UB180-1C).

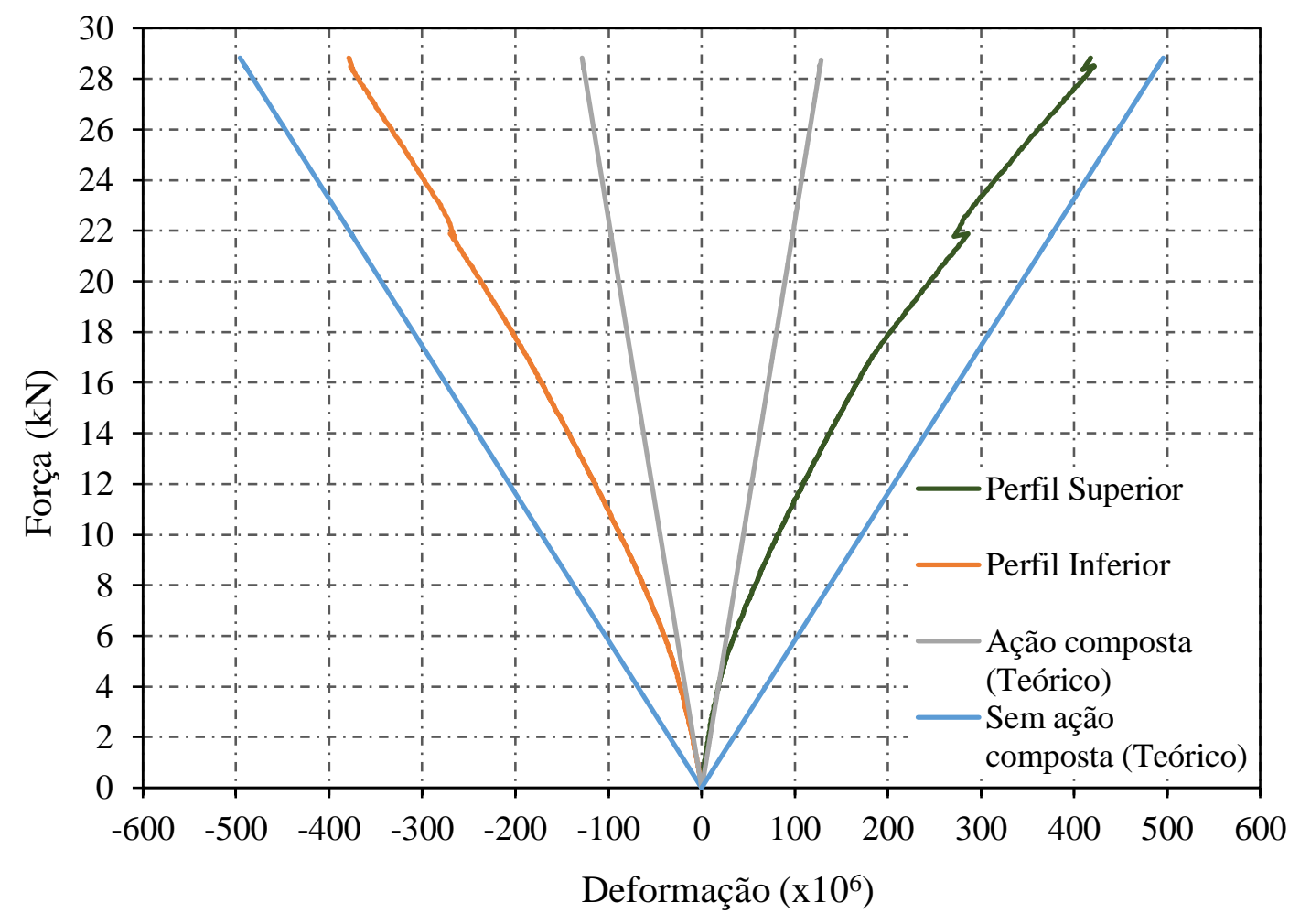

Fonte: Da autora.

O modo de falha distorcional no perfil superior foi percebido de forma mais acentuada nos protótipos que avançaram mais no carregamento (Figura 5.14). As talas conectadas nas mesas interferem no desenvolvimento da deformada de forma mais eficiente que as presilhas conectadas pela alma, assim como, na transferência dos esforços, contribuindo para o ganho de rigidez. 
Figura 5.14- Modo distorcional no protótipo UB180-1C ao final do ensaio.
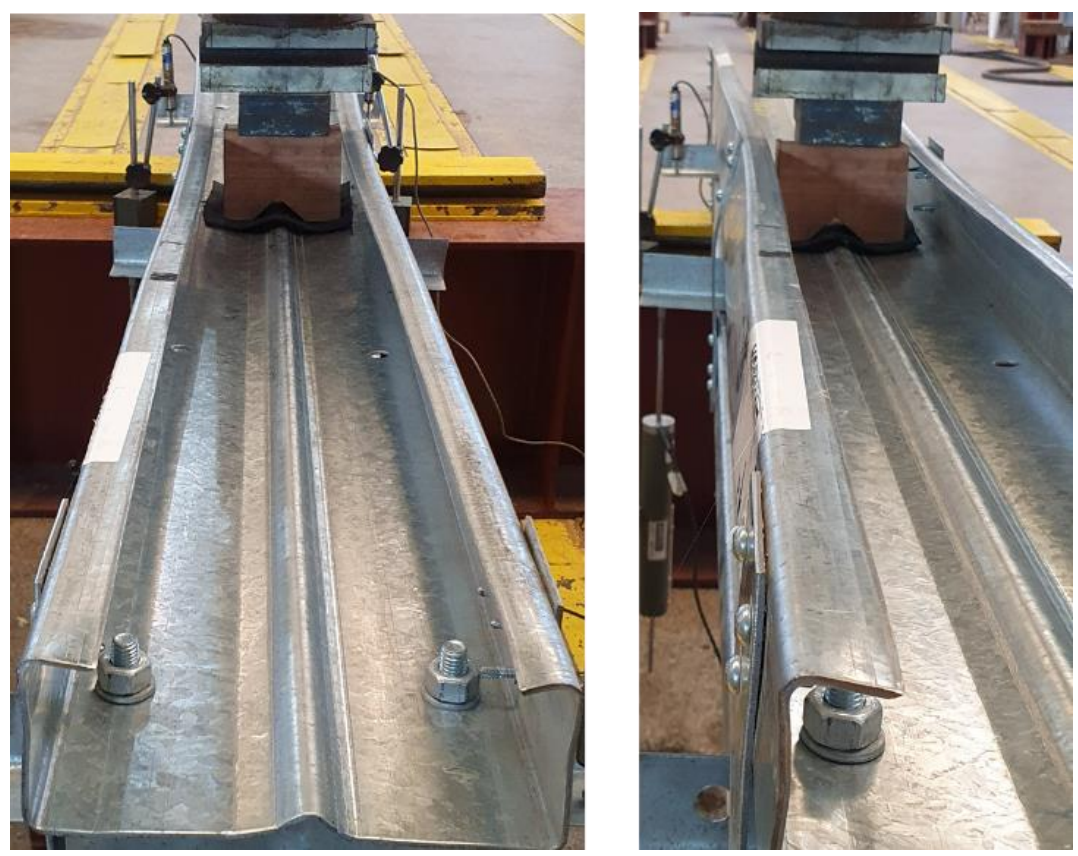

Fonte: Da autora.

Foi observado no decorrer do ensaio que as chapas apresentaram flexão associada a deformação dos perfis principais e com a transferência de esforços entre as barras, como ilustra a Figura 5.15.

Figura 5.15- Flexão das chapas de ligação.
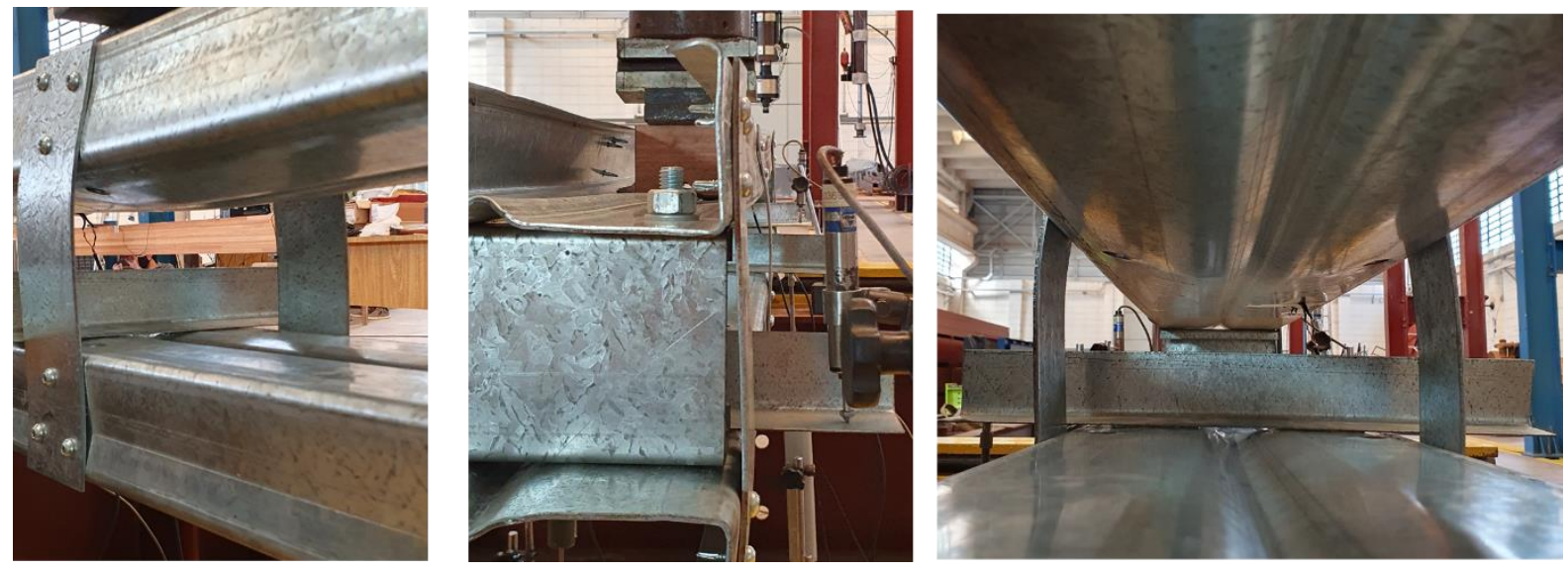

Fonte: Da autora.

\subsection{Ensaio das treliças}

Os resultados obtidos da análise experimental foram o esforço resistente e o comportamento dos protótipos. 


\subsubsection{Treliças da série 210J360}

A Figura 5.16 apresenta as curvas de força versus deslocamento vertical das peças com o nó central destravado. A força máxima aplicada pelo atuador no protótipo com uma presilha entre nós foi de $237,99 \mathrm{kN}$, e de $221,83 \mathrm{kN}$. A treliça 210J360.P2 foi ensaiada três vezes, porque foram realizados anteriormente dois testes para verificar outros sistemas de travamento mais simples disponíveis no laboratório.

Ambos os protótipos apresentaram deslocamento vertical próximo ou maior que os valores teóricos, como ilustrado na Figura 5.16.

Figura 5.16- Curvas força versus deslocamento vertical para as treliças da série $210 J 360$.

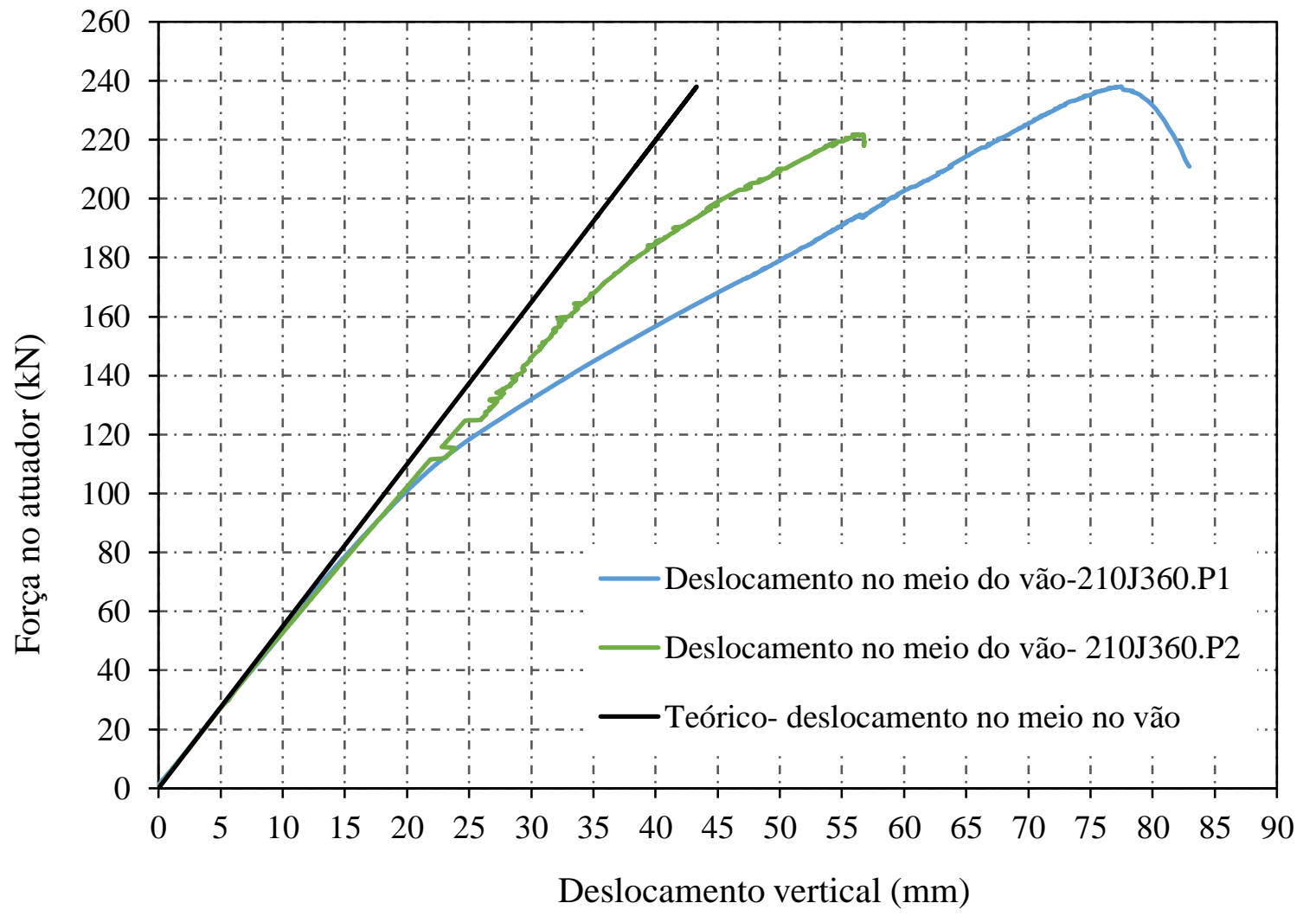

Fonte: Da autora.

O modo de falha observado para as treliças foi o distorcional (Figura 5.17) mais pronunciado na mesa superior do banzo comprimido, devido ao efeito da flexão na barra indicado pelos extensômetros. Não houve mudança perceptível de deformada entre as duas peças. 
Figura 5.17- Deformada distorcional típica da série $210 J 360$.

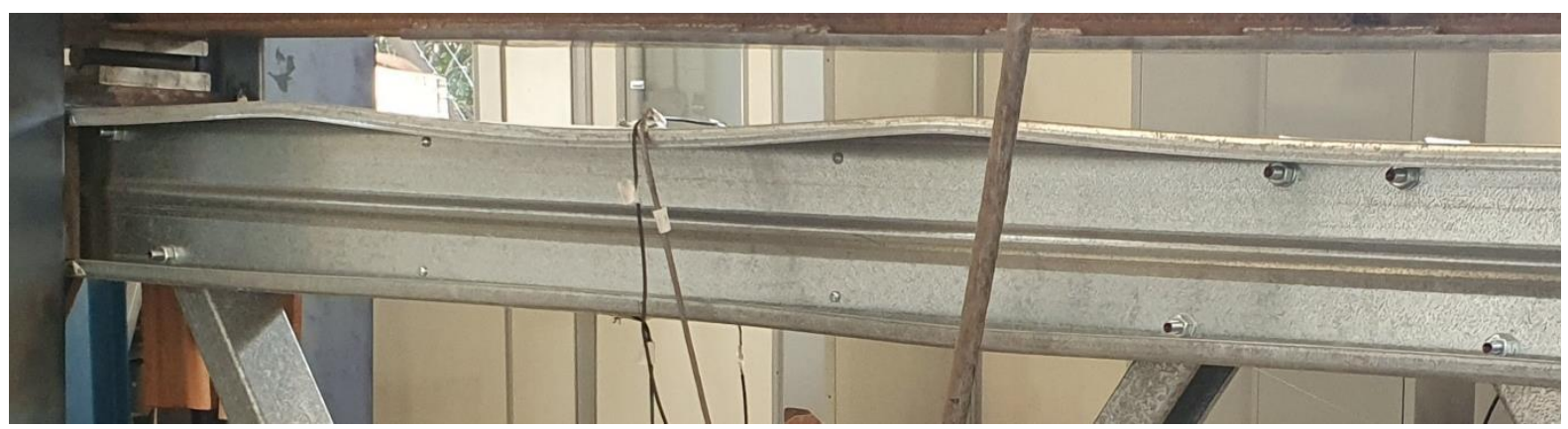

Fonte: Da autora.

A treliça 210J360.P2 apresentou um pequeno deslocamento fora do plano, inferior a 15 mm, conforme ilustra a Figura 5.18, e uma deformada plástica ao final do ensaio (Figura 5.19). A outra peça com o decorrer do ensaio exibiu em uma das barras uma deformada plástica, implicando na flexão lateral do conjunto, como mostrado na Figura 5.20.

Figura 5.18- Curvas força versus deslocamento horizontal para as treliças da série 210J360.

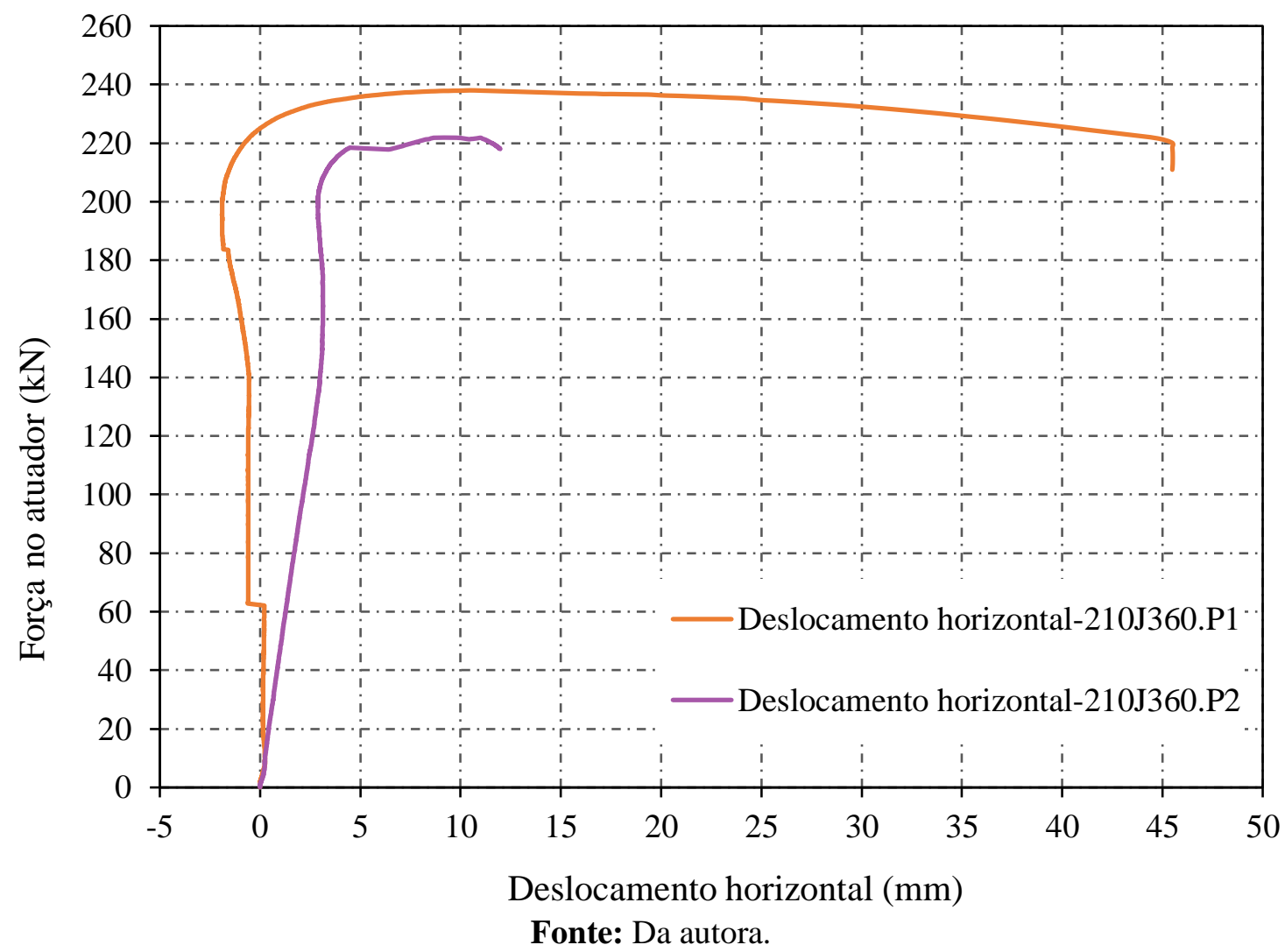


Figura 5.19- Mecanismo plástico formado ao final do ensaio (210J360.P1).

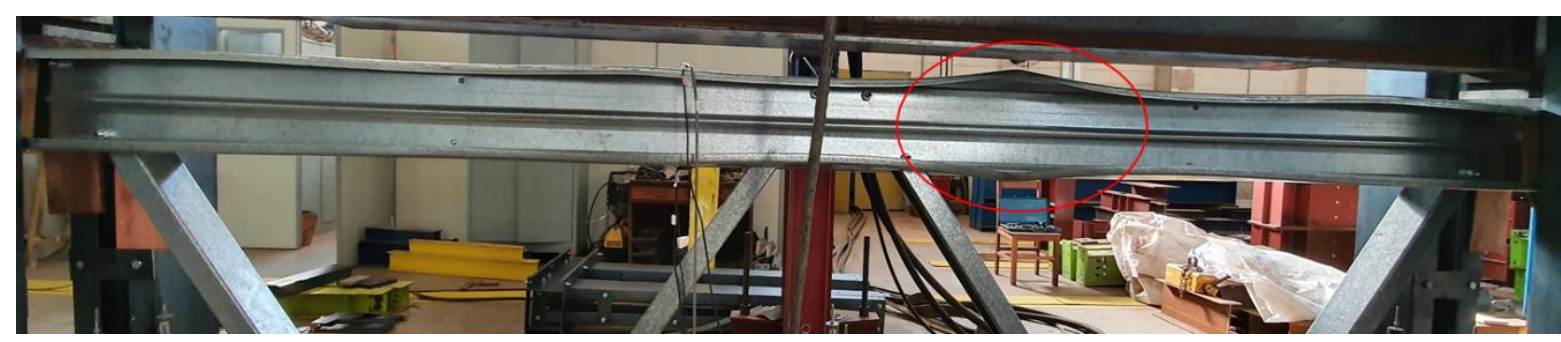

Fonte: Da autora.

Figura 5.20- Mecanismo plástico associado com o deslocamento fora do plano (210J360.P1).
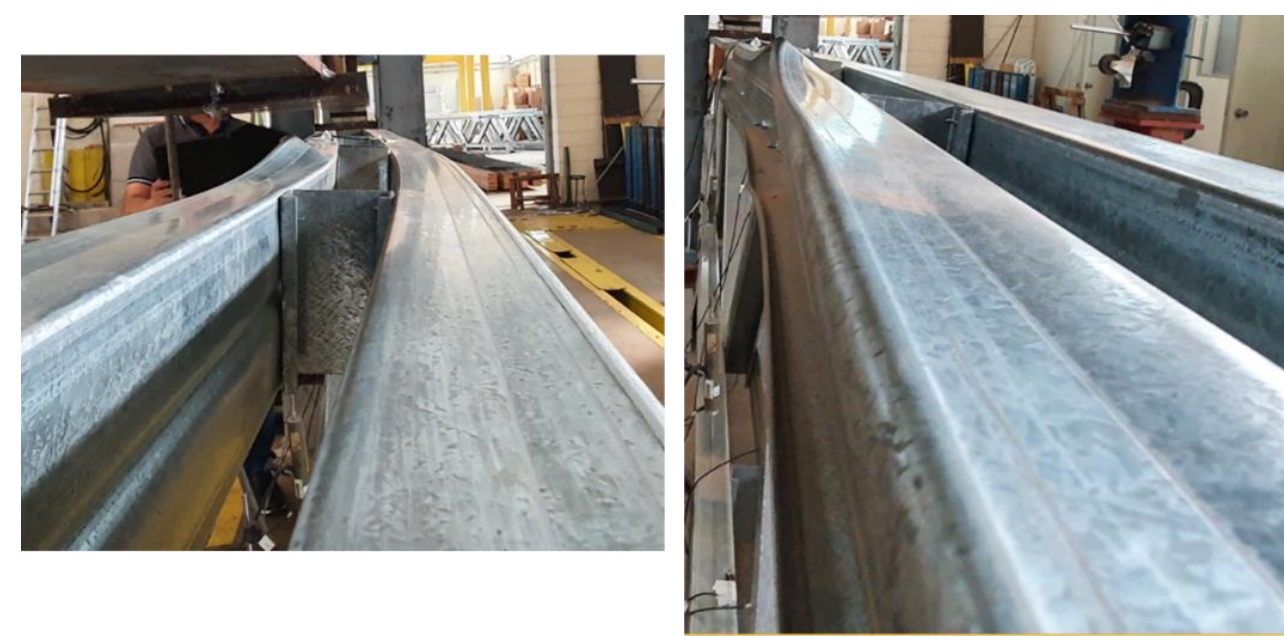

Fonte: Da autora.

Além dos deslocamentos, foram medidas as deformações específicas por meio de extensômetros uniaxiais. As deformações mostradas nos resultados são os valores médios dos extensômetros colados nas mesas, e o valor médio geral para banzo, como ilustrado na Figura 5.21 .

Figura 5.21- Valores médios utilizados nas curvas força versus deformação específica.

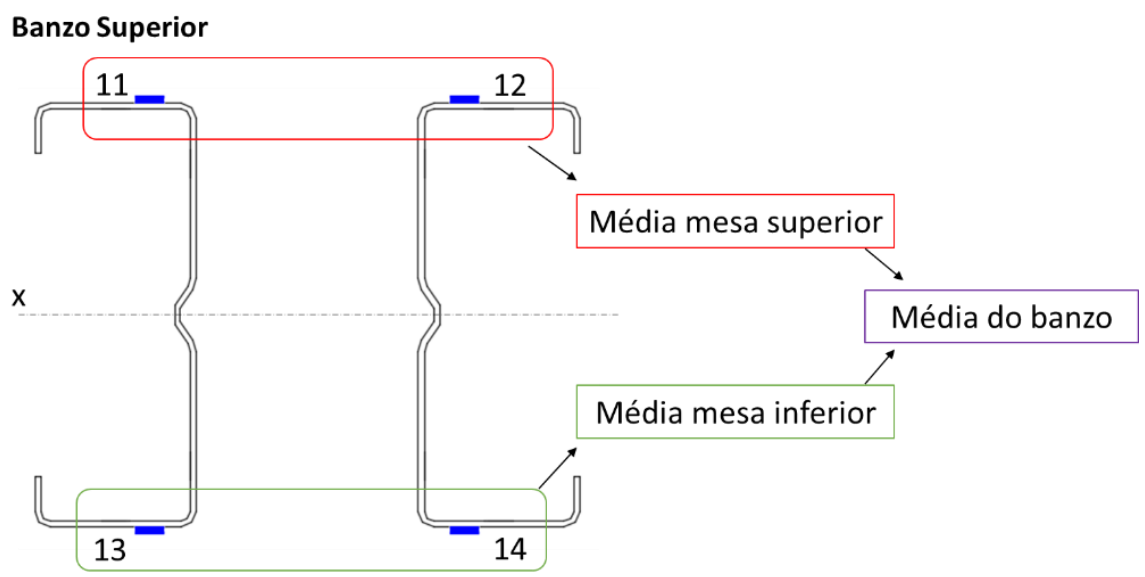

Fonte: Da autora. 
A Figura 5.22 e a Figura 5.23 apresentam as curvas força versus deformação específica para as peças 210J360.P2 e 210J360.P1 respectivamente; também foram adicionados os valores teóricos associados à ação da força normal de tração e compressão, e também considerando a flexo-compressão. Sendo este último composto por duas retas: uma que representa o alívio de tensão associado à flexão em relação ao eixo perpendicular à alma do perfil e outra que representa o acréscimo da tensão normal.

Por meio das figuras, nota-se que a mesa superior e a inferior de um mesmo banzo apresentaram deformações diferentes, indicando o efeito da flexão tanto no banzo superior comprimido quanto no inferior tracionado. Para as mesas que apresentaram o incremento de tensão, mesa superior do banzo superior e mesa inferior do banzo inferior, observa-se que o valor médio da deformação se situa entre a reta teórica que considera apenas o efeito da força normal e a outra que considera os dois esforços. O mesmo foi observado para o valor médio de deformação do banzo superior e inferior.

Considerando a deformação média da mesa inferior do banzo superior e da mesa superior do banzo inferior, verificam-se valores menores de deformação quando comparado com as duas retas teóricas.

Figura 5.22- Curva força versus deformação específica para a peça 210J360.P2.

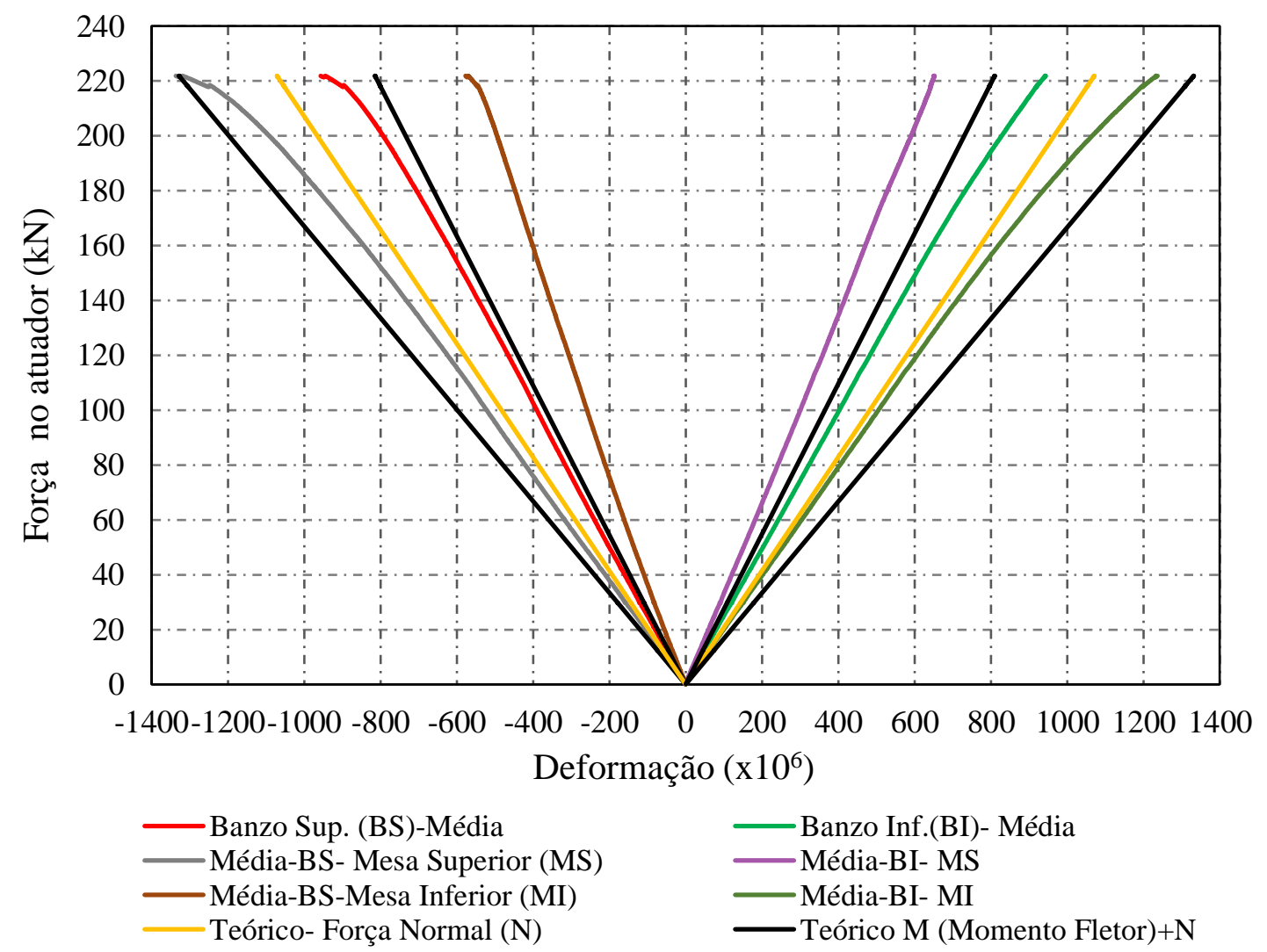

Fonte: Da autora. 
Figura 5.23- Curva força versus deformação específica para a peça 210J360.P1.

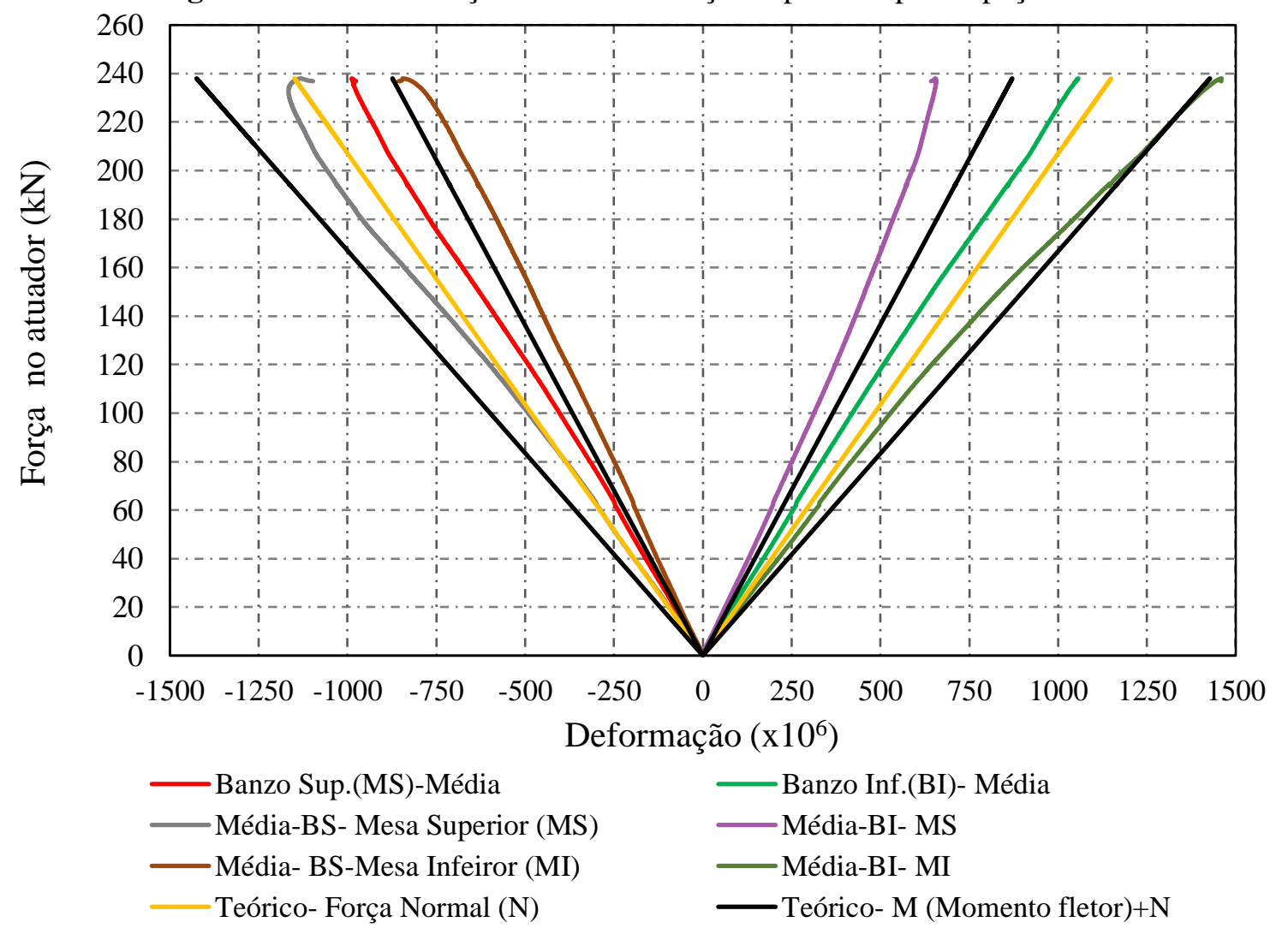

Fonte: Da autora.

Por meio dos valores da Tabela 3.2, nota-se que da análise que considera os perfis de forma independente, a força normal resistente crítica de 263,22 kN está associada ao modo global, e na ação composta igual a 742,08 kN, está associada ao modo distorcional. Atenta-se que o valor da força axial de compressão resistente referente à flambagem distorcional é o mesmo obtido pela análise do perfil individual.

Como verificado através do ensaio de rigidez, a ação composta não é promovida com o uso das presilhas, portanto, mesmo as peças apresentando o modo crítico da análise que considera a ação conjunta, o que se observa é uma normal resistente superior à teórica da análise isolada, a qual apresenta um modo crítico diferente do experimental. No entanto, essa hipótese de cálculo considera a barra isolada e com condições de contorno rotulada, o que de fato não ocorre devido à existência dos nós da treliça, que por meio das diagonais introduz rigidez nas extremidades dos trechos entre nós, alterando o comprimento de flambagem.

Dessa forma, a capacidade última do banzo igual a 535,5 kN (210J360.P1) e 499,1 kN (210J360.P2), calculada considerando o modelo de treliça ideal e igual a 2,25 vezes a força máxima aplica pelo atuador, foi inferior ao valor de $742,08 \mathrm{kN}$ que corresponde à previsão normativa da força axial de compressão resistente do modo distorcional. 


\subsubsection{Treliças da série 210J180}

A Figura 5.24 mostra as curvas de força versus deslocamento vertical ao meio do vão para peças com travamento lateral a cada nó, em que se observou que os deslocamentos verticais foram próximos ou maiores aos valores teóricos.

Figura 5.24- Curvas força versus deslocamento vertical para as treliças da série 210J180.

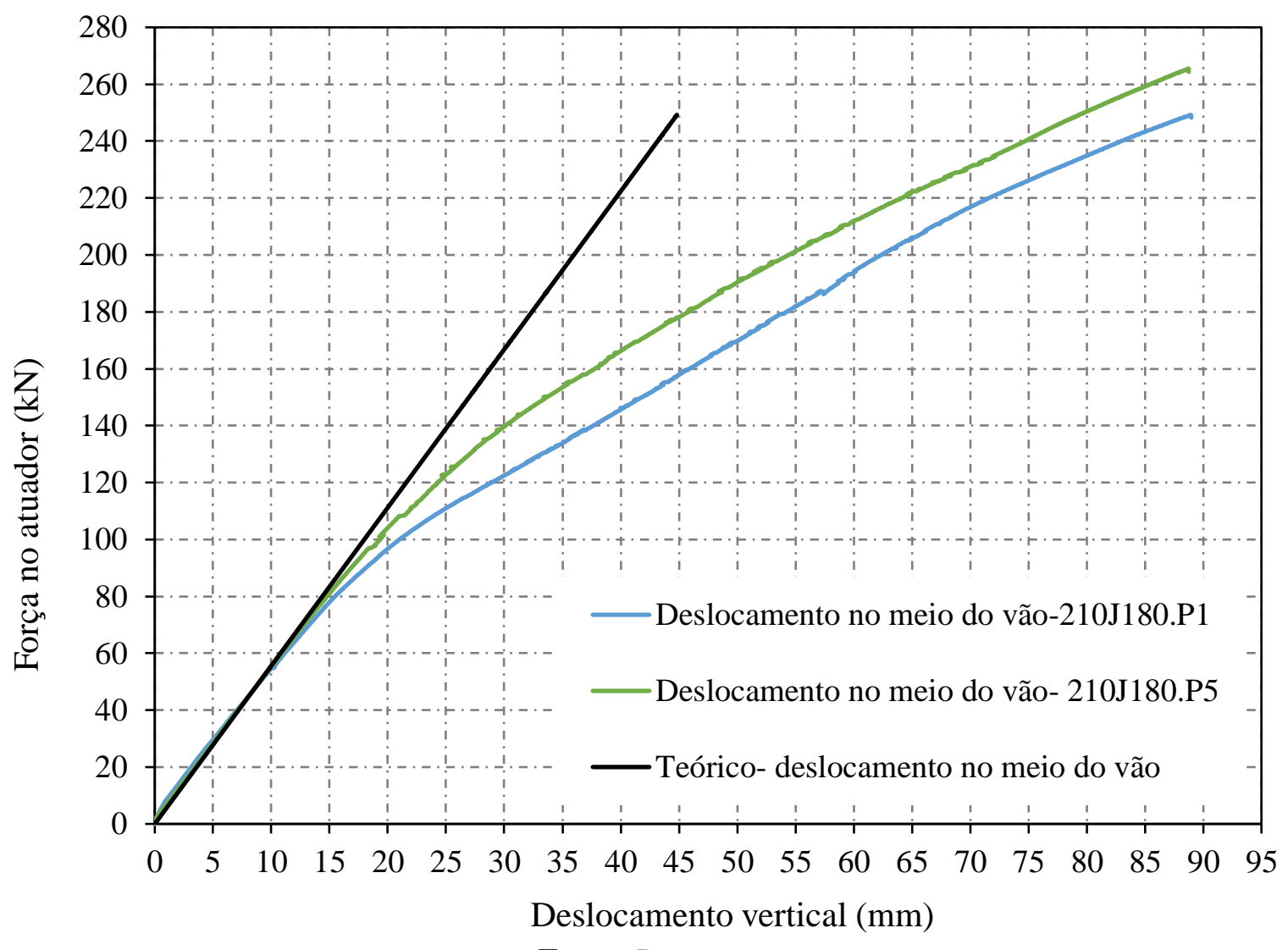

Fonte: Da autora.

As peças exibiram um pequeno deslocamento horizontal a partir de determinado nível de carregamento, não superando o valor de $10 \mathrm{~mm}$ ao final do ensaio, como mostra a Figura 5.25 .

O modo de falha observado foi o distorcional, com deformada mais evidente na mesa superior do banzo superior comprimido devido ao efeito da flexão, verificado pelos extensômetros na série 210J360. O comprimento de semionda se alterou, havendo uma redução para a peça com maior número de presilhas, como indicado na Figura 5.26. O aumento da capacidade resistente para a peça com o maior número de presilhas está associado a uma maior restrição das barras, que interfere na deformada do modo distorcional. 
Figura 5.25- Curvas força versus deslocamento horizontal para as treliças da série 210J180.

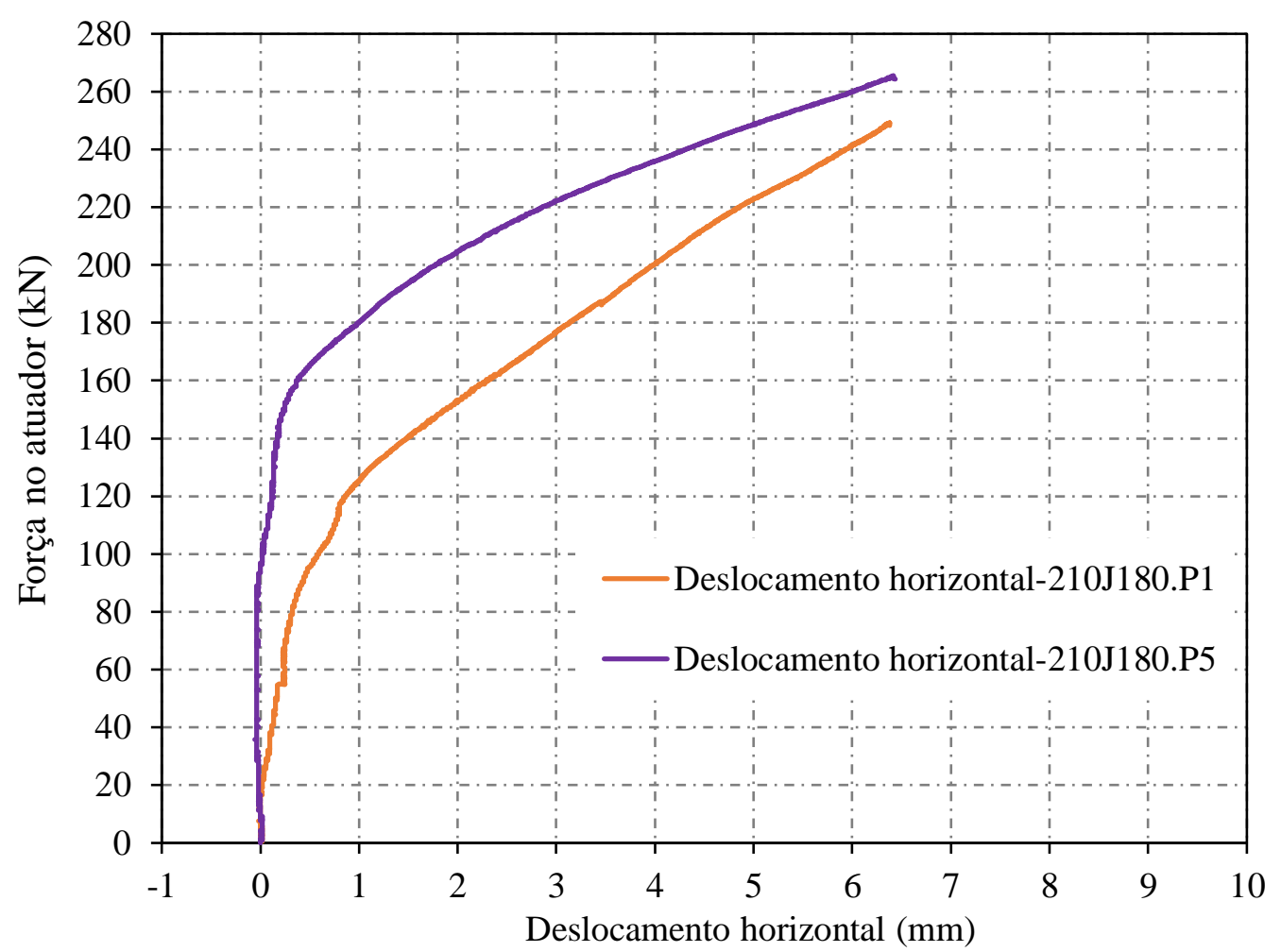

Fonte: Da autora.

Figura 5.26- Mudança de comprimento de semionda distorcional entre as peças.

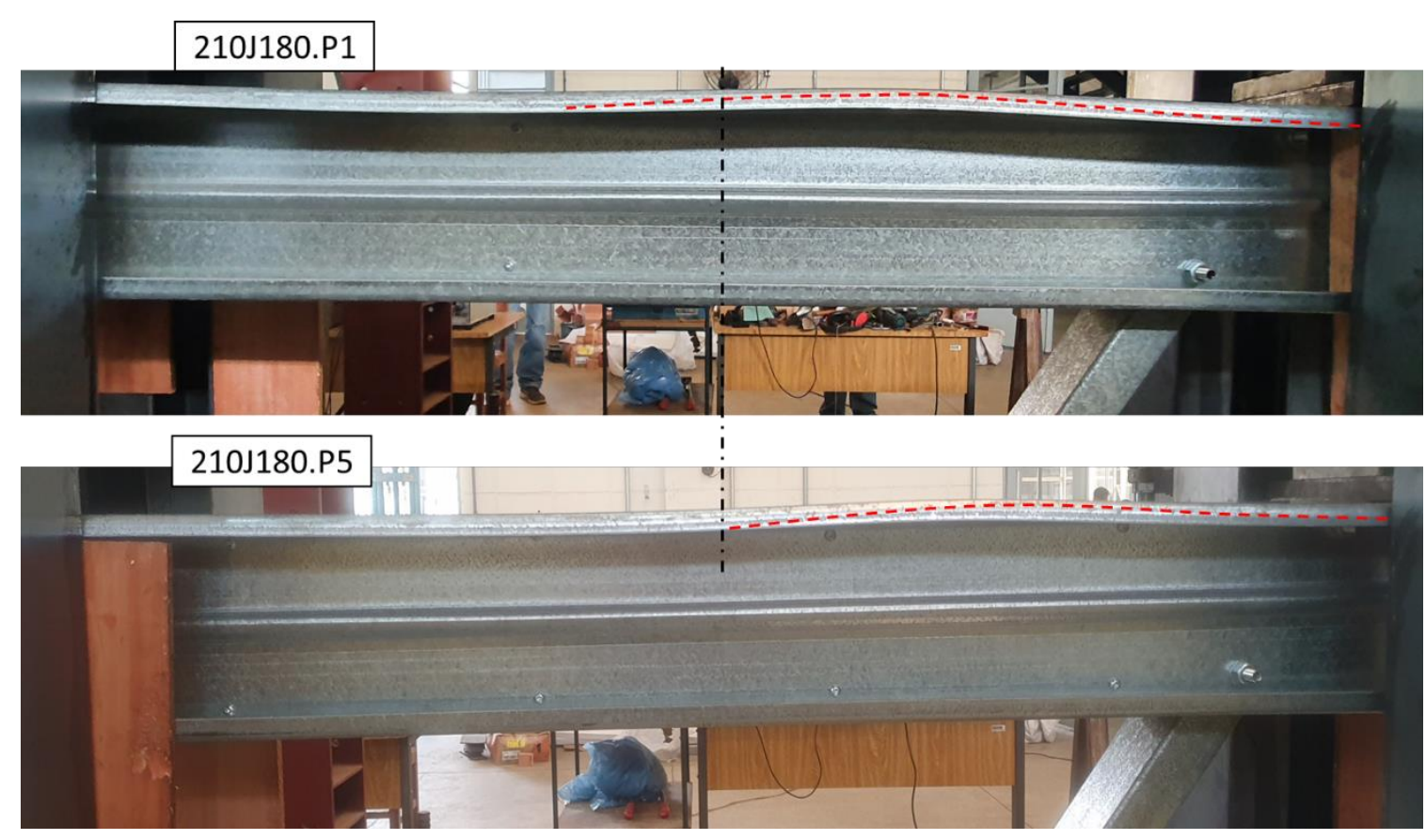

Fonte: Da autora.

As forças máximas aplicadas pelo atuador foram as seguintes: $249,22 \mathrm{kN}$ para o protótipo com uma presilha entre cada nó, e de $265,52 \mathrm{kN}$ para o com cinco presilhas entre nós. 
No comprimento destravado de $1800 \mathrm{~mm}$ foi observado um aumento da normal resistente para a peça com maior quantidade de presilhas. Assim como na série anterior, a força axial última do banzo, considerando o modelo de treliça ideal, foi inferior ao valor teórico associado ao modo distorcional de $742,08 \mathrm{kN}$.

\subsubsection{Treliças da série $120 \mathrm{~J} 360$}

A Figura 5.27 ilustra as curvas força versus deslocamento vertical para as treliças com banzos de menor altura e contidas lateralmente a cada $3600 \mathrm{~mm}$. A força máxima aplicada pelo atuador no protótipo com uma presilha entre cada nó foi de $123,93 \mathrm{kN}$ e de $114,05 \mathrm{kN}$ para o com quatro presilhas. Observou-se que não houve aumento da capacidade para a peça com maior número de presilhas.

Figura 5.27- Curvas força versus deslocamento vertical para a série $120 \mathrm{~J} 360$.

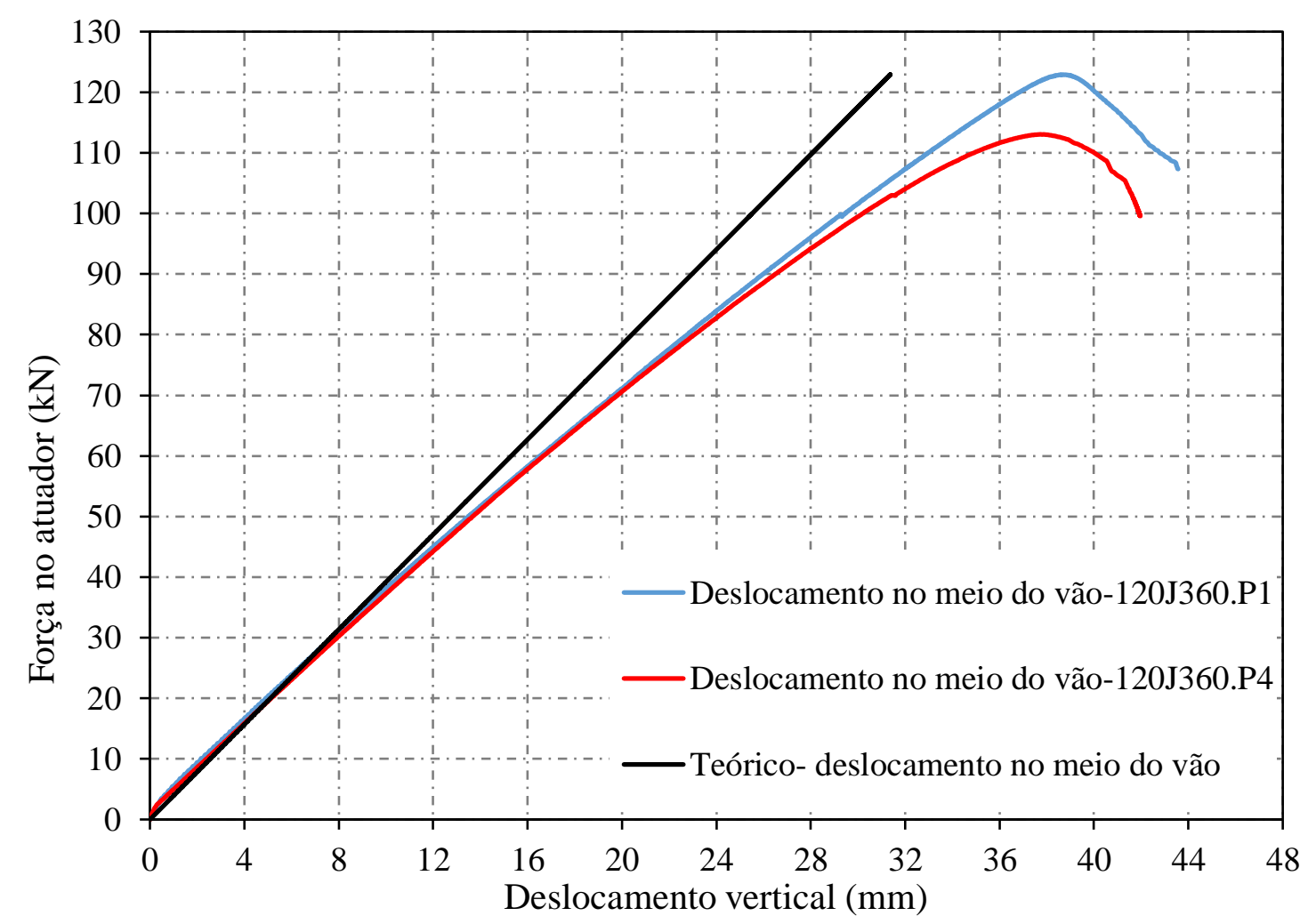

Fonte: Da autora.

Por meio da Figura 5.28, observa-se que ambos os protótipos apresentaram deslocamento horizontal crescente e acentuado nas proximidades da força última, caracterizando no banzo superior o modo de falha por flexão fora do plano da treliça, como 
ilustrado na Figura 5.29. Devido ao deslocamento horizontal, observou-se a mobilização das diagonais na sua maior inércia e consequentemente do banzo inferior tracionado.

Figura 5.28- Curvas força versus deslocamento horizontal para a série $120 \mathrm{~J} 360$.

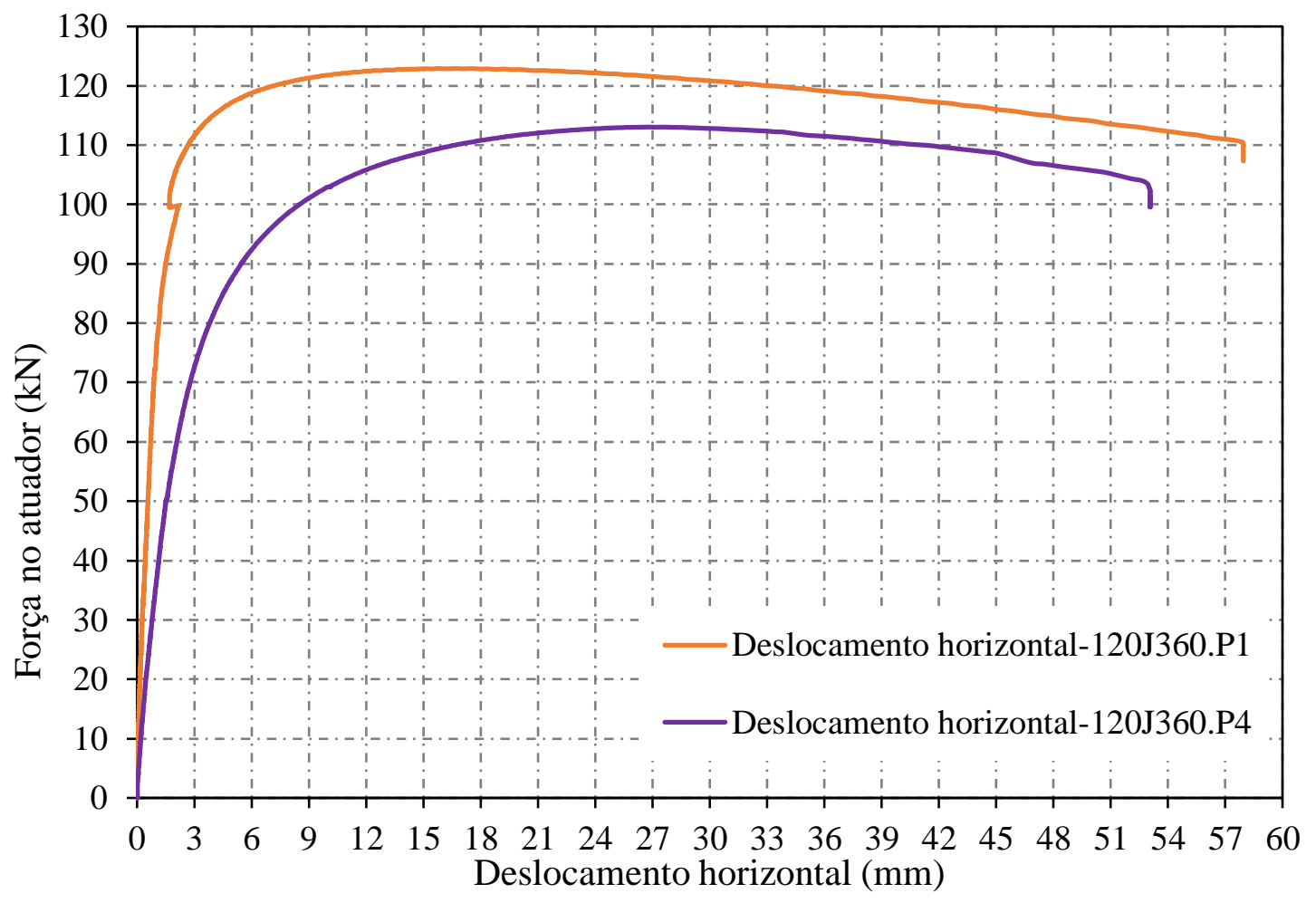

Fonte: Da autora.

Figura 5.29- Instabilidade por flexão fora do plano para as treliças da série $120 \mathrm{~J} 360$.
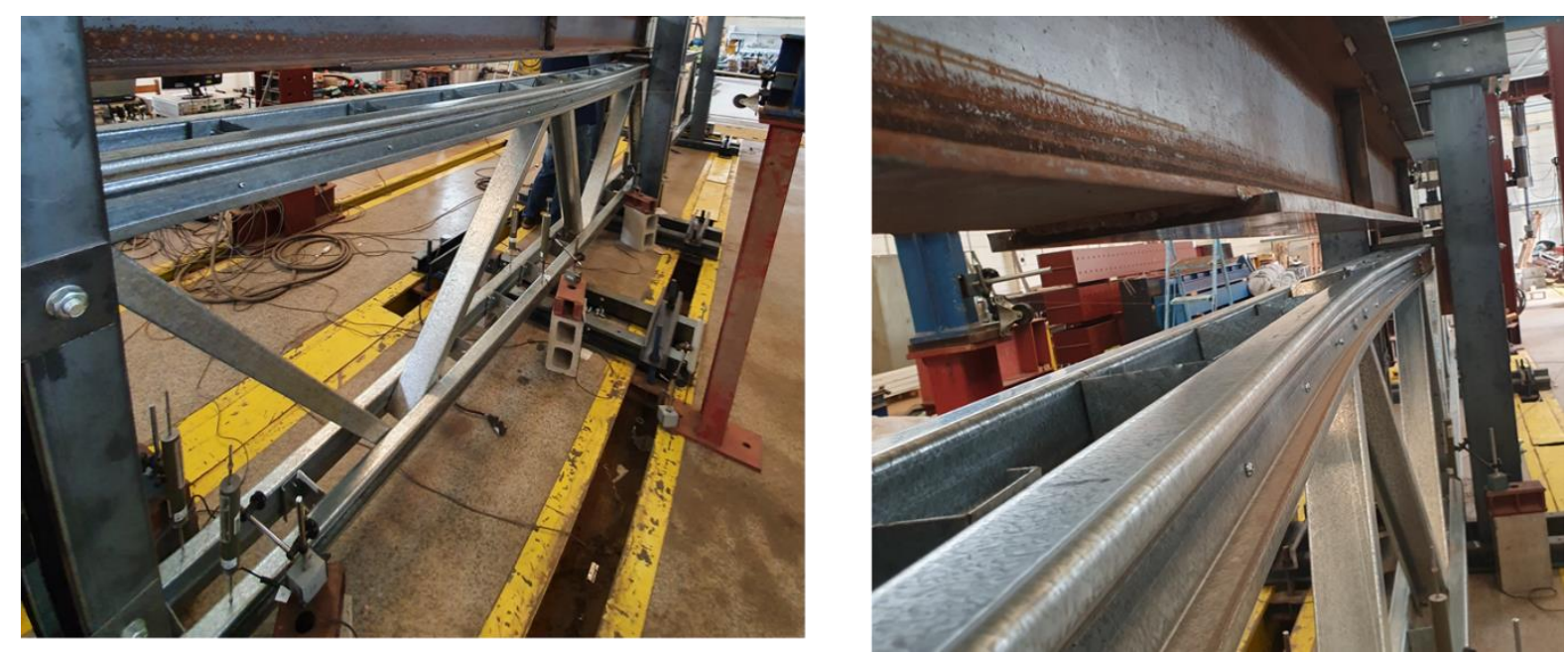

Fonte: Da autora.

Os resultados da capacidade última da barra comprimida iguais a $278,8 \mathrm{kN}$ (120J360.P1) e 256,6 kN (120J360.P4), para o modelo de treliça ideal, situam-se compreendidos entre os valores teóricos da força axial resistente para a compressão, associados 
à flambagem global, iguais a $62,14 \mathrm{kN}$ (perfis isolados) e a $548,81 \mathrm{kN}$ (barra totalmente composta), ambos indicados na Tabela 3.2.

A hipótese que corresponde à somatória da capacidade resistente de cada perfil foi conservadora, pois as barras não trabalham de forma independente, em razão da existência dos nós na treliça, que geram uma restrição no conjunto devido à rigidez no plano da treliça e fora do plano. Esta última está associada com as diagonais sendo solicitadas em sua maior inércia. Além disso, o banzo tracionado também tem uma função estabilizadora no conjunto quando associado ao modo global por flexão do banzo comprimido.

\subsubsection{Treliças da série 120J180}

A Figura 5.30 e a Figura 5.31 ilustram as curvas força versus deslocamento para as treliças contidas lateralmente a cada $1800 \mathrm{~mm}$. A força máxima aplicada pelo atuador para o protótipo com uma presilha entre cada nó foi de $145,83 \mathrm{kN}$ e de $138,89 \mathrm{kN}$ para o com cinco presilhas. Pode-se observar que ambos os protótipos apresentaram deslocamento horizontal crescente e acentuado nas proximidades da força máxima.

Figura 5.30- Curva força versus deslocamento vertical para a série $120 \mathrm{~J} 180$.

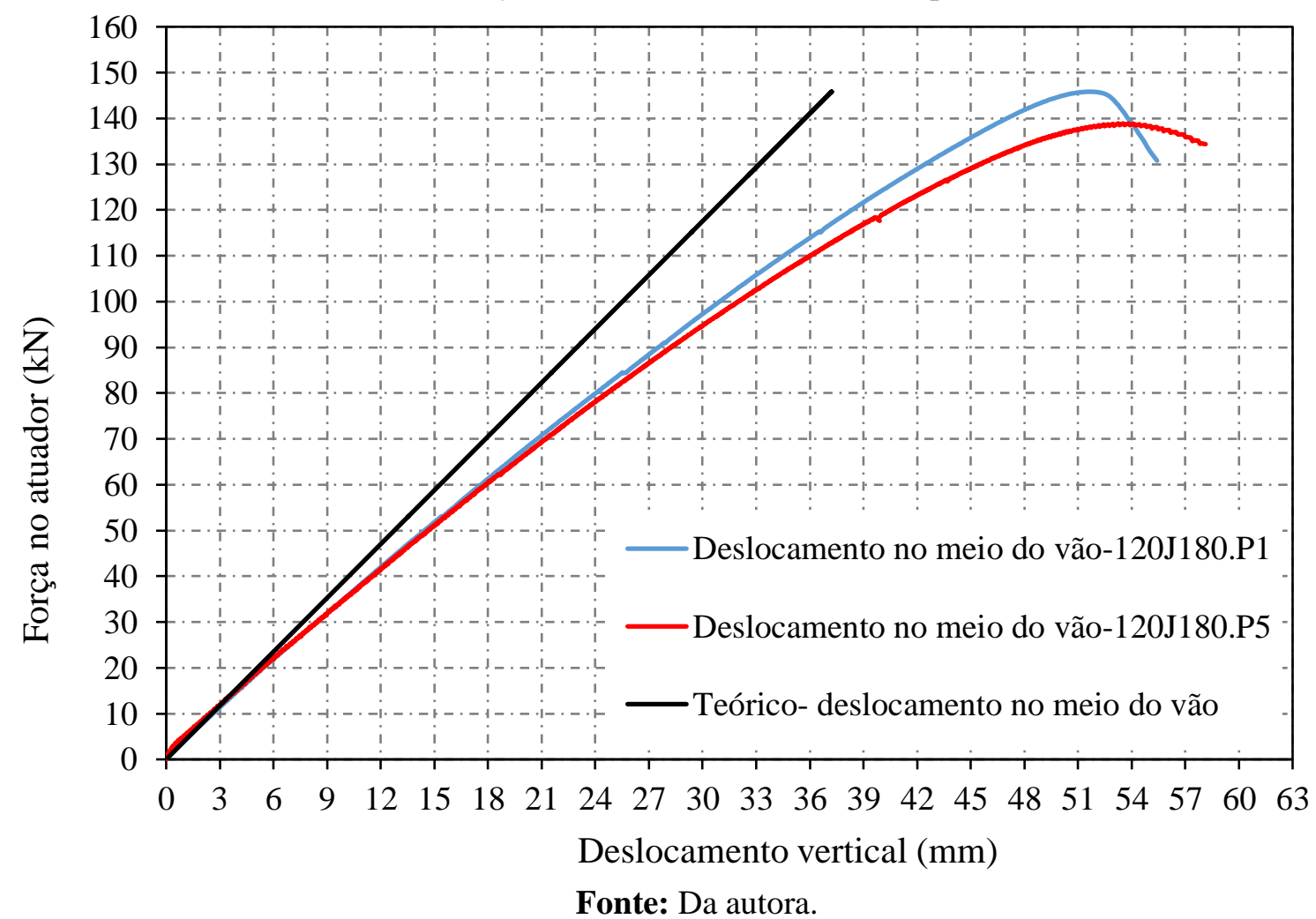


Figura 5.31- Curva força versus deslocamento horizontal para a série $120 \mathrm{~J} 180$.

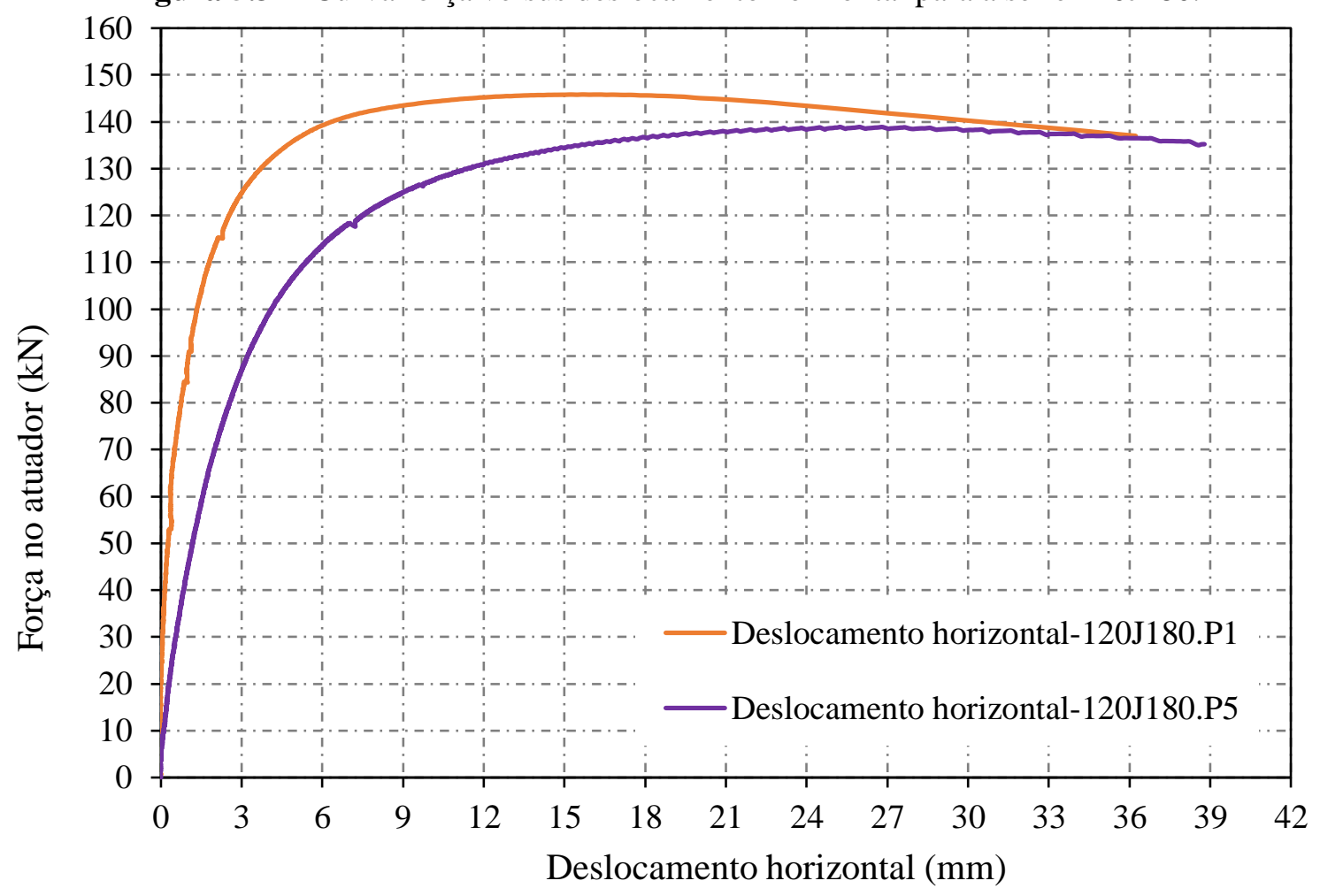

Fonte: Da autora.

Os protótipos da série 120J180 também apresentaram instabilidade por flexão fora do plano da treliça, como mostrado pela Figura 5.32. Associado ao modo de flexão fora do plano próximo ao final do ensaio, uma das barras apresentou uma deformada plástica distorcional progressiva, posteriormente ocorreu uma deformada na alma da outra barra do banzo, como ilustra a Figura 5.33

Figura 5.32- Instabilidade por flexão fora do plano para as treliças $120 \mathrm{~J} 180$.
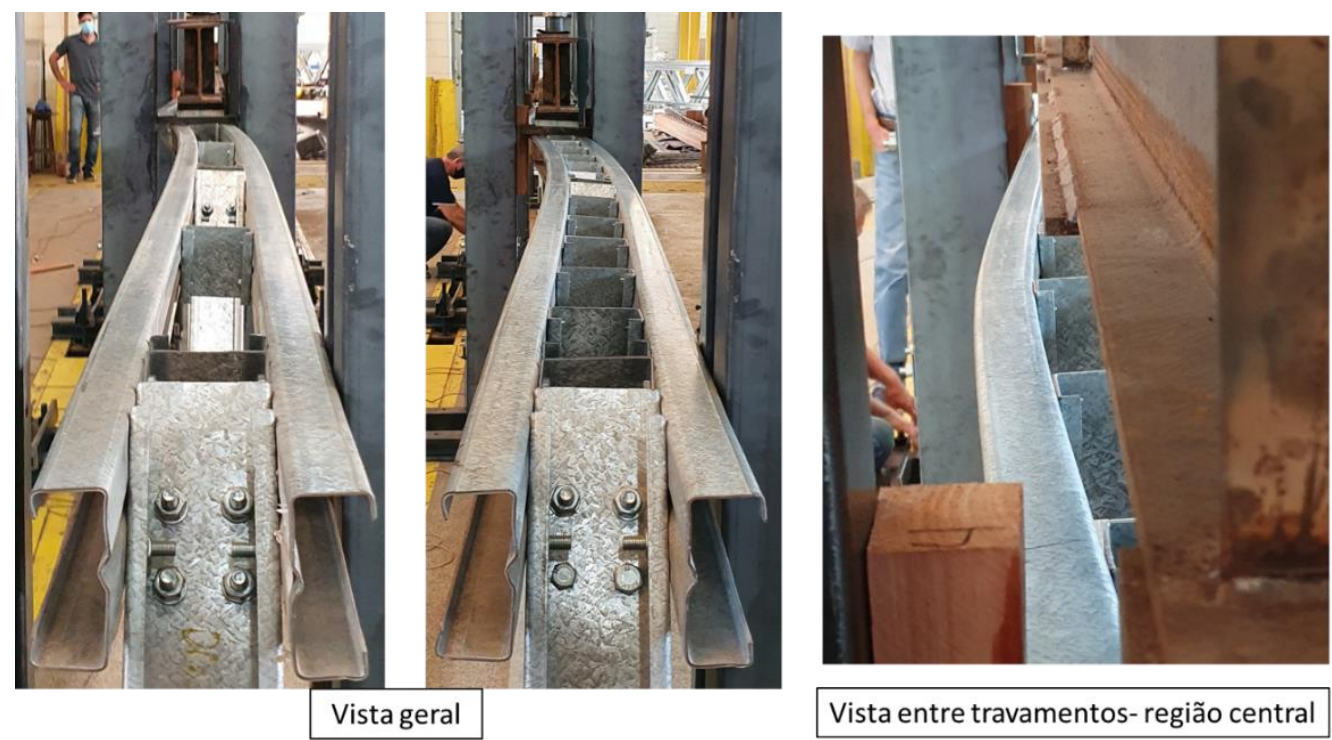

Fonte: Da autora. 
Figura 5.33- Deformada plástica característica para a série $120 \mathrm{~J} 180$ ao final do ensaio.

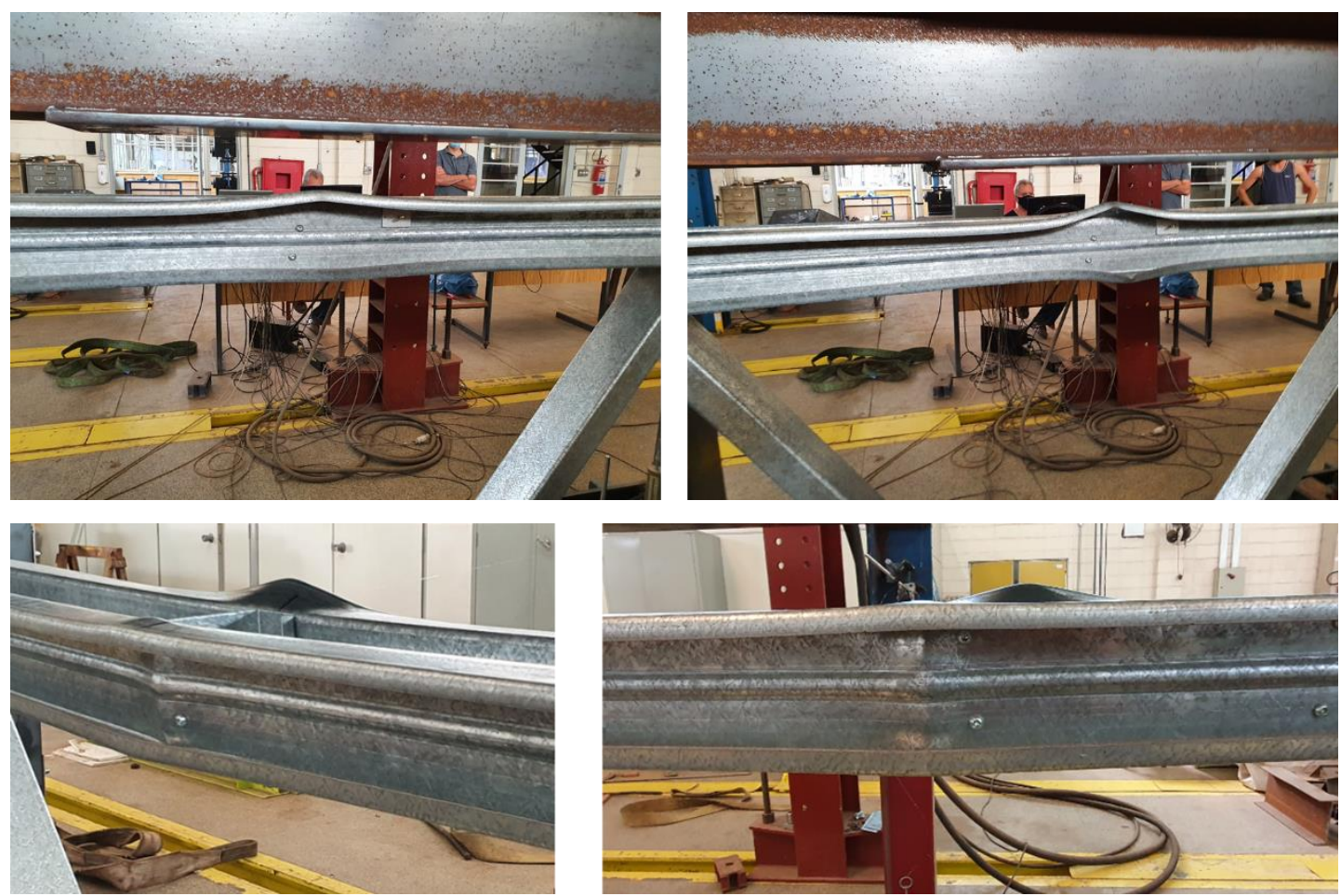

Fonte: Da autora.

A força última do banzo igual a $278,8 \mathrm{kN}(120 \mathrm{~J} 180 . P 1)$ e a $256,6 \mathrm{kN}$ (120J180.P5) considerando o modelo de treliça ideal, encontra-se entre os valores teóricos de $248,56 \mathrm{kN}$ (perfis isolados) e o que considera a barra totalmente composta, indicados na Tabela 3.3, porém, o modo crítico para a consideração de ação composta não corresponde ao modo de falha observado experimentalmente.

O valor experimental médio foi cerca de $29,5 \%$ superior ao obtido considerando a ação isolada; isso se deve à rigidez existente nos nós da treliça e não está associada à presença das presilhas de seção aberta, pois, como verificado pelo ensaio de flexão, a presilha não possibilita a ação conjunta. Observou-se que não houve uma grande diferença nas capacidades resistentes das duas treliças, sendo que a peça com uma presilha entre nó exibiu um valor ligeiramente maior.

\subsubsection{Flexo-compressão}

Como visto na Figura 5.22 e na Figura 5.23, as barras dos banzos apresentam influência da flexão, o que contribui para que a força axial resistente calculada considerando apenas o esforço normal apresente certa redução. Portanto, a flexo-compressão foi verificada por meio da equação de interação que está presente na ABNT NBR 14762:2010 e ANSI/AISI S100:2020. 
Na equação 5.1, $N_{c, S k}$ é a força axial solicitante característica e $M_{x, S k}$ é o momento fletor solicitante característico em relação ao eixo perpendicular à alma do perfil; assim como, $N_{c, R k}$ e $M_{\chi, R k}$ são a força axial resistente característica e o momento fletor resistente característico em relação ao eixo perpendicular à alma, respectivamente. A obtenção dos momentos fletores característicos solicitante e resistente foi indicada no Apêndice C.

$$
\frac{N_{C, S k}}{N_{C, R k}}+\frac{M_{x, S k}}{M_{x, R k}}
$$

Os valores obtidos seguem organizados na Tabela 5.6 e ilustrados na Figura 5.34. Os valores para a força axial resistente característica indicados na tabela foram obtidas no item 3.3.1, em que foram adotados os valores para a consideração de comportamento mecânico independente dos perfis.

Tabela 5.6- Resultados obtidos para os protótipos considerando a flexo-compressão.

\begin{tabular}{ccccccccc}
\hline Protótipo & $\begin{array}{c}\mathbf{N}_{\mathbf{c}, \mathbf{S k}} \\
(\mathbf{k N})\end{array}$ & $\begin{array}{c}\mathbf{N}_{\mathbf{c}, \mathbf{R k}} \\
(\mathbf{k N})\end{array}$ & $\begin{array}{c}\text { Modo } \\
\mathbf{d e} \\
\mathbf{f a l h a}\end{array}$ & $\begin{array}{c}\mathbf{N}_{\mathbf{c}, \mathbf{S k}} \\
\mathbf{N}_{\mathbf{c}, \mathbf{R k}}\end{array}$ & $\begin{array}{c}\mathbf{M}_{\mathbf{x}, \mathbf{S k}} \\
(\mathbf{k N} . \mathbf{c m})\end{array}$ & $\begin{array}{c}\mathbf{M}_{\mathbf{x}, \mathbf{R k}} \\
(\mathbf{k N} . \mathbf{c m})\end{array}$ & $\frac{\mathbf{M}_{\mathbf{x}, \mathbf{S k}}}{\mathbf{M}_{\mathbf{x}, \mathbf{R k}}}$ & $\frac{\mathbf{N}_{\mathbf{c}, \mathbf{S k}}}{\mathbf{N}_{\mathbf{c}, \mathbf{R k}}}+\frac{\mathbf{M}_{\mathbf{x}, \mathbf{S k}}}{\mathbf{M}_{\mathbf{x}, \mathbf{R k}}}$ \\
\hline 210J360.P1 & 530,26 & 742,08 & $\mathrm{D}$ & 0,71 & 1747,36 & 6599,80 & 0,27 & 0,98 \\
210J360.P2 & 494,26 & 742,08 & $\mathrm{D}$ & 0,67 & 1622,60 & 6599,80 & 0,25 & 0,91 \\
210J180.P1 & 555,28 & 742,08 & $\mathrm{D}$ & 0,75 & 1829,80 & 6599,80 & 0,28 & 1,03 \\
210J180.P5 & 591,60 & 742,08 & $\mathrm{D}$ & 0,80 & 1949,50 & 6599,80 & 0,30 & 1,09 \\
120J360.P1 & 281,67 & 62,14 & $\mathrm{~F}$ & 4,53 & 483,62 & 2249,70 & 0,21 & 4,75 \\
120J360.P4 & 253,35 & 62,14 & $\mathrm{~F}$ & 4,08 & 447,07 & 2249,70 & 0,20 & 4,28 \\
120J180.P1 & 323,95 & 248,56 & $\mathrm{~F}$ & 1,30 & 569,08 & 2249,70 & 0,25 & 1,56 \\
120J180.P5 & 308,53 & 248,56 & $\mathrm{~F}$ & 1,24 & 542,00 & 2249,70 & 0,24 & 1,48 \\
\hline
\end{tabular}

Notas: $\mathbf{N}_{\mathbf{c}, \mathbf{S k}}$ e $\mathbf{M}_{\mathbf{x}, \mathbf{S k}}$ : Valores obtidos considerando a força máxima aplica pelo atuador no ensaio e a configuração da treliça com suas excentricidades e diagonais com nós não rotulados.

$\mathbf{N}_{\mathbf{c}, \mathbf{R k}}$ : Valor corresponde a $2 \times \mathrm{N}_{\mathrm{c}, \mathrm{Rk} 1}$, em que $\mathrm{N}_{\mathrm{c}, \mathrm{Rk} 1}$ é a força axial resistente à compressão de um perfil componente, calculada pelo modelo teórico que considera a barra isolada, isto é, $\mathrm{K}_{\mathrm{y}} \mathrm{L}_{\mathrm{y}}$ é igual ao comprimento destravado, desse modo, desconsidera-se a existência do nó localizado entre o travamento lateral de $360 \mathrm{~cm}$ (a cada dois nós da treliça).

* Modo de falha associado ao valor de $\mathbf{N}_{\mathbf{c}, \mathbf{R k}}$.

D- Modo distorcional F- Modo de flexão fora do plano da treliça (em torno do eixo paralelo à alma).

Fonte: Da autora. 
Figura 5.34- Resultados para a flexo-compressão considerando os esforços resistentes dos perfis isolados.

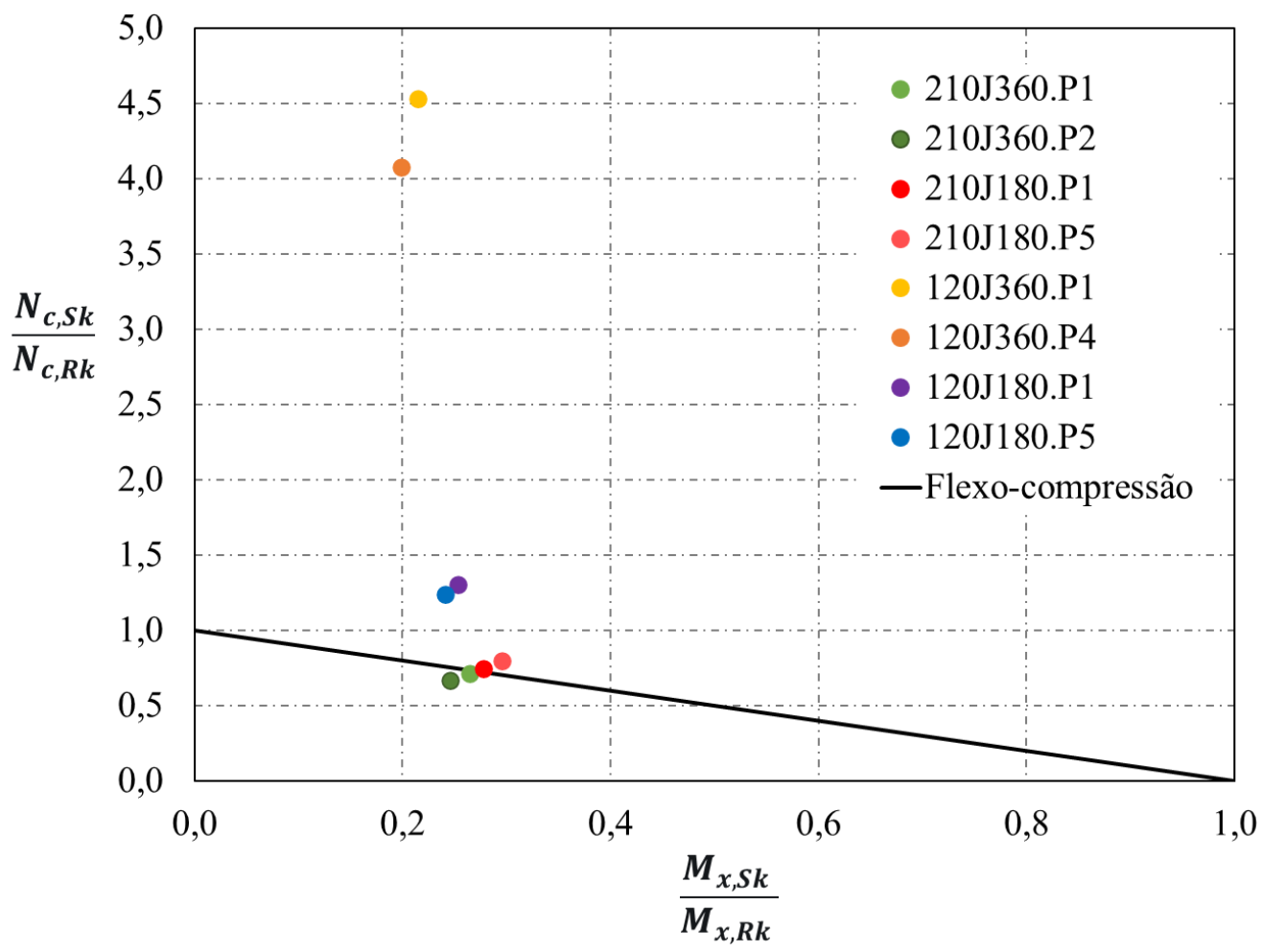

Fonte: Da autora.

Por se tratar de uma comparação entre valores experimentais e previsões teóricas, é necessário que o valor obtido pela equação 5.1 seja maior que um, ou pelo menos ajustado ao modelo teórico, valores inferiores à unidade mostram que o resultado do ensaio é inferior ao indicado pela norma e, portanto, contra a segurança.

O esforço normal experimental para a série $210 J 360$ foi inferior ao valor característico da força axial de compressão resistente, associado à flambagem distorcional, em ambos os comprimentos destravados. As peças de menor comprimento destravado apresentaram valores ligeiramente superiores à unidade e, portanto, a previsão teórica para a hipótese de ação isolada apresenta-se razoável para ser empregada em projeto.

Os resultados dos protótipos da série 120J exibiram boa concordância com a estimativa normativa mesmo sem a consideração do efeito da flexão. A hipótese que considera o comportamento mecânico de cada perfil separadamente se mostrou conservadora para os protótipos com maior comprimento destravado, pois a existência dos nós da treliça confere rigidez tanto no plano da treliça quanto fora do plano que altera o comprimento efetivo de flambagem utilizado na análise da compressão centrada. Dessa forma, para comprimento de 
flambagem fora do plano igual a $360 \mathrm{~cm}$ (120J360) o esforço normal resistente se torna inferior a quatro vezes ao obtido para os protótipos 120J180.

Adotando um comprimento de flambagem fora do plano igual a $180 \mathrm{~cm}$ para os protótipos 120J360, isto é, considerando a restrição imposta pelo nó entre travamentos a previsão normativa se torna menos conservadora, como ilustra a Figura 5.35 .

Figura 5.35- Resultados para a flexo-compressão considerando os esforços resistentes dos perfis

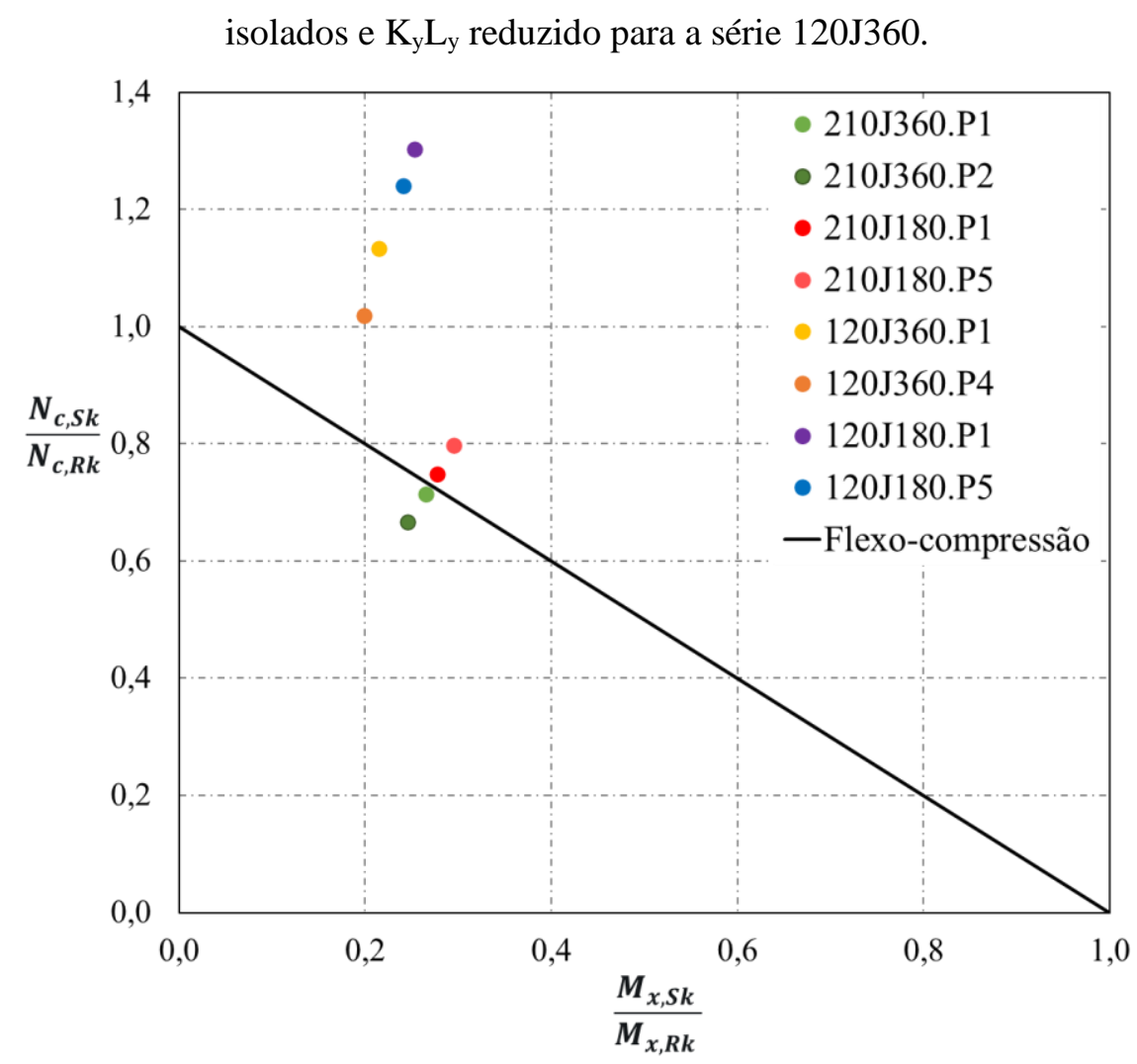

Fonte: Da autora.

Considerando as propriedades da barra totalmente composta para a série $120 \mathrm{~J} 360$, que apresentou modo de flexão em torno do eixo de menor inércia do perfil, os resultados considerando a flexo-compressão seguem indicados na Tabela 5.7.

Os protótipos $120 \mathrm{~J} 360$ apresentaram valores inferiores a um; para os protótipos 120J180 o valor crítico apresenta o modo de falha distinto ao experimental, pois nessa hipótese o momento de inércia paralelo à alma $\left(\mathrm{I}_{\mathrm{y}}\right)$ se eleva e deixa de ser o menor valor de força axial de flambagem global elástica $\left(N_{e}\right)$. 
Tabela 5.7- Resultados obtidos para os protótipos considerando a flexo-compressão e propriedades da barra composta.

\begin{tabular}{ccccccccc}
\hline Protótipo & $\begin{array}{c}\mathbf{N}_{\mathbf{c}, \mathbf{S k}} \\
(\mathbf{k N})\end{array}$ & $\begin{array}{c}\mathbf{N}_{\mathbf{c}, \mathbf{R k}} \\
(\mathbf{k N})\end{array}$ & $\begin{array}{c}\text { Modo } \\
\mathbf{d e} \\
\mathbf{f a l h a}^{*}\end{array}$ & $\begin{array}{c}\mathbf{N}_{\mathbf{c}, \mathbf{S k}} \\
\mathbf{N}_{\mathbf{c}, \mathbf{R k}}\end{array}$ & $\begin{array}{c}\mathbf{M}_{\mathbf{x}, \mathbf{S k}} \\
(\mathbf{k N . ~ c m})\end{array}$ & $\begin{array}{c}\mathbf{M}_{\mathbf{x}, \mathbf{R k}} \\
(\mathbf{k N} . \mathbf{c m})\end{array}$ & $\frac{\mathbf{M}_{\mathbf{x}, \mathbf{S k}}}{\mathbf{M}_{\mathbf{x}, \mathbf{R k}}}$ & $\frac{\mathbf{N}_{\mathbf{c}, \mathbf{S k}}}{\mathbf{N}_{\mathbf{c}, \mathbf{R k}}}+\frac{\mathbf{M}_{\mathbf{x}, \mathbf{S k}}}{\mathbf{M}_{\mathbf{x}, \mathbf{R k}}}$ \\
\hline 120J360.P1 & 281,67 & 548,81 & $\mathrm{~F}$ & 0,51 & 483,62 & 2249,70 & 0,21 & 0,73 \\
120J360.P4 & 253,35 & 548,81 & $\mathrm{~F}$ & 0,46 & 447,07 & 2249,70 & 0,20 & 0,66 \\
\hline
\end{tabular}

Notas: $\mathbf{N}_{\mathbf{c}, \mathbf{S k}}$ e $\mathbf{M}_{\mathbf{x}, \mathbf{S k}}$ : Valores obtidos considerando a força máxima aplica pelo atuador no ensaio e a configuração da treliça com suas excentricidades e diagonais com os nós não rotulados.

* Modo de falha associado ao valor de $\mathbf{N}_{\mathbf{c}, \mathbf{R k}}$.

F- Modo de flexão fora do plano da treliça (em torno do eixo paralelo à alma).

$\mathbf{N}_{\mathbf{c}, \mathbf{R k}}$ : Valor corresponde a força axial resistente à compressão da barra totalmente composta, calculada pelo modelo teórico que considera a barra isolada, isto é, $\mathrm{K}_{\mathrm{y}} \mathrm{L}_{\mathrm{y}}$ é igual ao comprimento destravado, desse modo, desconsidera-se a existência do nó localizado entre o travamento lateral de $360 \mathrm{~cm}$ (a cada dois nós da treliça).

Fonte: Da autora. 


\section{CONCLUSÕES}

As análises teórica e experimental permitiram ampliar o entendimento sobre o comportamento estrutural de treliças com barra composta em perfis formados a frio submetida predominantemente à força normal.

O efeito do cisalhamento é importante nas barras compostas, pois esse esforço deve ser resistido principalmente pela alma da seção. Os elementos que passam a desempenhar a função de alma são as presilhas e chapas, que normalmente estão inseridas em alguns pontos ao longo do comprimento, o que faz com que apresente uma rigidez reduzida. Caso a presilha apresente pouca eficiência na transmissão dos esforços, as barras passam a estar apenas espaçadas, isto é, não se verifica a contribuição da composição.

Os resultados obtidos do ensaio de rigidez foram:

- $\quad$ A presilha em perfil de seção aberta conectada à alma das barras principais apresentou pouca eficiência na transferência dos esforços devido a sua deformabilidade ao cisalhamento, apresentando valores de rigidez inferiores ou próximos ao limite inferior efetivo para ambas as alturas do perfil e principalmente no menor vão, onde o efeito do cortante foi mais pronunciado. Para o vão maior observou-se um pequeno ganho de rigidez em relação a soma dos valores obtidos para os perfis individuais, isto se deve ao efeito da flexão ser mais acentuado.

- A utilização de chapas unindo as mesas das barras principais se mostrou mais eficiente, pois possibilita um melhor travamento entre as peças e a transmissão do esforço cortante para os componentes principais.

- $\quad$ O tipo de parafuso utilizado teve pouca influência nos resultados, e o aumento de rigidez foi pequeno com o acréscimo de presilhas.

- $\quad$ Observou-se por meio do ensaio de rigidez e do modelo simplificado que a posição do parafuso na seção transversal impacta na rigidez. Portanto, a fixação mais eficiente das presilhas ocorre quando a posição do parafuso na alma está mais próxima das mesas, pois possibilita uma mobilização maior das presilhas.

Os resultados obtidos no ensaio das treliças foram os seguintes:

- As treliças com banzos de maior altura apresentaram modo de falha distorcional, com deformada mais acentuada na mesa e enrijecedor superior devido à flexão na barra, indicada pelos extensômetros. As treliças com o perfil de $120 \mathrm{~mm}$ exibiram o modo global por flexão em torno do eixo de menor inércia do perfil, isto é, fora do plano da treliça, nas peças de 
maior comprimento destravado, notou-se a mobilização das diagonais e do banzo tracionado devido ao deslocamento acentuado do nó central. Conforme apresentado na tabela 5.6, verificase que para as treliças com banzos de maior altura considerar o efeito da flexo-compressão fazse necessário, tendo em vista a relação da força axial solicitante pela resistente ser inferior a um.

- $\quad$ Para as treliças com banzo de perfil de menor altura mesmo desprezando o efeito do momento fletor as previsões teóricas para compressão avaliaram satisfatoriamente a capacidade das treliças considerando a hipótese de ação isolada. Porém, verifica-se para as peças com maior comprimento destravado que a previsão normativa foi conservadora, associada ao tratamento da barra como um elemento isolado e nós articulados, o que não ocorre devido à presença das diagonais, o que implica em uma alteração do comprimento efetivo de flambagem.

Como as barras apresentam esbeltez global reduzida quando aplicada a recomendação da norma obtém-se uma grande quantidade de presilhas, principalmente no comprimento travado a cada nó.

Foi verificado pelos resultados experimentais que a maior quantidade de presilhas adicionadas entre nós não necessariamente possibilita uma maior capacidade resistente, apenas o protótipo com banzo de maior altura e travamento lateral de menor comprimento apresentou 6,5\% de acréscimo na força máxima aplicada pelo atuador em relação ao protótipo com apenas uma presilha.

Quanto ao tipo de parafuso, verificou-se, por meio do ensaio de rigidez, que ambos apresentam comportamentos semelhantes e que não há uma diferença significativa no ganho de rigidez ao se utilizar o parafuso sextavado ou o autoperfurante para conectar as presilhas.

Portanto, o uso do parafuso autoperfurante é mais vantajoso, pois a produtividade na fabricação das barras dos banzos é maior, dispensando a furação prévia da barra, necessária quando se utiliza o parafuso sextavado; além disso, o autoperfurante apresenta menor custo unitário. 


\section{REFERÊNCIAS BIBLIOGRÁFICAS}

ÁDÁNY, S., 2004, Buckling mode classification of members with open thin-walled crosssections by using the finite strip method. In Research report. Johns Hopkins University,

AMERICAN INSTITUTE OF STEEL CONSTRUCTION (AISC).ANSI/AISC 360.

Specification for Structural Steel Buildings. Chicago, Illinois, 2016.

AMERICAN IRON AND STEEL INSTITUTE (AISI). ANSI/AISI S100. North American Specification for the Design of Cold-Formed Steel Structural Members. Washington, D.C., 2016 Edition (Reaffirmed 2020), 2020.

AMERICAN SOCIETY FOR TESTING AND MATERIALS - ASTM. ASTM A370-17a:

Standard Test Method and Definitions for Mechanical Testing of Steel Products. West Conshohocken, 2017.

ASSOCIAÇÃO BRASILEIRA DE NORMAS TÉCNICAS (ABNT). NBR 14762:

Dimensionamento de estruturas de aço constituídas por perfis formados a frio. Rio de Janeiro: ABNT, 2010.

BASÁGLIA, C. D. (2004). Sobre o comportamento estrutural de terças de aço considerando a interação com as telhas. Dissertação (Mestrado) - Escola de Engenharia de São Carlos, Universidade de São Paulo, São Carlos, 2004.

BRANQUINHO, M.A. Análise de estabilidade e dimensionamento de porta-paletes seletivos com base no método da análise direta. 2021. 372 p. Tese (Doutorado em Ciências - Engenharia Civil (Engenharia de Estruturas)) - Escola de Engenharia de São Carlos, Universidade de São Paulo, São Carlos, 2021.

CHIEN, E. Y. L.; RITCHIE J. K. Design and construction of composite floor systems. CISC - Canadian Institute of Steel Construction. Markham, 1984. 323 p.

DABAON, M; ELLOBODY, E.; RAMZY, K. Experimental investigation of built-up coldformed steel section battened columns. Thin-Walled Structures, 92, p. 137-145. 2015.

DAR, M. A; SAHOO, D.R; JAIN, A. K; SHARMA, S.Monotonic tests and numerical validation of cold-formed steel battened built-up columns. Thin-Walled Structures, vol 159,107275. 2020.

DESMOND, T. P.; PEKÖZ, T. e WINTER, G. Intermediate Stiffeners for Thin-Walled Members. 5th International Specialty Conference on Cold-Formed Steel Structures. Session 02: buckling behavior and postbuckling strength of flat elements and shells . Proceedings. St. Louis, Missouri.1980.

EUROPEAN STANDARD (EN). EN 1993-3-1: Eurocode 3 - Design of steel structures Part 3-1: Part 1-3: General rules - Supplementary rules for cold-formed members and sheeting: CEN, 1993:2006.

FRATAMICO, C. D. Experiments, analysis, and design of built-up cold-formed steel columns. Johns Hopkins University. Baltimore, Maryland. 2017. 
FRATAMICO, C. D; TORABIAN, S; ZHAO, X; RASMUSSEND, K.J.R; SCHAFER, B.W. Experiments on the global buckling and collapse of built-up cold-formed steel columns.

Journal of Constructional Steel Research, vol 144, p. 65-80. 2018.

GALAMBOS, T. V. Guide to Stability Design Criteria for Metal Structures. John Wiley \& Sons, 4. ed. New York, 1998. 911p.

GEORGIEVA, I., L. SCHUEREMANS, AND L. PYL. Composed columns from cold-formed steel Z-profiles: Experiments and code-based predictions of the overall compression capacity. Engineering Structures. n.37, p. 125-134. 2012.

GEORGIEVA, I.; SCHUEREMANS, L; PYL, L.; VANDEWALLE, L. Experimental investigation of built-up double-Z members in bending and compression. Thin-Walled Structures. vol. 53, p. 48-57. 2012a.

GEORGIEVA, I.; SCHUEREMANS, L; PYL, L.; VANDEWALLE, L. Numerical study of built-up double-Z members in bending and compression. Thin-Walled Structures. vol. 60, p. 85-97. $2012 b$.

HANCOCK, G. J.; T. M. MURRAY; D. S. ELLIFRITT. 2001. Cold-formed steel structures to the AISI specification. New York. CRC Press.

INSTITUTO BRASILEIRO DE SIDERURGIA/CENTRO BRASILEIRO DA CONSTRUÇÃO EM AÇO - Treliças Tipo Steel Joist. IBS/CBCA, Rio de Janeiro, 2007.

KHERBOUCHE, S.; MEGNOUNIF, A. Numerical study and design of thin walled cold formed steel built-up open and closed section columns. Engineering Structures, vol. 179, p.670-682. 2019.

MAIA, W. F. Análise teórica e experimental de barras em dupla cantoneira de aço formada a frio submetidas à compressão. Tese (Doutorado) - Escola de Engenharia de São Carlos, Universidade de São Paulo, São Carlos, 2012.

MARTINS, A.D; DINIS, P.B; CAMOTIM. D. On the influence of local-distortional interaction in the behaviour and design of cold-formed steel web-stiffened lipped channel columns. Thin-Walled Structures, 101, p. 181-204. 2016.

MEZA, F. J The Behaviour of Cold-Formed Steel Built-up Structural Members. The University of Sheffield. Sheffield. 2018.

MEZA, F. J; BECQUE, J; HAJIRASOULIHA, I. Experimental study of cold-formed steel built-up columns. Thin-Walled Structures, vol. 149, art. 106291. 2020.

PHAN, D.K.; RASMUSSEN, K. J.R. Flexural rigidity of cold-formed steel built-up members. Thin-Walled Structures, vol. 140, p.438-449. 2019.

PHAN, D.K.; RASMUSSEN, K. J.R; SCHAFER, B.W. Tests and design of built-up section columns. Journal of Constructional Steel Research, vol. 181, 106619. 2021 
PFEIL, Walter; PFEIL, Michèle. Estruturas de aço - Dimensionamento prático de acordo com a NBR 8800:2008. $8^{\text {a }}$ Edição. Rio de Janeiro. Editora LTC, 2009.

RASMUSSEN, K. J.R; KHEZRI, M; SCHAFER, B.W.; ZHANGT, H. The mechanics of built-up cold-formed steel members. Thin-Walled Structures, vol. 154, art. 106756. 2020.

REIS, A.; CAMOTIM, D. Estabilidade estrutural. Lisboa, Portugal: McGRAW-HILL de Portugal. 470p, 2001.

RONDAL, J.; M. NIAZI. Stability of built-up beams and columns with thin-walled members. Journal of Constructional Steel Research. v.16, p. 329-335.1990.

VIJAYANAND, S; M. ANBARASU. Effect of spacers on ultimate strength and behavior of cold-formed steel built-up columns. Procedia Engineering, 173. p. 1423-1430. 2017.

SAMARRA, Fabio Aurélio. Estudo numérico-experimental de treliças tubulares planas para coberturas padronizadas para grandes vãos. 2007. Dissertação de Mestrado em Engenharia Civil - Universidade Estadual de Campinas, Campinas, 2007.

SCHAFER, B.W. Review: the direct strength method of cold-formed steel member design.Journal of constructional steel research. vol 64 . p. 766-778. 2008.

SCHAFER, B.W., PEKÖZ, T. Computational modeling of cold-formed steel: characterizing geometric imperfections and residual stresses. Journal of Constructional Steel Research, v.47, p. 193-210, 1998a.

SCHAFER, W. B.; PEKÖZ, T. Cold-Formed Steel Members with Multiple Longitudinal Intermediate Stiffeners. Journal of Structural Engineering, v.124, p.1175-1181. 1998b.

SCHAFER, B.W., PEKÖZ, T. Direct Strength Prediction of Cold-Formed Steel Members Using Numerical Elastic Buckling Solutions. In: 14th International Specialy Conference on Cold-Formed Steel Structures, pp. 69-76, St Louis, Missouri, USA. 1998c.

SHERMAN, D.R; YURA, J.A. Bolted double angle compression members. Journal of Constructional Steel Research.vol. 46.p. 470-471. 1998.

STONE, T.A.; LABOUBE, R.A. Behavior of cold-formed steel built-up I-sections. ThinWalled Structures, vol. 43, p. 1805-1817. 2005.

TEMPLE, M.C.; G.M. ELMAHDY. Slenderness ratio of main member between interconnectors of built-up compression members. Canadian Journal of Civil Engineering n.23.1996.

TIMOSHENKO, S. P.; GERE, J. M. Theory of Elastic Stability. New York, McGraw Hill, 1961. $541 \mathrm{p}$.

TING T.C.H. The Behaviour of Axially Loaded Cold-formed Steel Back-to-back Cchannel Built-up Columns. Curtin University-School of Engineering \& Science, Department of Civil \& Construction Engineering. 2013. 
TING, T.C.H.; ROY, K; LAU, H.H., LIM, JAMES, BP. Effect of screw spacing on behavior of axially loaded back-to-back coldformed steel built-up channel sections. Advances in Structural Engineering, vol. 21(3), p. 474-48. 2018.

VIEIRA, Rodrigo Cuberos. Estudo comparativo entre terças de aço, convencionais em vigas, em treliças planas e em treliças multiplanares. 2009. Dissertação de Mestrado em Engenharia Civil - Universidade Estadual de Campinas, Campinas, 2009.

WHITTLE. J; RAMSEYER. C. Buckling capacities of axially loaded, cold-formed, built-up C-channels. Thin-Walled Structures, vol 47, p. 190-201. 2009.

YOUNG, B.; K. J. R. RASMUSSEN. Shift of effective centroid of channel columns. Journal of Structural Engineering, vol. 125(5), p. 524-531. 1999.

YU, W. W.; LABOUBE, R. A. Cold-formed steel design. 4.ed. Hoboken: John Wiley \& Sons, 2010.

ZAHARIA. R, DUBINA.D. Stiffness of joints in bolted connected cold-formed steel trusses. Journal of Constructional Steel Research, vol 62 (3), pg. 195-203. 2006.

ZHOU. T, LI. Y, WU. H, LU. Y, REN.L.Analysis to determine flexural buckling of coldformed steel built-up back-to-back section columns. Journal of Constructional Steel Research, vol 166, 105898. 2020. 


\section{APÊNDICE A - MODELO NÚMERICO SIMPLIFICADO: ENSAIO DE RIGIDEZ}

O modelo numérico em elementos finitos foi desenvolvido no software comercial ABAQUS. A discretização da geometria do perfil foi simplificada na região de dobra dos vértices, sendo considerada com cantos vivos em vez de cantos arredondados. A espessura nominal de $3 \mathrm{~mm}$ foi reduzida em $0,05 \mathrm{~mm}$ a fim de se descontar a espessura do revestimento de zinco utilizado nas chapas dos perfis, pois não desempenha função estrutural.

O elemento finito de casca foi utilizado por ser adequado as estruturas de parede fina; o tipo de elemento empregado na análise foi o S4R, que possui 4 nós e 6 graus de liberdade por nó: três translações e três rotações, associadas aos eixos coordenados $\mathrm{X}, \mathrm{Y}$ e Z . Os elementos que possuem a letra " $R$ " na biblioteca do ABAQUS possuem integração reduzida, isto é, utilizam menos pontos de integração o que possibilita uma redução do tempo de processamento, porém pode acarretar mudança de forma do elemento submetido à flexão, sendo assim necessário um mecanismo de estabilização como o "hourglass control" presente no tipo S4R.

O elemento sólido do tipo C3D8R foi utilizado para modelar de forma simplificada os aparelhos de apoio, nos quais foram aplicadas as condições de contorno. O apoio móvel foi representado restringindo a translação na direção da aplicação da força em uma linha localizada no meio da superfície inferior do apoio. Um nó da extremidade da linha foi restringido à translação na direção transversal da viga. Para o apoio fixo, foram restringidos os deslocamentos na direção da aplicação do carregamento e os na direção longitudinal da peça; também se fixou o nó de extremidade na direção transversal. A Figura A.1 ilustra as condições de contorno utilizadas.

Figura A.1- Condições de contorno.
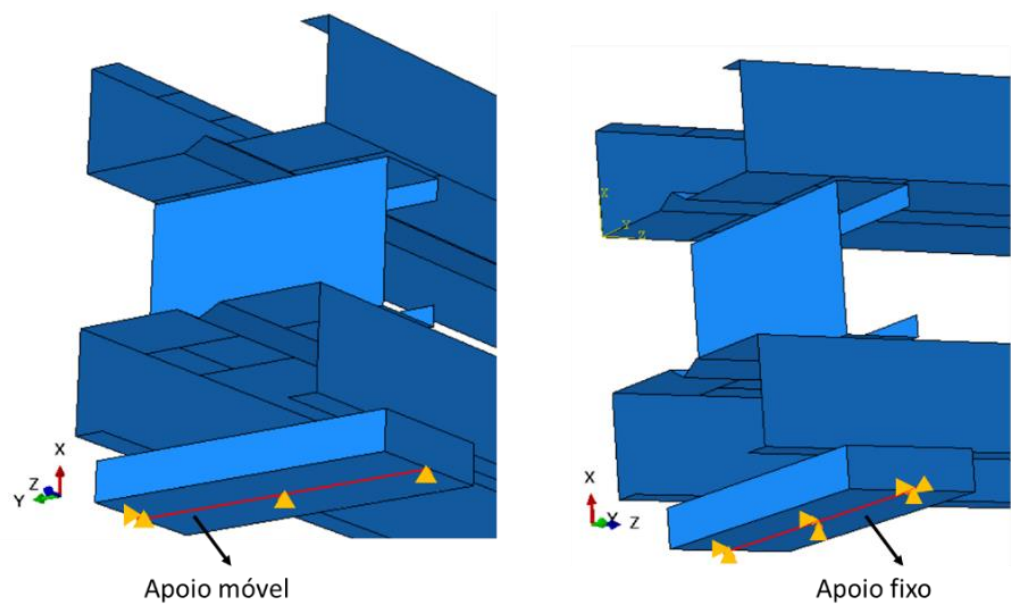

Fonte: Da autora. 
Os apoios foram conectados ao perfil inferior considerando compatibilidade total dos deslocamentos, de modo que não haja deslocamento relativo entre as superfícies ("tie" na nomenclatura do ABAQUS). As presilhas também foram conectadas aos perfis superior e inferior pelo mesmo tipo de restrição empregado na região dos apoios.

Utilizou-se essa simplificação na ligação banzo-presilha a fim de se obter um modelo inicial que apresentasse uma ligação rígida entre as peças e assim poder realizar reduções na área de contato que possibilitassem representar a rigidez obtida experimentalmente e verificar a influência da posição da ligação associada a essas reduções.

O carregamento foi aplicado diretamente na superfície do perfil superior na região onde foi utilizado o calço de madeira no ensaio por meio de um deslocamento vertical unitário. A Figura A.2 ilustra a região da aplicação do deslocamento e um esquema geral do modelo.

Figura A.2- Esquema geral e região da aplicação do carregamento.

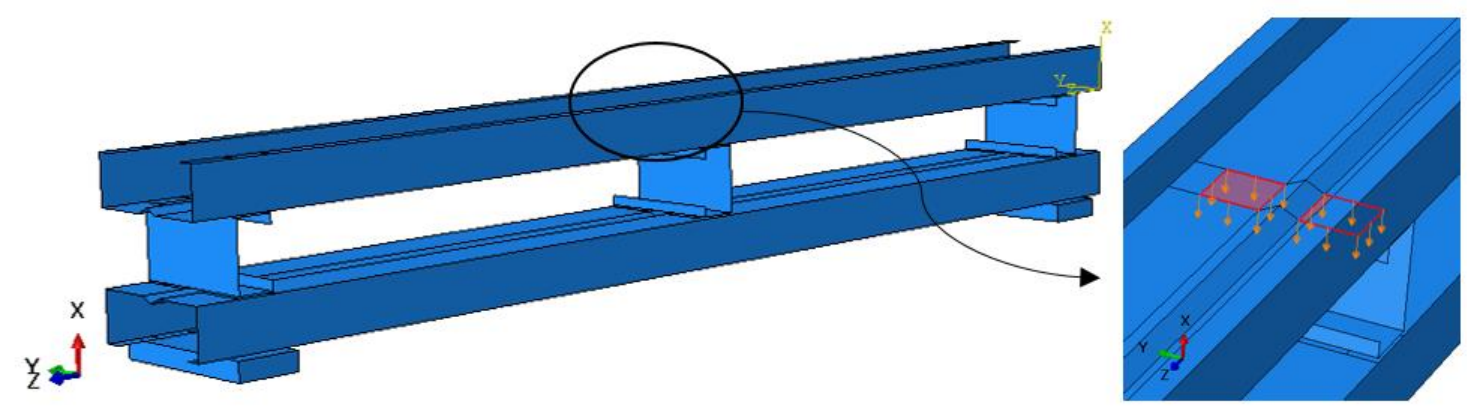

Fonte: Da autora.

As propriedades do aço adotadas em regime elástico foram as seguintes: Módulo de elasticidade de 200.000 MPa e coeficiente de Poisson de 0,3. A plasticidade foi introduzida por meio dos resultados de ensaios de tração em corpos de aço padronizados (ASTM A370:2014), contidos no Apêndice B, os quais são obtidos considerando a área inicial dos corpos de provas, portanto a estricção não é levada em consideração.

Portanto, esses valores devem passar por uma conversão obtendo-se os valores denominados por "true" de tensão e deformação, essa conversão é realizada por meio das equações (A.1) e (A.2).

$$
\begin{gathered}
\sigma_{\text {true }}=\sigma_{e}\left(1+\varepsilon_{e}\right) \\
\varepsilon_{\text {true }}=\ln \left(1+\varepsilon_{e}\right)
\end{gathered}
$$


A malha utilizada para os perfis de aço formados a frio constitui-se de elementos quadrilaterais com dimensão máxima de $10 \mathrm{~mm}$ de lado. Os apoios tiveram uma malha menos refinada com dimensão de $20 \mathrm{~mm}$. A escolha do tamanho da malha foi realizada considerando o estudo de refinamento.

Em uma análise não linear, as imperfeições geométricas iniciais são geralmente introduzidas por uma superposição linear dos modos de flambagem (autovetores). Por meio do software Abaqus, a deformada foi importada através do código *IMPERFECTION que permite a ponderação do campo de deslocamentos importado de forma que os valores de imperfeição sejam adotados de forma adequada. Por meio desta abordagem de adoção das imperfeições, a discretização da malha nas análises prévia e final devem ser as mesmas (BRANQUINHO,2021). Essa análise foi realizada, e os modos críticos distorcional e local adotados em ambos os perfis estão ilustrados na Figura A.3.

Figura A.3- Modos de instabilidade adotados para a imperfeição geométrica inicial ampliado em 20 vezes.

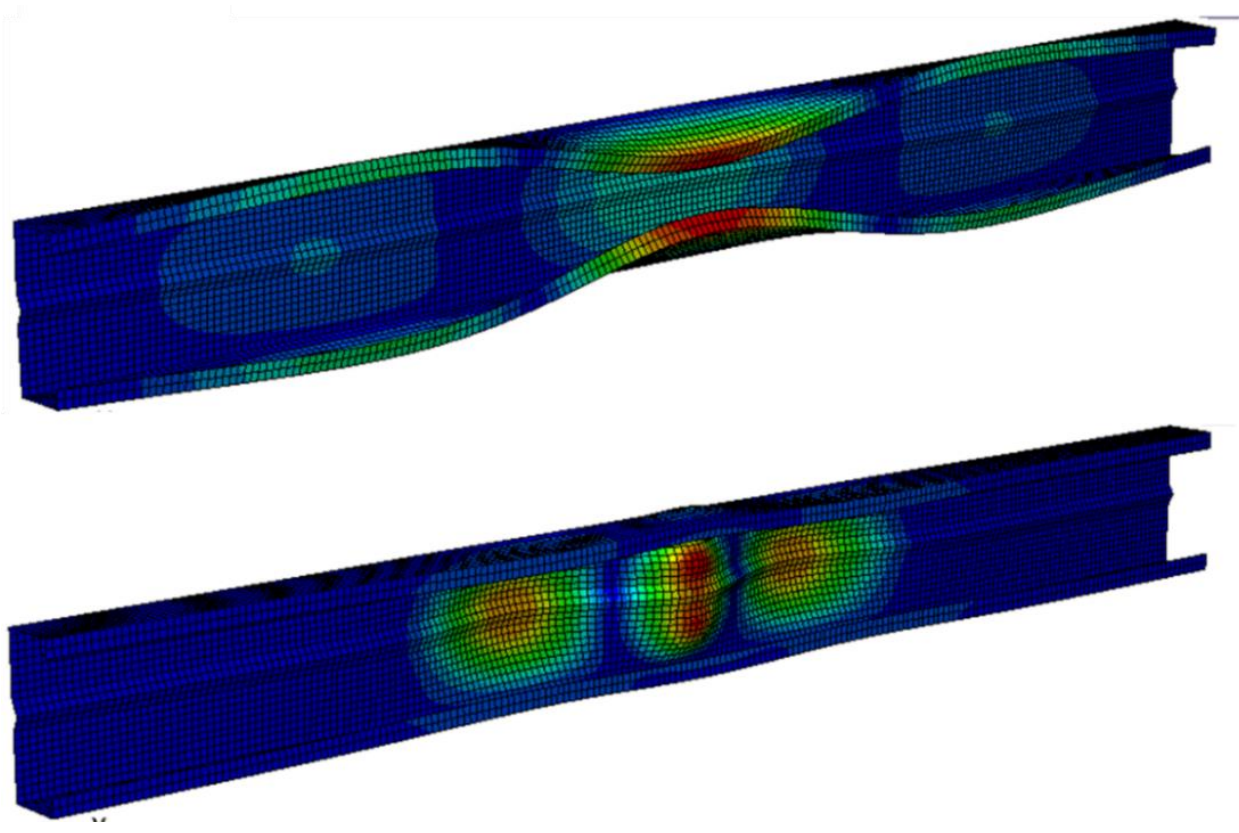

Fonte: Da autora.

Esses modos foram ponderados conforme o estudo probabilístico indicado por Pekoz e Schafer (1998a), onde foram considerados os quantis de $25 \%$ e $75 \%$. O método de processamento utilizado na análise não linear foi o do comprimento de arco.

O primeiro modelo realizado possui toda a área de contato entre o perfil e a presilha conectada, isto é, a largura da mesa da presilha e toda a altura da alma entre os enrijecedores; 
os demais modelos apresentaram uma redução apenas no comprimento no sentido da alma dos perfis principais, como ilustrado na Figura A.4.

Essa foi a primeira simplificação realizada baseada em observações dos protótipos (Figura A.5), porém essa configuração não ocorre para todos os pontos conectados, havendo uma certa variabilidade ao longo do comprimento e entre os protótipos. Outras possibilidades seriam a combinação de redução em ambos os sentidos da área de contato devido também ao raio de curvatura da presilha.

Figura A.4- Redução da área de ligação pela dimensão no sentido da altura dos perfis principais.

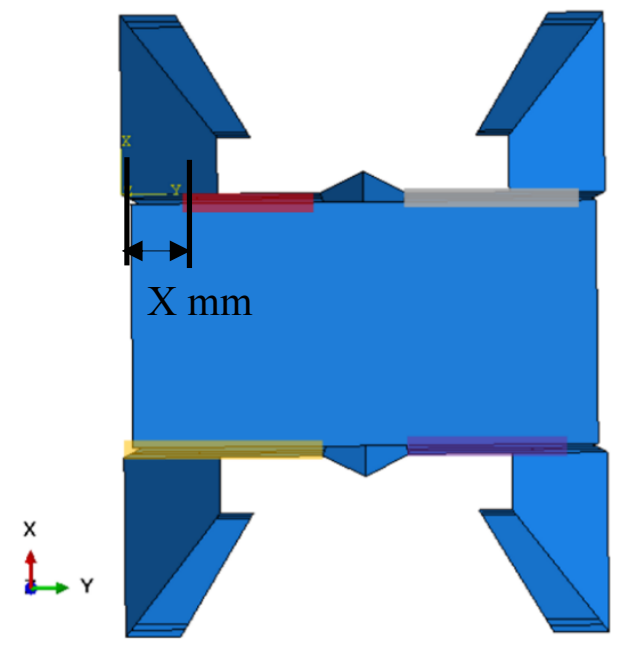

Fonte: Da autora.

Figura A.5- Exemplo de área de contato em um dos protótipos.

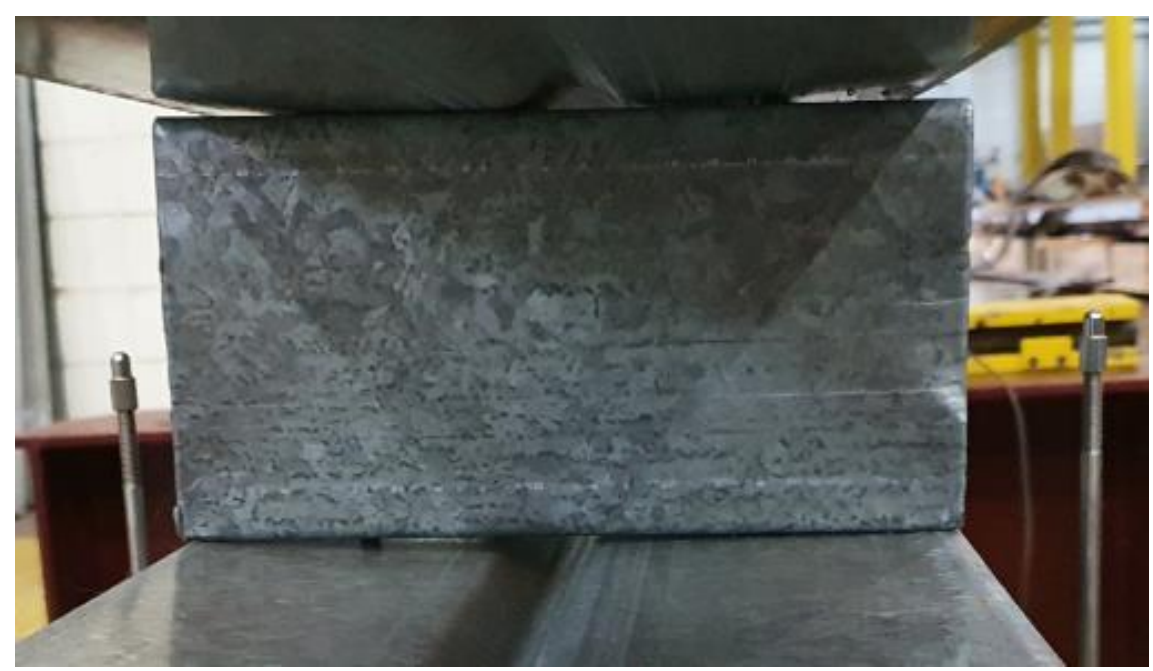

Fonte: Da autora. 
Os resultados obtidos para o modelo do protótipo UB180-1A considerando cinco reduções na área e as probabilidades de que o banco de dados de imperfeição exceda o valor adotado na análise em 25 e $75 \%$ seguem organizados na Tabela A.1.

A Figura A.6 e a Figura A.7 apresentam as curvas força versus deslocamento para as duas amplificações das imperfeições consideradas.

Pelos resultados apresentados, observa-se que, com a redução da área de contato a rigidez se aproxima do modelo experimental, porém ocorre uma redução da capacidade final. Com relação ao modo de falha o modelo numérico apresenta o mesmo modo distorcional.

Pode-se verificar que, com a redução da área de contato as inclinações das curvas se alteram, havendo, portanto, uma redução do valor e uma menor restrição ao modo distorcional, pois o mesmo se caracteriza pela mudança de posição dos vértices da seção. Assim, a posição do parafuso mais próxima ao enrijecedor da alma restringe menos a rotação do conjunto mesa e alma, fazendo com que o modo de instabilidade ocorra de forma antecipada caso seja mais bem restringido.

A ponderação dos modos com o quantil de $25 \%$, gerou rigidez ligeiramente inferior ao do quantil de $75 \%$, assim os valores numéricos se aproximaram mais dos experimentais.

Tabela A.1- Razão entre o valor experimental e o numérico para o protótipo com uma presilha interna (UB180-1A).

\begin{tabular}{|c|c|c|}
\hline Protótipo- UB180-1A & $P(\Delta>d)=0,75$ & $\mathrm{P}(\Delta>\mathrm{d})=0,25$ \\
\hline & $E I_{y \operatorname{Exp}} / E I_{y M E F}$ & $E I_{y \operatorname{Exp}} /_{E I_{y M E F}}$ \\
\hline Toda área de contato & 0,704 & 0,726 \\
\hline Redução 1- 10 mm (-11,76\%) & 0,734 & 0,762 \\
\hline Redução 2- 15 mm $(-17,64 \%)$ & 0,791 & 0,818 \\
\hline Redução 3- 20 mm (-23,52\%) & 0,817 & 0,847 \\
\hline Redução 4- 25 mm (-29,40\%) & 0,913 & 0,946 \\
\hline Redução 5- 30 mm $(-35,28 \%)$ & 0,955 & 0,987 \\
\hline
\end{tabular}

Fonte: Da autora. 
Figura A.6- Curva força versus deslocamento para UB180-1A considerando $\mathrm{P}(\Delta>\mathrm{d})=0,75$.

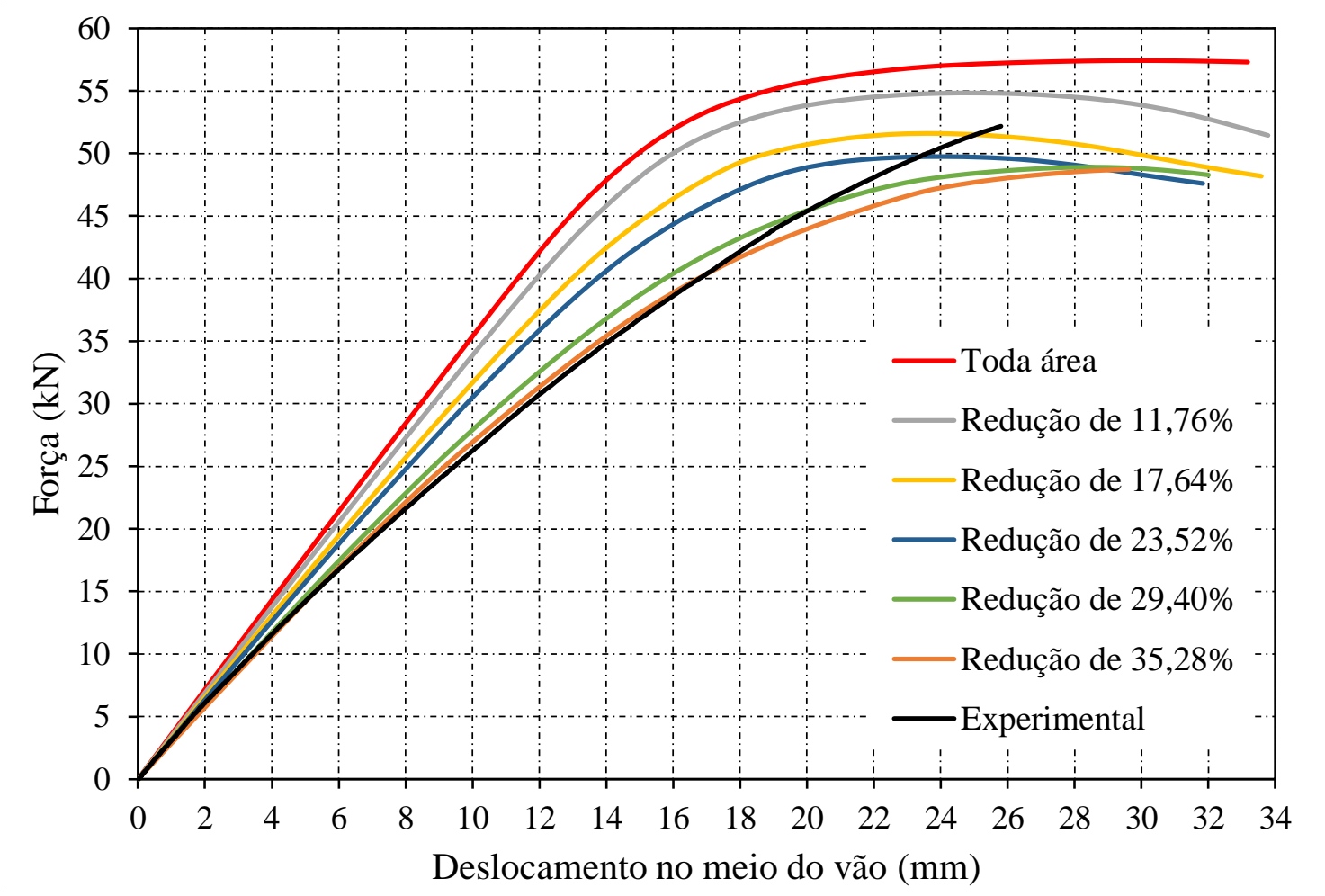

Fonte: Da autora.

Figura A.7- Curva força versus deslocamento para UB180-1A considerando $P(\Delta>d)=0,25$.

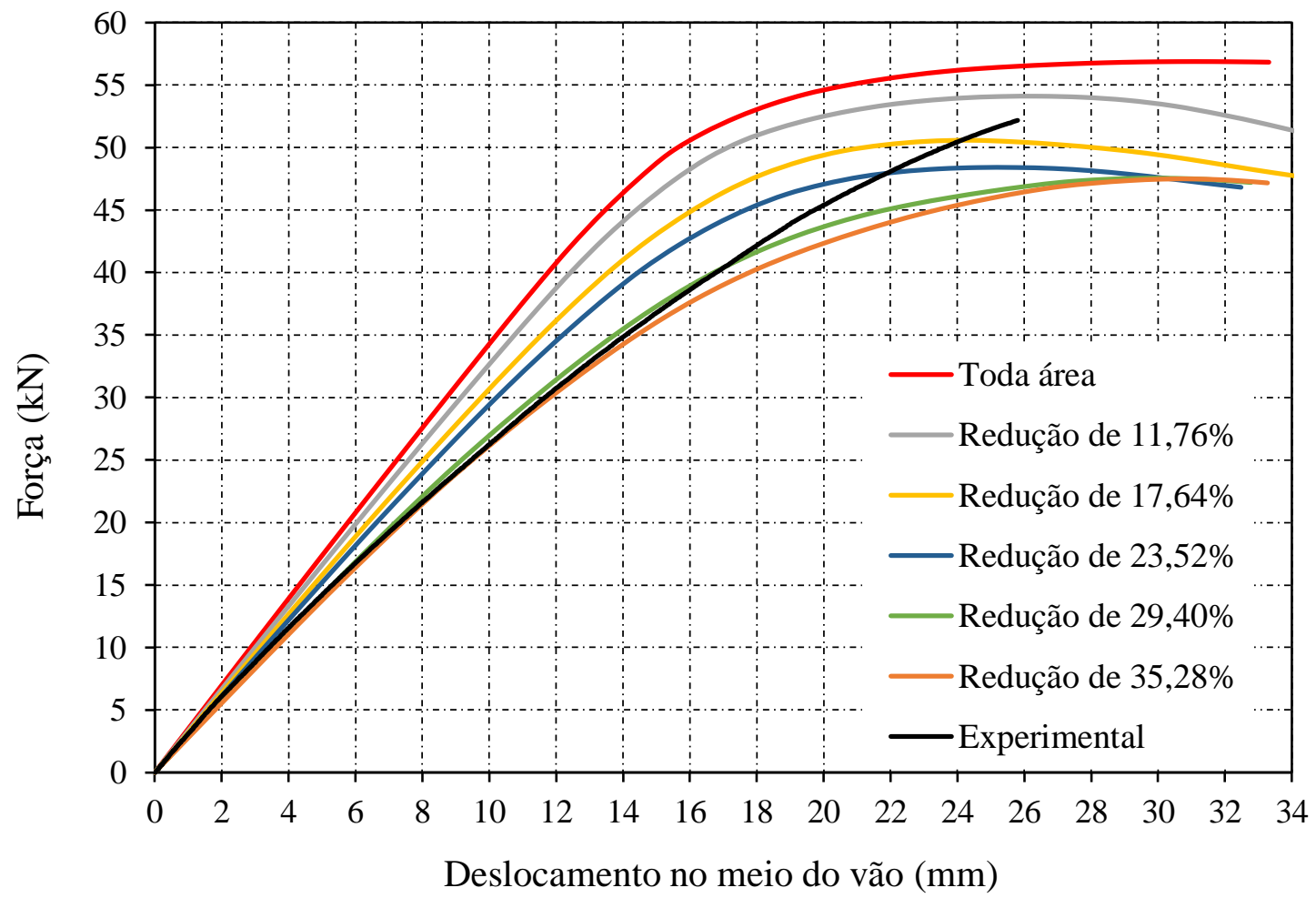

Fonte: Da autora. 
A Tabela A.2 traz os resultados obtidos considerando o maior valor experimental para os protótipos com três presilhas internas. Observou-se, assim como para o protótipo anterior, que, quanto maior a área de contato, mais rígida é a resposta do modelo, sendo que a redução 4 e a 5 apresentam as respostas mais próximas ao modelo experimental.

Também se verificou que a ponderação dos modos com o quantil de $25 \%$, gerou uma rigidez ligeiramente inferior ao do quantil de $75 \%$; assim, os valores numéricos se aproximaram mais dos experimentais.

Tabela A.2- Razão entre o valor experimental e o numérico para o protótipo com 3 presilhas internas.

\begin{tabular}{ccc}
\hline Protótipo- UB180-3X & $\mathbf{P}(\Delta>\mathbf{d})=\mathbf{0 , 7 5}$ & $\mathbf{P}(\Delta>\mathbf{d})=\mathbf{0 , 2 5}$ \\
\cline { 2 - 3 } & $\boldsymbol{E} \boldsymbol{I}_{\boldsymbol{y} \boldsymbol{E x p}} / \boldsymbol{E}_{\boldsymbol{y} \boldsymbol{M} \boldsymbol{E \boldsymbol { F }}}$ & $\boldsymbol{E I}_{\boldsymbol{y} \boldsymbol{E x p}} / \boldsymbol{E}_{\boldsymbol{y} \boldsymbol{M} \boldsymbol{E} \boldsymbol{F}}$ \\
\hline Toda área de contato & 0,748 & 0,773 \\
Redução 1- 10 mm (-11,76\%) & 0,780 & 0,806 \\
Redução 2- 15 mm (-17,64\%) & 0,826 & 0,859 \\
Redução 3- 20 mm (-23,52\%) & 0,862 & 0,893 \\
Redução 4- 25 mm (-29,40\%) & 0,934 & 0,978 \\
Redução 5- 30 mm (-35,28\%) & 1,009 & 1,052 \\
\hline
\end{tabular}

Fonte: Da autora.

A Figura A.8 e a Figura A.9 apresentam as curvas força versus deslocamentos para as duas amplificações das imperfeições consideradas, onde observa-se que com a redução da área as curvas se aproximam das curvas experimentais no trecho inicial, porém existe uma redução da capacidade final. 
Figura A.8- Curva força versus deslocamento para UB180-3x considerando $\mathrm{P}(\Delta>\mathrm{d})=0,75$.

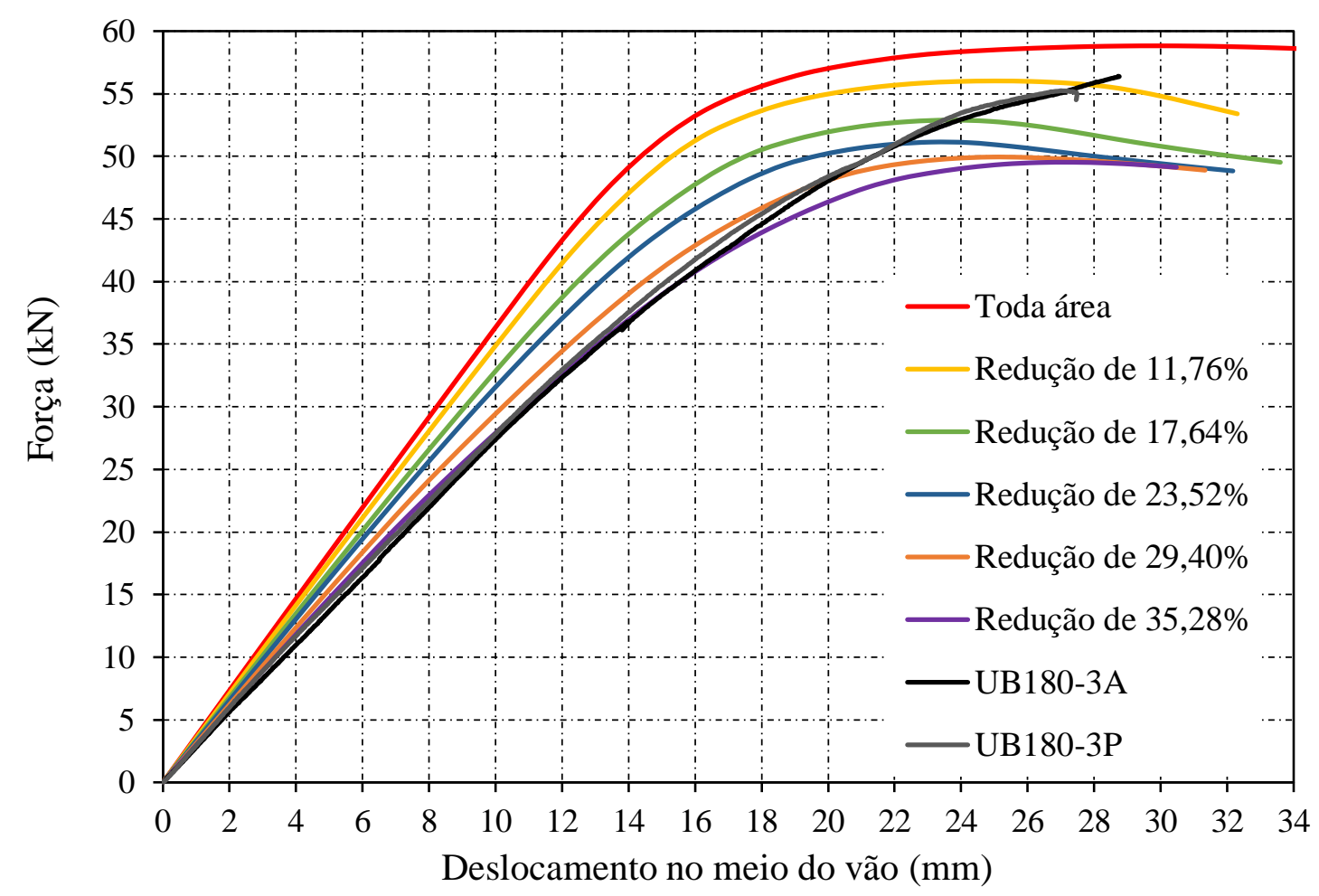

Fonte: Da autora.

Figura A.9- Curva força versus deslocamento para UB180-3x considerando $\mathrm{P}(\Delta>\mathrm{d})=0,25$.

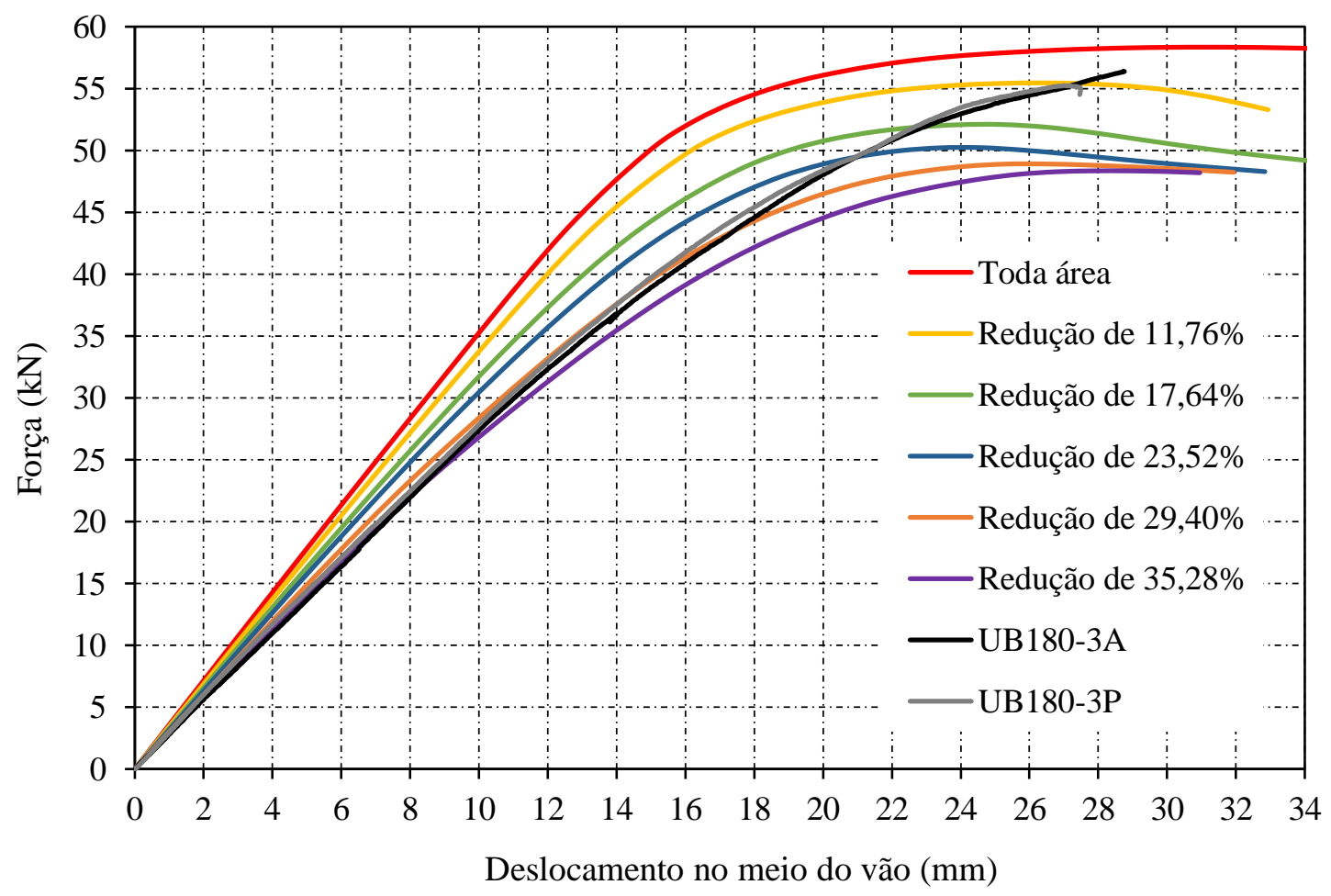

Fonte: Da autora. 
A Tabela A.3 traz os resultados obtidos, considerando o maior valor experimental obtido para o protótipo com cinco presilhas internas. Verificou-se o mesmo comportamento indicado anteriormente. A Figura A.10 e a Figura A.11 apresentam as curvas força versus deslocamentos para as duas amplificações das imperfeições consideradas.

Tabela A.3- Razão entre o valor experimental e o numérico para o protótipo com 5 presilhas internas.

\begin{tabular}{ccc}
\hline Protótipo- UB180-5X & $\mathbf{P}(\Delta>\mathbf{d})=\mathbf{0 , 7 5}$ & $\mathbf{P}(\Delta>\mathbf{d})=\mathbf{0 , 2 5}$ \\
\cline { 2 - 3 } & $\boldsymbol{E I}_{\boldsymbol{y} \boldsymbol{E x p} / \boldsymbol{E I}_{\boldsymbol{y} \boldsymbol{M} \boldsymbol{E} \boldsymbol{F}}}$ & $\boldsymbol{E I}_{\boldsymbol{y} \boldsymbol{E x p}} / \boldsymbol{E I}_{\boldsymbol{y} \boldsymbol{M} \boldsymbol{E} \boldsymbol{F}}$ \\
\hline Toda área de contato & 0,791 & 0,806 \\
Redução 1- 10 mm (-11,76\%) & 0,811 & 0,829 \\
Redução 2- 15 mm (-17,64\%) & 0,832 & 0,856 \\
Redução 3- 20 mm (-23,52\%) & 0,866 & 0,890 \\
Redução 4- 25 mm (-29,40\%) & 0,922 & 0,951 \\
Redução 5- 30 mm (-35,28\%) & 0,972 & 1,011
\end{tabular}

Fonte: Da autora (2021).

Figura A.10- Curva força versus deslocamento para UB180-5x considerando $\mathrm{P}(\Delta>\mathrm{d})=0,75$.

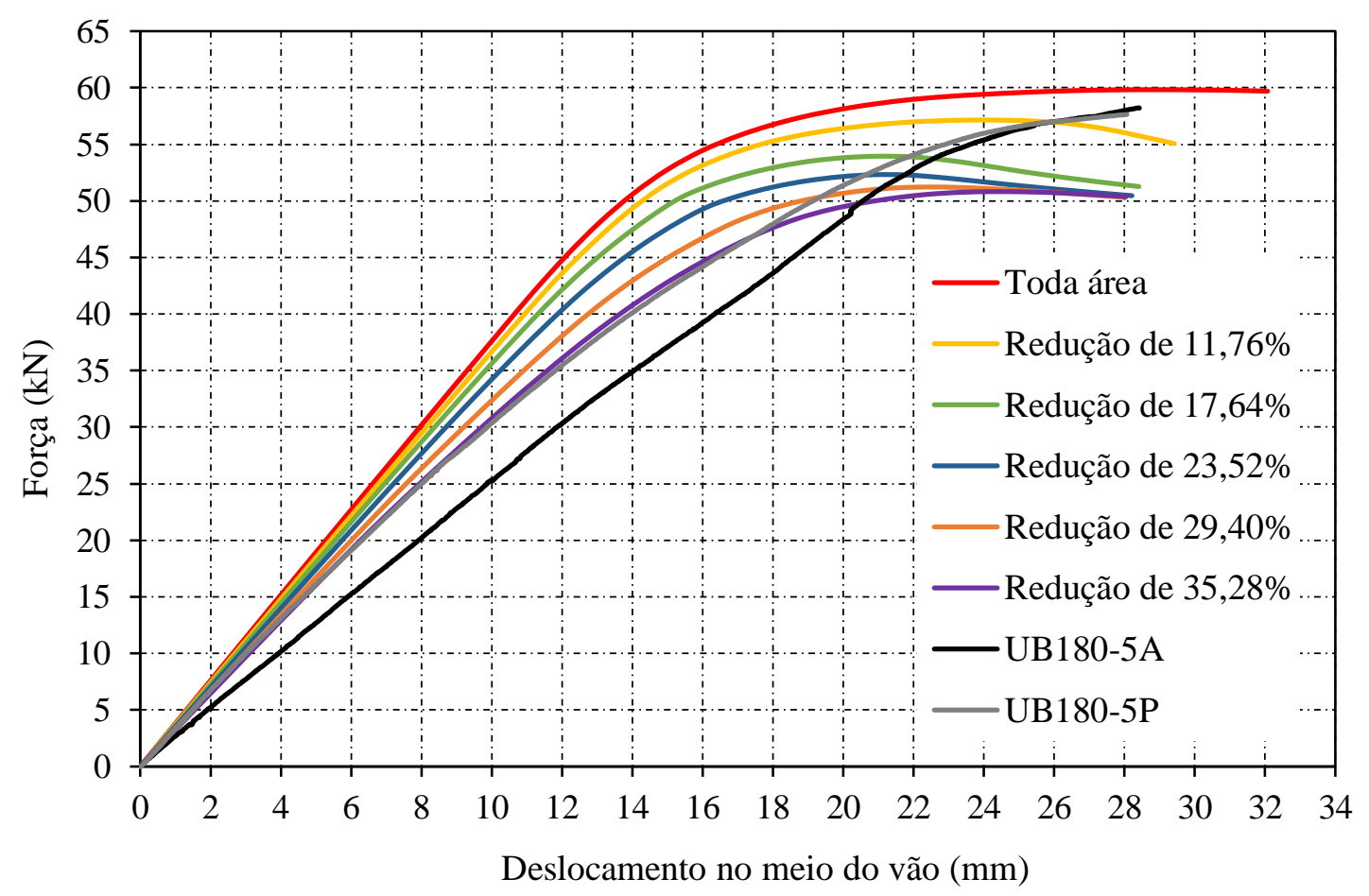

Fonte: Da autora. 
Figura A.11- Curva força versus deslocamento para UB180-5x considerando $\mathrm{P}(\Delta>\mathrm{d})=0,25$.

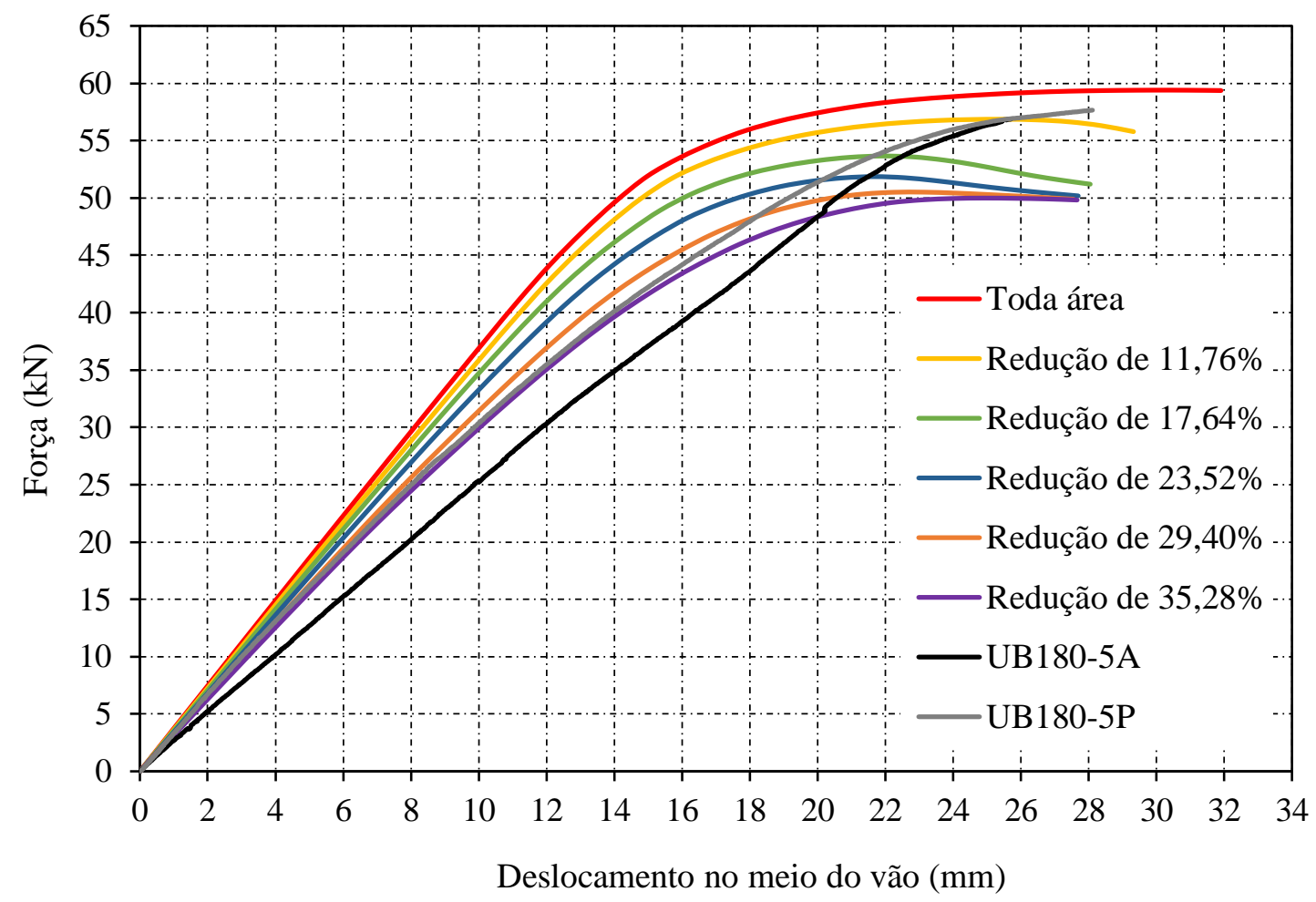

Fonte: Da autora.

O comportamento observado nos modelos com comprimento de $1800 \mathrm{~mm}$ não foi verificado para o comprimento de $3600 \mathrm{~mm}$, onde, com as reduções de área de contato, não se observou uma variação da rigidez significativa, como pode ser observado na Tabela A.4 e na Figura A.12, que traz os resultados para o protótipo UB360-5A .

Tabela A.4- Razão entre o valor experimental e o numérico para o protótipo com cinco presilhas internas no vão de $3600 \mathrm{~mm}$.

\begin{tabular}{|c|c|c|}
\hline Protótipo- UB360-5A & $P(\Delta>d)=0,75$ & $P(\Delta>d)=0,25$ \\
\hline & $E I_{y \operatorname{Exp}} / E I_{y M E F}$ & $E I_{y} \operatorname{Exp} / E I_{y M E F}$ \\
\hline Toda área de contato & 0,869 & 0,877 \\
\hline Redução 1- 10 mm (-11,76\%) & 0,874 & 0,884 \\
\hline Redução 2- 15 mm (-17,64\%) & 0,880 & 0,892 \\
\hline Redução 3- 20 mm (-23,52\%) & 0,887 & 0,900 \\
\hline Redução 4- 25 mm (-29,40\%) & 0,896 & 0,908 \\
\hline Redução 5- 30 mm (-35,28\%) & 0,905 & 0,920 \\
\hline
\end{tabular}

Fonte: Da autora. 
Figura A.12-Curva força versus deslocamento para UB360-5A considerando $P(\Delta>d)=0,75$.

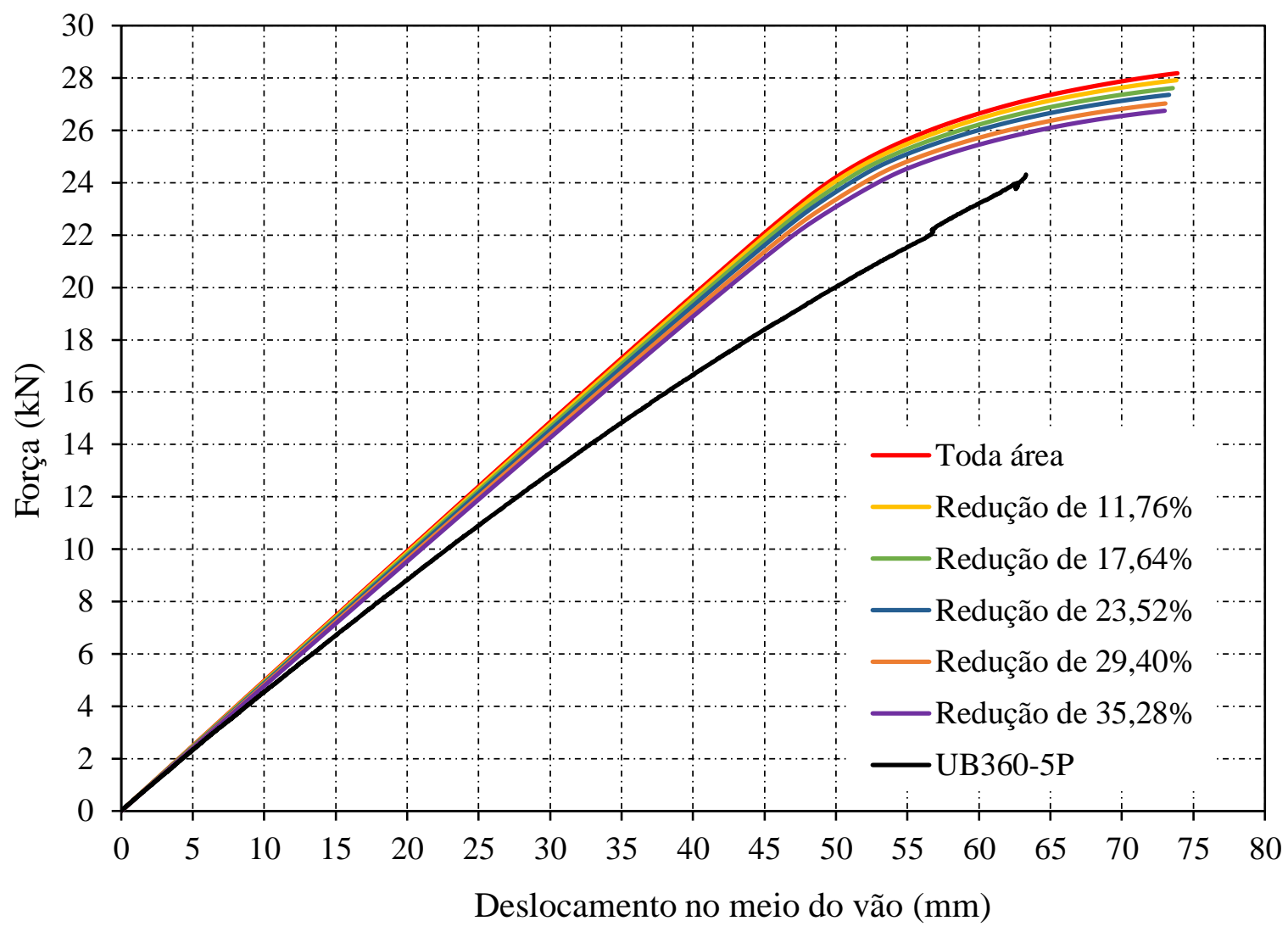

Fonte: Da autora.

A Tabela A.5 e a Tabela A.6 reúnem os resultados obtidos para os modelos UB360-3X e UB360-1A respectivamente; assim como indicado anteriormente, não se observa uma sensibilidade considerável da rigidez com a redução das áreas de contato.

Tabela A.5- Razão entre o valor experimental e o numérico para o protótipo com três presilhas internas no vão de $3600 \mathrm{~mm}$.

\begin{tabular}{|c|c|c|}
\hline Protótipo- UB360-3x & $P(\Delta>d)=0,75$ & $P(\Delta>d)=0,25$ \\
\hline & $E I_{y E x p} / E I_{y M E F}$ & $E I_{y \operatorname{Exp}} / E I_{y M E F}$ \\
\hline Toda área de contato & 0,954 & 0,965 \\
\hline Redução 1- 10 mm (-11,76\%) & 0,959 & 0,972 \\
\hline Redução 2- 15 mm (-17,64\%) & 0,965 & 0,980 \\
\hline Redução 3- 20 mm (-23,52\%) & 0,973 & 0,988 \\
\hline Redução 4- 25 mm (-29,40\%) & 0,983 & 0,999 \\
\hline Redução 5- 30 mm $(-35,28 \%)$ & 0,991 & 1,009 \\
\hline
\end{tabular}


Tabela A.6- Razão entre o valor experimental e o numérico para o protótipo com uma presilha interna no vão de $3600 \mathrm{~mm}$.

\begin{tabular}{ccc}
\hline Protótipo- UB360-1A & $\mathbf{P}(\Delta>\mathbf{d})=\mathbf{0 , 7 5}$ & $\mathbf{P}(\Delta>\mathbf{d})=\mathbf{0 , 2 5}$ \\
\cline { 2 - 3 } & $\boldsymbol{E} \boldsymbol{I}_{\boldsymbol{y} \text { Exp }} / \boldsymbol{E}_{\boldsymbol{y} \boldsymbol{M E F}}$ & $\boldsymbol{E I}_{\boldsymbol{y} \boldsymbol{E x p}} / \boldsymbol{E}_{\boldsymbol{y} \boldsymbol{M E F}}$ \\
\hline Toda área de contato & 0,962 & 0,973 \\
Redução 1- 10 mm (-11,76\%) & 0,966 & 0,979 \\
Redução 2- 15 mm (-17,64\%) & 0,971 & 0,985 \\
Redução 3- 20 mm (-23,52\%) & 0,978 & 0,993 \\
Redução 4- 25 mm (-29,40\%) & 0,987 & 1,003 \\
Redução 5- 30 mm (-35,28\%) & 0,995 & 1,012
\end{tabular}

Fonte: Da autora. 


\section{APÊNDICE B - CARACTERIZAÇÃO DO MATERIAL}

A caracterização mecânica do material dos perfis foi realizada através de ensaios de tração direta em corpos de prova, conforme as especificações da norma americana ASTM A370-17a (ASTM, 2017). As dimensões dos corpos de prova utilizados para caracterização do aço são apresentadas na Figura B.1.

Figura B.1 - Dimensões dos corpos de prova (em milímetros)

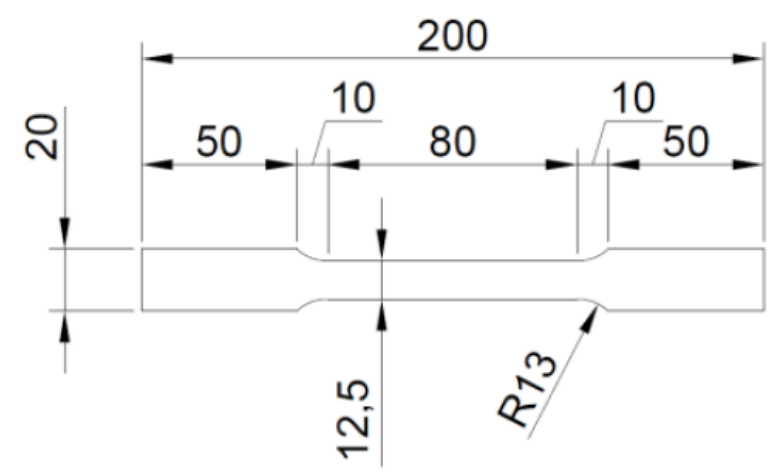

Fonte: Da autora.

Foram extraídos corpos de prova das mesas e da alma de ambos os perfis em estudo, conforme mostrado nas Figura B.2, Figura B.3 e Figura B.4. Assim, ao todo foram realizados ensaios de tração direta em nove corpos de prova.

Figura B.2- Locais de extração dos corpos de prova: perfil UAE 120.

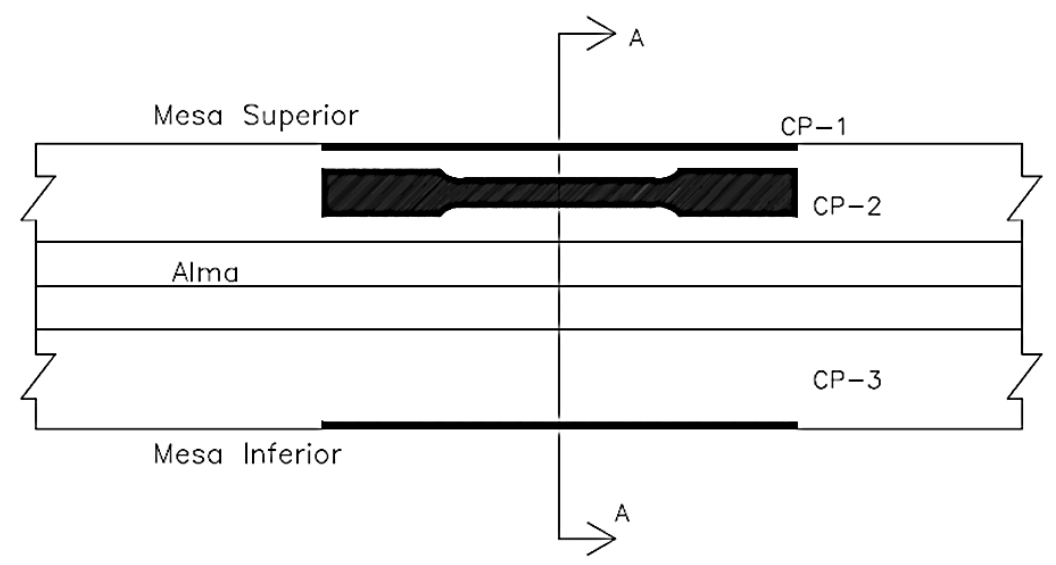

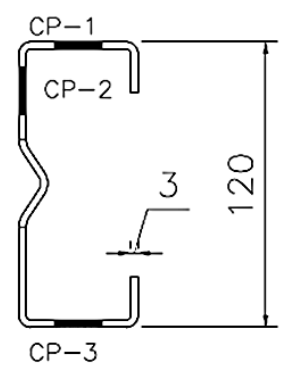

CORTE A-A

Fonte: Da autora. 
Figura B.3- Locais de extração dos corpos de prova: perfil UAE 210.
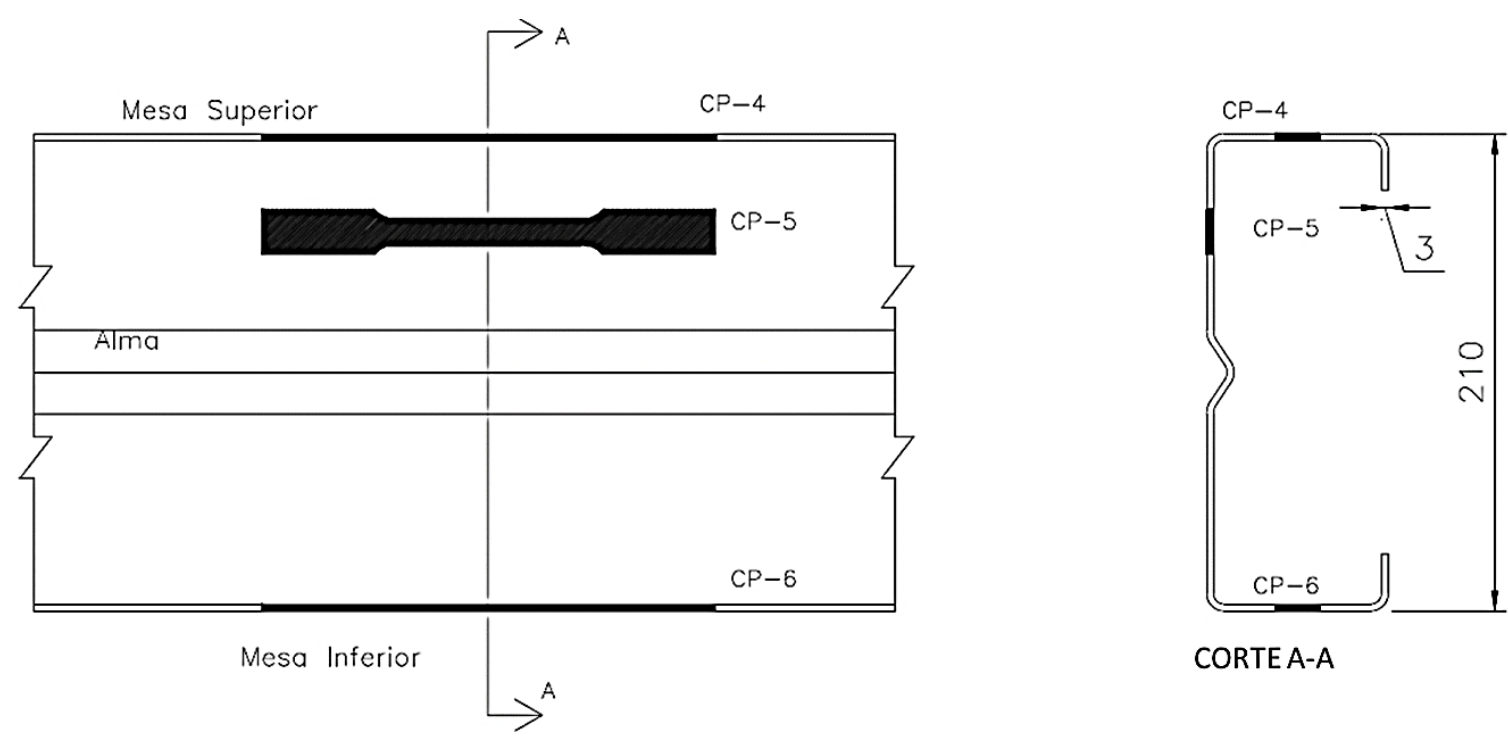

CORTE A-A

Fonte: Da autora.

Figura B.4- Locais de extração dos corpos de prova: perfil UE 110.

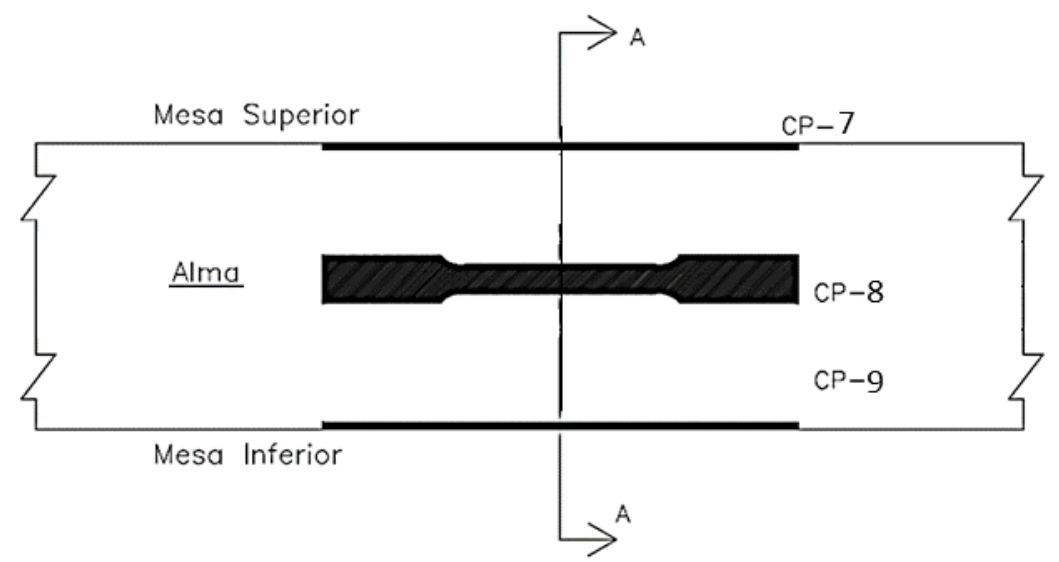

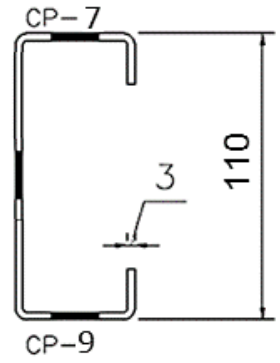

CORTE A-A

Fonte: Da autora.

Os resultados da caracterização do aço são apresentados nas Tabela B.1 e Tabela B.2 para o ensaio de rigidez e das treliças respectivamente. A resistência ao escoamento foi obtida pelo método offset $0,2 \%$. A partir dos dados da tabela, verifica-se que os requisitos estabelecidos na NBR 14762 (ABNT, 2010) foram atendidos, pois o alongamento após a ruptura superou $10 \%$ para a base de medida igual a $50 \mathrm{~mm}$ e a relação entre resistência à ruptura e resistência ao escoamento $f_{u} / f_{y}$ foi maior do que 1,08 . 
Tabela B.1-Resultados da caracterização do material do ensaio de flexão das barras isoladas.

\begin{tabular}{ccccccc}
\hline $\mathbf{C P}$ & $\begin{array}{c}\text { Altura x } \\
\text { espessura } \\
(\mathbf{m m})\end{array}$ & $\begin{array}{c}\text { Extração do } \\
\mathbf{C P}\end{array}$ & $\boldsymbol{f}_{\boldsymbol{u}}(\mathbf{M P a}$ & $\boldsymbol{f}_{\boldsymbol{y}}(\mathbf{M P a})$ & $\mathbf{A}(\boldsymbol{\%})$ & $\boldsymbol{f}_{\boldsymbol{u}} / \boldsymbol{f}_{\boldsymbol{y}}$ \\
\hline $\mathbf{1}$ & \multirow{3}{*}{$120 \times 3,00$} & Mesa Superior & 588,45 & 469,70 & $22,00 \%$ & 1,25 \\
$\mathbf{2}$ & Alma & 584,28 & 465,00 & $22,00 \%$ & 1,26 \\
$\mathbf{3}$ & & Mesa Inferior & 590,73 & 451,40 & $23,00 \%$ & 1,31 \\
& & Média & 587,82 & 462,03 & $22,33 \%$ & 1,27 \\
\hline $\mathbf{4}$ & \multirow{5}{*}{$210 \times 3,00$} & Mesa Superior & 586,41 & 469,50 & $18,00 \%$ & 1,25 \\
$\mathbf{6}$ & & Alma & 589,91 & 466,60 & $22,00 \%$ & 1,26 \\
& & Mesa Inferior & 589,28 & 462,50 & $21,00 \%$ & 1,27 \\
& & Média & 588,53 & 466,20 & $20,33 \%$ & 1,26
\end{tabular}

Fonte: Da autora.

Tabela B.2-Resultados da caracterização do material do ensaio de flexão das treliças.

\begin{tabular}{ccccccc}
\hline $\mathbf{C P}$ & $\begin{array}{c}\text { Altura x } \\
\text { espessura } \\
(\mathbf{m m})\end{array}$ & $\begin{array}{c}\text { Extração do } \\
\mathbf{C P}\end{array}$ & $\boldsymbol{f}_{\boldsymbol{u}}(\mathbf{M P a})$ & $\boldsymbol{f}_{\boldsymbol{y}}(\mathbf{M P a})$ & $\mathbf{A}(\boldsymbol{\%})$ & $\boldsymbol{f}_{\boldsymbol{u}} / \boldsymbol{f}_{\boldsymbol{y}}$ \\
\hline $\mathbf{1}$ & \multirow{3}{*}{ Mesa Superior } & 566,51 & 474,09 & $25,00 \%$ & 1,19 \\
$\mathbf{2}$ & $120 \times 3,00$ & Alma & 563,98 & 487,50 & $25,00 \%$ & 1,16 \\
$\mathbf{3}$ & & Mesa Inferior & 572,63 & 494,10 & $26,00 \%$ & 1,16 \\
& & Média & 567,70 & 485,23 & $25,33 \%$ & \\
\hline $\mathbf{4}$ & \multirow{5}{*}{ Mesa Superior } & 612,23 & 521,80 & $25,00 \%$ & 1,17 \\
$\mathbf{6}$ & Alma & 604,70 & 509,80 & $24,00 \%$ & 1,19 \\
& & Mesa Inferior & 598,34 & 505,30 & $26,00 \%$ & 1,18 \\
$\mathbf{7}$ & Média & 605,09 & 512,30 & $25,00 \%$ & \\
$\mathbf{8}$ & Presilha 110 & Alma & 562,76 & 465,15 & $22,00 \%$ & 1,21 \\
$\mathbf{9}$ & & Mesa Superior & 567,07 & 468,50 & $25,00 \%$ & 1,21 \\
& & Média & 564,58 & 466,97 & $25,33 \%$ & \\
\hline
\end{tabular}

Fonte: Da autora. 


\section{APÊNDICE C - MOMENTO FLETOR SOLICITANTE E RESISTENTE EM RELAÇÃO AO EIXO PRINCIPAL PERPENDICULAR À ALMA DO PERFIL}

O momento fletor resistente característico em relação ao eixo perpendicular à alma do perfil foi calculado pelas expressões do método da resistência direta contidas no Anexo C da norma brasileira, especificamente no item que trata das barras submetidas à flexão simples. Os valores de tensão crítica elástica foram obtidos por meio do software CUFSM v.5.01 (SCHAFER; ÁDÁNY, 2018) seguindo o mesmo procedimento indicado no item 3.1. O carregamento aplicado foi um momento fletor em torno do eixo perpendicular à alma do perfil.

A Figura C.1- ilustra a envoltória de mínimos obtidas da análise de estabilidade elástica.

Figura C.1- Análise de estabilidade elástica para os perfis submetido à flexão em torno do eixo perpendicular à alma.

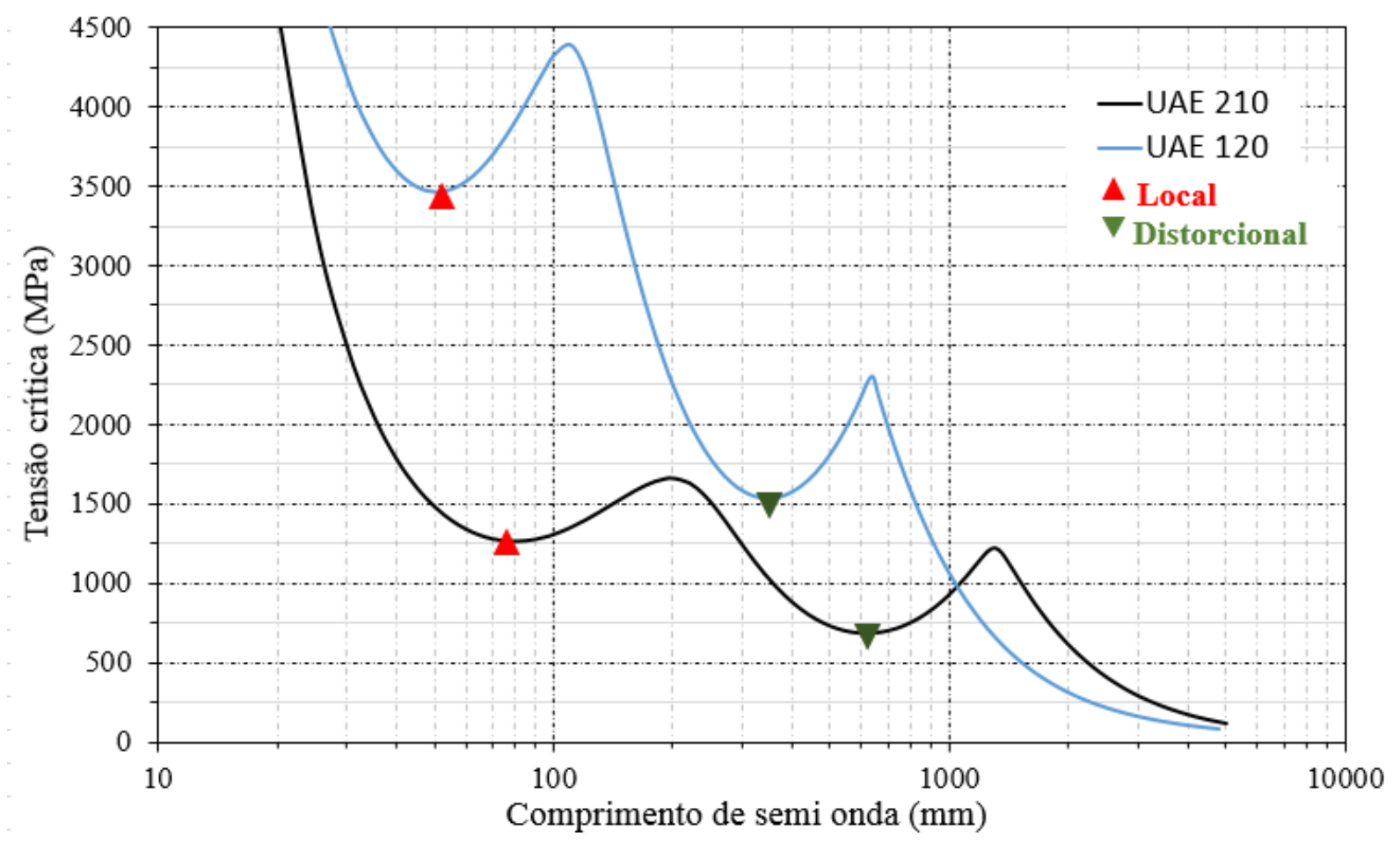

Fonte: Da autora.

No cálculo do momento resistente característico, a tensão de escoamento utilizada foi a obtida no ensaio de tração indicado no Apêndice B deste trabalho; o módulo de elasticidade (E) utilizado para o aço foi igual a $200.000 \mathrm{MPa}$. O momento solicitante característico foi obtido a partir de uma análise estrutural que considera a treliça com as excentricidades existentes, e os nós das diagonais não foram rotulados. As seções foram atribuídas de forma a representar as 
propriedades geométricas das barras da peça. O carregamento foi aplicado nos nós, sendo o valor total da carga igual à força máxima aplicada pelo atuador nos ensaios realizados; a condição de contorno utilizada foi a biapoiada.

Os valores obtidos para o momento fletor resistente característico $\left(M_{x, R k}\right)$ e solicitante $\left(M_{x, S k}\right)$ foram organizados na Tabela C.1, assim como o esforço normal solicitante característico $\left(N_{C, S k}\right)$ obtido, considerando as forças máximas aplicadas pelo atuador. A força axial resistente característica $\left(N_{c, R k}\right)$ indicada na tabela foi obtida no item 3.3.1.

Tabela C.1- Valores de tensão crítica elástica e esforços caraterísticos.

\begin{tabular}{|c|c|c|c|c|c|c|c|}
\hline Protótipo & $\begin{array}{c}\sigma_{\text {crítica }} \\
\text { Local } \\
\text { (MPa) }\end{array}$ & $\begin{array}{c}\sigma_{\text {critííca }} \\
\text { Distorcional } \\
\text { (MPa) }\end{array}$ & $\begin{array}{c}\text { Força máx. } \\
\text { aplica pelo } \\
\text { atuador } \\
(\mathbf{k N}) \\
\end{array}$ & $\begin{array}{c}N_{c, S k} \\
(\mathbf{k N})\end{array}$ & $\begin{array}{c}N_{c, R k} \\
(\mathbf{k N})\end{array}$ & $\begin{array}{c}M_{x, S k} \\
(\mathbf{k N} . \mathbf{c m})\end{array}$ & $\begin{array}{c}M_{x, R k} \\
(\mathbf{k N} . \mathbf{c m})\end{array}$ \\
\hline 210J360.P1 & 1263,19 & 683,68 & 237,99 & 530,26 & 742,08 & 1747,36 & 6599,80 \\
\hline 210J360.P2 & 1263,19 & 683,68 & 221,83 & 494,26 & 742,08 & 1622,60 & 6599,80 \\
\hline 210J180.P1 & 1263,19 & 683,68 & 249,22 & 555,28 & 742,08 & 1829,80 & 6599,80 \\
\hline 210J180.P5 & 1263,19 & 683,68 & 265,52 & 591,60 & 742,08 & 1949,50 & 6599,80 \\
\hline 120J360.P1 & 3465,48 & 1536,08 & 123,93 & 281,67 & 62,14 & 483,62 & 2249,70 \\
\hline 120J360.P4 & 3465,48 & 1536,08 & 114,05 & 253,35 & 62,14 & 447,07 & 2249,70 \\
\hline 120J180.P1 & 3465,48 & 1536,08 & 145,83 & 323,95 & 248,56 & 569,08 & 2249,70 \\
\hline 120J180.P5 & 3465,48 & 1536,08 & 138,89 & 308,53 & 248,56 & 542,00 & 2249,70 \\
\hline
\end{tabular}




\section{APÊNDICE D - RESULTADOS DO ENSAIO DAS TRELIÇAS- EXTENSÔMETROS}

A figura D.1 e a Figura D.2 apresentam as curvas força versus deformação específica para as peças 210J360.P2 e 210J360.P1 respectivamente.

Figura D.1- Curva força versus deformação específica para os extensômetros no protótipo 210J360.P2 e localização dos extensômetros.

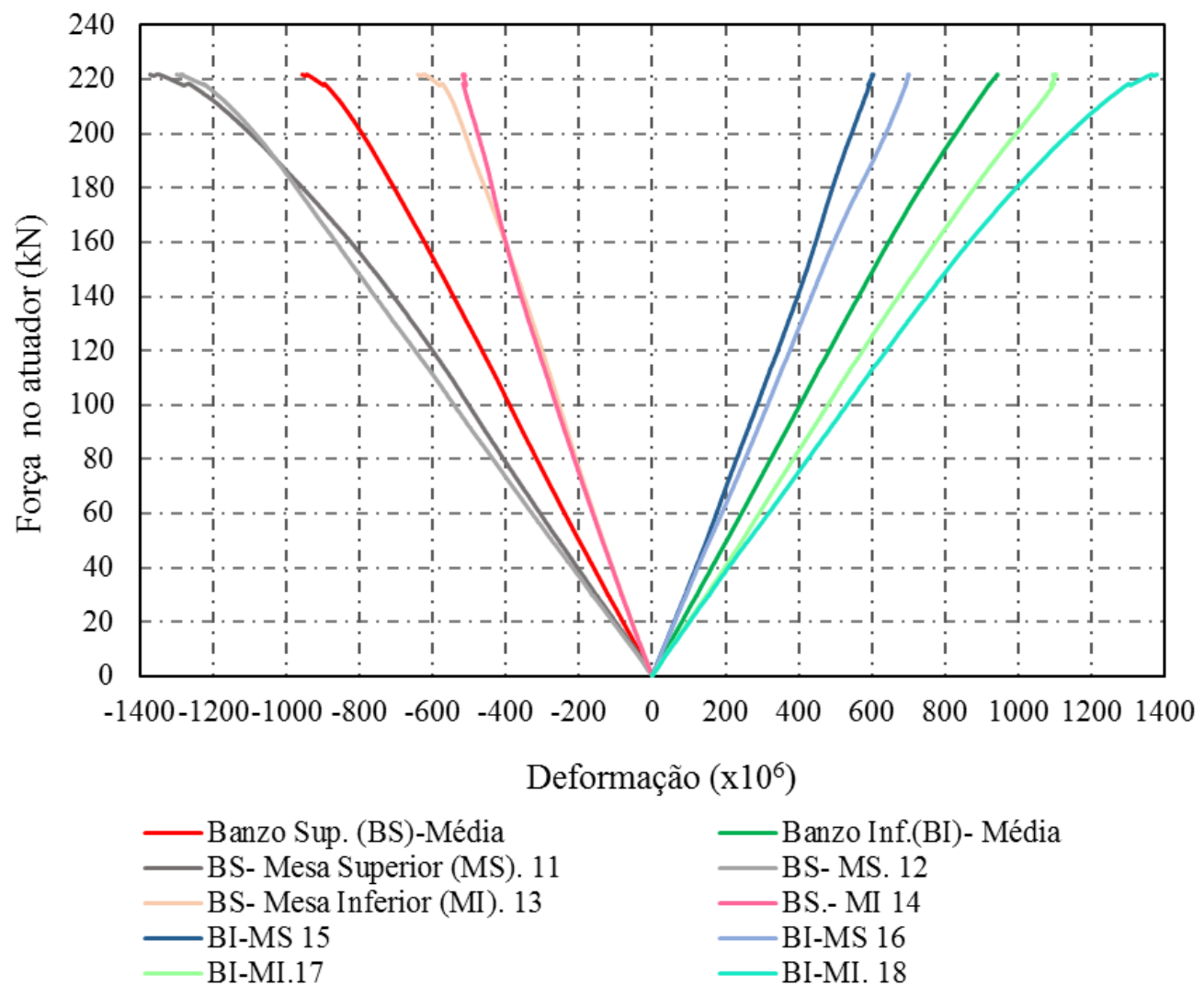

Banzo Superior

Banzo Inferior
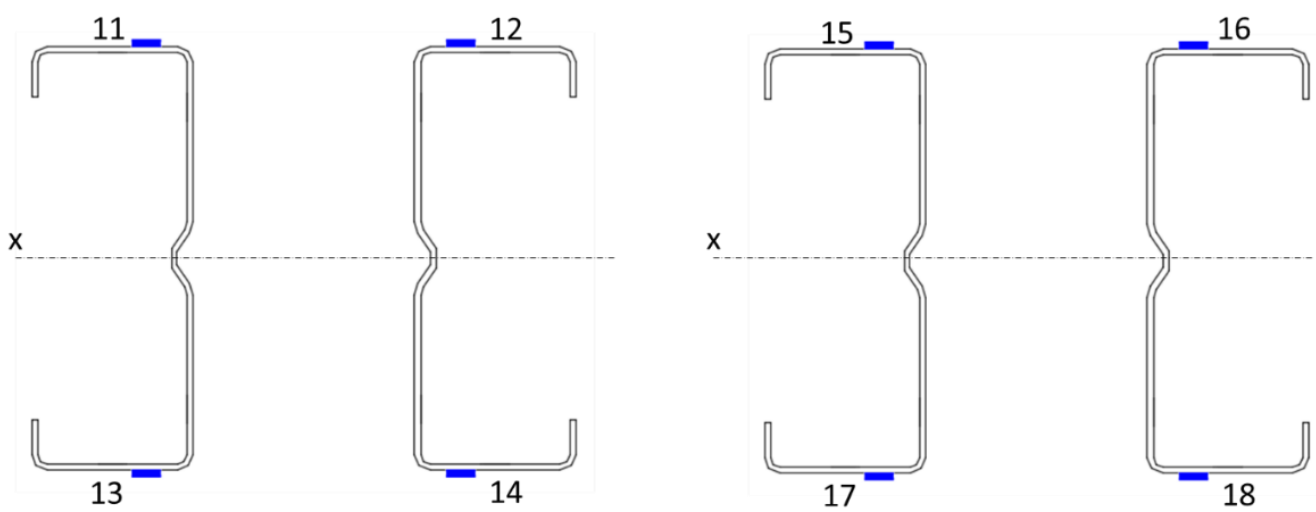
Figura D.2- Curva força versus deformação específica para os extensômetros no protótipo 210J360.P1.

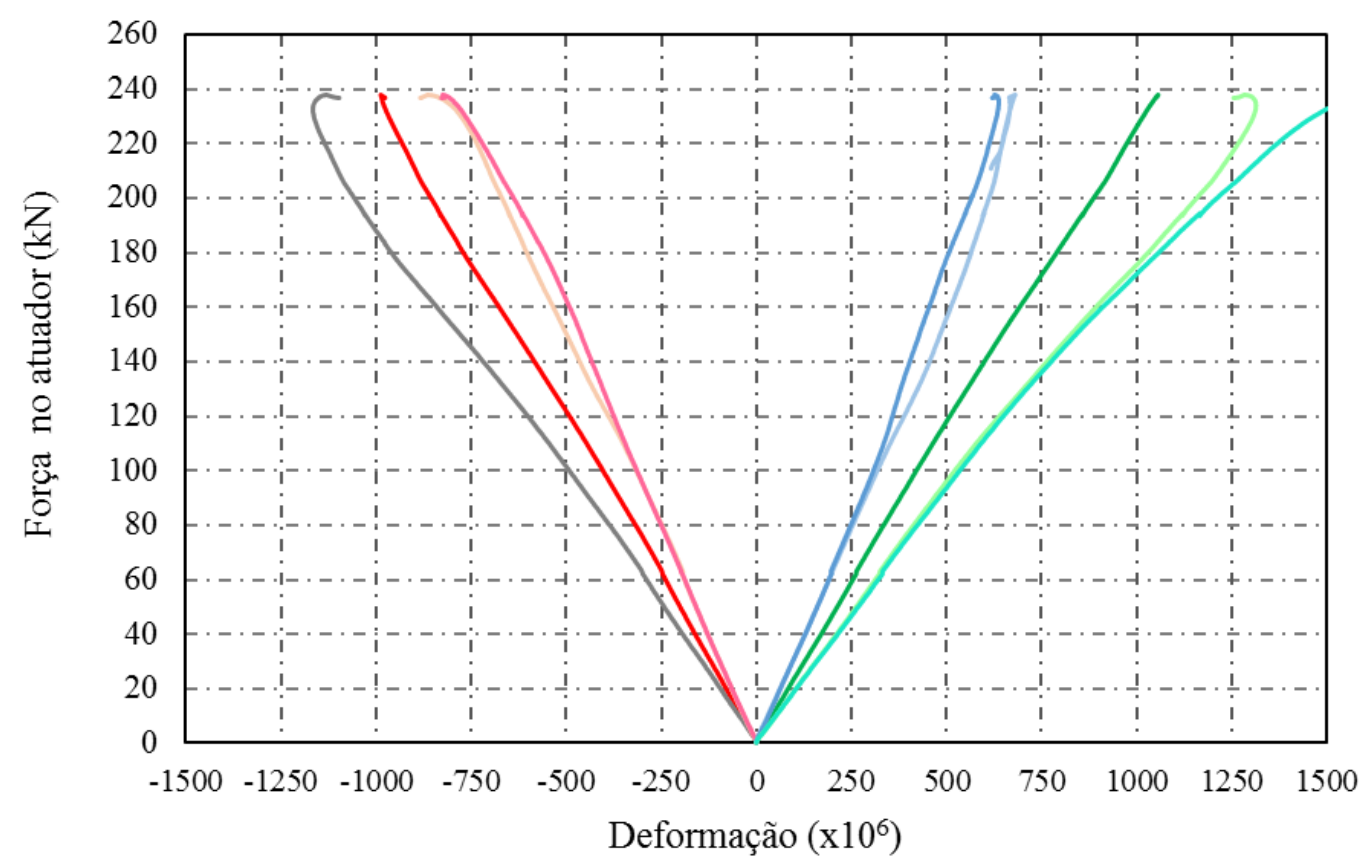

Banzo Sup.(MS)-Média

BS- Mesa Superior (MS). 11

-Banzo Inf.(BI)- Média

BS- MI. 14

BS- Mesa Inferior (MI).13

BI-MS. 16

-BI- MS. 15

BI-MI. 18

BI-MI. 17 